\author{
UNIVERSIDADE DE SÃO PAULO \\ ESCOLA DE ENGENHARIA DE SÃO CARLOS \\ DEPARTAMENTO DE ENGENHARIA DE ESTRUTURAS
}

MARIANA CORRÊA POSTERLLI

MODELAGEM DA EXPANSÃO DEVIDO À REAÇÃO ÁLCALI-AGREGADO DE CONCRETO ARMADO E REFORÇADO COM FIBRAS

SÃO CARLOS

2017 



\section{MODELAGEM DA EXPANSÃO DEVIDO À REAÇÃO ÁLCALI-AGREGADO DE CONCRETO ARMADO E REFORÇADO COM FIBRAS}

\section{VERSÃO CORRIGIDA}

A versão original encontra-se na Escola de Engenharia de São Carlos

Dissertação apresentada ao Departamento de Engenharia de Estruturas da Escola de Engenharia de São Carlos, Universidade de São Paulo, como parte dos requisitos necessários para obtenção do título de Mestre em Engenharia Civil (Estruturas).

Área de concentração: Estruturas

Orientador: Prof. Dr. Rogério Carrazedo

SÃO CARLOS 
AUTORIZO A REPRODUÇÃO TOTAL OU PARCIAL DESTE TRABALHO, POR QUALQUER MEIO CONVENCIONAL OU ELETRÔNICO, PARA FINS DE ESTUDO E PESQUISA, DESDE QUE CITADA A FONTE.

Posterlli, Mariana Correa

P857m Modelagem da expansão devido à reação álcaliagregado de concreto armado e reforçado com fibras / Mariana Correa Posterlli; orientador Rogério Carrazedo. São Carlos, 2017.

Dissertação (Mestrado) - Programa de Pós-Graduação em Engenharia Civil(Engenharia de Estruturas) e Área de Concentração em Estruturas - - Escola de Engenharia de São Carlos da Universidade de São Paulo, 2017.

1. Reação álcali-agregado. 2. Método dos elementos finitos posicional. 3. Modelo paramétrico. 4. Concreto armado e reforçado com fibras. I. Título. 


\section{FOLHA DE JULGAMENTO}

Candidata: Engenheira MARIANA CORREA POSTERLLI.

Título da dissertação: "Modelagem da expansão devido à reação álcaliagregado de concreto armado e reforçado com fibras".

Data da defesa: 21/02/2017.

Comissão Julgadora:

Prof. Dr. Rogério Carrazedo (Orientador)

(Escola de Engenharia de São Carlos/EESC)

Prof. Dr. Luiz Alkimin de Lacerda

(Universidade Federal do Paraná/UFPR)

Prof. Dr. Fernando Menezes de Almeida Filho (Universidade Federal de São Carlos/UFSCar - São Carlos)

Coordenador do Programa de Pós-Graduação em Engenheira Civil (Engenharia de Estruturas):

Prof. Titular Humberto Breves Coda

Presidente da Comissão de Pós-Graduação:

Prof. Associado Luís Fernando Costa Alberto
Resultado:
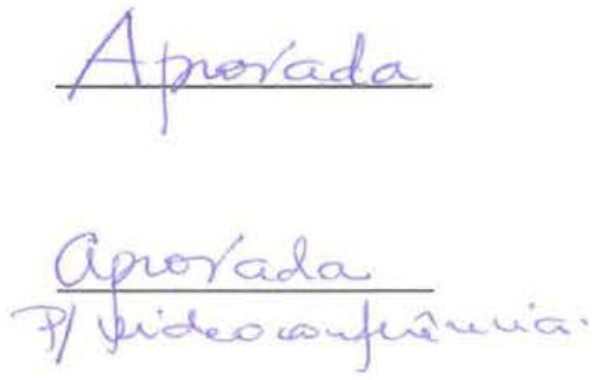
$\mid$ 
"Aos outros, dou o direito de ser como são. A mim, dou o dever de ser cada dia melhor." Chico Xavier 



\section{AGRADECIMENTOS}

Nestes agradecimentos, antes de qualquer coisa, devo toda a minha gratidão a Deus, por ter me alicerçado durante todo este árido caminho. Foi Nele que encontrei a paz e a serenidade necessários nos momentos de angústia e aflição, além de ser Ele a minha luz e o meu norte nos momentos de escuridão.

Agradeço a todos os meus familiares que contribuíram, cada um à sua maneira, para que eu pudesse concluir esta etapa em minha vida. Neste ponto, faço menção especial aos meus pais, que contribuíram de maneira imensurável não só para a realização deste trabalho, mas também em todos os aspectos de minha vida, contribuindo de maneira essencial para a formação da pessoa que sou hoje.

De forma especial também agradeço aos professores da Escola de Engenharia de São Carlos, os quais contribuíram não apenas para a minha formação acadêmica, mas também me incentivaram na constante busca por conhecimento.

Agradeço ainda aos amigos que tive o prazer de fazer ao longo destes sete anos em São Carlos, por fazerem com que esta longa caminhada fosse mais leve e alegre.

Agradeço ao Conselho Nacional de Desenvolvimento Científico e Tecnológico (CNPq) pela bolsa de mestrado concedida.

Por fim, agradeço também a todos os funcionários da Escola de Engenharia de São Carlos, especialmente os do Departamento de Engenharia de Estruturas que contribuíram, ainda que indiretamente, para que este trabalho fosse realizado. 



\section{RESUMO}

POSTERLLI, M. C. Modelagem da expansão devido à reação álcali-agregado de concreto armado e reforçado com fibras. 2017. p.157. Dissertação (Mestrado em Engenharia Civil (Estruturas)) - Escola de Engenharia de São Carlos, Universidade de São Paulo, São Carlos, 2017.

A reação álcali-agregado (RAA) é uma reação química complexa envolvendo os álcalis presentes no cimento Portland e minerais silicosos presentes em alguns tipos de agregados reativos. O produto dessa reação expande quando em contato com a água, causando fissuração e deformação, o que afeta a durabilidade e importantes propriedades mecânicas das estruturas de concreto. Entretanto, estruturas que estejam sob tensão de compressão, aplicada por carregamentos ou induzida pela presença de armadura, apresentam expansão reduzida na direção comprimida. Uma das ferramentas que se utiliza para a previsão da vida útil de estruturas afetadas pela RAA é a modelagem numérica da expansão do concreto, possibilitando a previsão e projeto de reparos necessários. Nesse contexto, modelos paramétricos combinam os principais fatores que influenciam a reação (reatividade dos constituintes, porosidade, temperatura, umidade e estado de tensões), possibilitando a determinação da distribuição e da taxa de expansão na estrutura. Nessa pesquisa foi desenvolvido um modelo paramétrico cujo principal interesse foi o estudo das tensões induzidas pela presença de fibras e armadura na expansão do concreto afetado pela RAA. O modelo implementado em elementos finitos tem como parâmetros nodais as posições, uma formulação alternativa ao método dos elementos finitos baseado em deslocamentos; a medida de deformação utilizada é a de Green e a lei constitutiva dos materiais é a de Saint-Venant-Kirchhoff. O material composto é discretizado por meio de uma matriz elástica bi-dimensional reforçado por fibras lineares perfeitamente aderidas à matriz. Comparações entre os resultados obtidos por meio do modelo desenvolvido e resultados de trabalhos experimentais comprovam a aplicabilidade e potencialidade do modelo numérico apresentado.

Palavras-chave: reação álcali-agregado, método dos elementos finitos posicional, modelo paramétrico, concreto armado e reforçado com fibras 



\begin{abstract}
POSTERLLI, M. C. Modeling of expansion due to alkali-aggregate reaction of reinforced concrete and fiber reinforced concrete. 2017. p.157. Dissertation (M. Sc. in Civil Engineering (Structures)) - School of Engineering of São Carlos, University of São Paulo, São Carlos, 2017.

The alkali-aggregate reaction (AAR) is a complex chemical reaction involving alkalis present in the Portland cement paste and siliceous minerals present in some types of reactive aggregates. The product of this reaction expands in contact with water, causing cracking and deformation that affects durability and important mechanical properties of the concrete structures. However, structures under compressive stress, applied or induced by the presence of rebars, the expansion is reduced in the compressed direction. One of the tools used to predict the service life of structures affected by AAR is the numerical modeling of the concrete expansion, allowing prevision and projecting repairs needed. In this context, parametric models combine the main factors that influence the reaction (reactivity of the constituents, porosity, temperature, humidity and stress state), enabling the determination of distribution and rate of expansion in the structure. In this research was developed a parametric model whose main interest was the study of stresses induced by the presence of fibers and rebars in the expansion of concrete affected by AAR. The model implemented in finite element has as nodal parameters positions, an alternative formulation to the finite element method based on displacement; the deformation measurement used is Green and the material constitutive law is the Saint-Venant-Kirchhoff. The composite material is discretized by a two-dimensional elastic matrix reinforced by perfectly adherent linear fibers. Comparisons between the results obtained from the developed model and results of experimental studies demonstrate the applicability and potential of the numerical model presented.
\end{abstract}

Keywords: alkali-aggregate reaction, positional finite element method, parametric model, reinforced concrete and concrete reinforced with fibers 



\section{SUMÁRIO}

1 INTRODUÇÃ

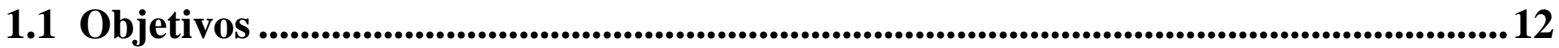

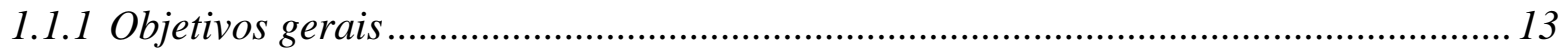

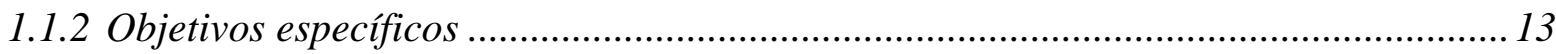

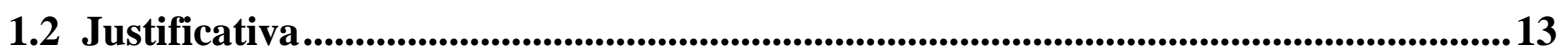

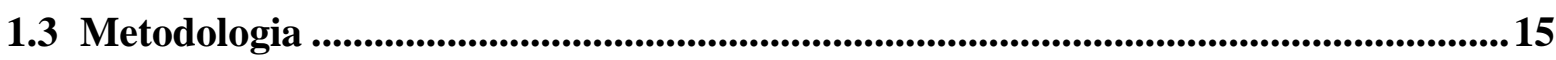

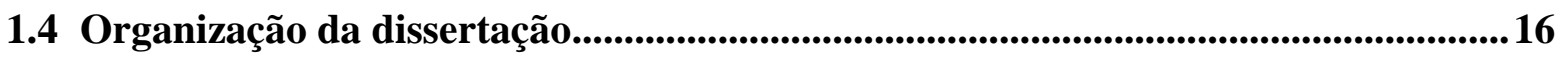

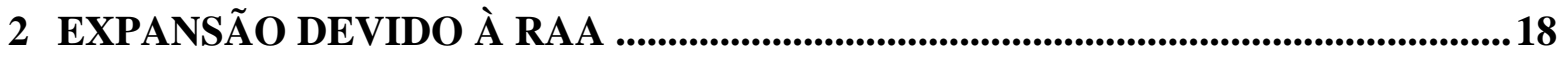

2.1 Mecanismos e estágios da reação ...........................................................................................18

2.2 Fatores de influência da reação .............................................................................21

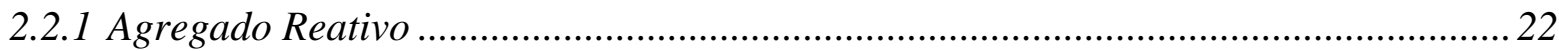

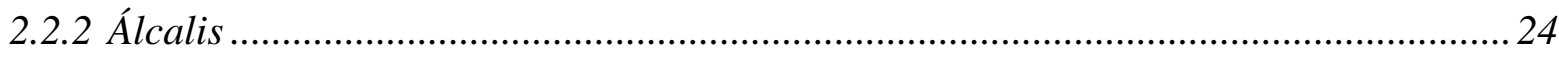

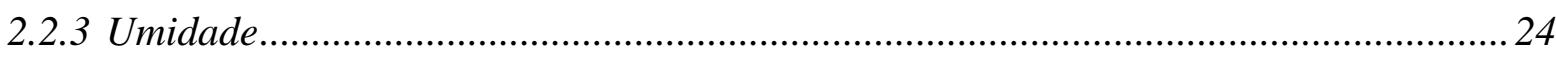

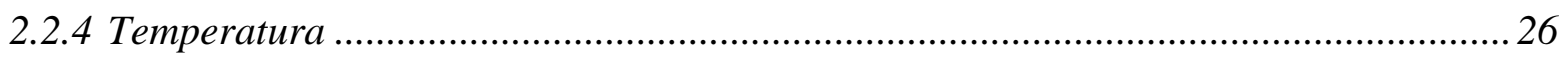

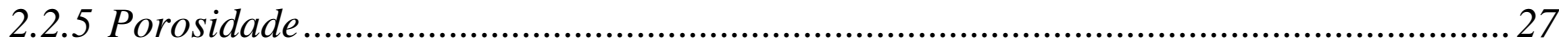

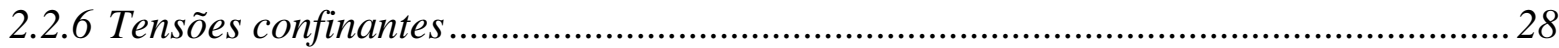

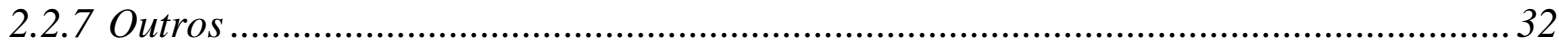

2.3 Efeitos da RAA nas propriedades mecânicas do concreto .......................................33

2.4 Características visuais de estruturas afetadas pela RAA............................................35

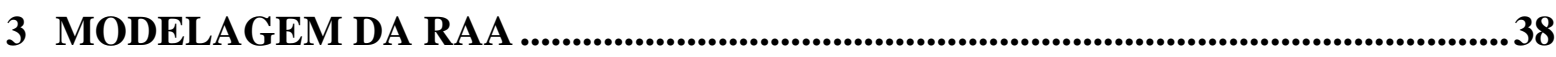

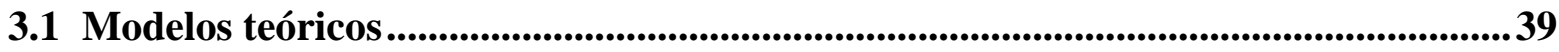

3.2 Modelos mesoscópicos..........................................................................................................41

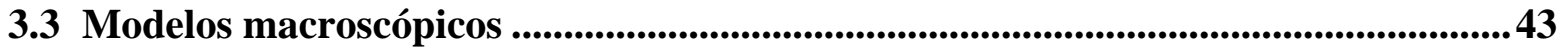

3.3.1 Modelo paramétrico de Léger et al. (1996).....................................................................4

3.3.2 Modelo paramétrico de Pappalardo Jr. et al. (2000) .................................................. 47

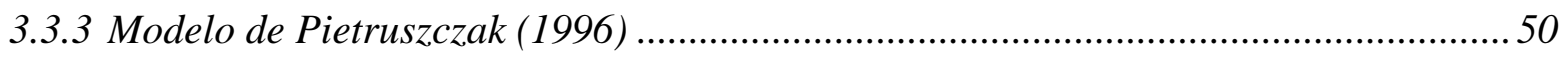

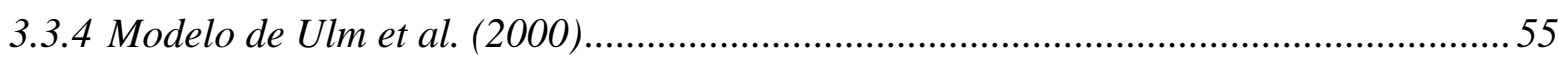

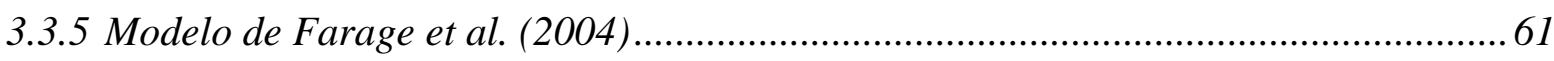




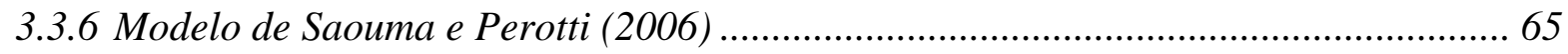

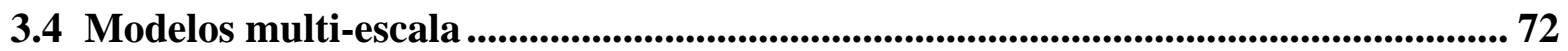

4 MODELO PARAMÉTRICO DE EXPANSÃO POR RAA .......................................... 74

4.1 Fatores de influência e leis de normalização .................................................................... 74

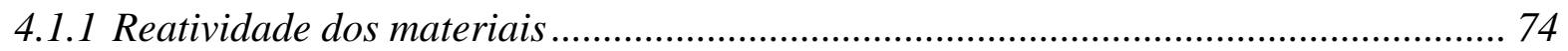

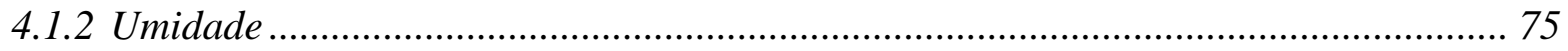

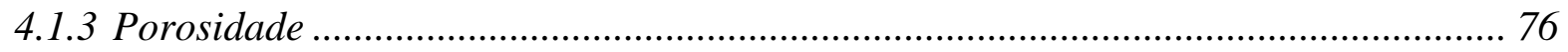

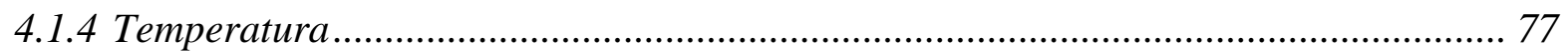

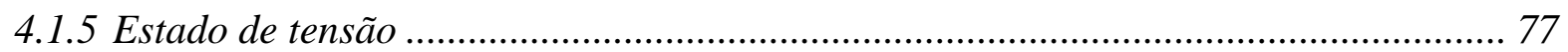

4.2 Equação para a expansão por RAA ................................................................... 79

5 MODELAGEM DO CONCRETO ARMADO AFETADO PELA RAA................... 84

5.1 Problema de equilíbrio estático ........................................................................................ 84

5.2 Elemento de chapa 2D (matriz de concreto) .......................................................... 87

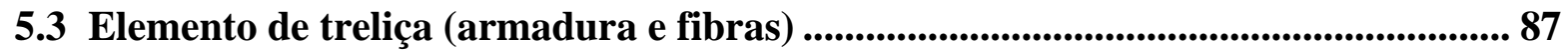

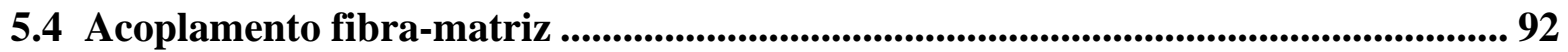

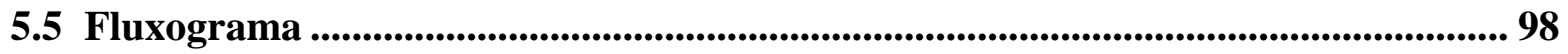

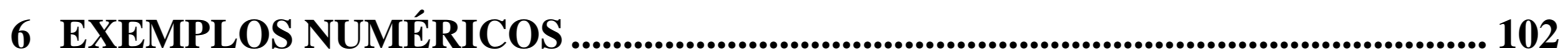

6.1 Exemplo 1: Viga em concreto armado sujeita à grandes deslocamentos ............... 102

6.2 Exemplo 2: Chapa reforçada com fibras longas ordenadas e fibras curtas aleatórias 107

6.3 Exemplo 3: Corpo de prova sujeito à expansão livre devido à RAA ..................... 113

6.4 Exemplo 4: Corpo de prova afetado por RAA sujeito a diferentes níveis de tensão aplicadas e induzidas. ................................................................................................... 117

6.4.1 Primeira série de ensaios: tensão aplicada ............................................................. 117

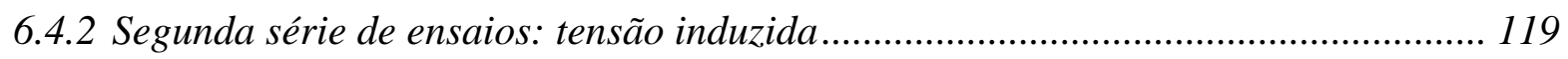

6.4.3 Terceira série de ensaios: tensões aplicadas e induzidas simultaneamente............... 122

6.5 Exemplo 5: Expansão em prisma de concreto armado ........................................ 127

6.6 Exemplo 6: Expansão de prisma contendo fibras ...................................................... 132

6.7 Exemplo 7: Viga em concreto armado sujeita à RAA.............................................. 138

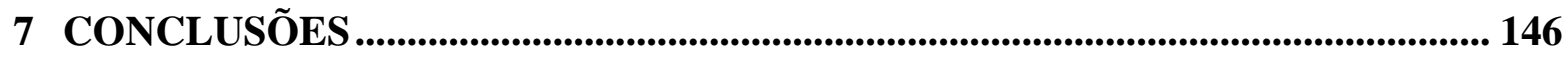

REFERÊNCIAS BIBLIOGRÁFICAS ...................................................................... 148 



\section{INTRODUÇÃO}

O concreto é um dos principais materiais de construção empregado no mundo devido à sua elevada resistência, facilidade com que os elementos estruturais podem ser obtidos de uma variedade de formas e tamanhos, disponibilidade de material e baixo custo (MEHTA; MONTEIRO, 2008). Porém, com o envelhecimento das obras tem-se constatado alteração das propriedades físicas e químicas do concreto em função das características de seus componentes e da resposta destes às condições impostas pelo ambiente (SOUZA; RIPER, 2009).

Entre os vários processos de deterioração que afetam as estruturas em concreto armado pode-se destacar a corrosão de armadura, ação de gelo e degelo, ataque por sulfato e reação álcali-agregado, que têm como consequência a redução do desempenho e da durabilidade das estruturas (SOUZA; RIPER, 2009).

A reação álcali-agregado (RAA) é uma reação química deletéria que ocorre entre os íons alcalinos presentes na pasta de cimento hidratada e os minerais presentes em alguns tipos de agregados reativos. Podem ser classificados três tipos de reação em função do mineral reativo presente no agregado: reação álcali-carbonato, reação álcali-silicato e reação álcali-sílica; destacando-se esta última como o tipo de reação mais comum no Brasil (HASPARYK, 2011).

O produto da reação álcali-sílica é um gel que expande na presença de água, gerando tensões e fissuração no concreto. As consequências dessa reação incluem a redução de importantes propriedades como a resistência e o módulo de elasticidade do concreto, o que leva a uma significativa redução da vida útil das estruturas afetadas (CARRAZEDO; LACERDA, 2008). Além disso, a fissuração provocada pela RAA aumenta a permeabilidade do concreto, o que pode favorecer o surgimento de outras manifestações patológicas, como, por exemplo, a corrosão de armaduras (SILVA, 2007).

A RAA tem como primeira referência Stanton (1940) que observou eflorescências e fissuras em estruturas rodoviárias na Califórnia. Desde então a RAA tem sido reconhecida como causa de deterioração de estruturas em mais de 50 países (FOURNIER; BÉRUBÉ, 2000). A Figura 1.1 a seguir ilustra o aspecto de algumas estruturas afetadas pela RAA. 


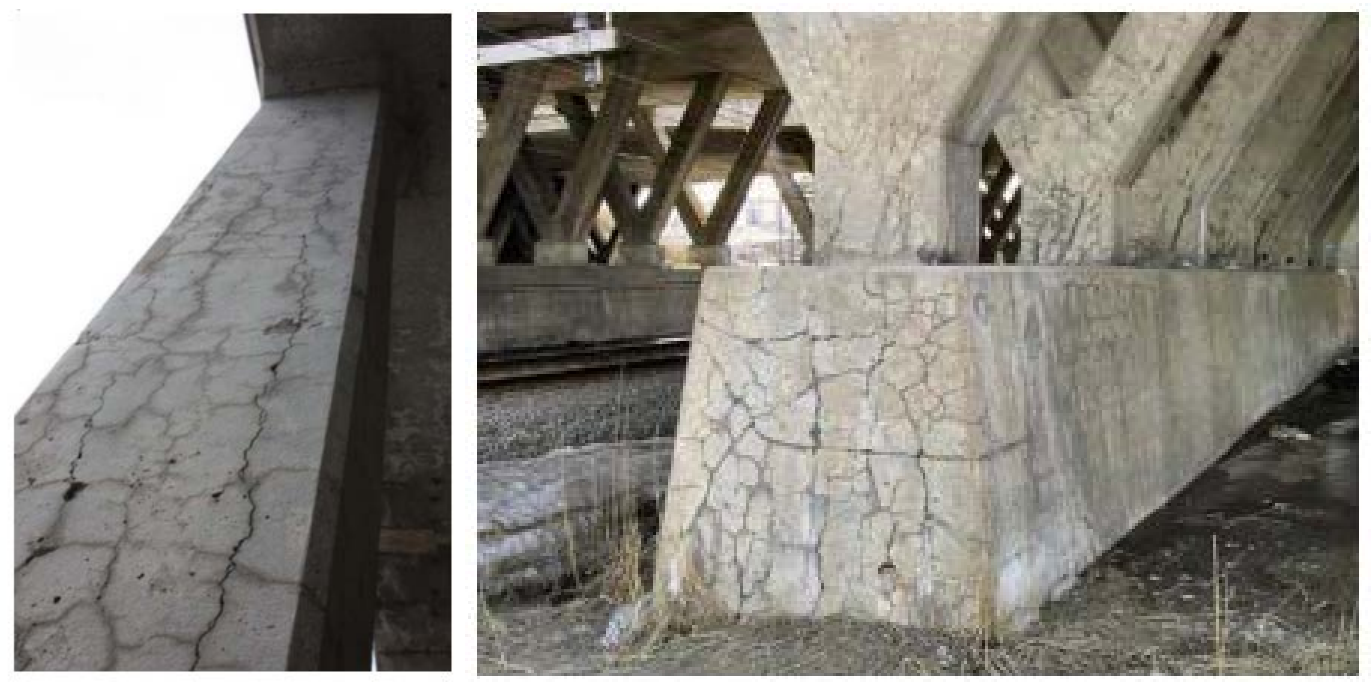

Figura 1.1 - Estruturas afetadas pela reação álcali-agregado.

Fonte: FHWA (2013).

No Brasil, os primeiros trabalhos sobre o tema são da década de 60 com a construção da Barragem de Jupiá, em que se constatou a reatividade do cascalho do leito do rio Paraná (PAULON, 1981). Contudo, o primeiro registro da manifestação patológica em uma estrutura se deu em 1985, na usina hidrelétrica de Apolônio Sales de Oliveira em Moxotó, desde então diversos outros casos foram observados em outras barragens brasileiras.

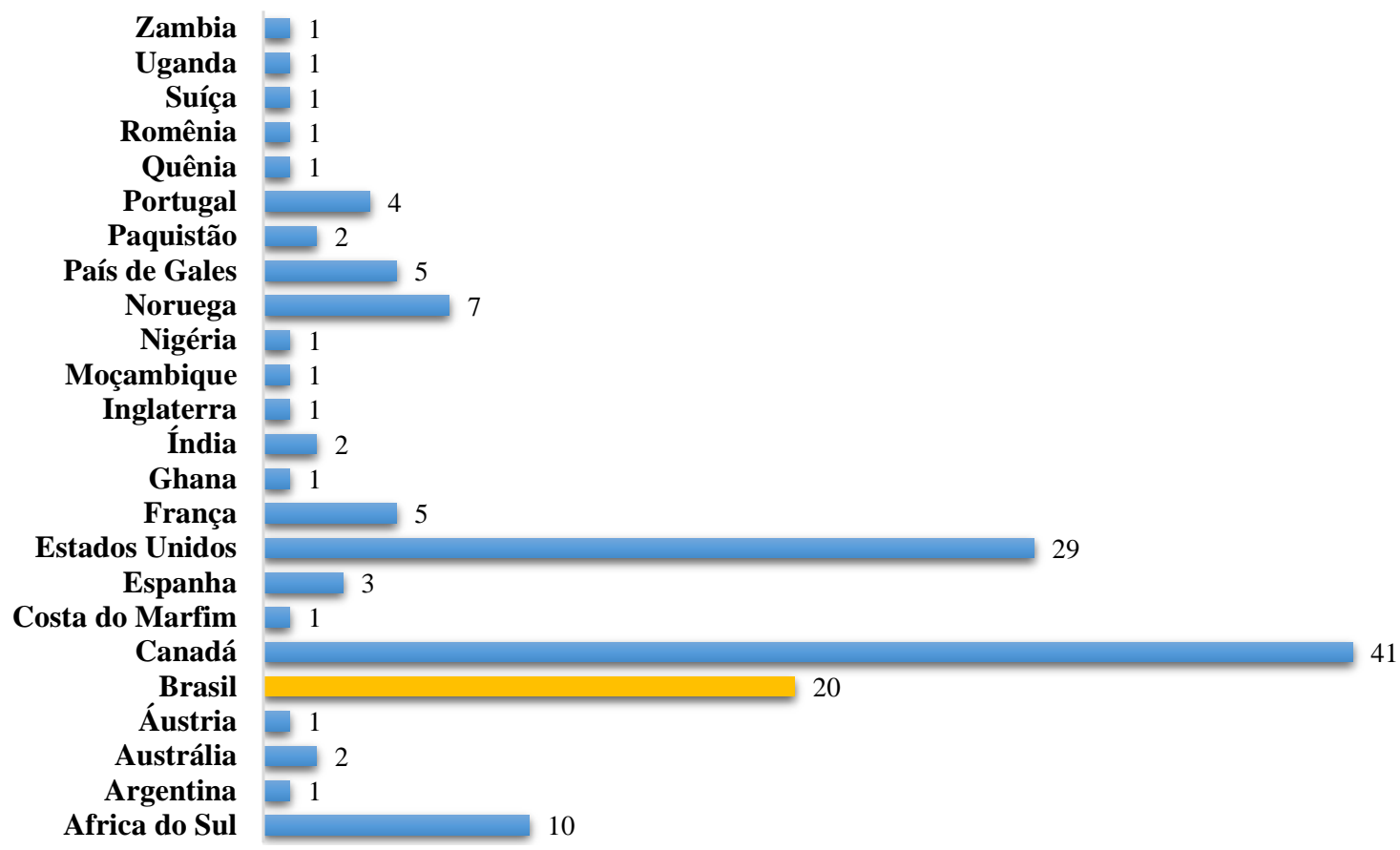

Figura 1.2 - Casos de RAA constatados em estruturas hidráulicas de diferentes países.

Fonte: Adaptado de Kihara et al. (1998). 
Hasparyk (2011) afirma que obras hidráulicas são estruturas bastante susceptíveis a apresentarem RAA por sofrerem grandes variações de temperatura e umidade. Desde a primeira constatação do problema no Brasil em 1985, mais de 20 casos de RAA foram identificados em barragens, conforme indica a Figura 1.2 que apresenta os números de casos de RAA registrados em estruturas hidráulicas construídas até 1998 no mundo.

Em 2005, com o desabamento do edifício Areia Branca na região metropolitana de Recife a RAA voltou a ter destaque no meio técnico e acadêmico brasileiro. Apesar de não ter sido a causa que levou ao colapso do edifício, laudos técnicos comprovaram a existência de RAA nos blocos de fundação do edifício, levando à investigação e comprovação da existência de cerca de 20 outros casos de fundações (com idades entre 3 e 30 anos) afetadas pela RAA na região (ANDRADE et al., 2006).

Em 2009, dados da Associação Brasileira do Cimento Portland (ABCP) destacam pelo menos 30 casos de estruturas hidráulicas afetadas pela RAA em pelo menos sete estados do Brasil, além de outros 30 casos em fundações de edifícios na região metropolitana do Recife (Battagin et al., 2009).

Sabe-se que muitos fatores podem afetar significativamente a extensão e a velocidade da reação, entre eles a mineralogia e tamanho do agregado, o conteúdo alcalino da solução, temperatura, umidade e tensões de confinamento (PAN et al., 2012). Assim, a principal medida a ser tomada para evitar a RAA nas estruturas de concreto é o controle da reatividade do agregado utilizado. Porém, muitas obras existentes já apresentam o problema instalado, o que fez necessário o desenvolvimento e aperfeiçoamento de modelos numéricos capazes de prever a extensão dos danos causados e possibilitar o projeto de reparos necessários (PIGNATELLI, 2012).

Devido à complexidade da reação e dos diferentes fatores que a influenciam, os modelos numéricos desenvolvidos apresentam diferentes escalas de abordagem na tentativa de prever a expansão e a redução das propriedades do concreto, conforme ilustrado na Figura 1.3. 


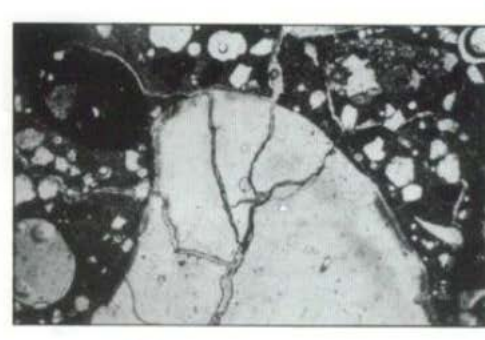

Microscópico

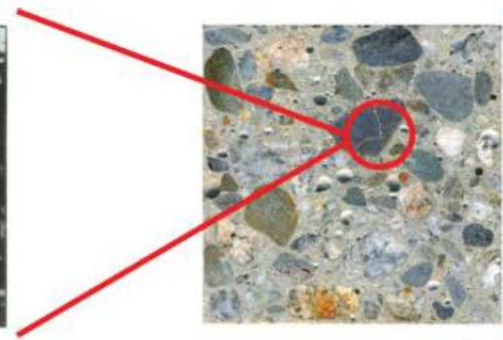

Mesoscópico

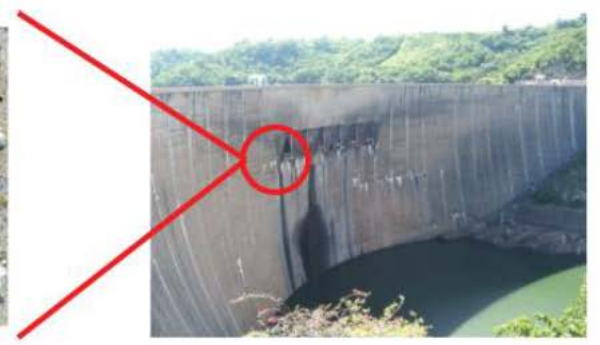

Macroscópico

Figura 1.3 - Escalas dos modelos numéricos que representam a RAA.

Fonte: Esposito e Hendriks (2013).

Existem modelos teóricos ou microscópicos, que estudam os mecanismos químicos envolvidos na reação, porém apresentam pouca relevância na análise de uma estrutura afetada pela RAA (HOBBS, 1981; FURUSAWA et al., 1994; BAZANT; STEFENS, 2000; LEMARCHAND et al., 2001). Os modelos mesoscópicos consideram a anisotropia do concreto e tem como foco o estudo dos mecanismos de fissuração e dano (COMBY-PEYROT et al., 2009; DUNANT; SCRIVENER, 2010). Por fim, os modelos macroscópicos, cujo objetivo é o estudo do campo de tensões e deslocamentos da estrutura afetada pela RAA.

Os modelos macroscópicos geralmente são formulados em elementos finitos e apresentam dois principais tipos de abordagens: paramétrica e químico-mecânica. Os modelos que apresentam abordagens paramétricas combinam parâmetros normalizados para cada fator de influência da reação (umidade, reatividade dos constituintes do concreto, temperatura e confinamento) por meio de uma equação que expressa a expansão do concreto (CHARLWOOD et al., 1992; THOMPSON et al., 1994; LÉGER et al., 1996; CAPRA; BOURNAZEL, 1998; PAPPALARDO Jr. et al., 2000). Nos modelos com abordagens químico-mecânicas a resposta mecânica do concreto é considerada dependente da difusão química dos produtos da reação (LARIVE, 1998; HUANG; PIETRUSZCZAK, 1999; ULM et al., 2000; LI; COUSSY, 2002; FARAGE et al., 2004; FAIRBAIN et al., 2005).

O presente trabalho pretende dar continuidade ao modelo macroscópico paramétrico cuja origem vem dos trabalhos desenvolvidos por Léger et al. (1996) e Pappalardo Jr. et al. (2000), com extensões propostas por Carrazedo (2004) e Carrazedo e Lacerda (2008). Extensões nesse modelo também foram apresentadas em Carrazedo et al. (2012), que considera a ortotropia da expansão em função da distribuição irregular dos agregados reativos e em Oliveira (2013), que incluiu o decaimento do módulo de elasticidade sugerido por Pietruszczak (1996). 
Nesse sentido, o principal interesse desse trabalho é o estudo do comportamento expansivo de estruturas em concreto armado e reforçado com fibras afetadas por RAA. Estudos envolvendo o efeito de restrições e tensões aplicadas no desenvolvimento da expansão por RAA indicam que, sob tensões de compressão (aplicadas ou induzidas pela presença de armadura), a expansão é restringida na direção comprimida, promovendo uma transferência dessa expansão para uma direção menos comprimida (HOBBS, 1988; CLARK, 1991; JONES; CLARK, 1996; FAN; HANSON, 1998; CAPRA; SELLIER, 2003; MULTON; TOUTLEMONDE, 2006; KAGIMOTO et al., 2014).

O modelo macroscópico de expansão por RAA apresentado neste trabalho é implementado por meio do Método dos Elementos Finitos Posicional (MEFP). Esse método considera como parâmetros nodais as posições, diferentemente de outras formulações que utilizam os deslocamentos. As deformações e deslocamentos são calculados utilizando-se uma configuração adimensional auxiliar e medidas não-lineares de deformação e tensão (medida de deformação de Green e lei constitutiva dos materiais de Saint-Venant-Kirchhoff); dessa maneira, as posições nodais representam os valores atuais para cada nó, considerando, naturalmente, a não linearidade geométrica.

O MEFP teve início com os trabalhos de Bonet et al. (2000) e Coda (2003), que propuseram uma formulação para análise não-linear geométrica de estruturas, a partir daí diversos outros trabalhos foram desenvolvidos para análise não-linear geométrica de treliças, pórticos, cascas, cascas laminadas, sólidos reforçados com fibras perfeitamente aderentes e considerando escorregamento e sólidos reforçados com partículas (CODA; GRECO, 2004; CODA; PACCOLA, 2007; CODA; PACCOLA, 2008; CODA et al., 2013; SAMPAIO et al., 2013; PACCOLA et al., 2015; PACCOLA; CODA, 2016).

Os trabalhos de Vanalli (2004) e posteriormente Vanalli et al. (2008) propõe uma maneira de incluir a rigidez das fibras na matriz sem aumentar o número de graus de liberdade do sistema e sem a necessidade de coincidência dos nós da fibra e da matriz, metodologia que aqui é empregada a fim de considerar as restrições de movimento e ganho de rigidez promovidos pela presença de armadura e fibras na matriz de concreto.

\subsection{Objetivos}

Tendo em vista os problemas estruturais, o elevado custo de reparo e a complexidade associada à RAA, este trabalho tem por objetivo desenvolver um modelo numérico que 
possibilite o adequado controle e recuperação de estruturas de concreto armado e reforçado com fibras em processo de degradação pela RAA.

\subsubsection{Objetivos gerais}

Desenvolver um modelo macroscópico paramétrico em MEFP para a avaliação das expansões ortotrópicas devido à RAA em estruturas de concreto armado e reforçadas com fibras. Pretende-se introduzir o efeito das restrições de movimento e ganho de rigidez da estrutura devido à presença de armadura e fibras; e a consequente redução da expansão nas direções solicitadas por maiores tensões de compressão.

\subsubsection{Objetivos específicos}

- Implementar um modelo numérico em MEFP para análise de sólidos elásticos bidimensionais reforçados com fibras;

- Implementar, no modelo numérico, a expansão por RAA dependente dos parâmetros de umidade, temperatura, porosidade e tensão;

- Avaliar a equação para a expansão desenvolvida por Carrazedo (2004) e a equação proposta por Larive (1998) a fim de melhor representar a curva de expansão do concreto afetado pela RAA;

- Avaliar a lei de normalização referente às tensões utilizada por Pappalardo Jr. et al. (2000) e a utilizada por Léger et al. (1996) para a melhor representação da redução da expansão por RAA em função das fibras e armaduras e de diferentes estados de tensão;

- Implementar, no modelo numérico, a degradação do módulo de elasticidade do concreto em função do avanço da RAA, conforme proposto por Pietruszczak (1996).

\subsection{Justificativa}

Dentro do meio técnico e acadêmico, é consenso que a prevenção da RAA é a melhor alternativa pois, uma vez iniciada a reação em estruturas prontas, é tecnicamente muito difícil interrompê-la e, muitas vezes, economicamente inviável (BATTAGIN et al., 2009). 
Dessa forma, a cada ano tem-se ampliado o interesse pela realização de pesquisas e estudos sobre o tema em todo o mundo. Os especialistas buscam soluções para correção dos efeitos da reação e alternativas para sua prevenção. A Figura 1.4 comprova esse interesse crescente, registrando a participação e quantidade de trabalhos técnicos apresentados desde 1974 na International Conference in Alkali-Aggregate Reactions in Concrete (ICAAR), conferência internacional sobre RAA (BATTAGIN et al., 2009).

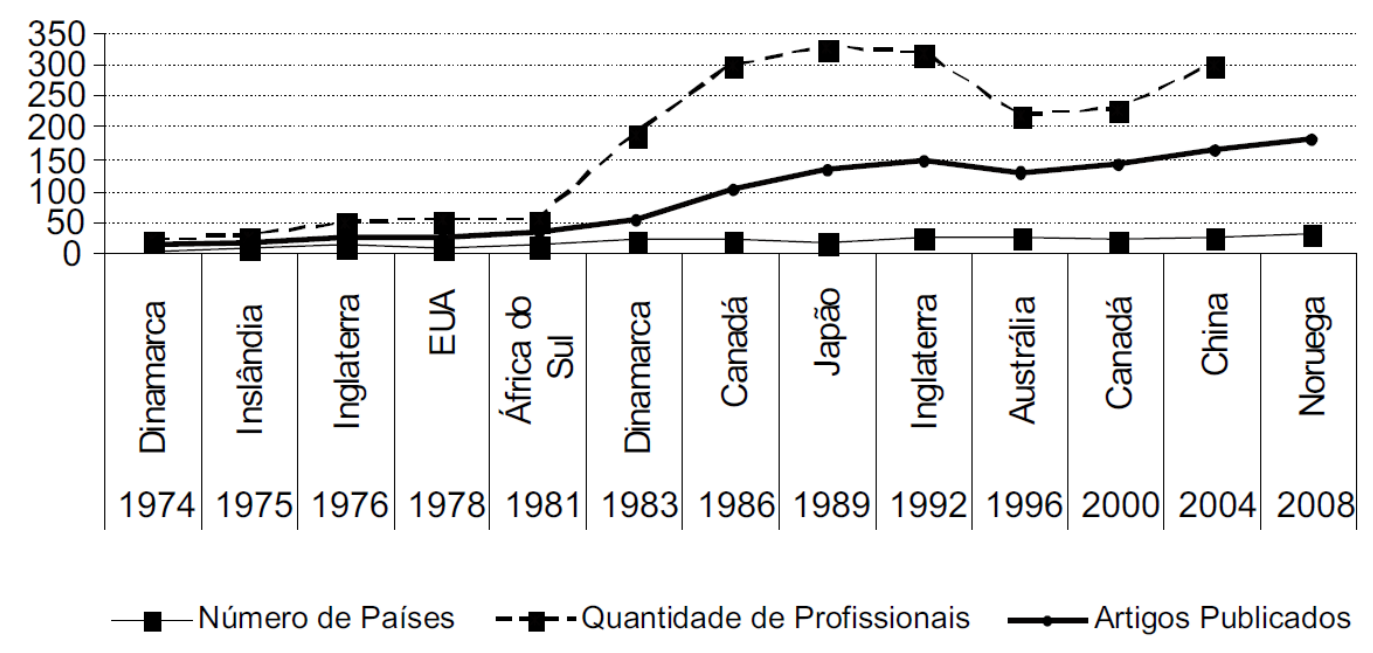

Figura 1.4 - Participação e trabalhos técnicos apresentados na ICAAR.

Fonte: Battagin et al. (2009)

Em 2008, os organizadores da ICAAR estimaram que o custo anual em reparo e reabilitação de obras afetadas pela RAA é de 2,6 bilhões de dólares, ocupando o segundo lugar em investimentos em reparo de estruturas de concreto, perdendo apenas para os custos com a corrosão (GOMES, 2008).

Tendo em vista os elevados custos associados à reabilitação das estruturas afetadas, torna-se necessário o desenvolvimento de um modelo numérico capaz de descrever devidamente a expansão do concreto sujeito à RAA, permitindo tanto a avaliação da segurança das estruturas afetadas quanto o planejamento e projeto de reparos necessários.

Nesse sentido, diversos modelos de expansão devido à reação álcali-agregado foram desenvolvidos, porém são poucos os modelos que consideram a restrição de movimento e tensão induzida pela presença de armadura, uma vez que os estudos desenvolvidos até o momento são mais voltados para barragens (estruturas em concreto massa), estendendo-se 
assim a oportunidade de pesquisa para estruturas armadas como barragens em arco, pontes, blocos de fundações e afins.

Além disso, o trabalho se alinha ao plano de pesquisa do orientador, ampliando as possibilidades de aplicação do modelo macroscópico paramétrico existente, cujas recentes contribuições podem ser verificadas em Oliveira (2013) e em Carrazedo et al. (2012).

\subsection{Metodologia}

O trabalho aqui apresentado envolveu o cumprimento das seguintes etapas que são detalhadas na sequência: (a) revisão bibliográfica (b) implementação do modelo mecânico em MEFP; (c) implementação do modelo de expansão por RAA e (d) validação do modelo numérico apresentado.

a) Revisão bibliográfica: o primeiro passo consistiu em uma revisão bibliográfica para melhor compreensão dos mecanismos físicos e químicos e estágios envolvendo a reação álcali-agregado. Além disso, foi realizada uma revisão dos principais modelos numéricos para a previsão da expansão, além de revisão sobre o Método dos Elementos Finitos Posicional.

b) Implementação do modelo mecânico: o modelo mecânico para representação do elemento em concreto armado foi implementado em linguagem Fortran utilizandose o MEFP. A matriz de concreto foi discretizada como um elemento finito bidimensional de chapa com comportamento elástico-linear; as armaduras e fibras do concreto foram discretizadas como elementos de treliça também com comportamento elástico-linear, sendo estas consideradas perfeitamente aderidas ao elemento de chapa.

c) Implementação do modelo de expansão por RAA: o terceiro passo consistiu na implementação da expansão devido à RAA no modelo mecânico. Foi considerada a distribuição espacial dos fatores que influenciam a reação por meio de leis de normalização que são apresentadas por Carrazedo (2004). Nessa etapa foi dado interesse especial ao fator do normalização associado às tensões de compressão, avaliando-se as leis propostas por Pappalardo Jr. et al. (2000) e as utilizadas por Léger et al. (1996). Também foram analisadas duas equações que expressam a expansão devido à RAA, a equação proposta por Larive (1998) e a de Carrazedo (2004) que é baseada no trabalho de Pietruszczak (1996). Ainda nessa etapa, foi 
implementado o decaimento do módulo de elasticidade com o avanço da RAA, conforme proposto por Pietruszczak (1996) e utilizado em Oliveira (2013).

d) Validação do modelo numérico: por fim, o último passo dessa pesquisa envolveu a seleção de exemplos numéricos a fim de validar tanto o modelo mecânico de chapa elástica reforçada com fibras quanto o modelo de expansão por RAA em concreto armado e reforçado com fibras.

\subsection{Organização da dissertação}

O Capítulo 1 apresenta brevemente o problema da reação álcali-agregado, as principais obras afetadas e seus efeitos na redução da durabilidade das estruturas. Também é apresentada a modelagem numérica da reação como uma ferramenta de avaliação de risco e controle da vida útil da estrutura.

O Capítulo 2 tem por objetivo apresentar definições, características e os principais mecanismos químicos envolvendo a RAA. Também são descritos os principais fatores de influência da reação e como cada um deles afeta a taxa e magnitude da expansão. Outro aspecto importante tratado neste capítulo é a influência da RAA nas propriedades mecânicas (resistência à tração, compressão e módulo de elasticidade) do concreto.

O Capítulo 3 apresenta os principais modelos numéricos existentes para descrever a reação álcali-agregado, dando especial destaque aos modelos macroscópicos, cujo objetivo está em descrever o campo de tensões e deslocamentos de uma estrutura afetada pela RAA.

O Capítulo 4 trata com maiores detalhes do modelo paramétrico de expansão empregado neste trabalho, apresentando as leis constitutivas de expansão avaliadas, discutindo os fatores que influenciam a reação e as simplificações adotadas pelo modelo.

O Capítulo 5 apresenta a formulação do Método dos Elementos Finitos Posicional para uma estrutura de concreto com adição de fibras e/ou armadura. Neste caso, a matriz é discretizada por meio de um elemento de chapa bidimensional e as fibras por elementos de treliça lineares. Os materiais são considerados elástico-lineares e o acoplamento fibra-matriz é considerado perfeitamente aderente.

No Capítulo 6 são apresentados 7 exemplos numéricos. Os três primeiros exemplos têm por objetivo validar o código desenvolvido para chapa com adição de fibras e para chapa submetida à expansão livre devido à RAA. Os últimos exemplos reproduzem numericamente 
ensaios de amostras de concreto armado e reforçado com fibras afetadas por RAA, validando e comprovando a potencialidade do modelo numérico desenvolvido.

Por fim, o Capítulo 7 apresenta as conclusões e dificuldades encontradas no decorrer deste trabalho e sugestões para trabalhos futuros. 


\section{EXPANSÃO DEVIDO À RAA}

\subsection{Mecanismos e estágios da reação}

Reação álcali-agregado é o termo geral que descreve diferentes tipos de reações químicas que ocorrem no concreto. Essas reações envolvem alguns tipos de minerais reativos presentes nos agregados e álcalis (derivados de sódio ou potássio) presentes na solução dos poros do concreto. O produto resultante dessas reações expande quando em contato com a água, causando fissurações e afetando a durabilidade da estrutura (HASPARYK, 2011).

A RAA pode ser classificada em três tipos em função da mineralogia do agregado reativo. A ABNT: NBR 15577-1 (2008) define os seguintes tipos de reações:

a) Reação álcali-sílica (RAS): participam da reação a sílica reativa dos agregados e os álcalis do cimento, formando como produto da reação um gel expansivo. É o tipo de reação que mais rapidamente se desenvolve (HASPARYK, 2011);

b) Reação álcali-silicato: é um tipo específico da reação álcali-sílica em que participam da reação os álcalis e silicatos reativos de alguns tipos de rochas. Em geral essa reação é mais lenta do que a reação álcali-sílica;

c) Reação álcali-carbonato (RAC): participam da reação álcalis e agregados rochosos carbonáticos. A reação também é conhecida por desdolomitização e forma como produto a brucita $\left(\mathrm{Mg}(\mathrm{OH})_{2}\right)$, um composto cristalizado que fissura e enfraquece a zona de transição, sem que ocorra a formação de gel (HASPARYK, 2011).

A reação álcali-sílica (RAS) é o tipo de reação mais frequente no Brasil e relatada como a principal responsável pela deterioração da maioria das estruturas (HASPARYK, 2011), portanto, serão dados maiores detalhes do mecanismo químico desta reação.

A RAS caracteriza-se por ser uma reação química complexa que ocorre entre a sílica cristalina amorfa presente no agregado reativo e os álcalis e íons hidroxila presentes na solução do fluido dos poros do concreto. O produto dessa reação é um gel que expande pela absorção de água (PAN et al., 2012). 
Dent Glasser e Kataoka (1982) dividem a reação entre os álcalis e os minerais silicosos (RAS) em duas fases:

a) Primeira fase: o agregado contendo sílica cristalina sofre ataque de íons hidroxila, rompendo as ligações de siloxano $(S i-O-S i)$ e produzindo silicato alcalino (de sódio ou potássio) e ácido silícico. O ácido silícico formado imediatamente reage com mais íons hidroxila, formando um gel sílico-alcalino.

$$
\begin{gathered}
S i-O-S i \equiv+R^{+}+\mathrm{OH}^{-} \rightarrow \equiv S i-O-R+H-O-S i \equiv \\
\equiv S i-O-H+R^{+}+O H^{-} \rightarrow \equiv S i-O-R+H_{2} O
\end{gathered}
$$

em que $R^{+}$representa um íon alcalino de sódio ou potássio.

b) Segunda fase: o gel sílico-alcalino higroscópico absorve água e expande.

$$
\equiv \mathrm{Si}-\mathrm{O}-\mathrm{R}+n \mathrm{H}_{2} \mathrm{O} \rightarrow \equiv \mathrm{Si}-\mathrm{O}^{-}-\left(\mathrm{H}_{2} \mathrm{O}\right)_{n}+\mathrm{R}^{+}
$$

A Figura 2.1 apresenta um esquema ilustrativo das etapas e reações envolvidas no processo de expansão devido à reação álcali-sílica.

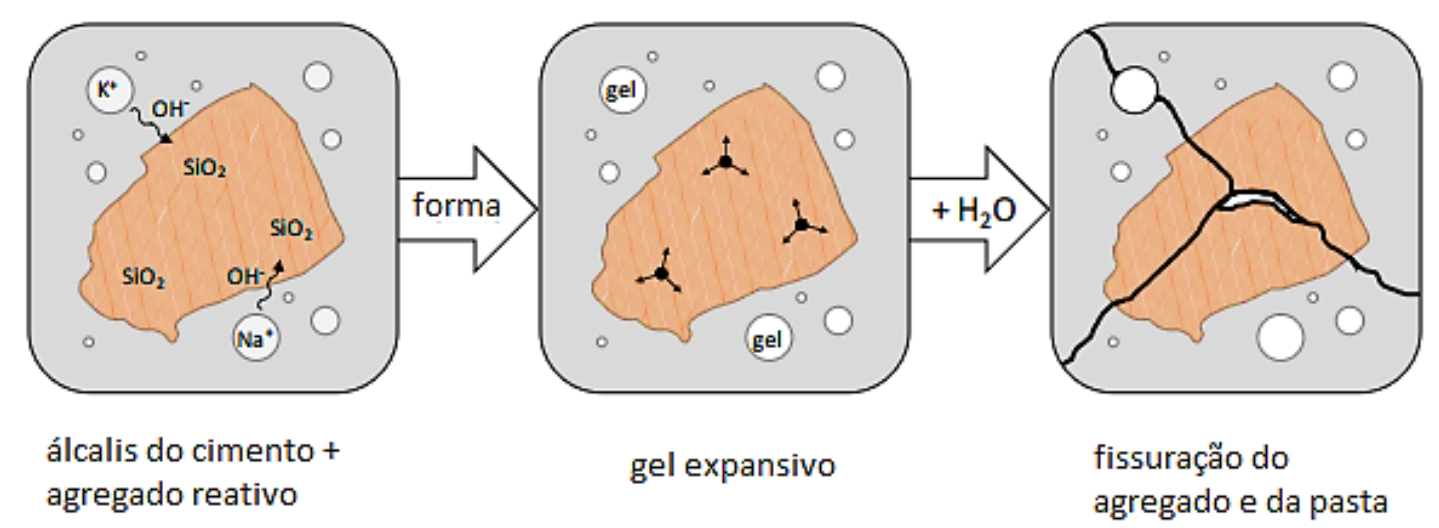

Figura 2.1 - Mecanismo da reação álcali-sílica.

Fonte: Deschenes (2009).

Para Léger et al. (1996), o processo de expansão do concreto afetado pode ser dividido em três estágios:

a) Primeiro estágio (iniciação): o concreto se torna saturado pelos produtos da reação, o gel sílico-alcalino. Para Carrazedo e Lacerda (2008) esse estágio apresenta pequena 
expansão, uma vez que os poros do concreto ainda não foram completamente preenchidos pelo gel;

b) Segundo estágio (desenvolvimento): período de desenvolvimento de pressão, o gel que agora preenche completamente os poros do concreto continua absorvendo água, o que provoca a expansão no concreto;

c) Terceiro estágio (repouso ou esgotamento): nesse estágio ocorre um esgotamento do material reativo, ou seja, não há mais produção de gel e o processo de expansão termina.

Dessa forma, a curva típica da expansão cresce assintoticamente, conforme pode ser observado na Figura 2.2.

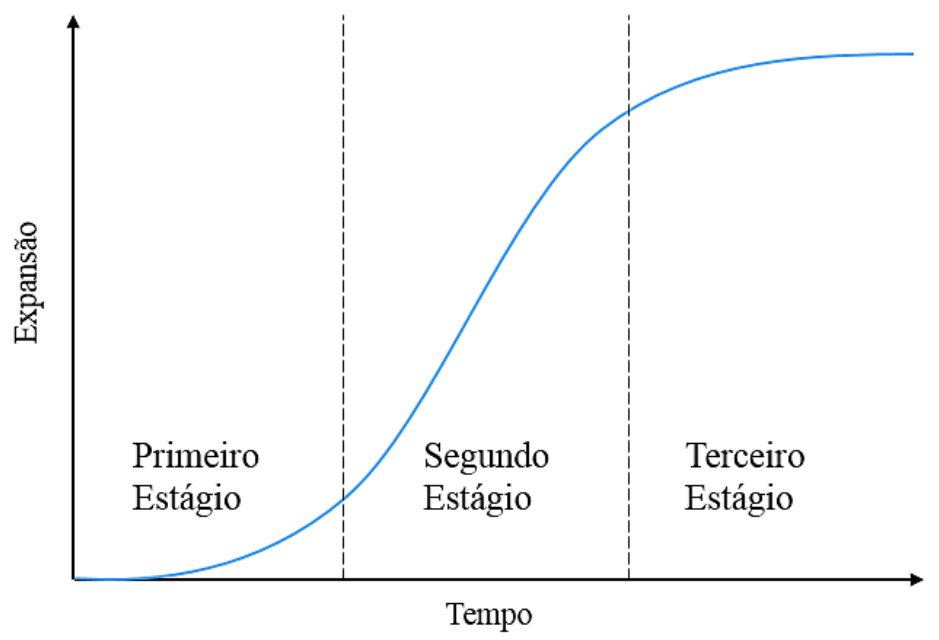

Figura 2.2 - Curva de expansão para concreto afetado por RAA.

Fonte: Adaptado de Madureira (2007).

Mais recentemente, o trabalho de Saouma et al. (2015) apresentou os seguintes estágios da RAA com base em interpretações petrográficas da evolução da reação:

a) Nucleação: a reação tem início ao redor do agregado, sem provocar expansão;

b) Desenvolvimento da reação: ocorre formação do gel nos poros do agregado reativo, dando início à expansão. O gel confinado nos poros do agregado exerce pressão, o que causa fissuração do agregado;

c) Aceleração da reação e deterioração: o processo de deterioração do concreto se torna mais perceptível, uma vez que as fissuras do agregado reativo começam a se propagar 
para a pasta de cimento. Essas fissuras vão aumentando em tamanho e quantidade; e o gel começa a migrar para vazios distantes do agregado reativo;

d) Deterioração severa: ocorre dano severo na estrutura, incluindo falhas como possível ruptura de armadura, distorção e perda de integridade estrutural.

A Figura 2.3 a seguir ilustra os diferentes estágios da reação álcali-agregado segundo Saouma et al. (2015). Na Figura 2.3, $\varepsilon^{\infty}$ representa a máxima deformação volumétrica observada nas estruturas devido à RAA.

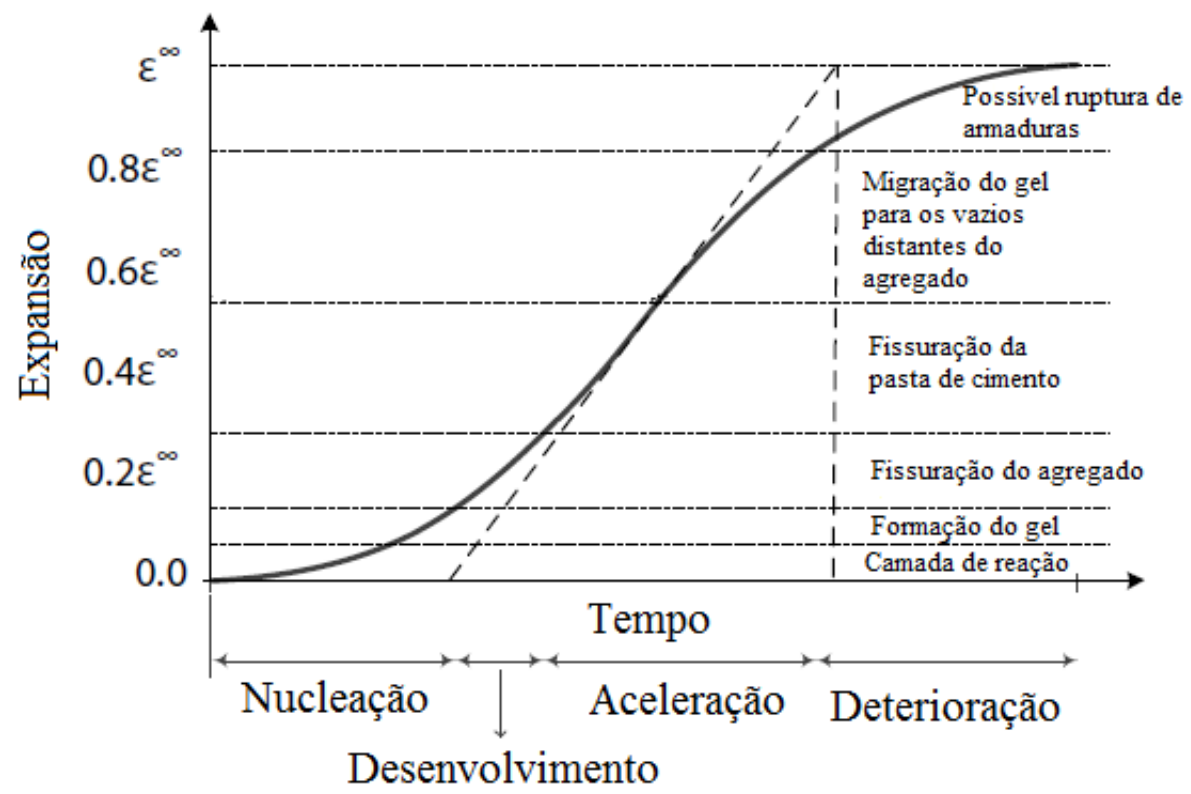

Figura 2.3 - Interpretação petrográfica da evolução da RAA.

Fonte: Saouma et al. (2015).

\subsection{Fatores de influência da reação}

As reações químicas que envolvem a reação álcali-agregado são bastante complexas e diversos fatores podem influenciar tanto a velocidade quanto a intensidade das expansões. A maioria dos autores cita o agregado reativo, o teor de álcalis, a umidade relativa, a porosidade, a temperatura e as tensões confinantes como os principais fatores que influenciam a reação, sendo os três primeiros essenciais (fatores condicionantes) para que a reação ocorra. 


\subsubsection{Agregado Reativo}

Para a ABNT: NBR 15577-1 (2008) agregado reativo ou deletério é aquele que reage quimicamente com a solução alcalina presente nos poros do concreto ou proveniente de fontes externas, resultando em expansão nas estruturas de concreto. Características como mineralogia, quantidade e dimensão dos agregados podem influenciar na sua reatividade.

Em geral, quanto mais desorganizada a estrutura do mineral, por exemplo, os minerais com estrutura amorfa (opala e vidro), maior a reatividade do agregado.

A Tabela 2.1 a seguir registra os resultados obtidos pela Associação Brasileira de Cimento Portland (ABCP) para ensaios de avaliação da reatividade de agregados comerciais.

Tabela 2.1 - Potencialidade reativa de agregados no Brasil.

Fonte: ABCP (2016).

\begin{tabular}{cccc} 
Estado & Total de & \multicolumn{2}{c}{ Potencialidade reativa (\%) } \\
\cline { 3 - 4 } & amostras & $\begin{array}{c}\text { Potencialmente } \\
\text { inócua }\end{array}$ & $\begin{array}{c}\text { Potencialmente } \\
\text { reativa }\end{array}$ \\
\hline Brasil & 1994 & 64 & 36 \\
SP & 532 & 66 & 34 \\
PE & 228 & 71 & 29 \\
PI & 45 & 44 & 56 \\
BA & 70 & 59 & 41 \\
RJ & 119 & 100 & 0 \\
RS & 41 & 27 & 73 \\
MG & 58 & 65 & 35 \\
\hline
\end{tabular}

Percebe-se que quase $40 \%$ dos agregados avaliados no Brasil apresentaram-se potencialmente reativos, o que ressalta a importância de se conhecer a mineralogia e consequente reatividade da rocha empregada como agregado no concreto (HASPARYK, 2011).

Além da mineralogia, a granulometria e a concentração do agregado reativo também mostram ter influência na reatividade.

Em geral, espera-se um aumento da expansão devido à RAA com a redução do tamanho das partículas, em virtude de uma maior área superficial do agregado reativo em contato com a solução dos poros do concreto. Entretanto, observações experimentais não comprovam essa hipótese, mostrando existir um tamanho "péssimo” intermediário que provoca as maiores expansões no concreto (RAJABIPOUR et al., 2015).

O estudo realizado por Stanton (1940) já indicava que o tamanho da partícula poderia influenciar a magnitude da expansão. A Figura 2.4 (a) mostra uma maior expansão para uma 
granulometria de agregado entre 0,18mm e 0,6mm. Reduzindo a dimensão das partículas de agregado (menores que $0,18 \mathrm{~mm}$ ) a expansão é reduzida, indicando assim um tamanho ou dimensão "péssima” de agregado reativo.

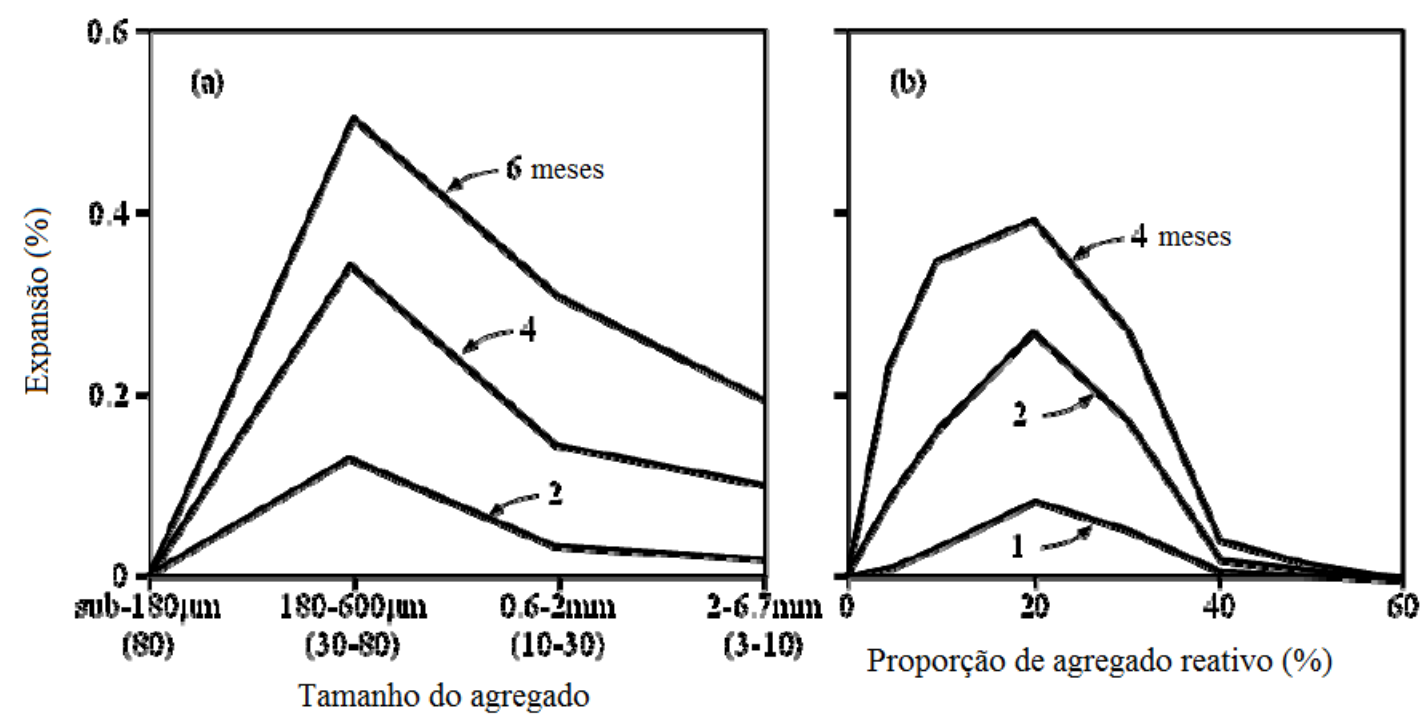

Figura 2.4 - Efeito do tamanho do agregado (a) e proporção (b) na expansão por RAA. Fonte: Stanton (1940).

O mesmo estudo ainda indica que a expansão não necessariamente aumenta com o aumento da quantidade de agregado reativo, conforme apresentado na Figura 2.4 (b). Pode-se observar que a expansão aumenta com o aumento da proporção de agregado reativo, até alcançar uma expansão máxima para 20\% de agregados reativos (teor péssimo); o aumento dessa proporção de agregado reativo leva a uma redução da expansão.

Sabe-se que a quantidade péssima de agregado reativo está diretamente relacionada à quantidade de álcalis presente no concreto. Dessa forma, uma pequena quantidade de sílica será consumida rapidamente pela reação, sem que haja a formação de gel; por outro lado, uma quantidade muito elevada de agregado reativo neutraliza os álcalis disponíveis antes mesmo do endurecimento do concreto e, consequentemente, o volume de gel produzido não acarretará dano ao concreto (MOUNDOUNGOU et al., 2014; SILVA, 2007). Também é possível que efeito semelhante aconteça com o tamanho péssimo do agregado e que este efeito esteja relacionado com a quantidade péssima de agregado reativo (RAJABIPOUR et al., 2015). 


\subsection{2 Álcalis}

Os íons alcalinos são os responsáveis pelo ataque à sílica presente nos agregados reativos, levando à formação e expansão do gel de RAA. Assim, os álcalis também são considerados fatores condicionantes para a reação (HASPARYK, 2011).

A ABNT: NBR 15577-1 (2008) define os álcalis (sódio e potássio) que participam da reação álcali-agregado como aqueles que são solubilizáveis imediatamente ou ao longo do tempo, podendo ser provenientes de fontes internas (cimento, agregados, adições minerais e água de amassamento) ou externas ao concreto (umidade ou soluções salinas que penetram no concreto).

O cimento Portland é considerado como principal fonte de álcalis no concreto, portanto, quanto maior o teor de álcalis no cimento e o consumo de cimento no concreto, maiores suas expansões. Como tentativa de evitar a RAA, profissionais da área de engenharia civil decidiram por limitar a 0,6\% o teor de álcalis no cimento (MEHTA; MONTEIRO, 2008).

Contudo, estudos como o desenvolvido por Stark (1980) utilizando diferentes combinações de agregados reativos e cimentos com vários teores de álcalis evidenciaram que limitar o teor de álcalis do cimento não era efetivo na prevenção da RAA pois, como já citado anteriormente, podem existir outras fontes de álcalis diferentes. Dessa forma, como medida de prevenção, optou-se por limitar a quantidade de álcalis totais no concreto a $3 \mathrm{~kg} / \mathrm{m}^{3}$ (HASPARYK, 2011; MEHTA; MONTEIRO, 2008).

Da mesma forma que a granulometria tem influência na reatividade do agregado, a finura do cimento também desempenha um papel importante na expansão por RAA. Estudos realizados por Hasparyk et al. (2007) mostraram que, quanto mais fino o cimento, maiores são as expansões observadas no concreto.

\subsubsection{Umidade}

Assim como a reatividade dos agregados e o teor de álcalis, a umidade ou a água presente no meio também é considerada fator condicionante para o desenvolvimento da reação álcaliagregado, atuando na dissolução da sílica, transporte de álcalis no concreto e no mecanismo de expansão do gel sílico-alcalino.

A água é fundamental no processo de cura e endurecimento do cimento, sendo utilizadas relações água/cimento que variam de 0,35 a 0,6 para concretos normais. Portanto, a umidade 
resultante da água de amassamento presente nos poros do concreto endurecido já pode atuar dando início à RAA (PIGNATELLI, 2012; HASPARYK, 2011).

A ABNT: NBR 15577-1 (2008) alerta que estruturas maciças, mesmo em ambientes secos, podem conservar umidade suficiente em seu interior para o desenvolvimento da reação. Swamy (1992) indica que a umidade presente no interior desse tipo de estrutura pode chegar a 80-90\%.

Esse mesmo autor também afirma que em ambientes com umidade inferior a $50 \%$ a expansão do concreto é praticamente nula, enquanto que em ambientes com umidade superior a $80 \%$ as expansões passam a ser prejudiciais à integridade do concreto (Figura 2.5), dessa forma, estruturas maciças que estão em contato direto com a água como barragens, pontes e fundações estão mais susceptíveis à deterioração por RAA (MEHTA; MONTEIRO, 2008).

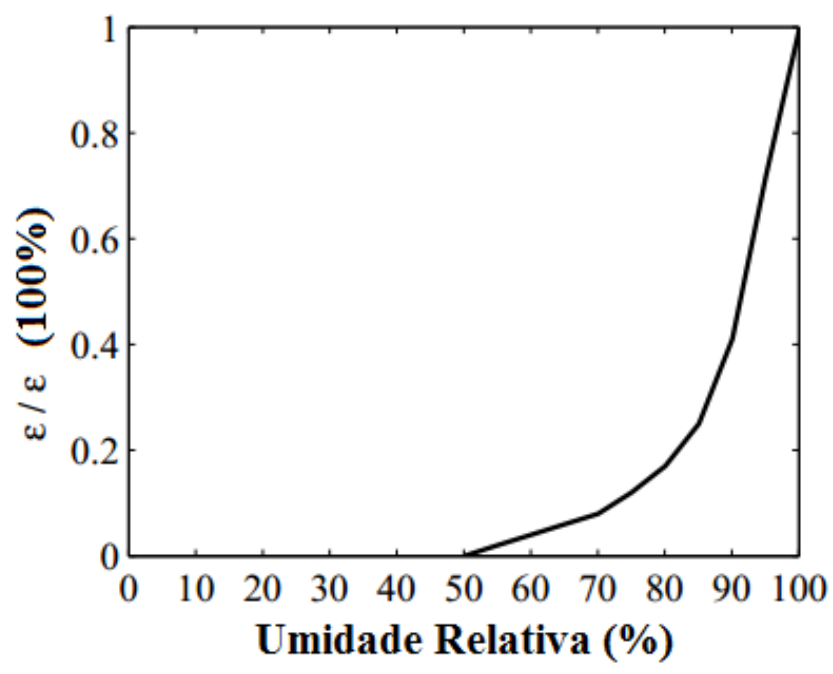

Figura 2.5 - Efeito da umidade relativa na expansão.

Fonte: Adaptado de Swamy (1992).

Estudos desenvolvidos por Larive (1998) e Multon e Toutlemonde (2010) abordaram o efeito do fornecimento de água tardio em amostras de concreto sujeitas à RAA. A Figura 2.6 mostra os resultados obtidos pelo estudo desenvolvido por Larive (1998). As observações desse estudo mostraram que a reação continua a se desenvolver mesmo sem o fornecimento direto de água. As amostras que passaram mais tempo sem o fornecimento de água (450 dias) apresentaram expansões menores do que as permaneceram apenas 90 dias sem o fornecimento de água. 


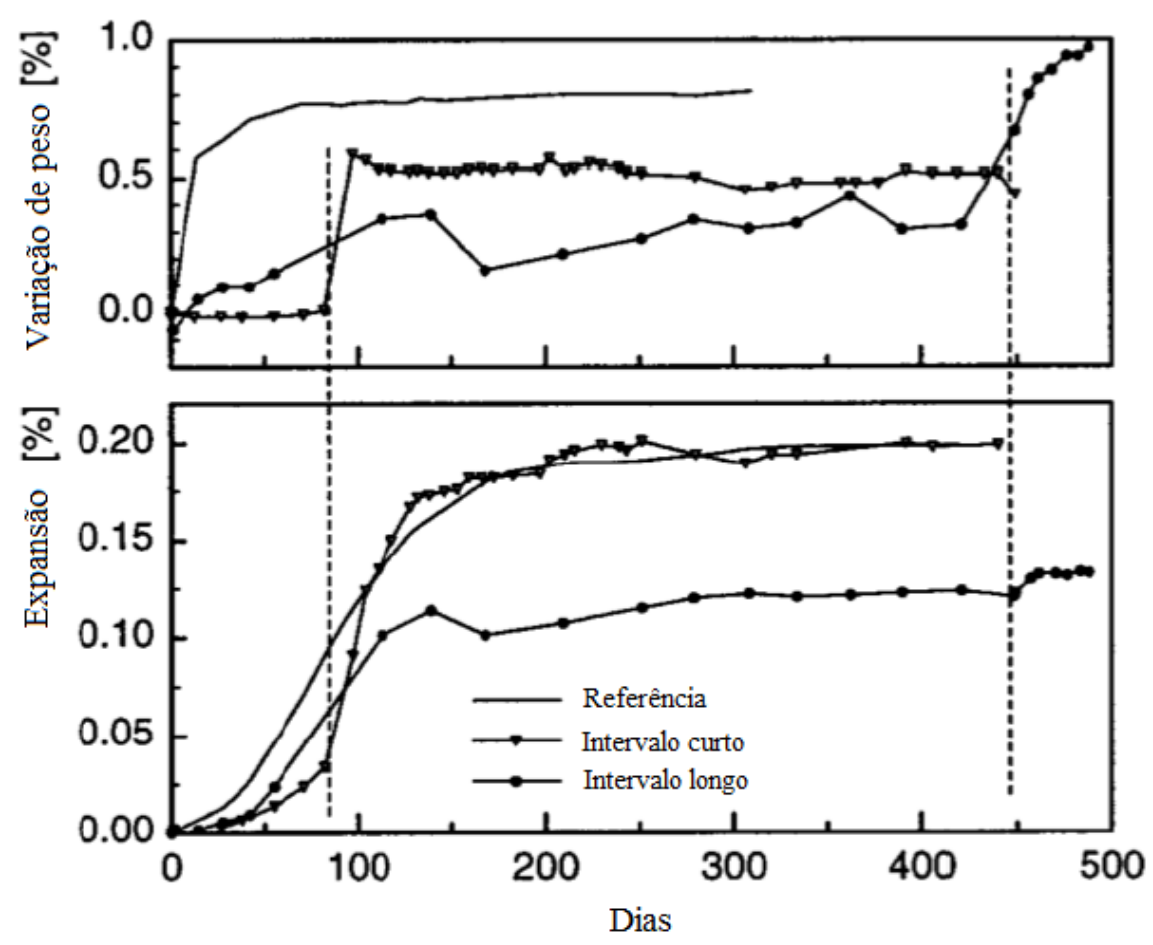

Figura 2.6 - Efeito do fornecimento de água tardio em amostras de concreto sujeitas à RAA. Fonte: Larive (1998).

Pesquisas recentes como a de Kagimoto et al. (2016) avaliaram o comportamento de amostras de concreto afetadas pela RAA sujeitas à ciclos de secagem e ressaturação. Os resultados obtidos indicam que após o processo de secagem e ressaturação, o interior das amostras apresentou maior expansão do que as partes mais superficiais, podendo-se concluir que a fissuração observada na superfície das amostras seja resultado dessa expansão diferencial.

\subsubsection{Temperatura}

Temperaturas elevadas tendem a aumentar a dissolução dos componentes da reação, podendo assim aumentar ou reduzir a taxa de expansão; mas têm pouca influência na máxima deformação volumétrica (CARRAZEDO; LACERDA, 2008).

O efeito da temperatura na expansão por RAA não apresenta uma interpretação fácil, uma vez que o aumento da temperatura, além de elevar a velocidade com que a reação ocorre, também reduz a viscosidade do gel. Um gel menos viscoso tem a capacidade de se espalhar mais facilmente pelos poros do concreto o que reduz o potencial expansivo do concreto (PIGNATELLI, 2012). 
A Figura 2.7 mostra os resultados dos experimentos realizados por Larive (1998). Nesse experimento, duas amostras de concreto foram submetidas a diferentes temperaturas, podendose observar que a amostra exposta a uma temperatura mais elevada apresentou uma maior taxa de expansão inicial, porém uma menor expansão final.

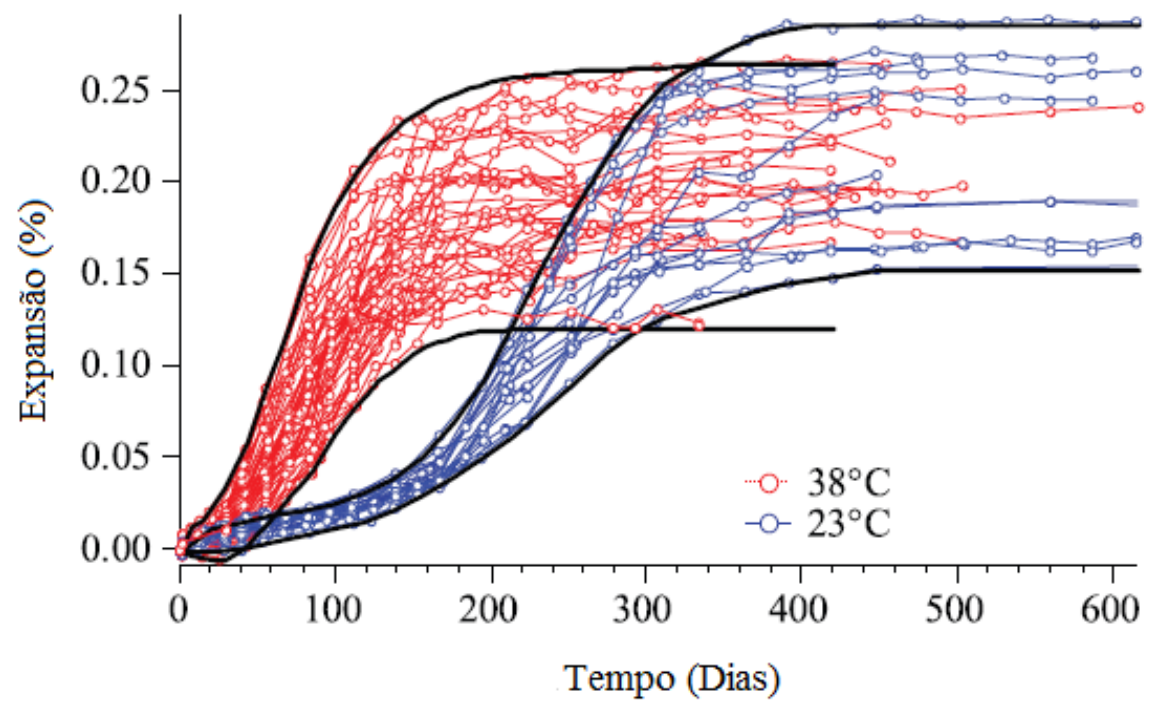

Figura 2.7 - Expansão devido à RAA para diferentes temperaturas.

Fonte: Larive (1998).

Segundo Urhan (1987), a elevação da temperatura aumenta tanto a velocidade da dissolução da sílica quanto a formação de $C-S-H$ no concreto, assim, acima de certa temperatura (geralmente $40^{\circ} \mathrm{C}$ ), a formação de $C-S-H$ supera a dissolução de sílica, reduzindo a expansão por RAA.

\subsubsection{Porosidade}

Madureira (2007) afirma que a porosidade tem influência na reação álcali-agregado de duas maneiras opostas. Se, por um lado, uma porosidade maior no concreto retém maior quantidade de água em seu interior, sendo indispensável para a ocorrência da RAA, uma maior porosidade também significa que o gel tem maior espaço físico para expandir antes de iniciar a pressão e fissuração no concreto.

Em concretos com baixa porosidade, a mobilidade da água e do gel no seu interior é limitada, reduzindo assim a expansão do gel e até mesmo a sua formação (CARRAZEDO, 2004). 


\subsubsection{Tensões confinantes}

A maioria das obras civis está sujeita a elevadas tensões, resultado de seu peso próprio e carregamento. Diversos estudos experimentais verificaram os efeitos da RAA em amostras submetidas a tensões de compressão aplicadas e induzidas pela presença de fibras e armadura: Hobbs (1988), Clark (1991), Swamy e Al-asali (1990), Jones e Clark (1996), Multon e Toutlemonde (2006), Saouma e Peroti (2006), Kagimoto et al. (2014).

Os experimentos conduzidos por Larive (1998) já indicavam que em concretos afetados por RAA sujeitos à tensão de compressão a taxa de expansão era reduzida na direção de compressão; indicando também que as expansões se tornam praticamente nulas para tensões de compressão acima de 8MPa.

Outros estudos também mostraram que, em uma estrutura afetada por RAA sujeita a tensões de compressão, a expansão restringida na direção comprimida é redistribuída para direções menos comprimidas da estrutura, gerando expansão anisotrópica no concreto. Este efeito ficou conhecido na literatura por "transferência de expansão" ou "redistribuição de expansão” (ESPOSITO, 2016). Dessa forma, a fissuração caracterizada como mapeada para o concreto sujeito a expansão livre passa agora a ser caracterizado por um padrão de fissuração em direção paralela à direção restringida como ilustra a Figura 2.8.

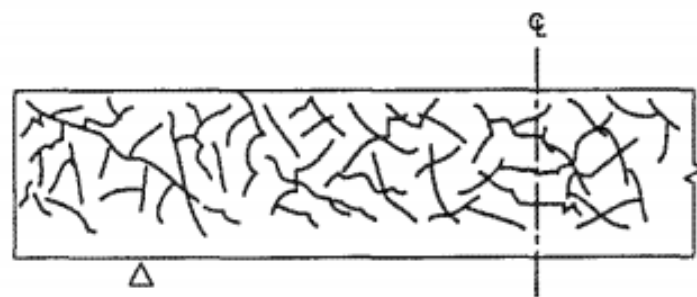

a)

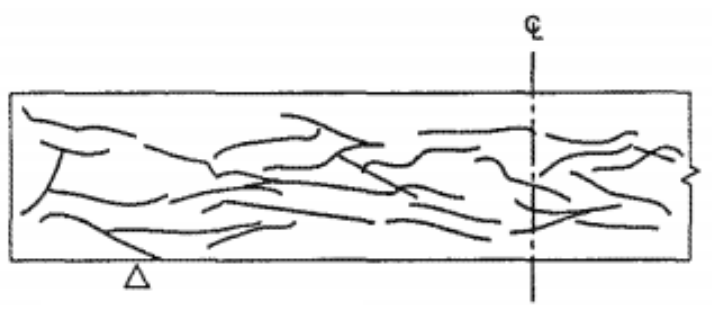

b)
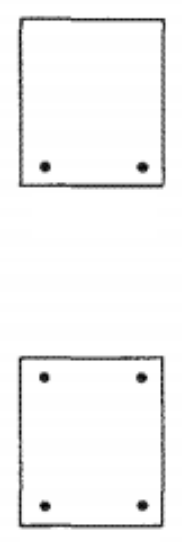

(b) armadura em ambas as faces. Fonte: ISE (1992).

A Figura 2.9 mostra os resultados experimentais obtidos por Multon e Toutlemonde (2006) para a expansão de corpos de prova cilíndricos sob diferentes níveis de tensão de 
compressão. Os resultados indicam que a expansão axial é reduzida e a expansão radial (direção menos comprimida) aumenta com o aumento da tensão de compressão aplicada. Este mesmo estudo também avaliou o efeito observado no concreto confinado por uma camisa de aço sob diferentes níveis de tensão, revelando que a expansão restringida na direção radial era transferida para a direção longitudinal.

(a)

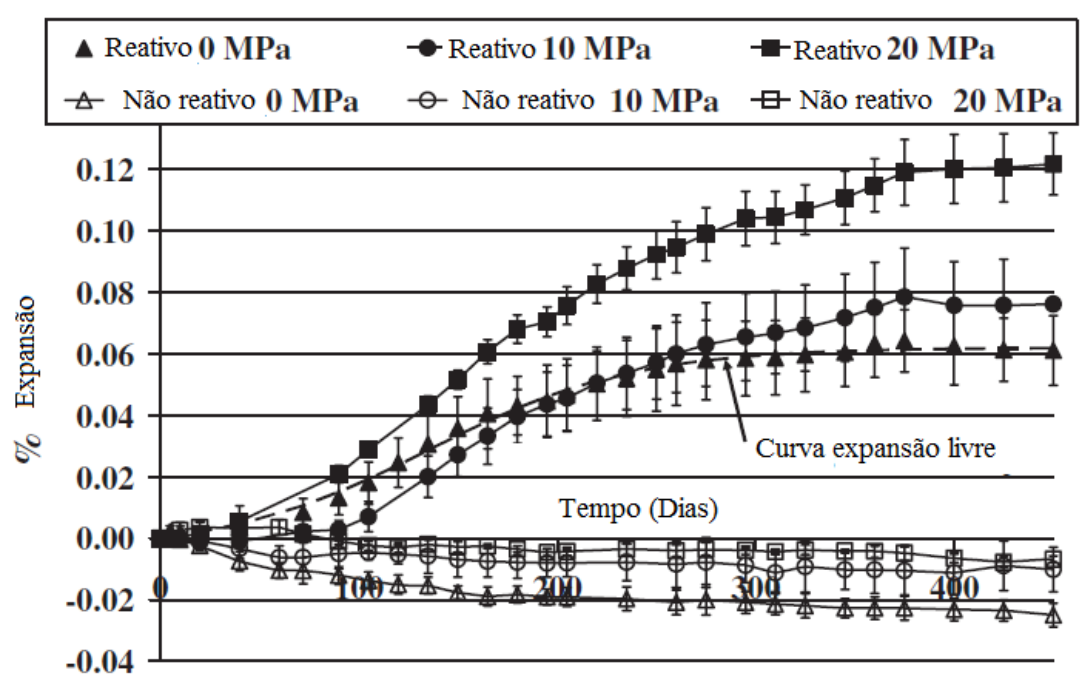

(b)

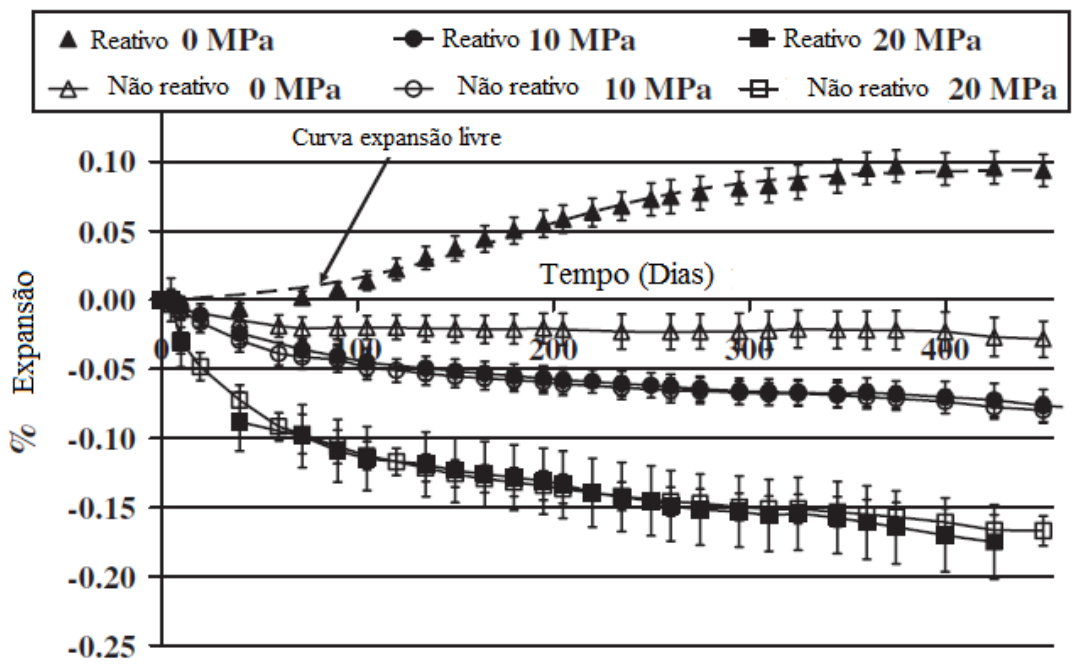

Figura 2.9 - Deformação (a) radial e (b) axial para concreto com e sem agregado reativo sob carregamento axial. Fonte: Multon e Toutlemonde (2006).

Jones e Clark (1996) também realizaram análises experimentais em corpos de prova cilíndricos, considerando diferentes níveis de tensão de compressão aplicadas, diferentes taxas de armadura e o efeito conjunto de tensões tanto de tração como de compressão em concreto contendo armadura. Alguns dos resultados encontram-se ilustrados na Figura 2.10 e 
comprovam que tanto o aumento das tensões de compressão quanto o aumento da taxa de armadura reduzem a expansão na direção comprimida.

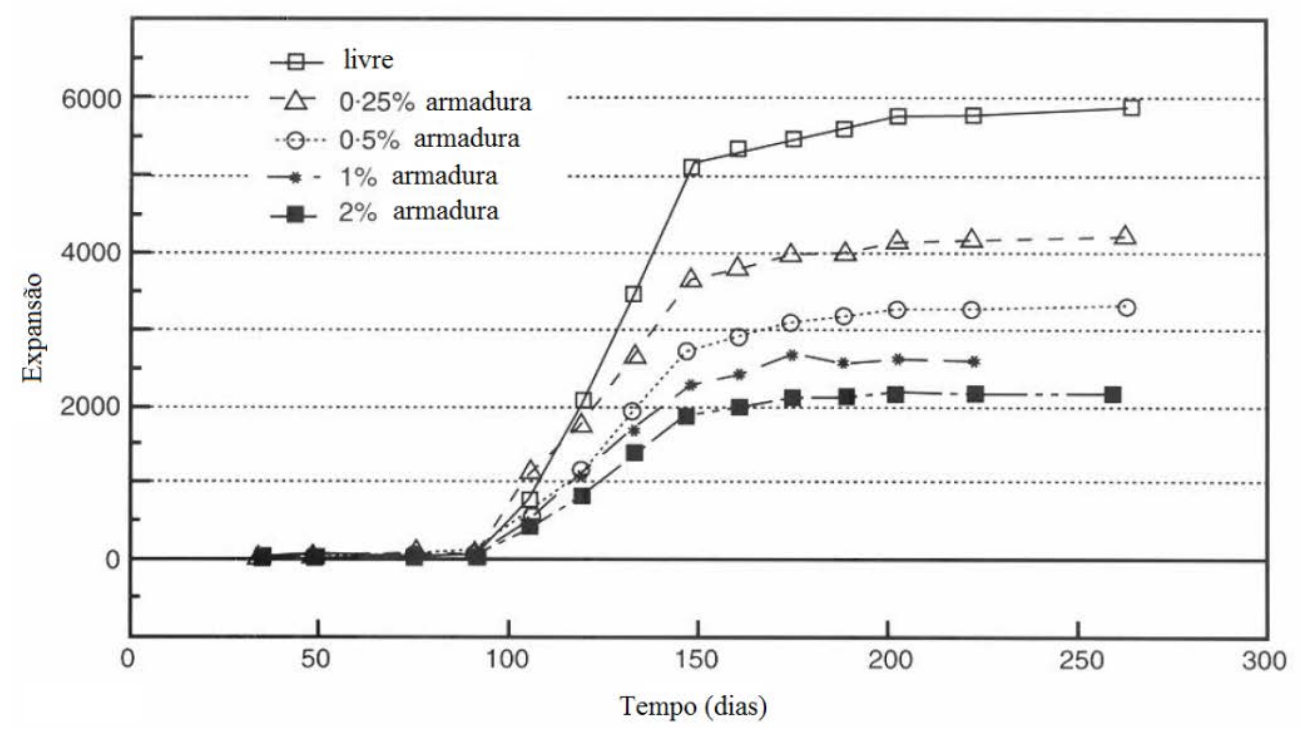

(a)

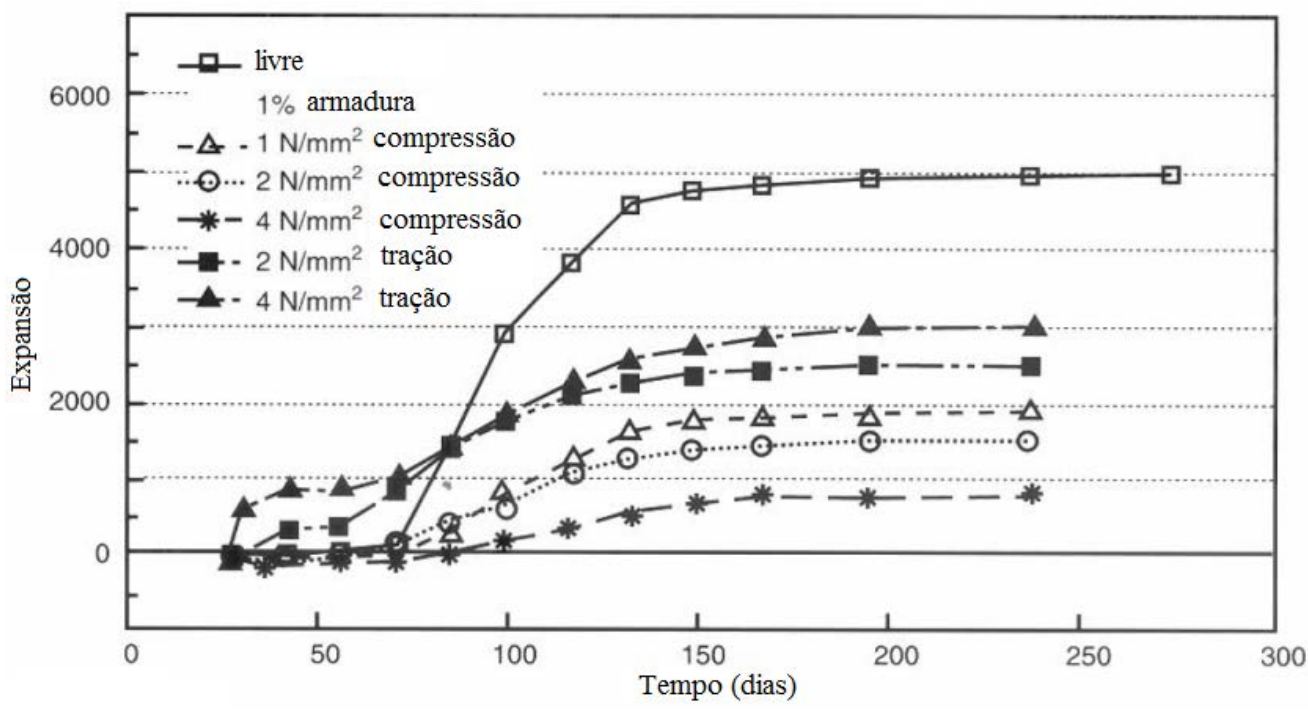

Figura 2.10 - Expansão de amostras de concreto (a) para diferentes taxas de armadura e (b) com armadura e submetidas a diferentes níveis de tensão.

Fonte: Jones e Clark (1996).

Smaoui et al. (2007) avaliaram o efeito da expansão em vigas de concreto armado afetadas pela RAA, comprovando que o aumento da taxa de armadura reduz a deformação na direção paralela à armadura, mas aumenta a deformação na direção perpendicular, mantendo uma deformação volumétrica total constante.

Noel et al. (2016) ressaltam o efeito chamado de "protensão química” nas estruturas de concreto armado afetadas pela RAA. Segundo os autores, a expansão restringida gera tensões 
no concreto e nas armaduras, provocando gradientes de deformação nas vigas. Na face inferior das vigas (região sujeita à tração) concentram-se as maiores taxas de armadura, portanto, ocorrem maiores tensões e menores deformações por RAA nessa região, resultando em uma curvatura negativa no elemento estrutural como mostra a Figura 2.11.

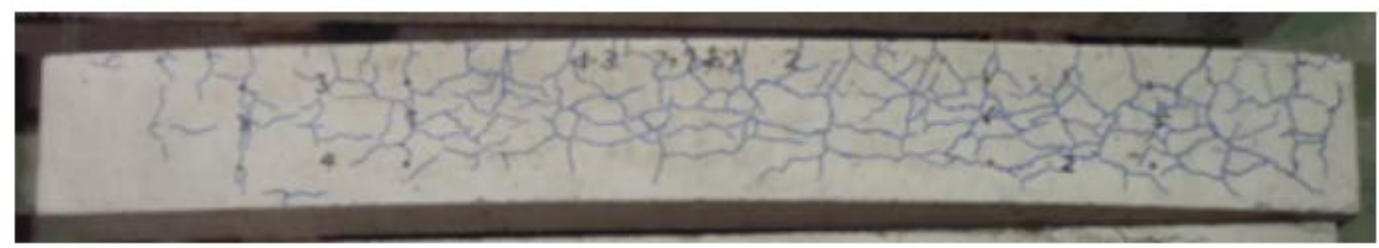

Figura 2.11 - Configuração arqueada em viga afetada pela RAA.

Fonte: Kobayashi et al. (2013).

Entretanto, ao contrário do que se espera (redução na deflexão da viga), o efeito de protensão química vem associado à fissuração resultante da RAA, o que, além de reduzir o módulo de elasticidade do concreto, ainda pode reduzir a ancoragem ou plastificar as armaduras de tração. Dessa forma, esse efeito pode afetar o modo de falha das estruturas de concreto armado (NOEL et al., 2016; KOBAYASHI et al., 2013).

Alguns pesquisadores como Swamy e Al-Asali (1990) entre outros, comprovaram experimentalmente que vigas afetadas pela RAA apresentam redução na sua capacidade de carga quando comparadas com estruturas não afetadas.

Outro importante efeito associado à redução da capacidade de carga de vigas afetadas pela RAA é apresentado por Miyagawa et al. (2006). Em 1990, no Japão, foram observadas cerca de 30 estruturas de concreto afetadas pela RAA apresentando ruptura frágil nas armaduras. As rupturas observadas ocorreram principalmente nos estribos, nas regiões de dobra da armadura (Figura 2.12), afetando a capacidade de carga da estrutura.

O mecanismo associado à ruptura proposto por Miyagawa et al. (2006) pode ser descrito por:

a) O processo de dobra da armadura gera deformações e fissuras na armadura;

b) Com o tempo as deformações e, consequentemente, a sensibilidade à fratura também aumentam;

c) O concreto fissurado devido à expansão por RAA facilita a entrada de umidade e cloretos (ambiente favorável à corrosão); 
d) A expansão por RAA gera concentração de tensões e fissuração na região de dobra da armadura o que pode levar à ruptura frágil do material. Além disso, a presença de tensões de tração na armadura e um ambiente potencialmente corrosivo podem resultar em avanço da fragilização da armadura.
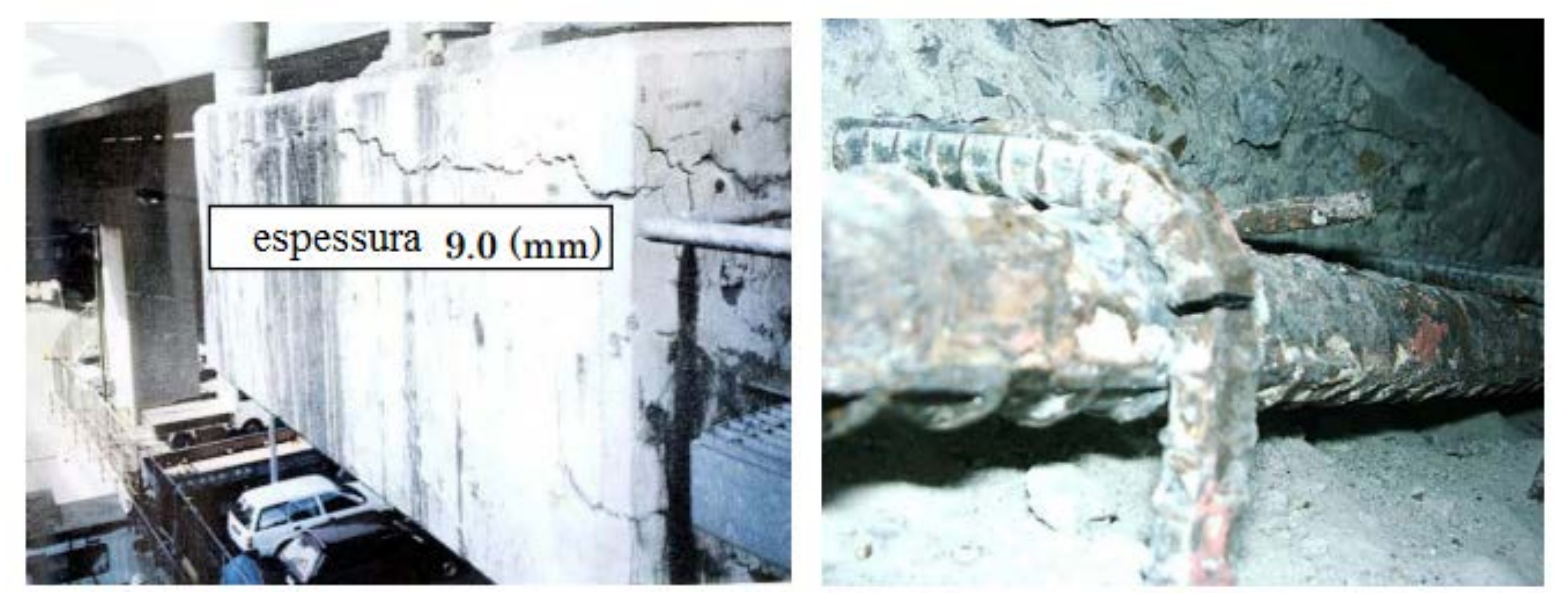

Figura 2.12 - Fratura de armadura em estrutura afetada pela RAA.

Fonte: Miyagawa et al. (2006).

Pode-se perceber que o campo de tensões ainda é um fator de influência da RAA que precisa ser estudado mais a fundo. Além das pesquisas acerca das tensões aplicadas e devido à presença de armaduras, ainda tem-se desenvolvido pesquisas experimentais sobre a influência de fibras na redução da expansão por RAA (Haddad e Smadi (2004), Carvalho et al. (2010) e Giaccio et al. (2015)) e outras analisando a aderência das fibras e armaduras em concretos sujeitos à RAA (Beglarigae e Yazici (2013); Villemure et al. (2016)).

\subsubsection{Outros}

Ainda é possível apontar a direção de lançamento do concreto durante o processo de concretagem como um fator que influencia a orientação da expansão e da formação de fissuras. Os experimentos realizados por Larive (1998) já apontavam que a expansão ocorre preferencialmente em direção paralela ao lançamento.

A Figura 2.13 compara as expansões obtidas para cilindros e prismas moldados com o mesmo concreto e mantidos sob as mesmas condições. Observa-se que a expansão perpendicular à direção do lançamento do concreto resultou semelhante tanto nos corpos de 
prova cilíndricos quanto nos prismas, além disso, também é possível constatar que a expansão paralela à direção do lançamento nos cilindros resultou superior à expansão na direção perpendicular ao lançamento.

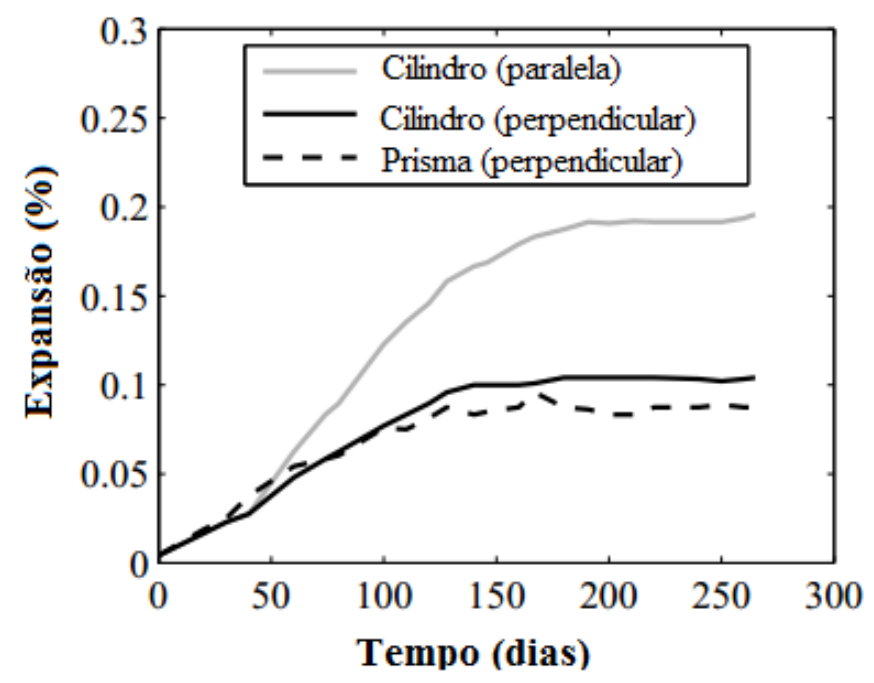

Figura 2.13 - Influência da direção de lançamento do concreto na expansão devido à RAA.

Fonte: Esposito (2016).

Esposito (2016) afirma que em amostras de concreto não afetadas pela RAA a resistência à tração na direção em que o concreto foi lançado é reduzida. Esse efeito é associado à distribuição dos poros no concreto, o que determina tanto a direção da expansão quanto a direção com menor resistência à tração.

\subsection{Efeitos da RAA nas propriedades mecânicas do concreto}

O avanço da reação pode causar micro fissuração e movimentação diferencial, afetando importantes propriedades mecânicas da estrutura (LÉGER et al., 1996).

Diversos autores observaram modificações no módulo de elasticidade, resistência à tração e à compressão para amostras sujeitas à RAA, contudo, os resultados observados apresentam grande variabilidade, uma vez que as condições de ensaio (temperatura, umidade e duração do ensaio), bem como as magnitudes de expansão observadas também variam de autor para autor. Um único consenso entre os pesquisadores é que o módulo de elasticidade reduz cerca de 50 a 60\% com a reação álcali-agregado (PIGNATELLI, 2012).

Deschenes (2009) agrupou resultados obtidos para módulo de elasticidade, resistência à tração e resistência à compressão de pesquisas utilizando agregado reativo realizadas no Reino 
Unido entre 1988 e 2006 e no Texas. A Figura 2.14 apresenta os resultados dessas pesquisas em função da expansão observada no concreto em comparação com os limites estabelecidos pelo ISE (1992), podendo-se comprovar que a resistência à tração e o módulo de elasticidade são as propriedades que sofrem maior influência da RAA.
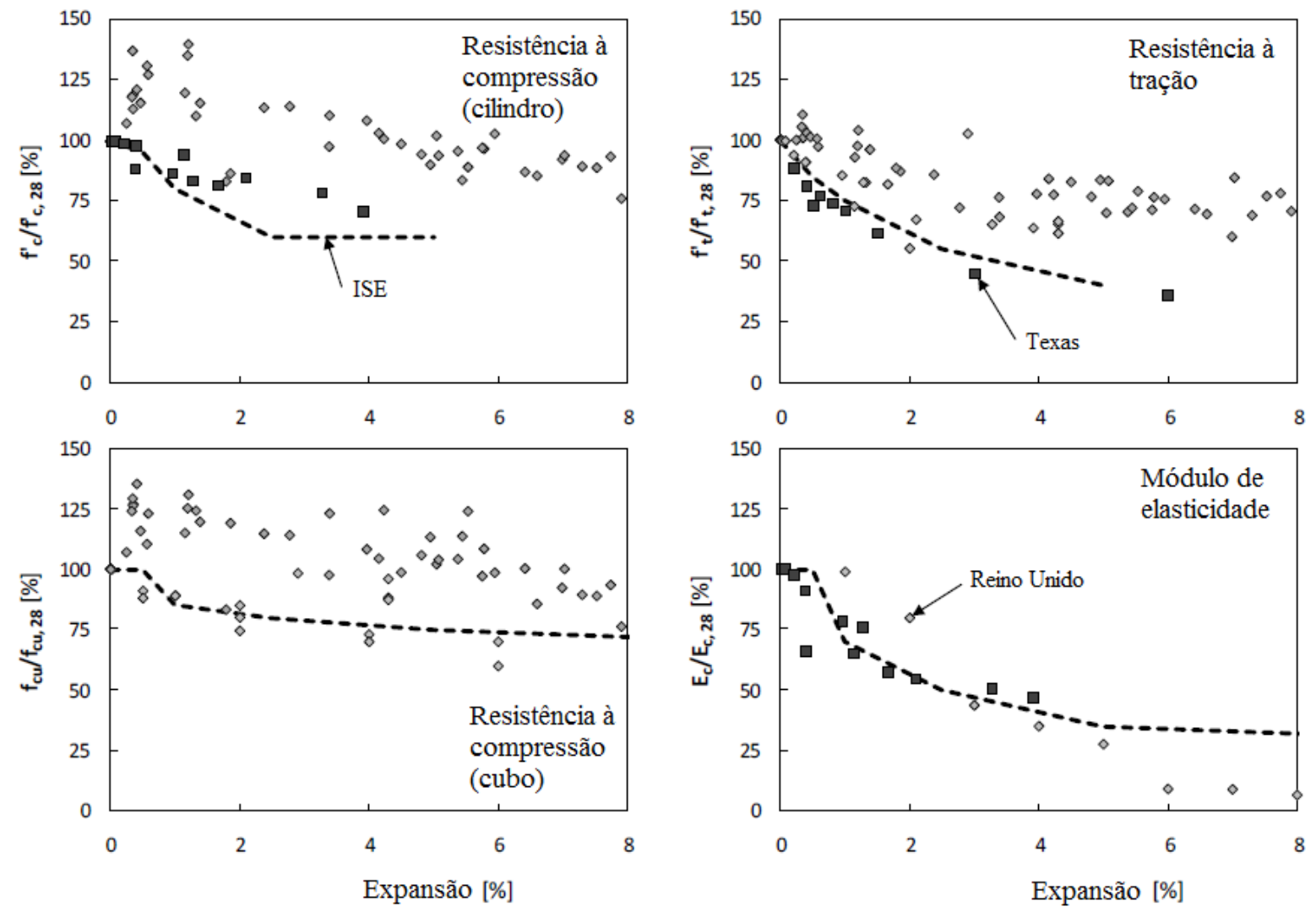

Figura 2.14 - Influência da RAA nas principais propriedades mecânicas do concreto.

Fonte: Deschenes (2009).

Hasparyk (2011) ressalta que o módulo de elasticidade é a propriedade mais sensível à RAA, sendo influenciada desde o início da reação. A resistência à compressão não é um bom parâmetro para se investigar a RAA, pois em função do estágio em que se encontra a reação seu valor pode crescer devido ao preenchimento dos poros pelos produtos da reação.

A Figura 2.15 ilustra a modificação das propriedades mecânicas de amostras de concreto afetadas pela RAA. Observa-se uma redução de 46\% para o módulo de elasticidade, enquanto que a resistência à compressão cresce por um período inicial (preenchimento dos poros do concreto pelo gel) até atingir um valor máximo e só depois reduz em 24\% (HASPARYK, 2005). 


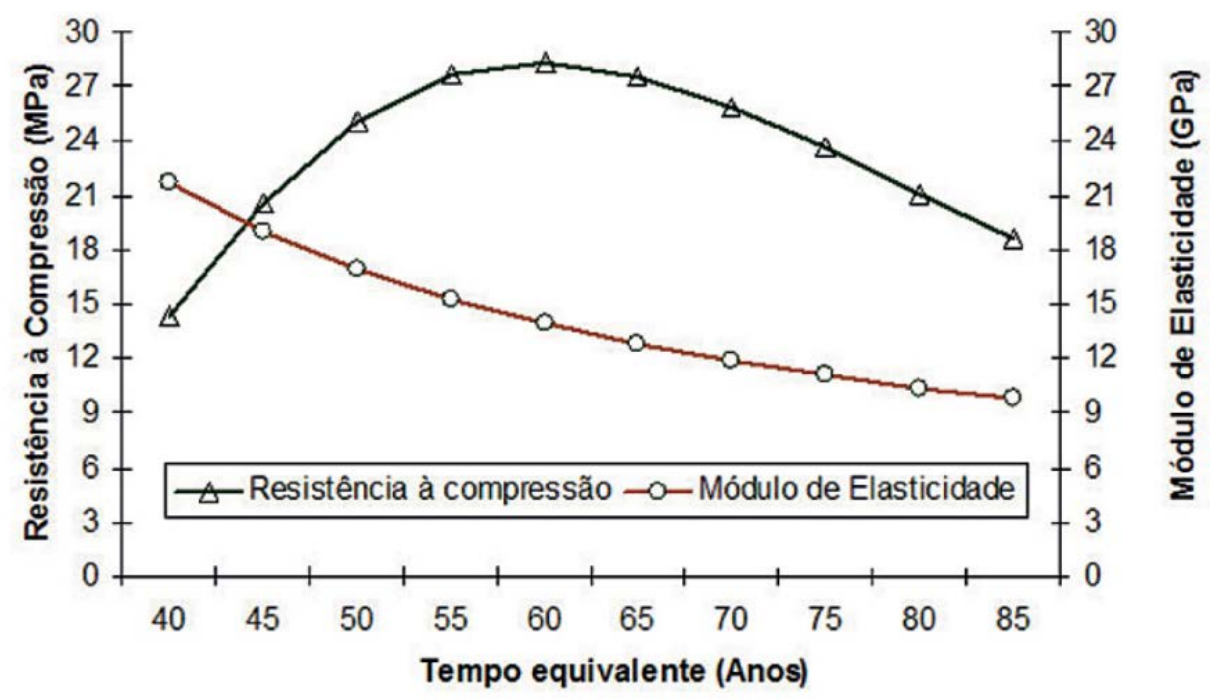

Figura 2.15 - Modelagem das propriedades mecânicas de testemunhos de concreto afetados pela RAA.

Fonte: Hasparyk (2005).

\subsection{Características visuais de estruturas afetadas pela RAA}

Os elementos de concreto afetados pela RAA podem apresentar diferentes características, em função dos diferentes fatores de influência aos quais possam estar sujeitos. Dessa forma, dependendo dos fatores e demais condições a RAA pode levar de 5 a 12 anos para se fazer perceptível nas estruturas (HASPARYK, 2011).

Hasparyk (2011) enumera as principais características de estruturas afetadas pela reação álcali-agregado:

a) Fissuração, podendo ser mapeada ou orientada (em concreto armado);

b) Exsudação de gel na superfície do concreto;

c) Eflorescência superficial e macro-fissuras com descoloração ao longo de suas bordas;

d) Desplacamento de argamassa;

e) Expansão visível, incluindo abertura de juntas.

A Figura 2.16 a seguir ilustra algumas das características de estruturas afetadas pela RAA. Ressalta-se que em estágio mais avançado, as fissuras resultado da RAA podem, além de afetar as propriedades mecânicas do concreto, permitir o ingresso de água e outros agentes agressivos, o que facilita a instalação de outros processos de degradação, como, por exemplo, a corrosão em estruturas armadas (HASPARYK, 2011).

Diversos pesquisadores afirmam que não há relato de estrutura que tenha vindo ao colapso em função exclusivamente da RAA, entretanto, a segurança das estruturas afetadas se 
torna seriamente comprometida a partir do momento em que ocorre ruptura das armaduras (MYAGAWA et al., 2006).
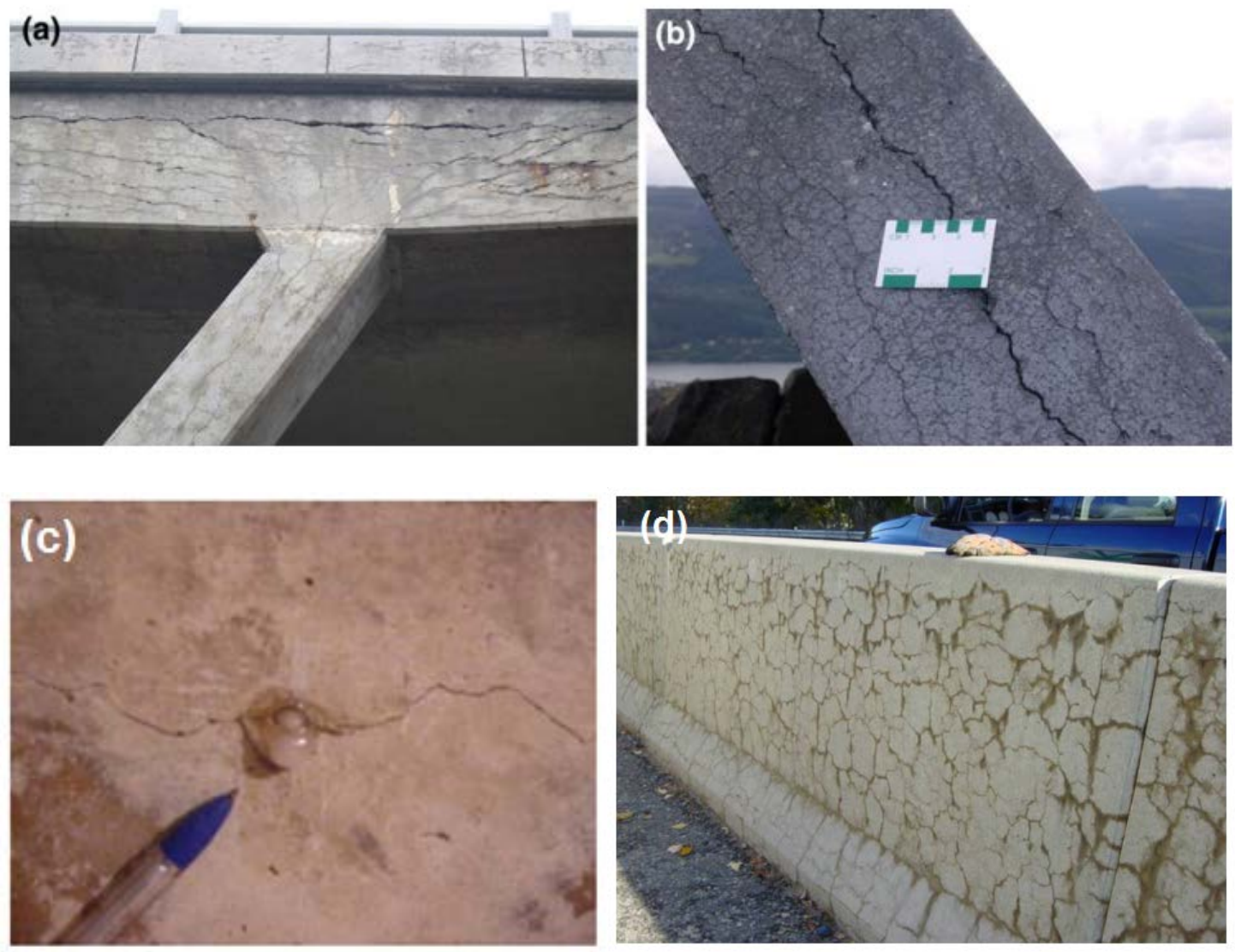

Figura 2.16: Manifestações patológicas resultantes da RAA. (a, b) Fissuração orientada e paralela à direção da armadura em elementos de concreto armado. (c) Exsudação de gel através de uma fissura. (d) Fissuração mapeada característica da RAA.

Fonte: (a,b) Fernandes e Broekmans (2013); (c) Hasparyk (2005); (d) FHWA (2013). 


\section{MODELAGEM DA RAA}

Como já citado anteriormente, a reação álcali-agregado é uma reação bastante complexa envolvendo muitos fatores e cujo processo ainda não foi completamente entendido. Nesse contexto, a modelagem da RAA se torna uma ferramenta útil para a previsão do comportamento estrutural, controle da segurança e projeto de reparos nas estruturas afetadas (PAPPALARDO et al., 2000).

Rajabipour et al. (2015) afirmam que a modelagem da RAA pode ser caracterizada em termos do método (analítico ou numérico), da extensão (à nível do material ou à nível da estrutura) e de hipóteses físicas envolvendo o modelo.

Para Wu et al. (2014), os modelos podem ser divididos em função da heterogeneidade do concreto:

a) Macro escala: considera o material homogêneo;

b) Meso escala: considera uma matriz da pasta de cimento hidratada, agregados, poros e zonas de transição entre o agregado e a pasta de cimento;

c) Micro escala: o material é constituído pela microestrutura da pasta de cimento endurecida, incluindo os produtos da hidratação, clínquer não-hidratado e micro poros.

Já para Pan et al. (2012), existem dois principais aspectos envolvendo a modelagem do comportamento de estruturas afetadas pela RAA: a modelagem da cinética da reação química e dos processos de difusão; e a modelagem do processo de fratura que é induzido pela expansão e causa degradação do concreto.

Ainda segundo Pan et al. (2012), os modelos matemáticos que descrevem a RAA podem ser divididos em três tipos: modelos teóricos, modelos mesoscópicos e modelos macroscópicos. Sobre estes serão dados maiores detalhes nas próximas seções. 


\subsection{Modelos teóricos}

Os modelos teóricos lidam com os mecanismos químicos da reação (processo de difusão, cinética da dissolução, formação e expansão do gel). O objetivo destes modelos está em prever a expansão péssima do concreto e o correspondente tamanho péssimo de agregado. Geralmente se baseiam na análise de um elemento de volume representativo, que consiste em uma partícula de agregado envolta por uma camada de pasta de cimento e descrevem a interação entre o gel e a matriz (PAN et al., 2012).

Embora esses modelos apresentem pouca relevância para a análise estrutural de elementos afetados, são fundamentais para o entendimento dos mecanismos e processos que levam à expansão (JURCUT, 2015).

Hobbs (1981) apresentou um modelo teórico para previsão do tempo de fissuração e expansão de argamassas sujeitas à RAA. A taxa de reação era considerada diretamente proporcional à quantidade de agregado reativo.

Groves e Zhang (1990) propuseram uma teoria para a previsão da expansão de argamassas incluindo partículas de sílica reativa. Para esse modelo, o gel, produto da RAA, é produzido na interface entre as partículas de agregado e a pasta de cimento, sendo a expansão da argamassa dada pelo aumento do volume da partícula de agregado e da camada de gel (produto da RAA).

Furusawa et al. (1994) também propuseram um modelo para previsão da expansão de argamassas. Esse modelo combina a difusão dos hidróxidos e álcalis com a expansão induzida pela reação. O modelo considera a existência de uma região porosa em volta do agregado e a expansão tem início apenas quando os produtos da reação já tiverem preenchido os vazios dessa região.

Bazant e Stefens (2000) desenvolveram um modelo baseado na análise de uma partícula cúbica de concreto contendo um único agregado reativo de forma esférica (Figura 3.1). O agregado reativo é envolto por uma camada de gel produto da RAA e tem expansão controlada pelos processos de difusão, dependentes da umidade relativa presente nos poros capilares. 


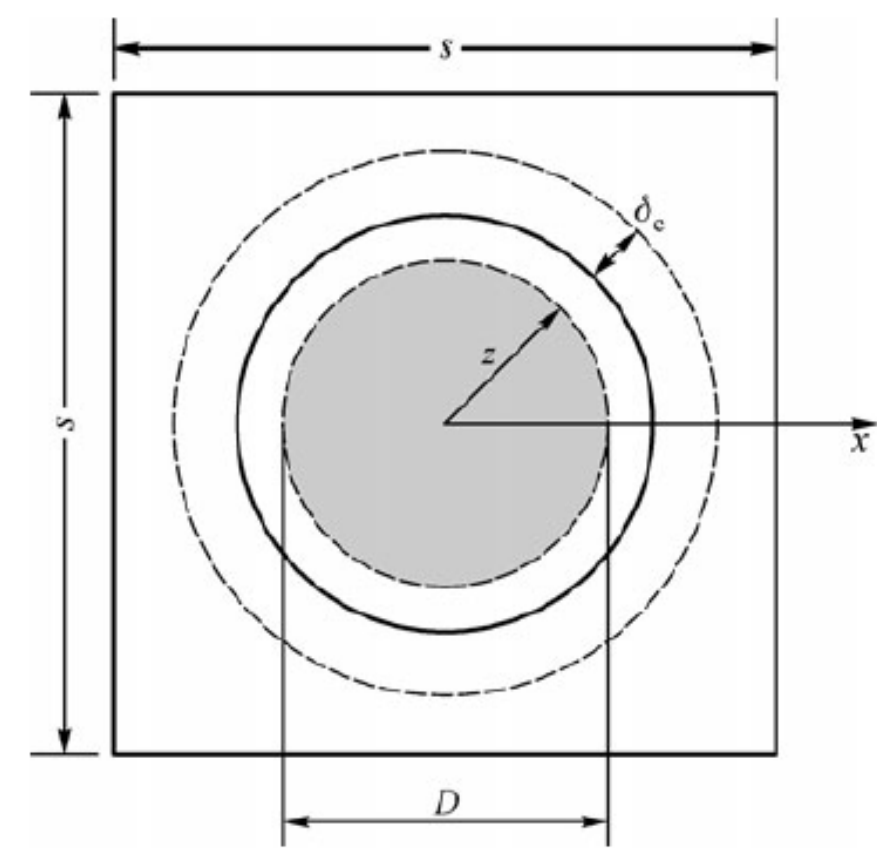

Figura 3.1 - Modelo representativo de concreto contendo uma única partícula esférica de agregado reativo ( $\delta$ é a espessura da camada de poros capilares e micro-fissuras em volta do agregado de raio D).

Fonte: Bazant e Stefens (2000).

O objetivo desse estudo era obter relações entre o diâmetro da partícula, a concentração de gel, a pressão e a umidade. Os resultados obtidos possibilitaram a elaboração das seguintes relações: quanto menor a partícula, maior a quantidade de gel formado; a pressão aumenta com o aumento do diâmetro da partícula até que seja atingido um tamanho crítico, a partir do qual a pressão diminui com o aumento do diâmetro; e, por fim, quanto menor o diâmetro do agregado, menor a umidade relativa nos poros do concreto, devido ao fato de a formação de gel consumir água (BAZANT; STEFENS, 2000).

Continuando o estudo anterior, Bazant et al. (2000) desenvolveram uma teoria com base na mecânica da fratura para prever o tamanho péssimo do agregado reativo. O modelo utiliza um arranjo regular das partículas cúbicas descritas anteriormente, conforme ilustrado na Figura 3.2. O gel presente na superfície do agregado reativo exerce pressão radial na pasta de cimento à sua volta, causando fissuração. 

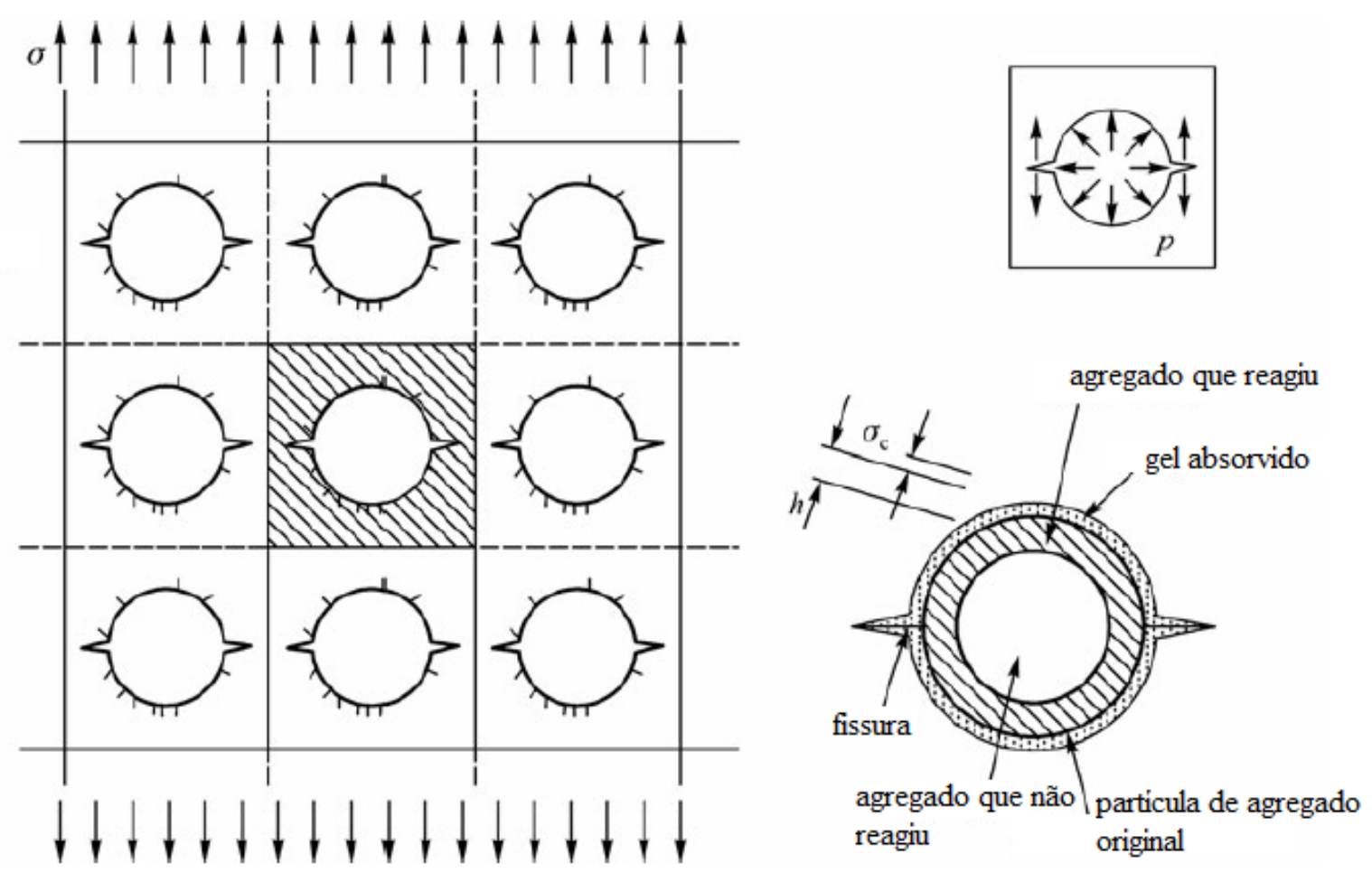

Figura 3.2 - Arranjo de partículas cúbicas contendo agregado reativo e detalhe para o gel de RAA expandindo para dentro da partícula de agregado e através dos poros capilares da pasta de cimento.

Fonte: Bazant e Stefens (2000).

\subsection{Modelos mesoscópicos}

Os modelos mesoscópicos geralmente tem por objetivo representar os mecanismos de degradação e fissuração. Para isso, os modelos em elementos finitos desenvolvidos representam a anisotropia do concreto, considerando as fases de agregado, pasta de cimento, vazios e gel a fim de melhor entender os mecanismos locais de deformação e de interação entre o gel e a matriz de concreto (PAN et al., 2012).

Esses modelos realizam algumas simplificações para representar a expansão devido à RAA. A Figura 3.3 ilustra que a expansão do gel pode ser tratada como uma expansão equivalente das partículas de agregado; como uma expansão do gel distribuído ao redor das partículas de agregado; ou como a expansão de bolsas de gel presentes nos agregados (PAN et al., 2012; DUNANT; SCRIVENER, 2010). 

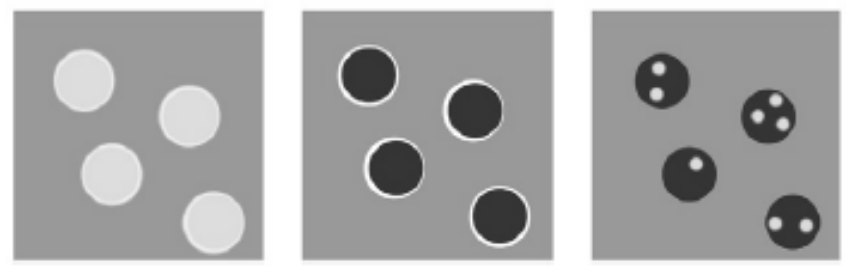

Figura 3.3 - Três simplificações para a expansão induzida pela RAA (a primeira ilustra a expansão homogênea do agregado, a segunda a expansão do gel ao redor do agregado e a terceira a expansão do gel presente nos poros do agregado).

Fonte: Dunant e Scrivener (2010.)

Comby-Peyrot et al. (2009) apresentaram um modelo em elementos finitos tridimensional capaz de representar a heterogeneidade do concreto afetado pela reação álcaliagregado. O modelo é composto por uma fase representando as partículas de agregado com comportamento elástico linear e uma fase que considera o dano da pasta de cimento.

O mecanismo de expansão é considerado isotrópico nos agregados reativos distribuídos aleatoriamente no modelo, conforme indica a Figura 3.4 (a); conseguindo reproduzir adequadamente o padrão de fissuração e degradação do concreto (Figura 3.4 (b)).

(a)

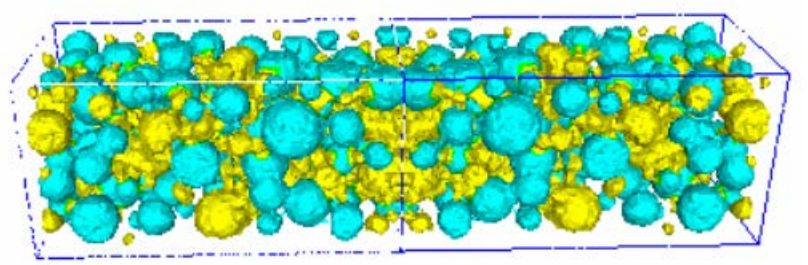

a)

(b)

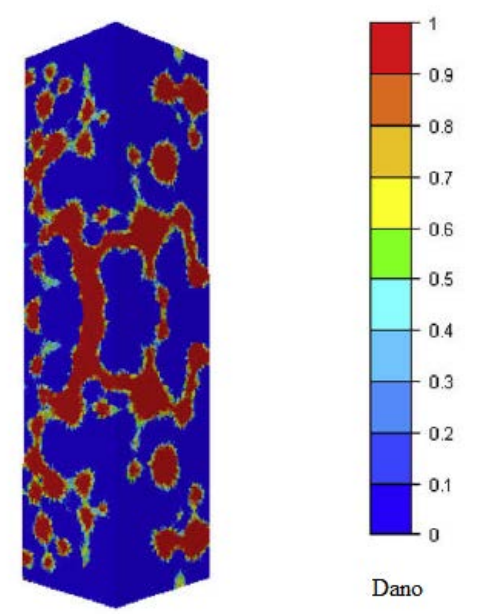

Figura 3.4 - (a) Distribuição aleatória de agregado reativo (em azul) e (b) evolução do dano na superfície do modelo numérico.

Fonte: Comby-Peyrot (2007). 
Dunant e Scrivener (2010) propuseram um modelo em elementos finitos em que o dano do concreto é induzido pela expansão de bolsas de gel presentes nos agregados.

Nesse modelo, os agregados são adotados de forma esférica e a pasta de cimento apresenta os detalhes de sua microestrutura, incluindo vazios (Figura 3.5). As zonas reativas (bolsas de gel) são inseridas nos agregados e expandem a cada passo de tempo.

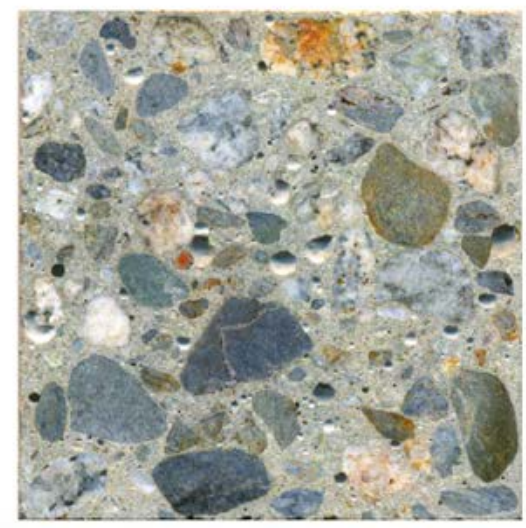

(a)

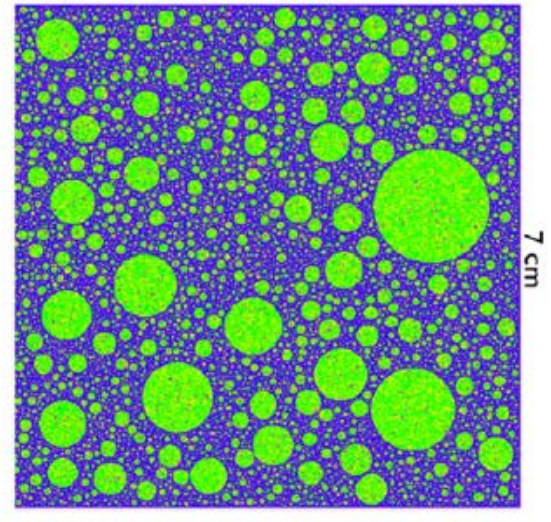

(b)

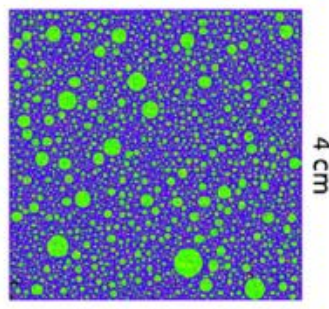

(c)

Figura 3.5 - (a) Amostra de concreto; (b) amostra simulada; (c) simulação da microestrutura do concreto. Fonte: Dunant e Scrivener (2010).

O comportamento do gel, produto da RAA, é considerado elástico linear, já o comportamento do agregado e da pasta levam em conta o dano provocado pela fissuração. Dessa forma, a expansão do gel gera tensões que fissuram o agregado e a pasta de cimento a sua volta, reduzindo as propriedades mecânicas do concreto.

\subsection{Modelos macroscópicos}

Modelos macroscópicos são aplicados na previsão do comportamento de estruturas afetadas pela reação álcali-agregado, pois possuem uma abordagem que se concentra em reproduzir o campo de tensões, deslocamentos e fissuração, possibilitando a quantificação da durabilidade das estruturas (PAN et al., 2012; JURCUT, 2015).

Esses modelos geralmente são formulados através do Método dos Elementos Finitos, considerando modelos mecânicos para o concreto (variando de linear elástico a modelos de dano isotrópicos e anisotrópicos, alguns considerando até retração, fluência e fissuração) acoplados ou desacoplados dos mecanismos químicos que envolvem a reação (geralmente são 
utilizadas leis de expansão que têm por base observações experimentais) (PAN et al., 2012; JURCUT, 2015).

\subsubsection{Modelo paramétrico de Léger et al. (1996)}

Os modelos macroscópicos paramétricos permitem a obtenção da taxa de deformação volumétrica do concreto através dos fatores que afetam a reação.

Léger et al. (1996) desenvolveram um modelo numérico aplicado a estruturas hidráulicas afetadas pela RAA. O modelo é capaz de associar a intensidade e a distribuição da expansão devido à RAA no concreto com alguns fatores de influência, entre eles, a umidade, reatividade dos constituintes presentes no concreto, temperatura e tensões de compressão induzidas ou aplicadas.

Os fatores de influência variam de 0 a 1 e são normalizados por meio de leis de normalização, cujos valores limites são adotados em função da estrutura analisada (dados obtidos experimentalmente ou através de monitoramento da estrutura). As leis de normalização adotadas por Léger et al. (1996) estão apresentadas na Figura 3.6.

(a)

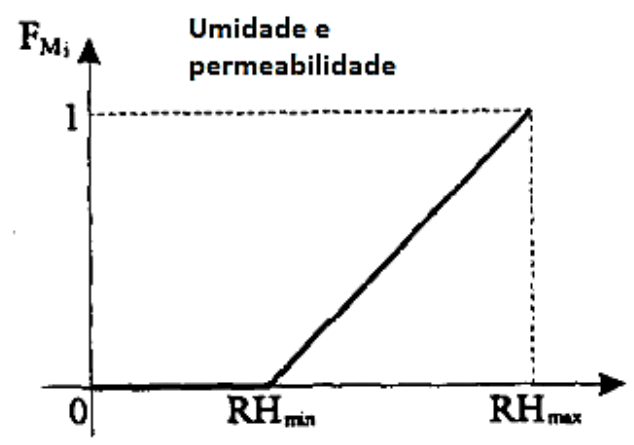

(c)

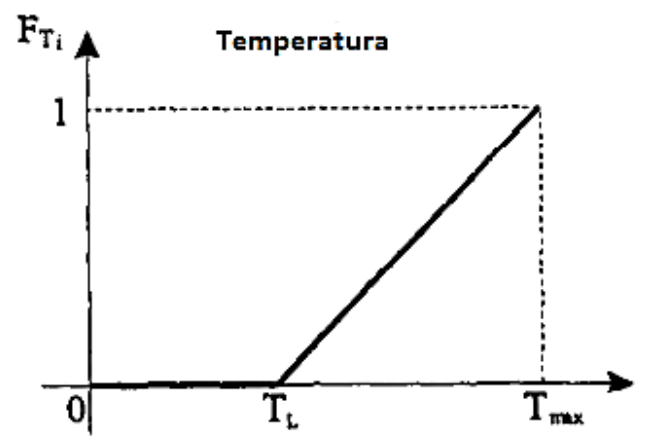

(b)

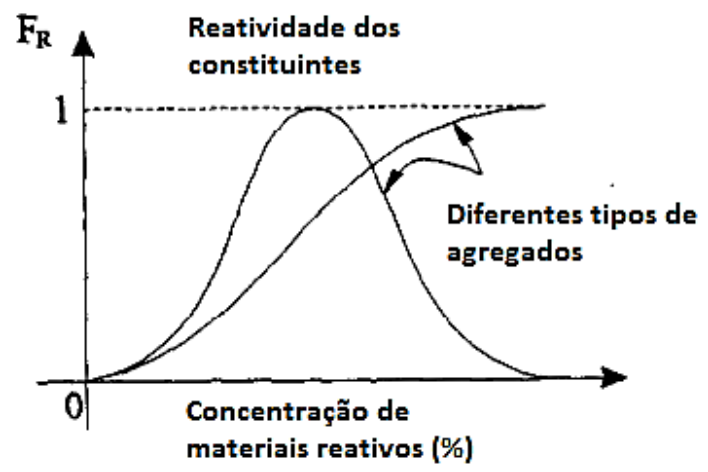

(d)

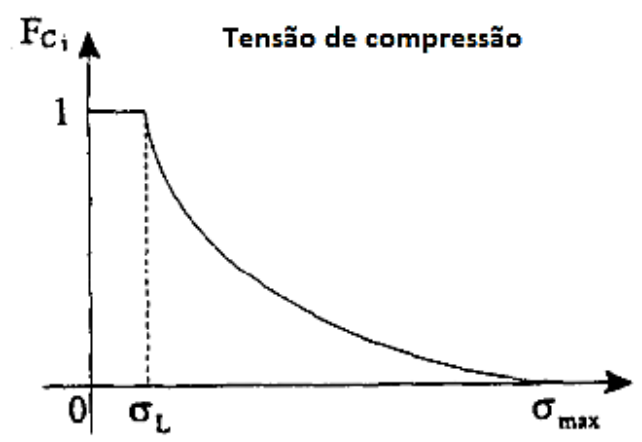

Figura 3.6 - Leis de normalização para os fatores de influência da RAA.

Fonte: Léger et al. (1996). 
A lei de normalização para a umidade relativa (Figura 3.6 (a)) considera necessário um mínimo de 75\% de umidade no concreto para que expansão suficiente seja observada. Portanto essa lei de normalização varia linearmente de $R H_{\text {min }}$, que representa a umidade relativa mínima, de aproximadamente $75 \%$, a $R H_{\text {max }}$, a umidade relativa máxima, ou seja, 100\%. Entretanto, uma vez que a análise dos mecanismos de transporte de água e umidade é um pouco complexa, os autores sugerem a consideração de $100 \%$ de umidade relativa para toda a estrutura (no caso das obras hidráulicas analisadas por estes autores) (LÉGER et al., 1996).

Obras massivas como barragens apresentam grande variabilidade na distribuição e concentração de agregados reativos e álcalis. Dessa forma, a lei de normalização para a reatividade dos constituintes apresentada na Figura 3.6 (b) varia de 0 a 1 para diferentes regiões da estrutura, em função da concentração de componentes reativos. Contudo, os autores ressaltam a dificuldade prática de se identificar a quantidade e localização dos componentes reativos na estrutura, sugerindo que seja considerada uma distribuição homogênea dos materiais reativos (agregados e álcalis) e, portanto, que seja adotado o valor máximo de 1 para esse fator.

A temperatura de $18^{\circ} \mathrm{C}$ é considerada a temperatura limite, abaixo da qual a expansão observada é reduzida. Para estruturas maciças, como o caso de barragens, para uma dada temperatura ambiente, existem variações de temperatura dentro da estrutura, resultando em gradientes de expansão que podem ser estimadas através de uma análise de transferência de calor. Estruturas menos espessas não apresentam esses gradientes de temperatura, sendo possível considerar a temperatura ambiente como a temperatura média da estrutura. Dessa forma, na Figura 3.6 (c) $T_{L}$ e $T_{\max }$ representam as temperaturas ambientes mínimas e máximas adotadas pelos autores como $18^{\circ} \mathrm{C}$ e $36^{\circ} \mathrm{C}$, respectivamente.

A lei de normalização para as tensões tem por objetivo levar em conta no modelo a redução da expansão na direção solicitada por compressão (aplicada ou induzida por armaduras). Essa lei de normalização tem como base o trabalho de Charlwood (1994), modelo em que a expansão do concreto, $\varepsilon_{g}$, é relacionada com a tensão de compressão, $\sigma_{i}$, pela Equação 3.1.

$$
\begin{array}{ccrl}
\varepsilon_{g}=\varepsilon_{u} \quad \text { para } & & 0 \leq \sigma_{i} \leq \sigma_{L} \\
\varepsilon_{g}=\varepsilon_{u}-K \log _{10}\left(\sigma_{i} / \sigma_{L}\right) & \text { para } & \sigma_{L} \leq \sigma_{i} \leq \sigma_{\max }
\end{array}
$$


em que $\varepsilon_{g}$ é a taxa de expansão restringida do concreto, $\sigma_{i}$ é a tensão principal na direção $i$, $\varepsilon_{u}$ é a expansão do concreto sob nível de tensão zero (expansão livre) e $K$ representa a declividade da linha que define a taxa de expansão do concreto em função do logaritmo das tensões.

Ainda na Figura 3.6 (d), $\sigma_{L}$ é a tensão abaixo da qual a expansão no concreto é igual à expansão livre, sendo adotada pelos autores igual a -0,3MPa; $\sigma_{\max }$ é a tensão acima da qual a expansão observada no concreto é nula; os autores sugerem que este valor esteja entre -5 e -10MPa, sendo, geralmente, adotado o valor de -8MPa.

Os parâmetros normalizados são então associados por meio da Equação 3.2, a fim de se determinar a expansão por RAA em cada instante de tempo $t$ em cada região ' $m$ ' dos ' $n$ ' elementos finitos que compõe a estrutura.

$$
\varepsilon_{R A A}^{m}(t)=\beta^{m}(t) \cdot\left[F_{C}(\sigma, t) \cdot F_{T}(t) \cdot F_{M}(t) \cdot F_{R}(t)\right]^{m}
$$

em que $F_{C}, F_{T}, F_{M}$ e $F_{R}$ são os fatores de influência normalizados devido à compressão, temperatura, umidade e reatividade, respectivamente. $F_{C}(\sigma, t)=1-K \log 10\left(\sigma_{i}^{m} / \sigma_{L}\right)$ é o fator de expansão normalizado associado às tensões de compressão e $\beta$ é um fator de calibração para ajustar os deslocamentos obtidos com o modelo com aqueles observados na estrutura.

A Equação 3.3 representa a equação do equilíbrio da estrutura:

$$
[K(t)]\{U(t)\}=\{R(t)\}
$$

em que $[K(t)]$ é a matriz de rigidez da estrutura, $\{U(t)\}$ e $\{R(t)\}$ são os vetores de deslocamentos e forças, respectivamente. A expansão por RAA contribui no vetor de forças conforme a Equação 3.4.

$$
\{R(t)\}=\sum\{\beta(t)\}^{m} \cdot\{R(t)\}^{m}
$$

em que a soma é feita contabilizando todas as ' $m$ ' regiões em que a estrutura foi subdividida, podendo-se escrever para cada uma dessas regiões a Equação 3.5.

$$
\{R(t)\}^{m}=\beta^{m}(t) \cdot \sum \int\left[B_{i}\right]^{T}\left[E_{i}(t)\right]\left[F_{C}(\sigma, t) \cdot F_{T}(t) \cdot F_{M}(t) \cdot F_{R}(t)\right]^{m} d V
$$


em que $\left[B_{i}\right]$ é a matriz de transformação de deformação-deslocamento para o elemento $i, V$ é o volume do elemento e a soma é feita para todos os elementos finitos da região ' $m$ ' $\left[E_{i}(t)\right]$ é a matriz das propriedades efetivas do material, uma função que considera o coeficiente de Poisson, resistência à tração, módulo de elasticidade, fluência, deformação por RAA e deformação total; assume-se que a resistência à tração e o módulo de elasticidade reduzem linearmente com o tempo de reação.

A matriz de rigidez da estrutura é obtida por meio da Equação 3.6.

$$
[K(t)]=\sum \int\left[B_{i}(t)\right]^{T}\left[E_{i}(t)\right]\left[B_{i}(t)\right] d V
$$

Após a solução do sistema de equações e obtenção dos deslocamentos, calculam-se as tensões para cada elemento finito utilizando-se a Equação 3.7.

$$
\left\{\sigma_{i}(t)\right\}=\left[E_{i}(t)\right] \cdot\left(\left[B_{i}\right]\{U(t)\}-\left\{\varepsilon_{R A A}(t)\right\}\right)
$$

A cada ciclo de iterações o parâmetro $\beta$ é calculado e ajustado a partir das deformações calculadas e das deformações obtidas do monitoramento das estruturas. Assim, com o modelo devidamente calibrado é possível estimar o comportamento futuro da estrutura afetada pela RAA (LÉGER et al., 1996).

\subsubsection{Modelo paramétrico de Pappalardo Jr. et al. (2000)}

Pappalardo Jr. et al. (2000), com base no modelo desenvolvido por Léger et al. (1996), propuseram um novo modelo paramétrico, cujos fatores de influência considerados são: temperatura, umidade, preenchimento dos poros e confinamento $\left(g_{T}, g_{U}, g_{P}\right.$ e $\left.g_{C}\right)$. As leis de normalização para esse modelo encontram-se ilustradas na Figura 3.7. 


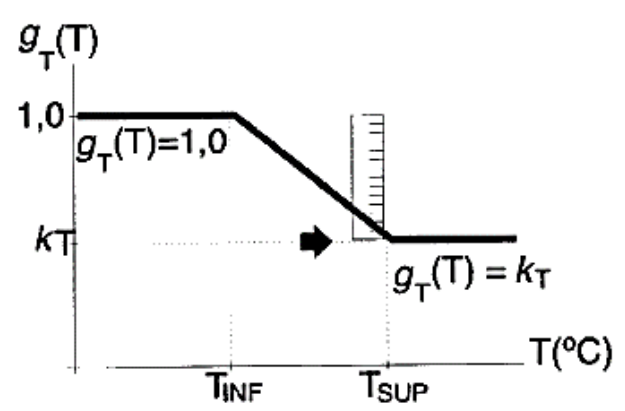

(a)

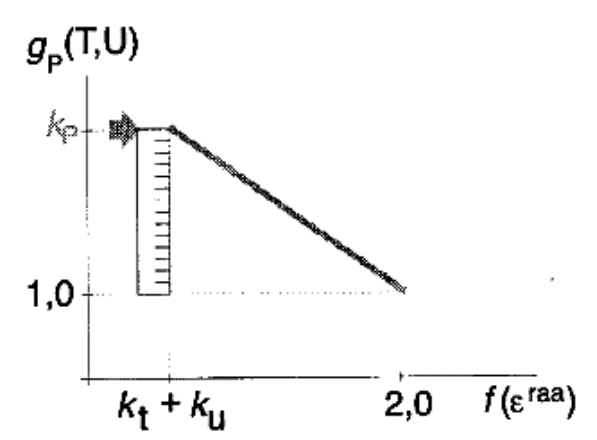

(c)

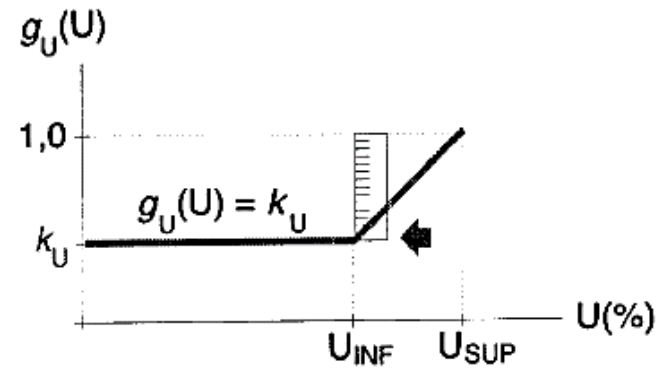

(b)

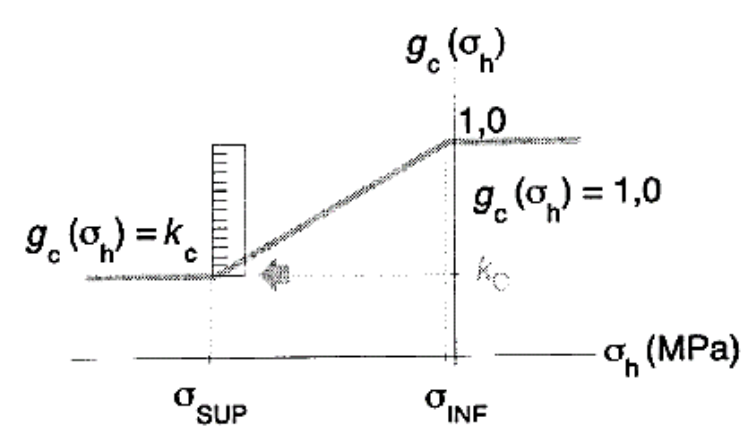

(d)

Figura 3.7 - Leis de normalização para os fatores de influência da RAA.

Fonte: Pappalardo Jr. et al. (2000).

em que $k_{T}, k_{U}, k_{P}$ e $k_{C}$ são variáveis de calibração que controlam a ponderação dos fatores de influência a partir dos dados de instrumentação para a calibração do modelo matemático.

A taxa de expansão volumétrica devido à RAA para cada ponto da estrutura é dada pela Equação 3.8.

$$
\dot{\varepsilon}_{R A A}=\frac{\varepsilon_{v o l}^{\max } \cdot\left(A_{2} g_{T}\right)}{\left[\left(A_{2} g_{T}\right)+\left(t-t_{P} g_{P}\right)\right]^{2}} \cdot \sqrt{g_{U} g_{C}}
$$

em que $\varepsilon_{v o l}^{\max }$ está relacionado à quantidade total de reagentes no concreto, $A_{2}$ indica o tempo necessário para a estabilização do processo de expansão, $t_{P} g_{P}$ é o tempo decorrido para o preenchimento total dos poros e início do processo de expansão.

O modelo proposto considera um comportamento viscoelástico para o concreto, modelo sólido padrão, cujo comportamento é representado pela associação de uma mola e um amortecedor. A deformação é proporcional à tensão $\sigma_{0}$, variando da deformação instantânea $\sigma_{0} / E_{0}$ em $\mathrm{t}=0$ até a deformação assintótica $\sigma_{0} / E_{\infty}$. O módulo assintótico é dado pela Equação 3.9. 


$$
E_{\infty}=\frac{E_{0}}{(1+\phi)}
$$

em que $\phi$ é o coeficiente de fluência, variando de 1,0 a 1,5 para concretos que não estejam afetados pela RAA. No caso de estruturas afetadas pela RAA, alguns experimentos indicam que a RAA tende a intensificar a fluência, podendo-se duplicar ou até mesmo quadruplicar o coeficiente de fluência de uma estrutura sã.

Os autores sugerem uma correlação linear entre o coeficiente de fluência e o estado de danificação da estrutura, assumindo valores para o coeficiente de fluência variando de 1,0 a 2,5.

As equações que regem a expansão química e a fluência do concreto foram incorporadas ao código do programa computacional ANSYS para serem realizadas as análises.

Como as tensões principais apresentam diferentes magnitudes, as expansões por RAA esperadas devem ser anisotrópicas, contudo, é limitação relacionada às sub-rotinas incorporadas pelo usuário do programa ANSYS a aplicação de expansões volumétricas, portanto, a Equação 3.8 é dada como função das tensões hidrostáticas, representando uma expansão isotrópica nas estruturas.

Para a análise térmica, considera-se o transporte de calor por condução e trocas de calor por convecção nas superfícies da estrutura. Considera-se variação anual linear da temperatura ambiente.

Para a análise de umidade, é considerado um modelo de percolação em meios porosos indeformáveis, verificando a difusão e percolação da água na estrutura.

O modelo ainda propõe a calibração dos parâmetros envolvidos na Equação 3.9, que devem ser ajustados com base em dados de instrumentação da estrutura.

Recentemente, Pappalardo Jr. et al. (2016) apresentaram um modelo capaz de considerar a ortotropia da expansão por RAA devido a presença de armaduras nas estruturas de concreto. O modelo constitutivo para o concreto armado considera tanto a não-linearidade do aço e do concreto, bem como o comportamento (escorregamento) da interface entre o aço e o concreto.

Esse modelo aplica as relações propostas por Charlwood (1994) explicitadas nas Equações 3.1 para considerar a redução da expansão em função das tensões de compressão induzidas pela presença de armaduras na estrutura. A expansão química devido à RAA é inserida para cada direção da estrutura a partir de uma associação deste tipo de expansão com a expansão térmica em softwares comerciais em MEF. 


\subsubsection{Modelo de Pietruszczak (1996)}

Pietruszczak (1996) apresentou um modelo para a descrever os efeitos mecânicos da RAA. Nesse modelo a expansão devido à RAA é considerada dependente da composição química do concreto e é acoplada à degradação das propriedades mecânicas do material.

O modelo considera o concreto como um material elastoplástico. A Equação 3.10 representa a parcela elástica do comportamento do material.

$$
\varepsilon^{e}=\left[C^{e}\right] \sigma+\frac{1}{3} \varepsilon_{A} \delta ; \quad \varepsilon_{A}=g\left(\delta^{T} \sigma, t\right)
$$

em que $\left[C^{e}\right]$ é a matriz elástica do material, $\delta$ é o delta de Kronecker, $\varepsilon_{A}$ representa a expansão volumétrica devido à RAA e $\delta^{T} \sigma$ representa a pressão hidrostática.

A expansão volumétrica devido à RAA também pode ser escrita em forma de taxa acumulada no tempo segundo a Equação 3.11.

$$
\dot{\varepsilon}_{\mathrm{A}}=g_{1}\left(\delta^{T} \sigma\right) \dot{g}_{2}(t)
$$

em que $g_{1}$ e $g_{2}$ são funções que representam, respectivamente, a influência das tensões de confinamento na expansão por RAA e a evolução da RAA com o tempo. Essas funções são expressas pelas Equações 3.12 e 3.13

$$
\begin{aligned}
& g_{1}\left(\delta^{T} \sigma\right)=\exp \left(\frac{-A_{1} \delta^{T} \sigma}{f_{c 0}}\right) \\
& g_{2}(t)=\frac{\varepsilon t}{\left(A_{2}+t\right)}
\end{aligned}
$$

em que $A_{1}$ e $A_{2}$ são constantes do material; $\varepsilon$ é a expansão livre devido à RAA e $f_{c 0}$ é a resistência à compressão uniaxial inicial do concreto.

Com o avanço da reação, as propriedades do concreto se deterioram, sendo o módulo de elasticidade a propriedade mais afetada pela RAA. Pietruszczak (1996) considera o decaimento do módulo de elasticidade com o avanço da RAA em seu modelo (Equação 3.14).

$$
E(t)=E_{0}\left[1-\left(1-A_{3}\right) \frac{g_{2}(t)}{\varepsilon}\right]
$$


em que $E$ é o módulo de elasticidade reduzido num instante de tempo $t, E_{0}$ é o módulo de elasticidade inicial do concreto, sem considerar a degradação pela RAA e $A_{3}$ é uma constante que representa o percentual máximo de degradação do módulo de elasticidade.

As condições de falha são definidas segundo as Equações 3.15.

$$
\begin{gathered}
F=\bar{\sigma}-k(\theta) \bar{\sigma}_{c}=0 \\
\bar{\sigma}_{c}=\frac{-a_{1}+\sqrt{\left(a_{1}^{2}+4 a_{2}\left(a_{3}+I / f_{c}\right)\right)}}{2 a_{2}} f_{c}
\end{gathered}
$$

em que $I=-\sigma_{i i}, \quad \bar{\sigma}=\left(1 / 2 s_{i j} s_{i j}\right)^{1 / 2}, \quad \theta=1 / 3 \sin ^{-1}\left(3 \sqrt{3} J_{3} / 2 \bar{\sigma}^{3}\right)$ e $J_{3}=1 / 3 s_{i j} s_{j k} s_{k i} \quad$ são os invariantes do tensor de tensões. $a_{1}, a_{2}$ e $a_{3}$ representam constantes do material e $f_{c}$ é a resistência à compressão uniaxial do concreto.

A superfície de falha é representada pelas Equações 3.16.

$$
\begin{gathered}
f=\bar{\sigma}-\beta(\xi) k(\theta) \bar{\sigma}_{c}=0 \\
\beta=\xi /(A+B \xi) ; \quad \xi=\left(\dot{e}_{i j}^{P} \dot{e}_{i j}^{P}\right)^{1 / 2} / \bar{\Phi}
\end{gathered}
$$

em que $e_{i j}$ representa a deformação desviadora, $\bar{\Phi}=(I, \theta)$, A e $B$ são constantes do material.

Considerando que o avanço da RAA também afete a resistência à compressão do concreto, tem-se a Equação 3.17.

$$
f_{c}(t)=f_{c 0}\left[1-\left(1-A_{4}\right) \frac{g_{2}(t)}{\varepsilon}\right]
$$

em que $A_{4}$ é uma constante que representa a degradação da resistência à compressão do concreto.

Dessa forma, para $f_{c}=f_{c}(t)$, a Equação 3.16 fica na forma da Equação 3.18.

$$
\frac{\partial f}{\partial t}=\frac{\partial f}{\partial \bar{\sigma}_{c}} \frac{\partial \bar{\sigma}_{c}}{\partial f_{c}} \frac{\partial f_{c}}{\partial g_{2}} \frac{d g_{2}}{d t}=-\beta(\xi) k(\theta) \frac{f_{c 0} A_{2}\left(1-A_{4}\right)}{\left(A_{2}+t\right)^{2}}\left(\frac{\bar{\sigma}_{c}}{f_{c}}-\frac{I}{2 a_{2} \bar{\sigma}_{c}+a_{1} f_{c}}\right)
$$


Mais tarde, com base no modelo apresentado por Pietruszczak (1996), Huang e Pietruszczak (1999) incluíram o efeito da temperatura no modelo. Tanto a expansão quanto a redução das propriedades mecânicas são consideradas afetadas pela elevação da temperatura.

Nesse modelo a relação constitutiva é dada pela Equação 3.19.

$$
\varepsilon=C^{e} \sigma+\frac{1}{3} \varepsilon_{A} m+\varepsilon_{T}
$$

em que $C^{e}$ é a matriz elástica, $m$ funciona como o operador delta de Kronecker, $\varepsilon_{A}$ representa a expansão volumétrica devido à RAA e $\varepsilon_{T}$ é a expansão térmica, dada pela Equação 3.20.

$$
\varepsilon_{T}=\frac{1}{3} \beta_{T}(T-\bar{T}) m
$$

em que $\beta_{T}$ é o coeficiente de expansão térmica, $T$ e $\bar{T}$ são as temperaturas absoluta e de referência, respectivamente.

A Equação 3.21 a seguir representa a expansão volumétrica devido à RAA.

$$
\dot{\varepsilon}_{A}=g_{1}\left(m^{T} \sigma\right) \dot{g}_{3}\left(t^{\prime}\right) ; \quad d t^{\prime}=g_{2}(T) d t
$$

em que $t^{\prime}$ é o tempo de ativação térmica, dependente do histórico de temperaturas, $g_{3}$ representa a expansão livre, $g_{1}$ e $g_{2}$ representam o efeito das tensões e temperatura na expansão, dadas pelas Equações 3.22 a 3.25.

$$
\begin{aligned}
& g_{1}\left(m^{T} \sigma\right)=\exp \left(\frac{A_{1} m^{T} \sigma}{f_{c 0}}\right) \\
& g_{3}\left(t^{\prime}\right)=\frac{\varepsilon t^{\prime}}{\left(A_{3}+t^{\prime}\right)} \\
& \dot{g}_{3}=\frac{\varepsilon\left(1-g_{3} / \varepsilon\right)^{2}}{A_{3}} g_{2}(T) \\
& g_{2}(T)=\frac{1}{2}\left(1+\tanh \left(\frac{T-T_{0}}{A_{2}}\right)\right)
\end{aligned}
$$

em que $A_{2}, A_{3}$ e $T_{0}$ são constantes do material. 
Esse modelo, assim como o anterior, também considera a redução do módulo de elasticidade e resistência à compressão devido ao avanço RAA.

Em 2008, Winnicki e Pietruszczak (2008) aprimoraram o modelo, utilizando-se da químico-plasticidade para avaliar a expansão por RAA em um modelo constitutivo em concreto armado.

Esse modelo utiliza o parâmetro $\zeta$ como medida da evolução da reação (Equação 3.26).

$$
\zeta(\tau)=\frac{\varepsilon(\tau)}{\bar{\varepsilon}} ; \quad \bar{\varepsilon}=\varepsilon(\tau \rightarrow \infty)
$$

em que $\varepsilon(\tau)$ representa a expansão volumétrica no concreto, $\tau$ é o parâmetro de tempo e $\bar{\varepsilon}$ é a expansão máxima que pode ser observada em dadas condições químicas (concentração de álcalis e agregados reativos) em situação livre de tensões de compressão atuantes.

Para um estado livre de tensões de compressão atuando na estrutura, $\zeta$ varia de 0 a 1. Em vista de diversos estudos que comprovam a redução da expansão na presença de tensões, assume-se, nesse caso, $\zeta$ variando de 0 a $\bar{\zeta}(\sigma)$, sendo este último parâmetro dado pela Equação 3.27.

$$
\bar{\zeta}(\sigma)=\exp \left(-A_{1} \sqrt{\frac{\langle-t r(\sigma)\rangle}{3 f_{c}}}\right)
$$

Assume-se que a cinética da reação segue as Equações 3.28.

$$
\begin{gathered}
\frac{d \zeta}{d \tau}=\gamma_{0}(\bar{\zeta}-\zeta) \text { para } \tau \geq \tau_{0} \\
\zeta=0 \text { para } \tau \leq \tau_{0}
\end{gathered}
$$

em que $\gamma_{0}$ é um parâmetro do material que descreve a taxa de reação em uma temperatura $T_{0}$ e umidade $R H_{0}$.

Da Equação 3.28, evidencia-se que a expansão por RAA é dada por um processo de expansão dividido em duas fases. Na primeira fase, enquanto os poros do concreto não foram completamente preenchidos pelos produtos da reação (gel), não é observada expansão volumétrica; já na segunda fase da reação, constata-se que a velocidade da expansão é 
influenciada pela temperatura e umidade. Dessa forma, o parâmetro de tempo $\tau_{0}$, está associado ao tempo de iniciação da reação.

O parâmetro de tempo $\tau$ se relaciona com o tempo real $t$ por meio da Equação 3.29.

$$
d \tau=g_{1}(T) g_{2}(R H) d t
$$

em que os parâmetros $g_{1}$ e $g_{2}$ são dados pelas Equações 3.30 e 3.31

$$
\begin{aligned}
& g_{1}(T)=\exp \left[U\left(\frac{1}{T_{0}}-\frac{1}{T}\right)\right] \\
& g_{2}(R H)=(R H / 100 \%)^{m}
\end{aligned}
$$

em que $g_{1}$ é a função proposta por Larive (1998) e empregada no trabalho de Ulm et al. (2000), modelo que será tratado com maiores detalhes na sequência. $g_{2}$ é uma função proposta por Capra e Bournazel (1998), em que $m$ é uma constante do material e vale 8.

Substituindo-se a Equação 3.29 na Equação 3.28, tem-se (Equação 3.32):

$$
\frac{d \zeta}{d t}=\gamma_{0} g_{1}(T) g_{2}(R H)[\bar{\zeta}(\sigma)-\zeta] \text { para } t \geq t_{0}
$$

Pode-se perceber que a cinética proposta para a reação considera os efeitos de umidade, temperatura e tensões. O modelo químico-plástico fica então escrito conforme a Equação 3.33.

$$
\varepsilon=\varepsilon_{e}(\zeta)+\varepsilon_{p}(\zeta)+\varepsilon_{c h}(\zeta)+\varepsilon_{T}(T)
$$

em que a deformação total é dada em função das deformações elásticas, plásticas, químicas e térmicas, respectivamente; todas como função de $\zeta$.

A parcela química da expressão é dada pela Equação 3.34 .

$$
\varepsilon_{c h}(\zeta)=\frac{1}{3} \zeta \bar{\varepsilon} \delta
$$

em que $\delta$ é o delta de Kronecker. 


\subsubsection{Modelo de Ulm et al. (2000)}

Ulm et al. (2000) desenvolveram um modelo químico-mecânico para a representação da expansão por RAA. Um modelo mecânico químico-elástico é utilizado para representar a pressão de expansão do gel na matriz de concreto.

Em escala mesoscópica unidimensional (1D), uma vez que o gel preencheu os poros do concreto, ele exerce pressão causando fissuração na matriz de concreto. Portanto, para a situação de expansão livre (sem atuação de tensão de compressão), a pressão interna de expansão do gel $p_{g}$ é equilibrada pela tensão $\sigma_{\mu}$ na matriz de concreto, conforme ilustra a Figura $3.8(a)$.

Para que o comportamento expansivo da RAA seja representado em uma escala macroscópica, o modelo considera o esqueleto de concreto e o gel de RAA como duas fases agindo em paralelo, conforme ilustra a Figura 3.8 (b).

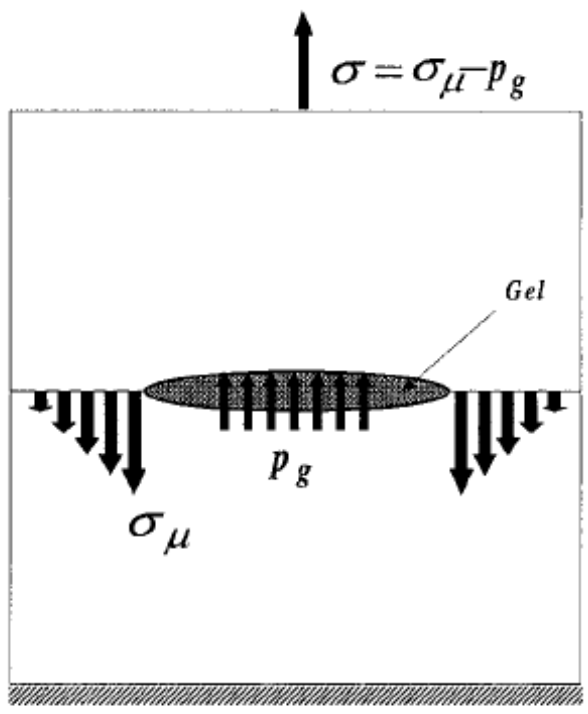

(a)

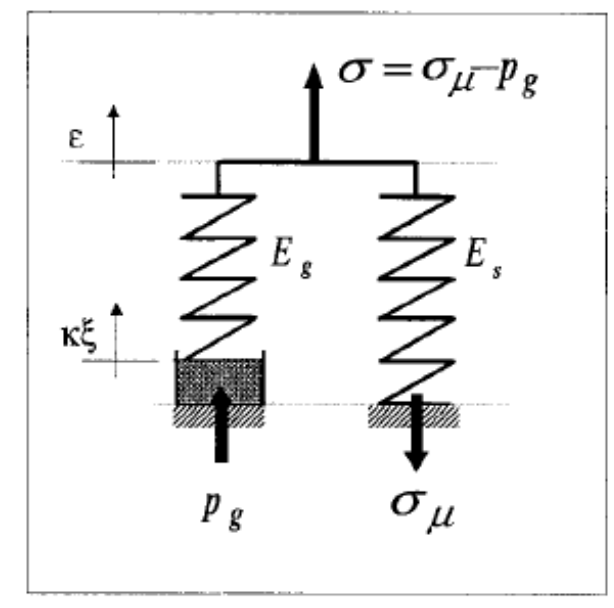

(b)

Figura 3.8 - (a) Mecanismo mesoscópico de expansão por RAA. (b) Modelo representativo de expansão em escala macroscópica.

Fonte: Ulm et al. (2000).

Na Figura 3.8, $\sigma$ é a tensão devido às forças externas e $\varepsilon$ é a deformação total correspondente. O comportamento da matriz de concreto é considerado elástico e é representado pela rigidez da mola $E_{s}$, com tensão correspondente $\sigma_{\mu}$. O gel é representado 
pela associação de uma mola elástica de rigidez $E_{g}$ e uma célula de pressão com pressão de expansão $p_{g}$. Dessa forma, o equilíbrio de tensões para o modelo químico-elástico 1D é dado pela Equação 3.35 .

$$
\sigma=\sigma_{\mu}-p_{g}=E_{s} \varepsilon+E_{g}(\varepsilon-k \xi)
$$

em que $\xi$ é a extensão química da reação proposta por Larive (1998) e varia de 0 (início da reação) a 1 (fim da reação). Este parâmetro é definido como a razão entre a expansão no tempo $t$ e a expansão no fim da reação. $k$ é o coeficiente de expansão intrínseco.

No caso de expansão livre, em que não atuam tensões de compressão, a equação de equilíbrio pode ser escrita segundo a Equação 3.36 .

$$
\sigma=0 ; \quad \varepsilon=\beta \xi ; \quad \beta=\frac{k E_{g}}{E_{g}+E_{s}}
$$

Dessa forma, a deformação total fica relacionada com o coeficiente de expansão $\beta$, sendo este dependente do coeficiente de expansão intrínseco e da rigidez dos materiais. Assim, a única variável desconhecida relacionada ao problema é a extensão química da reação $\xi$.

Para o modelo de expansão livre, a extensão química é que dita a evolução das deformações com o tempo. A Equação 3.37 apresenta uma lei cinética linear adotada para relacionar a afinidade da reação $A_{m}=A_{m}(\xi)$ com a taxa de reação $\dot{\xi}=d \xi / d t$.

$$
\sigma=0 ; \quad A_{m}(\xi)=k_{d} \frac{d \xi}{d t}
$$

em que $k_{d}$ é um coeficiente e $A_{m}(\xi)$ expressa o desequilíbrio envolvendo a formação do gel: decrescendo de um valor inicial $A_{m}(\xi=0)$ até o equilíbrio $A_{m}(\xi=1)$. A cinética da reação fica então definida pela Equação 3.38 .

$$
\sigma=0 ; \quad 1-\xi=t_{c} \frac{d \xi}{d t}
$$

em que $t_{c}=k_{d} / A_{m}(\xi=0)$ define o tempo característico da reação a ser determinado por meio de experimentos. 
Estendendo-se agora o modelo para o caso tridimensional, a partir de uma abordagem energética do problema 1D, a expressão de dissipação é dada pela Equação 3.39.

$$
\varphi d t=\sigma d \varepsilon-d \psi \geq 0
$$

em que $\sigma d \varepsilon$ é a energia de deformação e $\psi$ é a energia livre, dada pela Equação 3.40.

$$
\psi=\frac{1}{2}\left[E_{s} \varepsilon^{2}+E_{g}(\varepsilon-k \xi)^{2}\right]+g(\xi)
$$

em que o primeiro termo representa a energia livre das molas e $g(\xi)$ corresponde à energia livre na célula de amortecimento devido à expansão do gel. Substituindo-se a Equação 3.40 na Equação 3.39 tem-se a seguinte relação (Equação 3.41):

$$
\varphi d t=\left[\sigma-\left(E_{s} \varepsilon^{2}+E_{g}(\varepsilon-k \xi)\right)\right] d \varepsilon+\left[k E_{g}(\varepsilon-k \xi)-\frac{\partial g}{\partial \xi}\right] d \xi \geq 0
$$

Das Equações 3.35 e 3.41 tem-se a Equação 3.42.

$$
\sigma=\frac{d \psi}{d \varepsilon}=E_{s} \varepsilon+E_{g}(\varepsilon-k \xi)
$$

O segundo termo da Equação 3.41 representa a força envolvendo a reação e é dado pela Equação 3.43.

$$
A_{m}=-\frac{\partial \psi}{\partial \xi}=-k p_{g}-\frac{\partial g}{\partial \xi}
$$

A extensão para o caso tridimensional é feita substituindo os parâmetros escalares da Equação 3.42 por seus correspondentes parâmetros tensoriais, conforme a Equação 3.44 (para o caso isotrópico).

$$
\sigma_{i j}=\frac{\partial \psi}{\partial \varepsilon_{i j}}=\left(K_{s}-\frac{2}{3} G\right) \varepsilon \delta_{i j}+2 G \varepsilon_{i j}+K_{g}(\varepsilon-k \xi) \delta_{i j}=\left(K-\frac{2}{3} G\right) \varepsilon \delta_{i j}+2 G \varepsilon_{i j}-3 \beta K \xi \delta_{i j}
$$

em que $\varepsilon=\varepsilon_{i i} ; K=K_{s}+K_{g}=E / 3(1-2 v) ; G=E / 2(1+v)$. Sendo $E$ o módulo de Young e $v$ o coeficiente de Poisson. 
A contribuição da pressão de expansão $p_{g}=-K_{g}(\varepsilon-k \xi)$ na afinidade química não é considerada, dessa forma, para completar o modelo constitutivo 3D utiliza-se a Equação 3.45.

$$
\forall \sigma_{i j} ; 1-\xi=t_{c}(\theta, \xi) \frac{d \xi}{d t}
$$

em que $t_{c}(\theta, \xi)$ representa o tempo característico da reação proposto por Larive (1998) e que será explicado a seguir.

A cinética da reação segue a proposta por Larive (1998) e, para o caso de expansão livre a uma temperatura de referência $\theta=\theta_{0}$, é dada pela Equação 3.46.

$$
\sigma_{i j}=0 ; \quad \xi(t)=\frac{\varepsilon(t)}{\varepsilon(\infty)}
$$

em que $\varepsilon(\infty)=3 \beta$ é a expansão volumétrica assintótica de uma amostra sujeita à expansão livre.

Das Equações 3.45 e 3.46 obtém-se a Equação 3.47.

$$
\varepsilon(\infty)-\varepsilon(t)=t_{c}\left(\theta_{0}, \xi\right) \frac{d \varepsilon}{d t}(t)
$$

Os experimentos realizados por Larive (1998) revelaram que o tempo característico é dependente tanto da temperatura $\theta_{0}$ quanto da extensão química, conforme indica a Equação 3.48 .

$$
t_{c}=\tau_{c}\left(\theta_{0}\right) \lambda\left(\xi, \theta_{0}\right) \text { em que } \lambda\left(\xi, \theta_{0}\right)=\frac{1+\exp \left[-\tau_{l}\left(\theta_{0}\right) / \tau_{c}\left(\theta_{0}\right)\right]}{\xi+\exp \left[-\tau_{l}\left(\theta_{0}\right) / \tau_{c}\left(\theta_{0}\right)\right]}
$$

em que $\tau_{l}$ é o tempo de latência, que corresponde ao período de início da RAA (associado à dissolução da sílica presente nos agregados); $\tau_{c}$ é o tempo característico, que representa o período de desenvolvimento da reação (associado à formação do gel); ambos os tempos dependendo da temperatura e umidade relativa, segundo equações que serão apresentadas na sequência.

Das Equações 3.46, 3.47 e 3.48, pode-se chegar à seguinte relação (Equação 3.49): 


$$
\varepsilon(t)=\varepsilon(\infty) \xi(t) ; \quad \xi(t)=\frac{1-\exp \left[t / \tau_{c}\right]}{1+\exp \left[-t / \tau_{c}+\tau_{l} / \tau_{c}\right]}
$$

A Figura 3.9 a seguir ilustra graficamente a evolução da Equação 3.49 com o tempo, indicando também os valores para o tempo de latência e tempo característico.

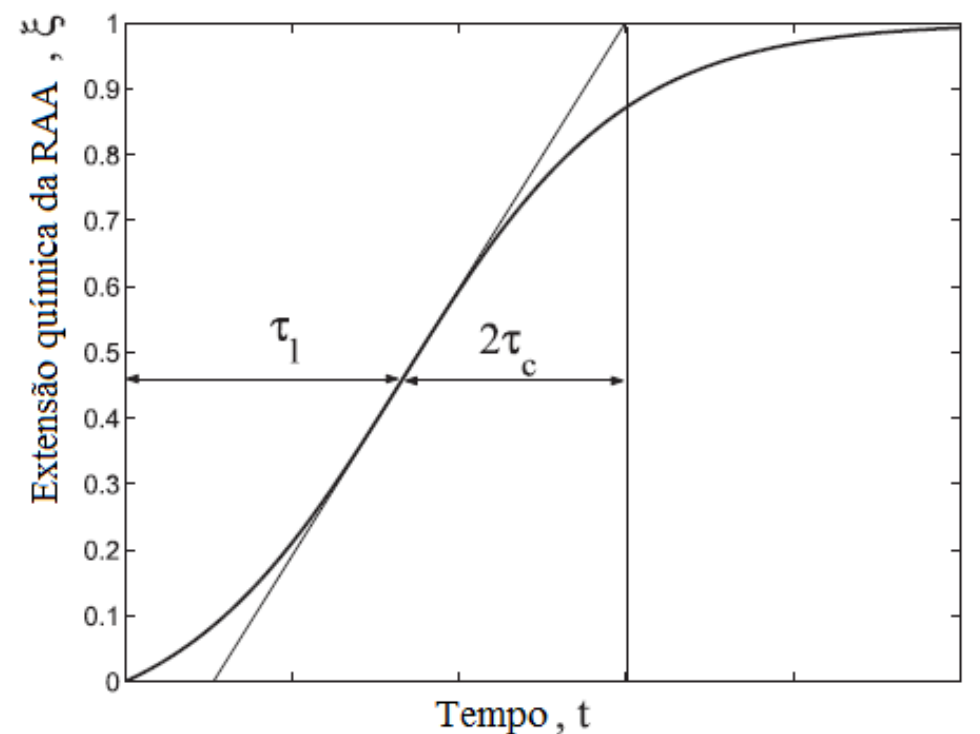

Figura 3.9 - Curva de extensão química da RAA.

Fonte: Saouma (2014).

Como já discutido anteriormente, os ensaios realizados por Larive (1998) revelaram a dependência do tempo de latência e do tempo característico tanto com a umidade relativa quanto com a temperatura.

No modelo empregado por Ulm et al. (2000), considera-se que apenas a temperatura influencia os tempos de latência e característico, segundo a Equação 3.50.

$$
\begin{gathered}
\tau_{c}(\theta)=\tau_{c}\left(\theta_{0}\right) \exp \left[U_{C}\left(1 / \theta-1 / \theta_{0}\right)\right] \\
\tau_{l}(\theta)=\tau_{l}\left(\theta_{0}\right) \exp \left[U_{L}\left(1 / \theta-1 / \theta_{0}\right)\right]
\end{gathered}
$$

em que $\theta$ é a temperatura atual, $\theta_{0}$ é a temperatura de referência, $U_{L}=9400 \pm 500 K$ e $U_{C}=5400 \pm 500 \mathrm{~K}$ são constantes representando a energia de ativação de Arrhenius.

O modelo de Wu et al. (2014) inclui o efeito da umidade na Equação 3.50 descrita anteriormente, conforme apresenta a Equação 3.51. 


$$
\tau_{i}(\theta, S)=\left(\tau_{i}\left(\theta_{0}, 1\right)+\frac{\tau_{i}\left(\theta_{0}, 0\right)-\tau_{i}\left(\theta_{0}, 1\right)}{1+a_{1, i} \exp \left(-a_{2, i}(1-2 S) / S(1-S)\right)}\right) \exp \left(U_{i}\left(\frac{1}{\theta}-\frac{1}{\theta_{0}}\right)\right)
$$

em que $S$ é a umidade relativa; o índice $i$ descreve o tempo de latência ou o tempo característico; e $\tau_{i}$ em função de 0 e 1 representa o início e o fim, respectivamente, da reação química. Os valores empregados por estes autores para estes coeficientes estão listados na Tabela 3.1.

Tabela 3.1: Coeficientes de aproximação que consideram a umidade relativa no tempo de latência e tempo característico.

Fonte: Wu et al. (2014).

\begin{tabular}{ccccc}
$i$ & $\tau\left(\theta_{0}, 0\right)$ & $\tau\left(\theta_{0}, 1\right)$ & $a_{1}$ & $a_{2}$ \\
\hline$\tau_{l}$ & 160 & 50 & 20 & $-18,5222$ \\
$\tau_{c}$ & 100 & 20 & 1 & 10,52 \\
\hline
\end{tabular}

Wu et al. (2014) também apresentam graficamente a dependência do tempo de latência e do tempo característico, tanto com a umidade relativa quanto com a temperatura, conforme ilustrado na Figura 3.10.

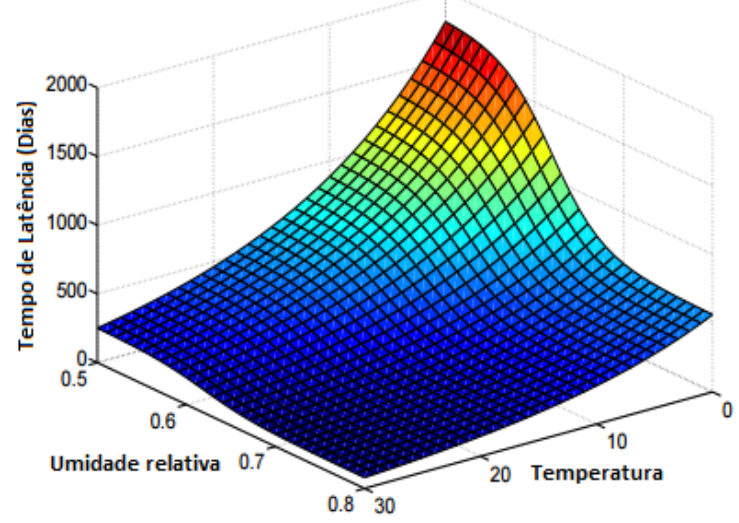

(a)

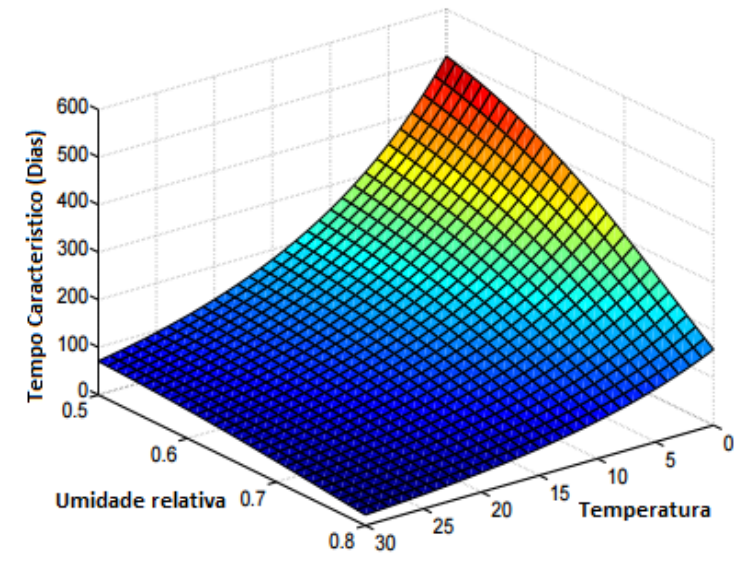

(b)

Figura 3.10 - (a) Tempo de latência em função da temperatura e da umidade relativa;

(b) Tempo característico em função da temperatura e umidade relativa.

Fonte: Wu et al. (2014).

A partir do modelo elastoplástico desenvolvido por Ulm et al. (2000), outros modelos foram desenvolvidos com abordagens na mecânica da fratura, como, por exemplo, os de Farage et al. (2004) e Fairbain et al. (2006); já outros consideraram a mecânica do dano em seus modelos: Comi et al. (2009) e Grimal et al. (2008) (PAN et al., 2012). 


\subsubsection{Modelo de Farage et al. (2004)}

O modelo de Farage et al. (2004) realiza alterações no modelo proposto por Ulm et al. (2000) a fim incluir a abertura de fissuras devido à expansão por RAA no modelo. Para isso, no modelo 1D de Ulm et al. (2000) é inserido um elemento coesivo para representar a abertura das fissuras induzidas pelas tensões de tração atuando na matriz de concreto. A Figura 3.11 ilustra o modelo proposto.

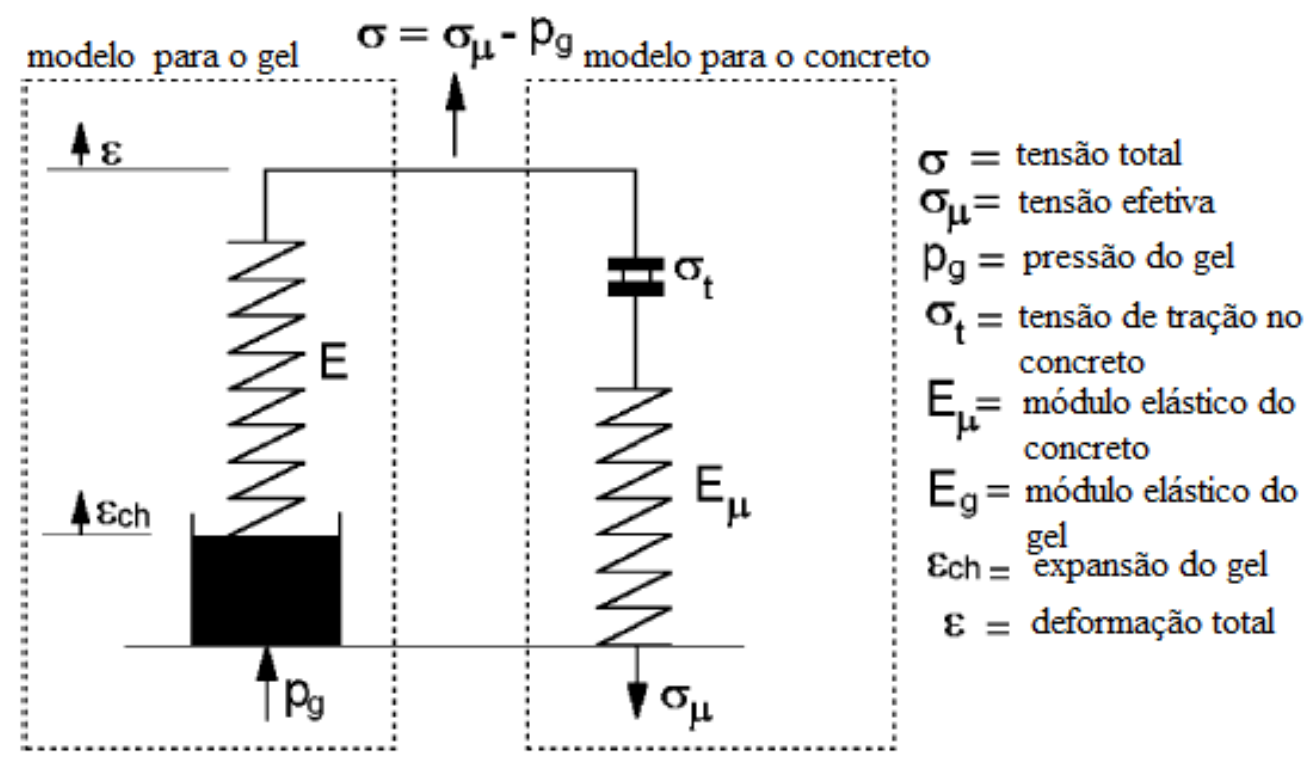

Figura 3.11 - Modelo 1D para representação do comportamento expansivo do concreto. Fonte: Farage et al. (2004).

A pressão do gel $p_{g}$ é dada pela Equação 3.52 .

$$
p_{g}=E_{g}\left(\varepsilon_{c h}-\varepsilon\right)
$$

em que $\varepsilon_{c h}$ é a deformação induzida pela expansão do gel, $\varepsilon$ é a deformação total na matriz de concreto e $E_{g}$ é o módulo de elasticidade do gel.

A pressão do gel é equilibrada pela tensão $\sigma_{\mu}$ gerada na matriz de concreto e, no caso de existirem tensões externas $\sigma$ atuando no sistema, a equação de equilíbrio é dada pela Equação 3.53.

$$
\sigma=\sigma_{\mu}-p_{g}
$$


A deformação total no material é dada pela soma da deformação elástica $\varepsilon^{e}$ e da deformação pós-fissuração $\varepsilon_{c h}$, segundo a Equação 3.54 .

$$
\varepsilon=\varepsilon^{e}+\varepsilon_{c h}
$$

O estado de fissuração é representado de maneira homogênea, substituindo-se a matriz elástica isotrópica do material por uma matriz anisotrópica, introduzindo os efeitos de degradação do concreto.

O critério de fissuração adotado para a detecção da superfície de fissura é o de Rankine. Considera-se a superfície de fissuração normal à direção da tensão principal e desacoplada das demais direções, no caso de problemas tridimensionais. A Figura 3.12 ilustra o comportamento da relação tensão-deformação pós-fissuração na direção normal à superfície da fissura.

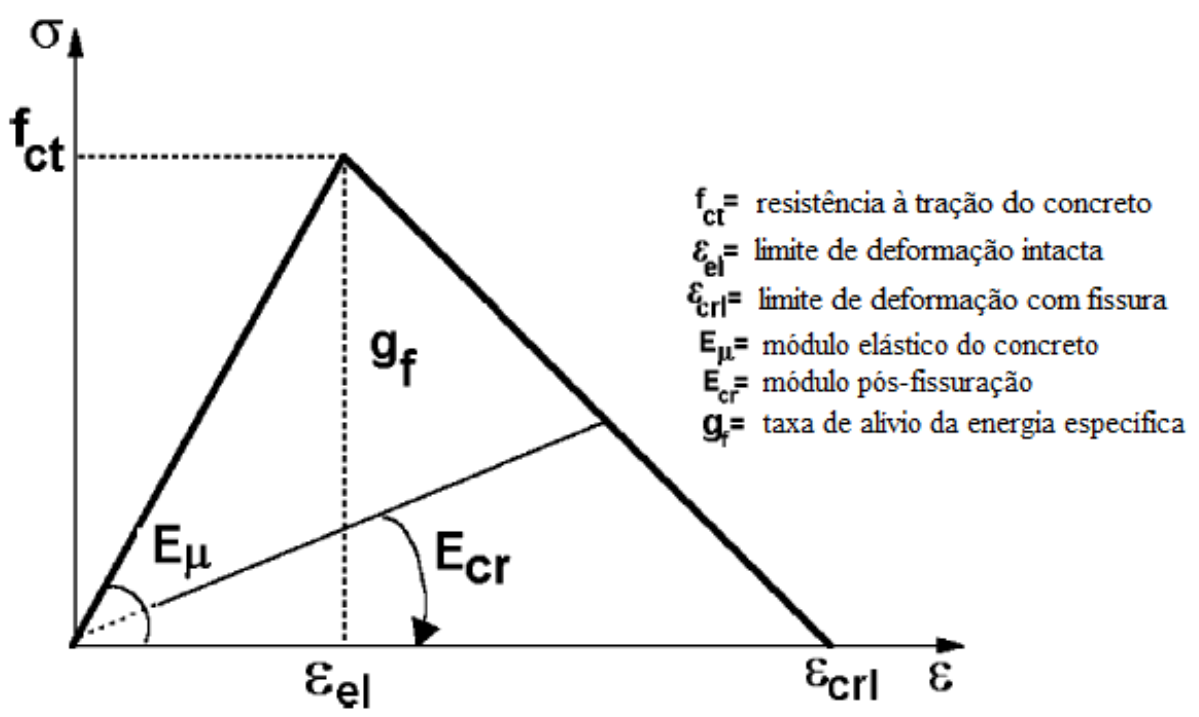

Figura 3.12 - Relação tensão-deformação 1D.

Fonte: Farage et al. (2004).

em que $\varepsilon_{c r l}$ é a deformação relacionada à abertura limite da fissura e que determina o fim do comportamento coesivo do material. $E_{c r}$ é o módulo pós-fissuração, que relaciona as tensões com as deformações para o concreto em estado fissurado.

Porém, essa relação constitutiva não é a que melhor representa o comportamento do concreto afetado pela RAA, uma vez que o gel, produto da RAA, mantém a capacidade de transmissão de forças, sem a redução da resistência à tração até uma certa deformação limite, 
conforme ilustrado na Figura 3.13 (a). Dessa forma, essa relação constitutiva permite que as fissuras se fechem ou se abram, dependendo do carregamento aplicado na estrutura, conforme a relação apresentada na Figura 3.13 (b).

(a)

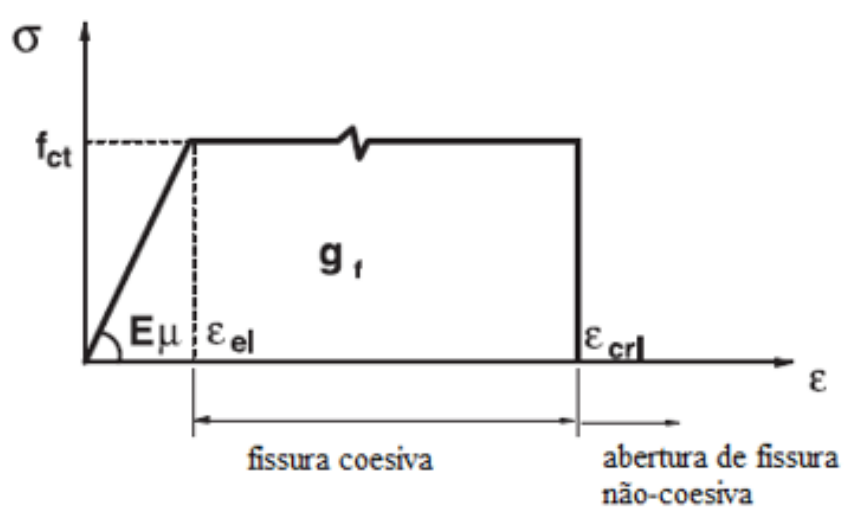

(b)

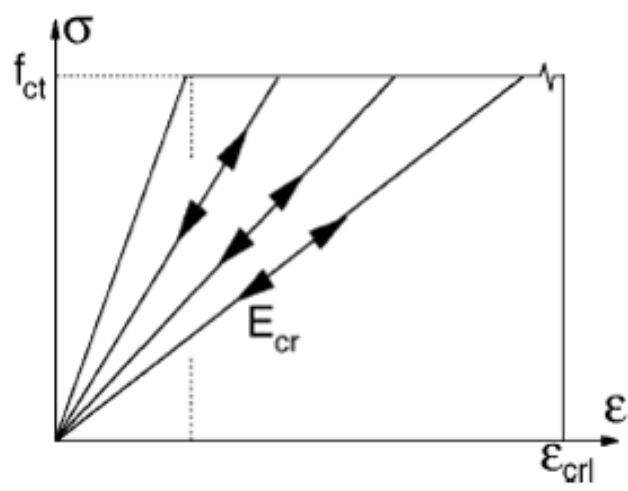

Figura 3.13 - (a) Relação tensão-deformação considerando a ductilidade pós-fissuração; (b) Mecanismo de fechamento e abertura de fissuras.

Fonte: Farage et al. (2004).

A expansão por RAA adotada no modelo é a proposta por Larive (1998). A taxa de expansão livre no concreto é dada pela Equação 3.55.

$$
\dot{\varepsilon}_{c h}=\frac{\varepsilon_{\infty}}{\tau_{c}} \frac{\left(\exp \left(\frac{T}{\tau_{c}}\right)+\exp \left(\frac{-T+\tau_{l}}{\tau_{c}}\right)\right)}{\left(1+\exp \left(\frac{-T+\tau_{l}}{\tau_{c}}\right)\right)}
$$

em que $T$ representa o tempo, $\varepsilon_{\infty}$ é a deformação volumétrica assintótica, $\tau_{c}$ e $\tau_{l}$ representam os tempos característico e de latência, respectivamente.

Sob expansão livre, o comportamento do concreto é considerado isotrópico e, portanto, a taxa de expansão volumétrica devido à RAA pode ser dada por: $\dot{\varepsilon}_{c h}^{V}=3 \dot{\varepsilon}_{c h}$.

Para o caso tridimensional, adota-se um sistema global (x, y, z) e um sistema local (1, 2, 3) que coincide com as direções das tensões principais. Assim, a parcela que representa a pressão do gel é dada pela Equação 3.56. 


$$
p_{g}=B\left[\begin{array}{ccc}
3 \varepsilon_{c h}-\varepsilon_{V} & 0 & 0 \\
0 & 3 \varepsilon_{c h}-\varepsilon_{V} & 0 \\
0 & 0 & 3 \varepsilon_{c h}-\varepsilon_{V}
\end{array}\right]
$$

em que $B=\frac{E_{g}}{3\left(1-2 v_{g}\right)}, v_{g}$ é o coeficiente de Poisson do gel e $\varepsilon_{V}=\varepsilon_{x}+\varepsilon_{y}+\varepsilon_{z}$ representa a deformação volumétrica

A relação tensão-deformação para o caso tridimensional fica dada pela Equação 3.57.

$$
\dot{\sigma}_{\mu}=D \dot{\varepsilon}
$$

Portanto, enquanto a tensão na direção principal 1 for menor do que a resistência à tração do material, o elemento finito é considerado intacto e sua matriz elástica é dada pela Equação 3.58 .

$$
D=d\left[\begin{array}{cccccc}
1 & \frac{v}{1-v} & \frac{v}{1-v} & 0 & 0 & 0 \\
\frac{v}{1-v} & 1 & \frac{v}{1-v} & 0 & 0 & 0 \\
\frac{v}{1-v} & \frac{v}{1-v} & 1 & 0 & 0 & 0 \\
0 & 0 & 0 & \frac{1-2 v}{2(1-v)} & 0 & 0 \\
0 & 0 & 0 & 0 & \frac{1-2 v}{2(1-v)} & 0 \\
0 & 0 & 0 & 0 & 0 & \frac{1-2 v}{2(1-v)}
\end{array}\right]
$$

em que $d=\frac{E_{\mu}(1-v)}{(1+v)(1-2 v)}$

Após a constatação da fissuração, a matriz $D$ é substituída pela matriz $D_{c r}$ que representa o estado de degradação do material. Como cada uma das direções é considerada desacoplada das demais, existe a possibilidade de formação de três superfícies de fissura por elemento. Para cada uma das possíveis configurações de fissuração existe uma matriz $D_{c r}$ distinta: 
a) Uma fissura: a seguinte condição deve ser respeitada $\varepsilon_{1}>\varepsilon_{e l}, \varepsilon_{2} \leq \varepsilon_{e l}$ e $\varepsilon_{3} \leq \varepsilon_{e l}$; a matriz é dada pela Equação 3.59

$$
D_{c r}=\left[\begin{array}{cccccc}
E_{c r} & 0 & 0 & 0 & 0 & 0 \\
0 & d & \frac{v}{1-v} d & 0 & 0 & 0 \\
0 & \frac{v}{1-v} d & d & 0 & 0 & 0 \\
0 & 0 & 0 & 0 & 0 & 0 \\
0 & 0 & 0 & 0 & \frac{1-2 v}{2(1-v)} d & 0 \\
0 & 0 & 0 & 0 & 0 & 0
\end{array}\right]
$$

b) Duas fissuras: $\varepsilon_{1}>\varepsilon_{e l}, \varepsilon_{2}>\varepsilon_{e l}$ e $\varepsilon_{3} \leq \varepsilon_{e l}$; a matriz é dada pela Equação 3.60

$$
D_{c r}=\left[\begin{array}{cccccc}
E_{c r} & 0 & 0 & 0 & 0 & 0 \\
0 & E_{c r} & 0 & 0 & 0 & 0 \\
0 & 0 & E_{\mu} & 0 & 0 & 0 \\
0 & 0 & 0 & 0 & 0 & 0 \\
0 & 0 & 0 & 0 & 0 & 0 \\
0 & 0 & 0 & 0 & 0 & 0
\end{array}\right]
$$

c) Três fissuras: $\varepsilon_{1}>\varepsilon_{e l}, \varepsilon_{2}>\varepsilon_{e l}$ e $\varepsilon_{3}>\varepsilon_{e l}$; a matriz é dada pela Equação 3.61

$$
D_{c r}=\left[\begin{array}{cccccc}
E_{c r} & 0 & 0 & 0 & 0 & 0 \\
0 & E_{c r} & 0 & 0 & 0 & 0 \\
0 & 0 & E_{c r} & 0 & 0 & 0 \\
0 & 0 & 0 & 0 & 0 & 0 \\
0 & 0 & 0 & 0 & 0 & 0 \\
0 & 0 & 0 & 0 & 0 & 0
\end{array}\right]
$$

As comparações entre resultados experimentais com os resultados obtidos pelo modelo mostram que esse modelo é capaz de representar a anisotropia da expansão devido à RAA em função de diferentes estados de tensão e restrições aplicadas às estruturas.

\subsubsection{Modelo de Saouma e Perotti (2006)}

O modelo termo-químico-mecânico de Saouma e Perotti (2006) também toma como base a cinética da reação apresentada por Larive (1998) e Ulm et al. (2000), associando pesos 
ao tensor de tensões do concreto para representar o efeito de redistribuição da expansão volumétrica devido à RAA.

Esse modelo assume as seguintes hipóteses:

a) A RAA sofre considerável influência da temperatura, portanto, o modelo considera o efeito da variação da temperatura com o tempo na expansão por RAA;

b) A expansão por RAA é restringida devido às tensões de compressão, sendo redirecionada para outras direções principais menos comprimidas. Isso é feito assumindo pesos para cada uma das direções principais;

c) Tensões de compressão ou tração relativamente elevadas tendem a inibir a expansão devido à formação de microfissuras e macrofissuras que absorvem a expansão do gel;

d) Elevadas tensões de compressão hidrostáticas desaceleram a reação;

e) Estados de compressão triaxial reduzem, mas não eliminam a expansão;

f) O módulo de elasticidade e a resistência à tração são reduzidos com a expansão por RAA.

A Equação 3.62 representa a taxa de expansão volumétrica devido à RAA proposta por este modelo.

$$
\dot{\varepsilon}_{v o l}^{R A A}(t)=\left.\Gamma_{t}\left(f_{t}^{\prime}, \sigma_{1} \mid C O D\right) \Gamma_{c}\left(\bar{\sigma}, f_{c}^{\prime}\right) f(h) \dot{\xi}(t, \theta) \varepsilon^{\infty}\right|_{\theta=\theta_{0}}
$$

em que COD é o deslocamento por abertura de fissuras; $\xi(t, \theta)$ é a equação proposta por Larive (1998) que expressa a expansão volumétrica devido à RAA, variando com o tempo e com a temperatura (Equações 3.63 e 3.64); $\varepsilon^{\infty}$ é a máxima expansão volumétrica livre determinada por ensaios de laboratório à temperatura de referência $\theta_{0}$ e $f(h)=h^{m}$ é uma função de redução em função da umidade relativa apresentada por Capra e Bournazel (1998), em que $m$ geralmente assume o valor de 8 .

$$
\begin{gathered}
\tau_{c}(\theta)=\tau_{c}\left(\theta_{0}\right) \exp \left[U_{C}\left(1 / \theta-1 / \theta_{0}\right)\right] \\
\tau_{l}\left(\theta, I_{\sigma}, f_{c}^{\prime}\right)=f\left(I_{\sigma}, f_{c}^{\prime}\right) \tau_{l}\left(\theta_{0}\right) \exp \left[U_{L}\left(1 / \theta-1 / \theta_{0}\right)\right]
\end{gathered}
$$

A Equação 3.64 reproduz o efeito de desaceleração da expansão no caso em que tensões de compressão hidrostáticas estejam atuando sobre a estrutura. Nessa equação, a primeira parcela é dada pela Equação 3.65. 


$$
\begin{aligned}
& f\left(I_{\sigma}, f_{c}^{\prime}\right)=1 \text { se } I_{\sigma}>0 \\
& f\left(I_{\sigma}, f_{c}^{\prime}\right)=1+\alpha \frac{I_{\sigma}}{3 f_{c}^{\prime}} \text { se } I_{\sigma} \leq 0
\end{aligned}
$$

em que $I_{\sigma}=\left(\sigma_{I}+\sigma_{I I}+\sigma_{I I I}\right) / 3$ é o primeiro invariante do tensor de tensões e $f_{c}^{\prime}$ é a resistência à compressão. $\alpha=4 / 3$ é um parâmetro adotado, baseado nas análises experimentais de Multon (2003).

A dependência do tempo de latência com o invariante das tensões atuando na estrutura acopla as fases química e mecânica nesse modelo.

Voltando à Equação 3.62, a parcela $\Gamma_{t}\left(f_{t}^{\prime}, \sigma_{1} \mid C O D\right)$ considera a redução da expansão por RAA devido às fissuras geradas pelas tensões de tração. Nesse caso, o gel é acomodado pelas fissuras e, portanto, expansões menores são observadas. A Equação 3.66 reproduz para um modelo de fissuração o decaimento hiperbólico desse parâmetro.

$$
\begin{gathered}
\Gamma_{t}=1 \text { se } C O D_{\text {max }} \leq \gamma_{t} w_{c} \\
\Gamma_{t}=\Gamma_{r}+\left(1-\Gamma_{r}\right) \frac{\gamma_{t} w_{c}}{C O D_{\text {max }}} \text { se } \gamma_{t} w_{c}<C O D_{\text {max }}
\end{gathered}
$$

em que $\gamma_{t}$ é a fração da resistência à tração abaixo da qual o gel é acomodado pela fissura, $\Gamma_{r}$ é o fator de retenção da RAA residual sob tração. $C O D_{\max }$ é o máximo deslocamento devido à abertura de fissuras em um dado ponto da estrutura e $w_{c}$ é a máxima abertura de fissura na curva de alívio da tração.

A parcela $\Gamma_{c}\left(\bar{\sigma}, f_{c}^{\prime}\right)$ da Equação 3.62 considera a redução da expansão volumétrica devido à RAA sob tensão de compressão, caso em que o gel é acomodado e espalhado nas microfissuras geradas no concreto. Essa parcela é dada pela Equação 3.67.

$$
\begin{gathered}
\Gamma_{c}=1 \text { se } \bar{\sigma} \leq 0 \text { Tração } \\
\Gamma_{c}=1-\frac{e^{\beta} \bar{\sigma}}{1+\left(e^{\beta}-1\right) \bar{\sigma}} \text { se } \bar{\sigma}>0 \text { Compressão }
\end{gathered}
$$


em que $\bar{\sigma}=\left(\sigma_{I}+\sigma_{I I}+\sigma_{I I}\right) /\left(3 f_{c}^{\prime}\right)$. Ressalta-se que as equações anteriores também são capazes de reduzir a expansão para casos em que as tensões de compressão atuem em apenas uma ou em duas direções da estrutura.

A representação gráfica das Equações 3.66 e 3.67 associadas às tensões de tração e compressão que atuam na estrutura encontram-se ilustradas na Figura 3.14.

(a)
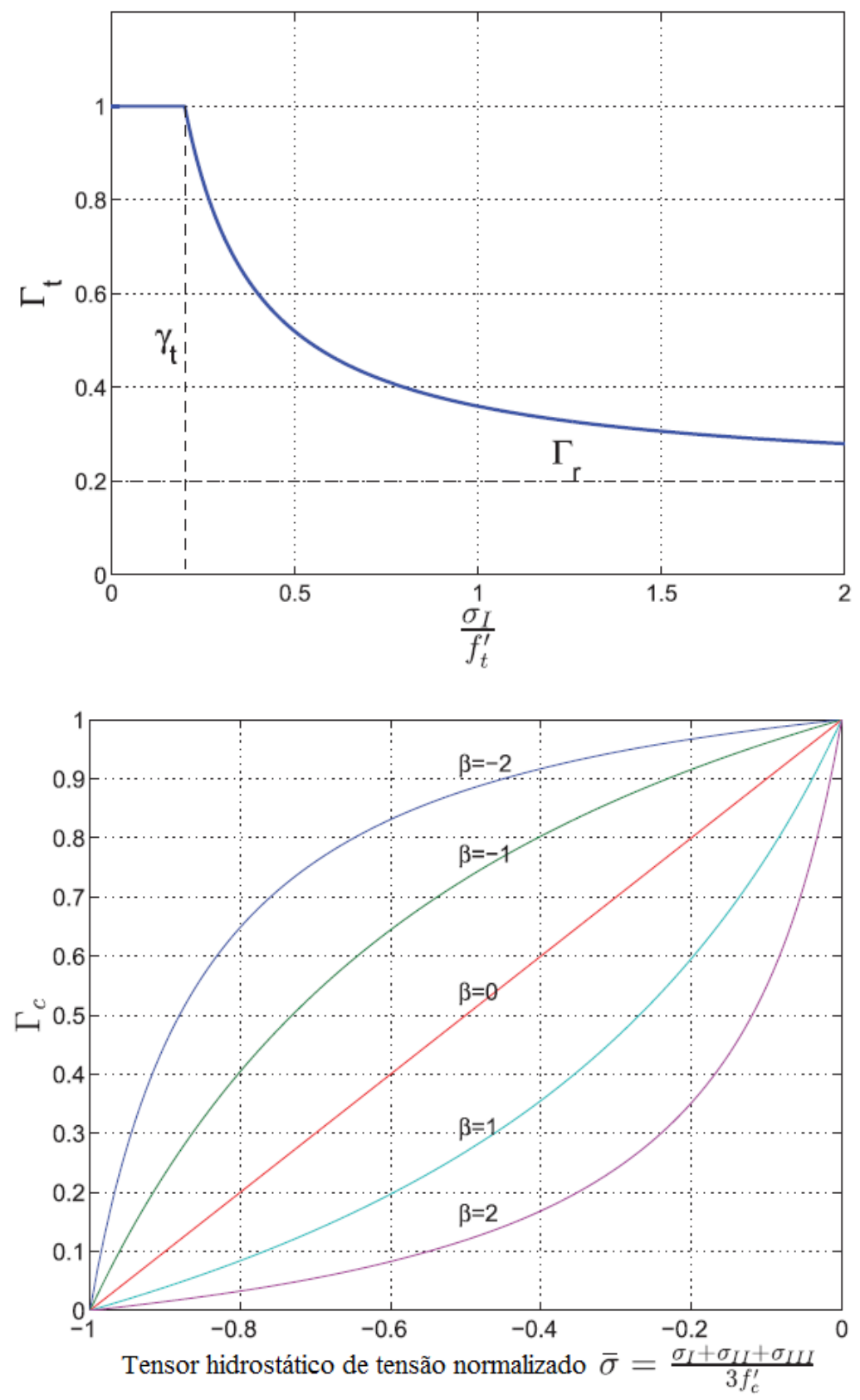

(b)

Figura 3.14 - Representação gráfica dos parâmetros de redução associados às (a) tensões de tração e (b) compressão atuando na estrutura.

Fonte: Saouma e Perotti (2006). 
No modelo, a expansão volumétrica deve ser redistribuída para as três direções principais, de acordo com a sua propensão a expandir, isso é feito com base em pesos associados às tensões de cada direção. Considerando-se as tensões associadas às três direções principais $k$, $l$ e $m$, a Figura 3.15 ilustra três possíveis estados de tensão e os pesos associados a cada uma das direções principais.

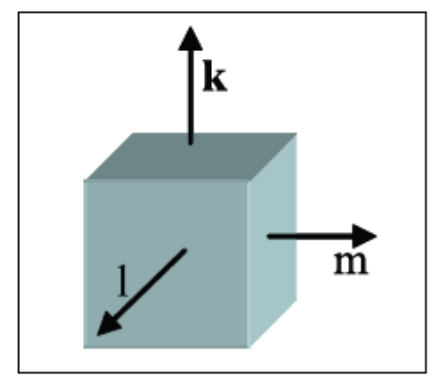

(a) Direções principais

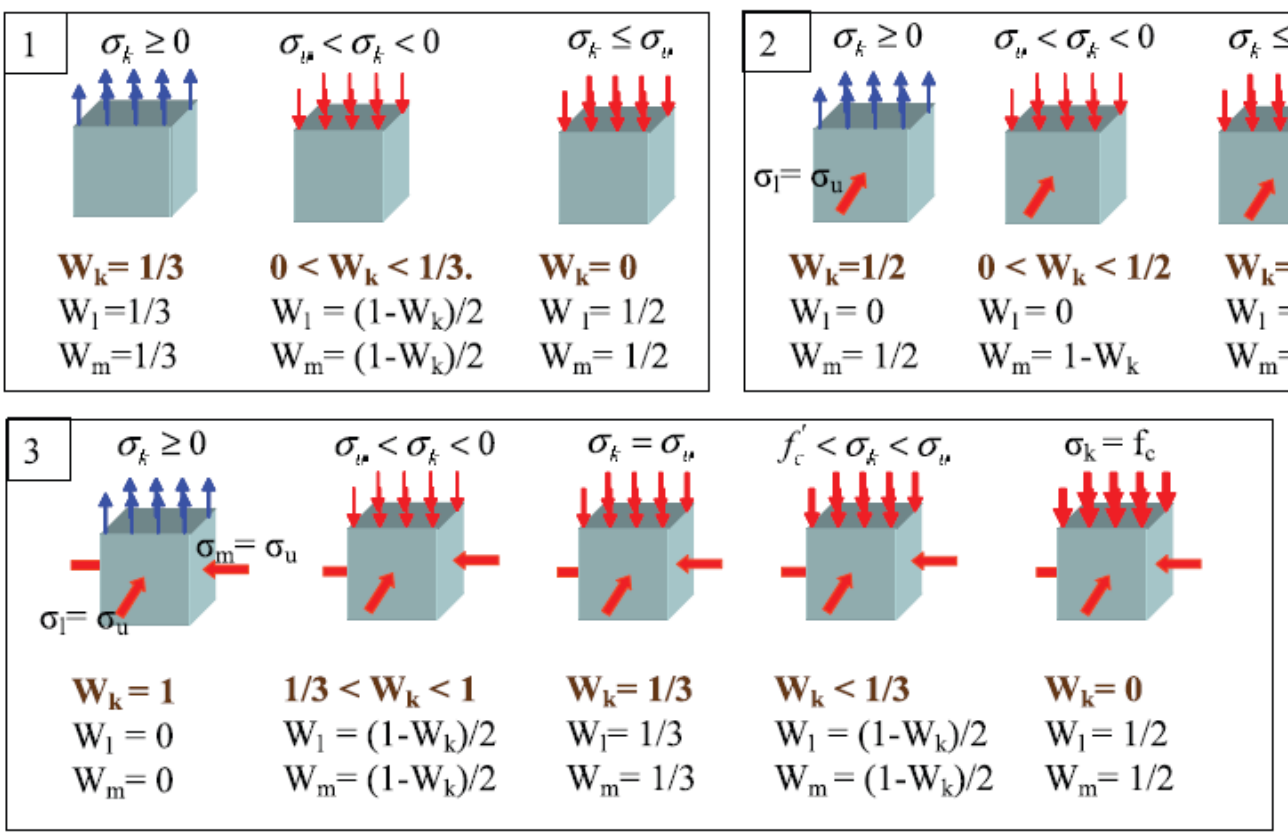

(b) Pesos

Figura 3.15 - Pesos associados à redistribuição da expansão volumétrica da RAA para alguns casos. Fonte: Saouma e Perotti (2006).

1) Estado uniaxial de tensão:

(a) No primeiro caso, de tração uniaxial: a expansão volumétrica devido à RAA é igualmente distribuída para todas as três direções; 
(b) Sob tensão de compressão maior do que um limite $\sigma_{u}$ : o peso na direção correspondente $k$ deve ser menor do que 1/3. A expansão por RAA é então igualmente redistribuída para as outras duas direções;

(c) Se a tensão de compressão for menor do que $\sigma_{u}$ : a expansão por RAA na direção correspondente é tomada como sendo igual a zero e os pesos associados às demais direções ficam valendo $1 / 2$.

2) Estado biaxial de tensão: em que há uma tensão de compressão igual a $\sigma_{u}$ atuando em uma das três direções principais. Nesse caso, o peso associado a essa direção será sempre igual a zero.

(a) Tração atuando em uma das outras duas direções: pesos iguais a 1/2 para as duas direções;

(b) Compressão maior do que $\sigma_{u}$ em uma direção: o peso correspondente a essa direção deve ser menor do que 1/2, o peso complementar é associado à terceira direção;

(c) Compressão menor do que $\sigma_{u}$ : o peso correspondente associado a essa direção é zero e o peso de 1 é associado à terceira direção.

3) Estado triaxial de tensão: $\sigma_{u}$ atua em duas das três direções principais.

(a) Tração na direção $k$ : toda a expansão ocorre na direção $k$;

(b) Compressão maior do que $\sigma_{u}$ : tem-se um estado de compressão triaxial e o peso correspondente pode variar de 1 a 1/3. A expansão complementar é igualmente distribuída para as outras duas direções;

(c) Compressão igual a $\sigma_{u}$ : tem-se um estado de compressão triaxial perfeito. Nesse caso o peso associado a todas as direções é igual a 1/3.

(d) Compressão menor do que $\sigma_{u}$ mas maior do que a resistência à compressão: o peso associado à direção $k$ deve ser menor do que 1/3 e a expansão complementar é igualmente distribuída nas outras duas direções;

(e) Compressão igual à resistência à compressão do concreto: o peso associado a essa direção é igual a zero e os pesos associados às outras duas direções valem $1 / 2$.

Esses pesos foram adotados com base em resultados experimentais como os de Multon (2003) e Larive (1998). O valor de $\sigma_{u}$ (tensão abaixo da qual não é verificada expansão devido 
à RAA) é adotado como sendo igual a -10MPa. A taxa de expansão devido à RAA para cada uma das direções é dada pela Equação 3.68.

$$
\dot{\varepsilon}_{i}=W_{i} \dot{\varepsilon}_{v o l}^{R A A}
$$

em que $W_{i}$ são os pesos associados a cada uma das direções e dependem das tensões que atuam em cada uma das direções, como ilustra a Figura 3.16.
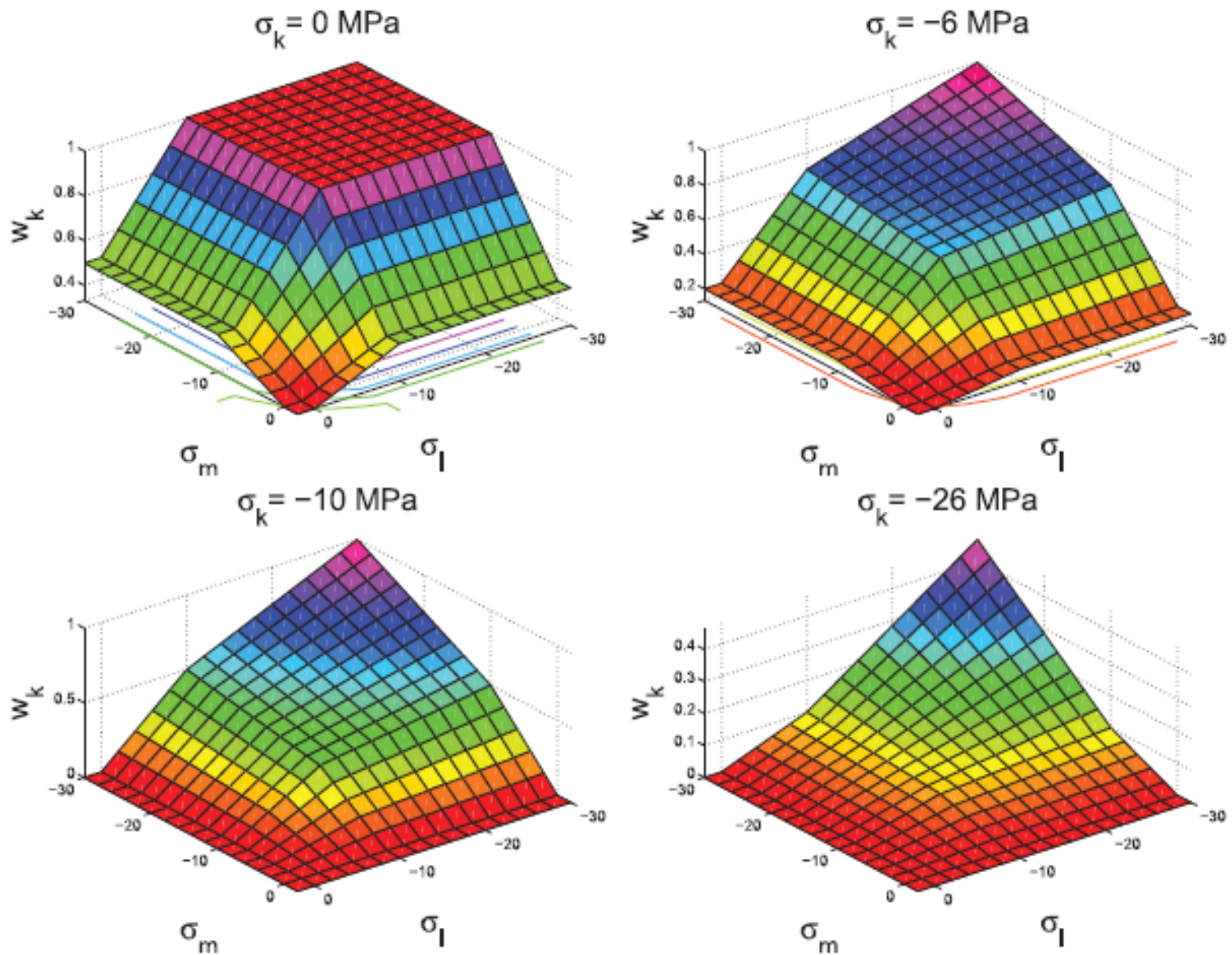

Figura 3.16 - Pesos associados à direção principal $k$ em função do estado de tensão.

Fonte: Saouma e Perotti (2006).

A associação de pesos para a atribuição da expansão por RAA para cada uma das direções principais resulta em uma expansão anisotrópica.

Além disso, esse modelo também considera a degradação das propriedades físicas do concreto. A redução do módulo de elasticidade e da resistência à tração seguem as Equações 3.69 e 3.70 . 


$$
\begin{aligned}
& E(t, \theta)=E_{0}\left[1-\left(1-\beta_{E}\right) \xi(t, \theta)\right] \\
& f_{t}(t, \theta)=f_{t, 0}\left[1-\left(1-\beta_{f}\right) \xi(t, \theta)\right]
\end{aligned}
$$

em que $E_{0}$ e $f_{t, 0}$ são, respectivamente, o módulo de elasticidade e resistência à tração inicial do concreto; $\beta_{E}$ e $\beta_{f}$ são os correspondentes valores residuais, quando a expansão por RAA tende à máxima expansão esperada $\varepsilon^{\infty}$. Saouma (2014) sugere a utilização de 70\% como valor para os parâmetros $\beta_{E}$ e $\beta_{f}$.

\subsection{Modelos multi-escala}

Modelos macroscópicos são utilizados para a previsão do comportamento estrutural, permitindo que reparos sejam devidamente executados em estruturas afetadas pela RAA. Contudo, o campo de tensões obtido por esses modelos não se mostra devidamente preciso, uma vez que a cinética da reação utilizada por esses modelos toma como base resultados obtidos experimentalmente. Dessa forma, diversos autores sugerem o desenvolvimento de uma abordagem em que os modelos macroscópicos sejam derivados de simulações microscópicas (PAN, et al., 2012; RAJABIPOUR et al., 2015).

Wu et al. (2014) apresentam um modelo hidro-termo-químico-mecânico para a representação em escala mesoscópica da expansão devido à RAA. Nesse modelo, a partir de um scanner microscópico, obtém-se um modelo 3D para a pasta de cimento endurecida (Figura 3.17 (a)), representando a microescala do concreto; a mesoescala do concreto é representada por meio de agregados aleatoriamente distribuídos na matriz da pasta de cimento homogênea (Figura 3.17 (b)). 


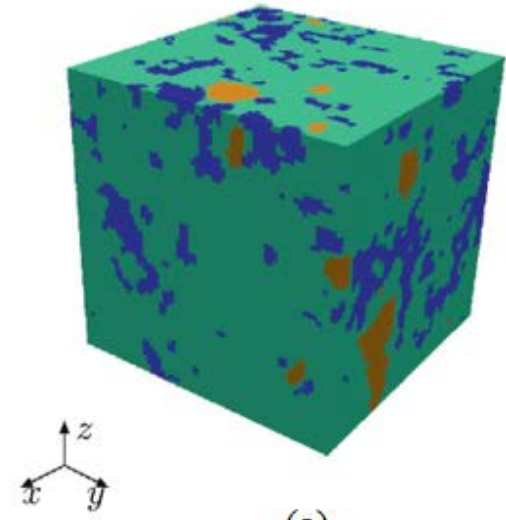

(a)

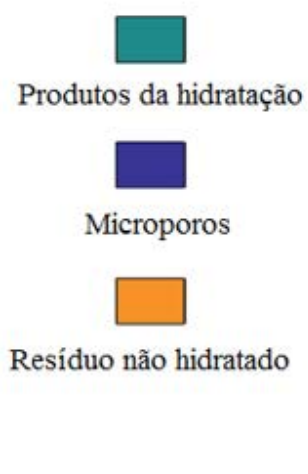

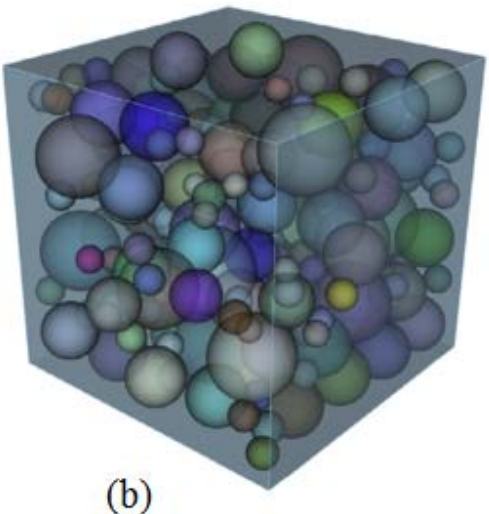

)

Figura 3.17 - (a) Microescala da pasta de cimento; (b) Mesoescala contendo os agregados distribuídos aleatoriamente.

Fonte: Wu et al. (2014).

Nesse modelo, a degradação induzida pela extensão química da RAA tem início nos microporos da pasta de cimento, sendo a extensão química influenciada pela umidade e pela temperatura. A correlação entre o dano efetivo devido à RAA e a extensão química da reação é obtida por meio de técnicas de homogeneização computacional, permitindo uma associação do dano na microescala com a falha observada na macroescala. 


\section{MODELO PARAMÉTRICO DE EXPANSÃO POR RAA}

O modelo numérico para a expansão por RAA empregado neste trabalho tem como base o modelo macroscópico paramétrico apresentado por Carrazedo (2004), o qual se baseia nos modelos paramétricos propostos por Léger et al. (1996) e Pappalardo Jr. et al. (2000), e na equação constitutiva apresentada por Pietruszczak (1996). Modificações nesse modelo também foram apresentadas em Carrazedo et al. (2012) e em Oliveira (2013), considerando, respectivamente, a ortotropia do gel e o decaimento do módulo de elasticidade com o avanço da reação.

Carrazedo (2004) propõe a obtenção da distribuição espacial e normalização dos fatores que influenciam a reação. Esses fatores normalizados devem então ser combinados por meio de uma lei constitutiva, a fim de se obter a taxa de deformação volumétrica devido à reação álcaliagregado.

A seguir são detalhados tanto os fatores de influência considerados pelo modelo bem como as leis de normalização e a equação constitutiva utilizada.

\subsection{Fatores de influência e leis de normalização}

Dada a complexidade da reação álcali-agregado, o modelo proposto por Carrazedo (2004) realiza algumas simplificações nas condições que influenciam a reação.

\subsubsection{Reatividade dos materiais}

Os agregados e íons alcalinos geralmente não têm a mesma origem e estão espalhados irregularmente na estrutura, existindo, como consequência, concentração de material reativo em algumas regiões. O modelo aqui empregado simplifica essa distribuição aleatória, considerando-a uniforme em toda a estrutura e representada por meio de dois parâmetros: a 
máxima expansão volumétrica esperada $\left(\varepsilon_{v o l}^{\max }\right)$ e o índice de reatividade $\left(A_{1}\right)$ associado à velocidade de ocorrência e estabilização da reação.

\subsubsection{Umidade}

É essencial para a ocorrência da expansão, pois além de fornecer os íons hidroxila ainda possibilita a dissolução e movimentação dos íons alcalinos na estrutura; além disso, os produtos da reação expandem pela absorção de água.

O modelo de Carrazedo (2004) requer análises de difusão e percolação de água pela estrutura, uma vez que tem por objetivo a aplicação a estruturas maciças como barragens, as quais apresentam diferentes teores de umidade para cada região analisada. Como simplificação, o modelo apresentado neste trabalho considera uma umidade constante para toda a estrutura avaliada.

Dessa forma, a umidade presente na estrutura determina a quantidade ou existência de expansão por RAA, ou seja, o modelo considera que o aumento de umidade irá aumentar a magnitude da expansão, não afetando a sua velocidade.

Léger et al. (1996) consideram necessário pelo menos 75\% de umidade relativa para que uma expansão considerável seja observada no concreto; assim, a Figura 4.1 representa a lei para normalização adotada para a obtenção do parâmetro relativo à umidade $\left(F_{m}\right)$.

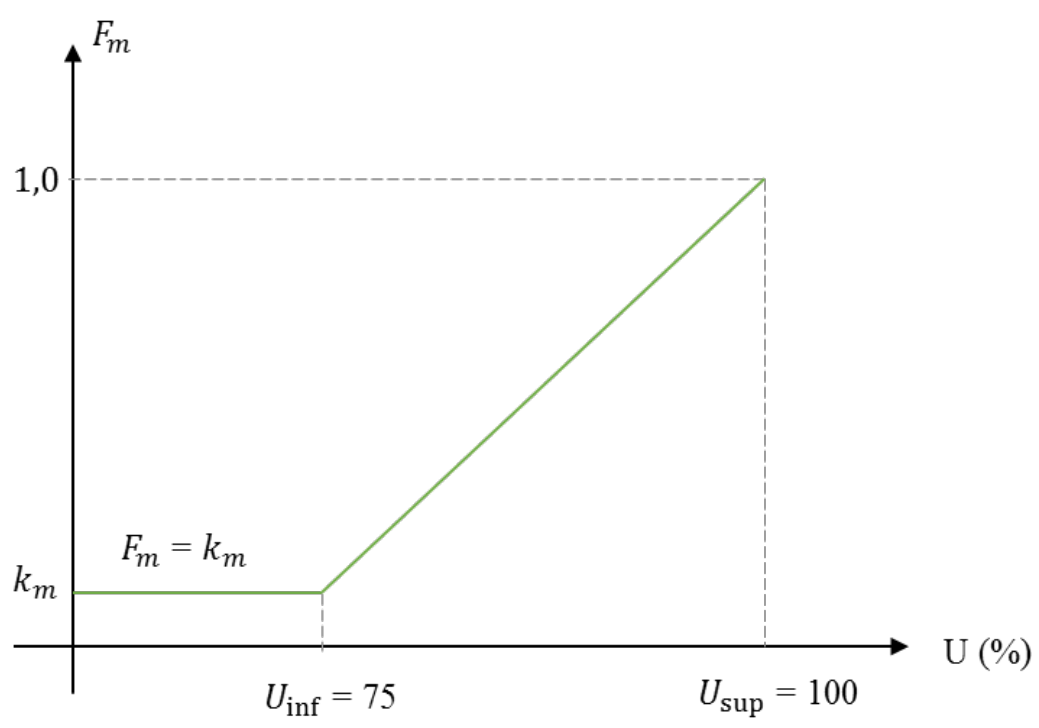

Figura 4.1 - Lei de normalização para a umidade.

Fonte: Pappalardo Jr. et al. (2000). 
Na Figura 4.1 anterior é possível observar o parâmetro $k_{m}$, uma variável de calibração como as apresentadas no modelo de Pappalardo Jr. et al. (2000) que possibilitam a ponderação de cada parâmetro do modelo matemático a partir de dados experimentais e de instrumentação das estruturas.

\subsubsection{Porosidade}

O gel higroscópico, produto da reação, se acomoda nos poros presentes no concreto e expande pela absorção de água. Contudo, a expansão do concreto apenas é evidenciada quando o volume dos poros é completamente preenchido pelo gel e esse começa a exercer pressão no seu entorno.

No modelo, a porosidade afeta o tempo para início da reação, representado pelo parâmetro $\left(t^{p}\right)$. Assim, a equação que define a expansão devido à RAA apenas evidencia expansão quando todos os poros do concreto estiverem preenchidos por gel.

Como consequência do valor de $t^{p}$, dependendo do passo de tempo adotado para as análises, pode ser introduzido um erro. Este erro pode ser evitado utilizando-se uma lei de conversão em forma de escada (Figura 4.2).

Dessa forma, o parâmetro referente à porosidade $\left(F_{p}\right)$ é descrito pela lei de conversão em forma de escada, em que Ndiv representa o número de divisões da lei de normalização para um intervalo de análise $\Delta t$ que seja múltiplo de $t^{p}$ (CARRAZEDO; LACERDA, 2008).

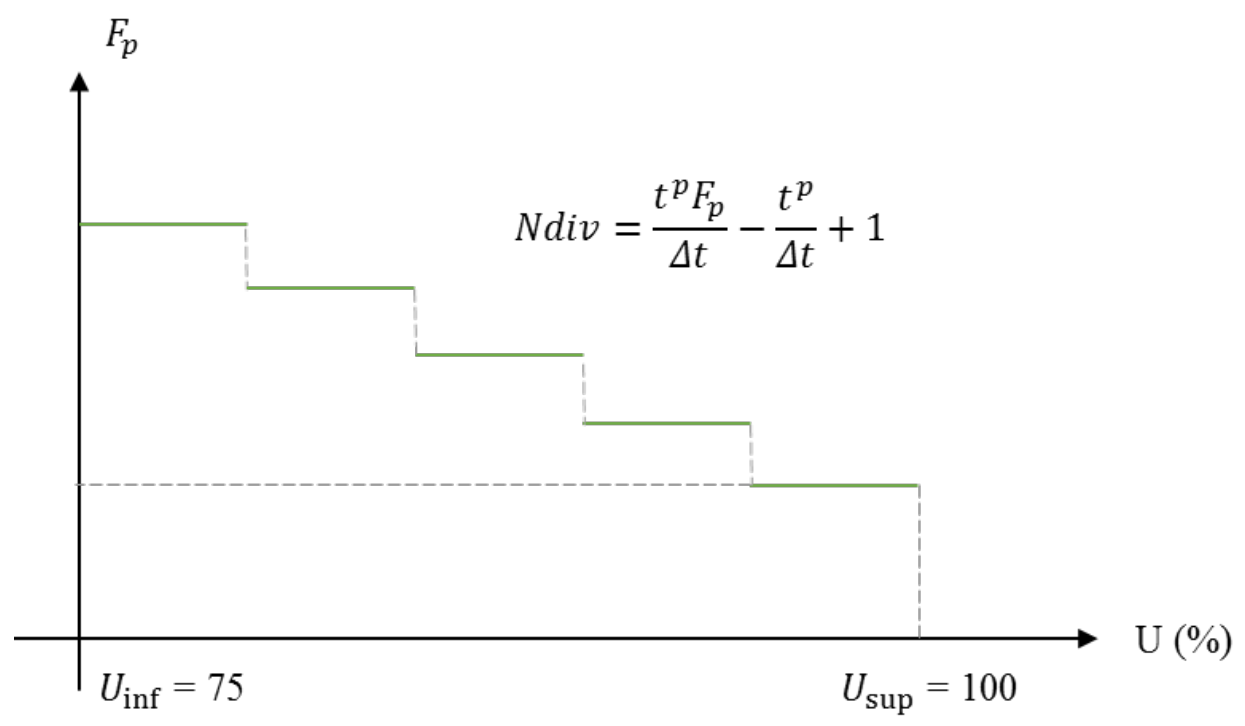

Figura 4.2 - Lei de normalização para a porosidade.

Fonte: Carrazedo (2004). 


\subsubsection{Temperatura}

A temperatura influencia a velocidade da reação, uma vez que a dissolução dos agentes da reação aumenta com a elevação da temperatura. O modelo aqui apresentado considera que a elevação da temperatura aumenta a velocidade da reação, mas não modifica a máxima expansão volumétrica.

O modelo de Carrazedo (2004) requer análises de transferência e condução de calor pela estrutura, novamente, o modelo aqui empregado não contempla os gradientes de temperatura observados principalmente em estruturas maciças de concreto.

A Figura 4.3 ilustra a lei linear para a normalização da temperatura $\left(F_{t}\right)$. Ressalta-se que os limites inferiores e superiores adotados para essa lei de normalização variam conforme a estrutura analisada. Neste caso, os limites foram os mesmos adotados por Léger et al. (1996).

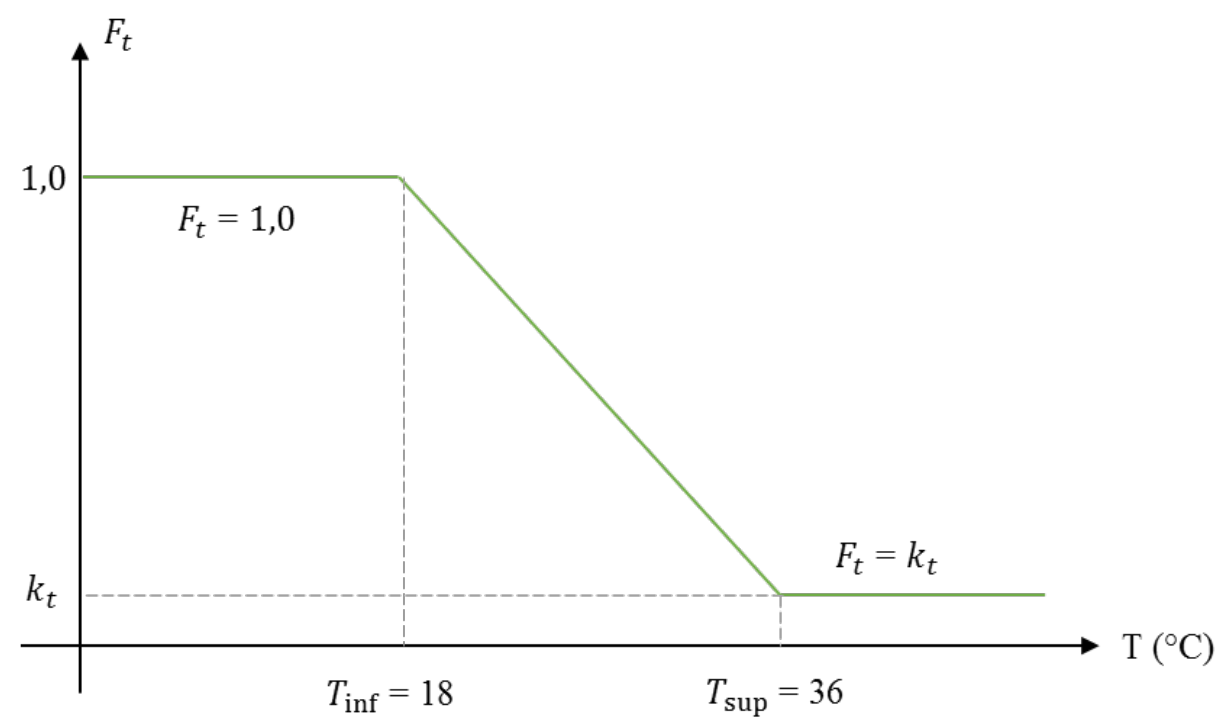

Figura 4.3 - Lei de normalização para a temperatura.

Fonte: Pappalardo Jr. et al.(2000).

\subsubsection{Estado de tensão}

A expansão do concreto é consideravelmente reduzida se este for restringido, tanto por tensão de compressão aplicada quanto por armadura (CLARK, 1991).

O modelo numérico aqui desenvolvido é capaz de representar a ortotropia da expansão, entretanto não foi implementada a transferência da expansão para a direção menos comprimida. Inicialmente o estado de tensão é determinado através dos carregamentos básicos como peso próprio e carregamento externo. Como o estado de tensão é afetado pela RAA, realiza-se um 
procedimento iterativo para a determinação dos estados de tensão seguintes e calcula-se um novo valor para o fator de influência $F_{c}$.

Neste trabalho foram avaliadas duas leis de normalização referentes ao efeito das tensões aplicadas ou induzidas pela presença de armadura na expansão por RAA. A Figura 4.4 representa a lei de normalização apresentada por Léger et al. (1996) e os respectivos limites de tensão adotados pelo mesmo autor.

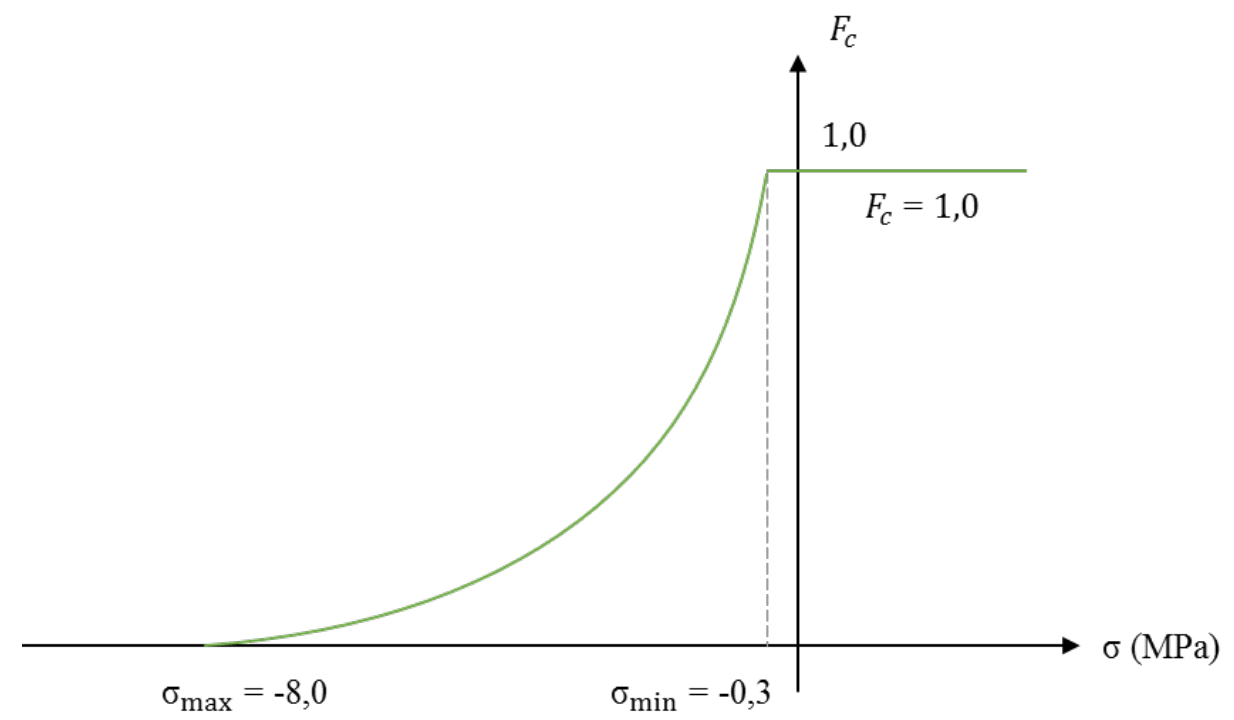

Figura 4.4 - Lei de normalização para as tensões.

Fonte: Léger et al.(1996).

Essa lei de normalização tem como base o trabalho de Charlwood (1994). Nesse modelo, o fator de influência é relacionado com a tensão de compressão na direção principal $\sigma_{i}$ pela Equação 4.1.

$$
\begin{array}{ccc}
F_{c}=1,0 & \text { para } & \sigma_{\text {min }} \leq \sigma_{i} \\
F_{c}=1-K \log _{10}\left(\sigma_{i} / \sigma_{\text {min }}\right) & \text { para } & \sigma_{\text {max }} \leq \sigma_{i} \leq \sigma_{\text {min }}
\end{array}
$$

em que $\sigma_{i}$ é a tensão principal na direção $i$ e $K$ define a curvatura do gráfico que relaciona as tensões com o fator de influência, assumindo o valor de 0,701 para $\sigma_{\max }=-8,0 \mathrm{MPa}$.

A outra lei de normalização avaliada é apresentada na Figura 4.5 e é proposta por Pappalardo Jr. et al. (2000). Nesse caso, o parâmetro $F_{c}$ obtido para cada passo de tempo entra na equação constitutiva para representação da expansão por RAA como $\sqrt{F_{c}}$. 


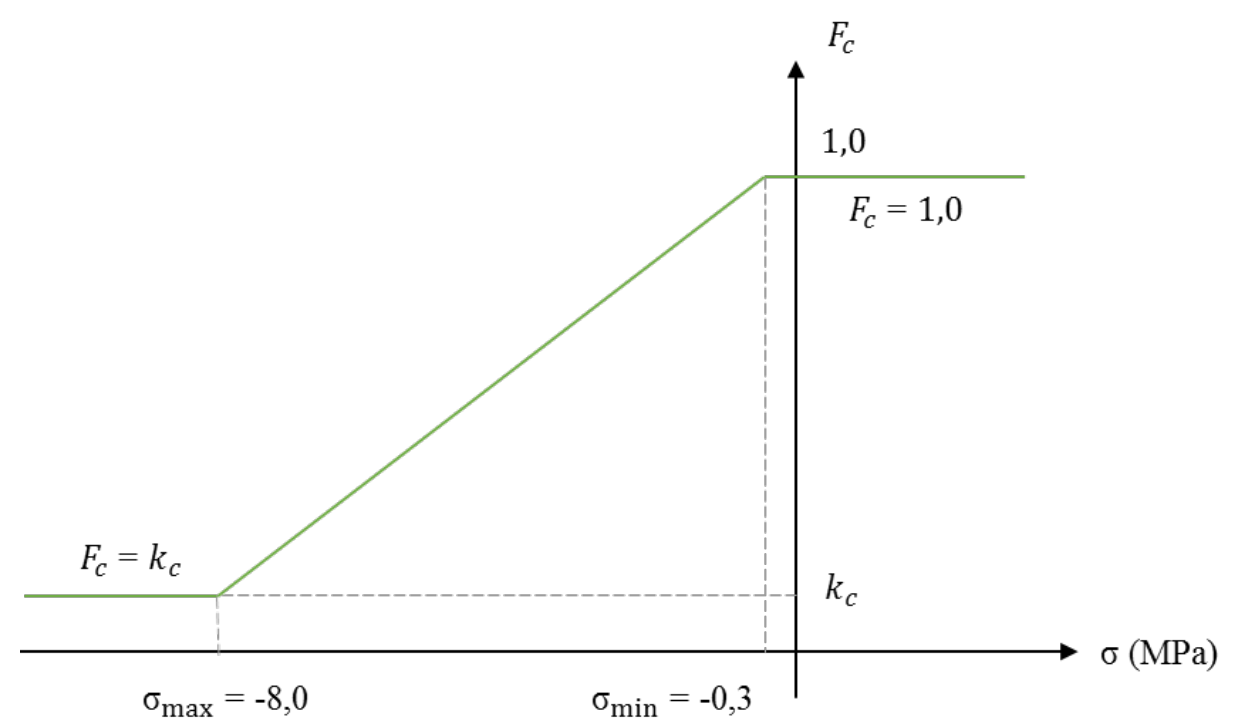

Figura 4.5 - Lei de normalização para as tensões.

Fonte: Pappalardo Jr. et al.(2000).

\subsection{Equação para a expansão por RAA}

Os fatores de influência relacionados à temperatura, umidade, porosidade e tensões de confinamento normalizados segundo as leis apresentadas anteriormente, são combinados por meio de uma equação constitutiva para expressar a taxa de deformação devido à reação álcaliagregado.

O modelo apresentado por Pappalardo Jr. et al. (2000) associa à uma equação constitutiva os parâmetros que influenciam a reação. A Equação 4.2 expressa a taxa de expansão volumétrica devido à RAA proposta.

$$
\dot{\varepsilon}_{R A A}=\frac{\varepsilon_{v o l}^{\max } A_{1} F_{t}}{\left(A_{1} F_{T}+t-t^{p} F_{p}\right)} \sqrt{F_{c} F_{m}}
$$

em que $\dot{\varepsilon}_{R A A}$ é a taxa de expansão devido à reação álcali-agregado; $\varepsilon_{v o l}^{\max }$ é a máxima expansão volumétrica esperada ou a expansão volumétrica livre devido à RAA; $A_{1}$ é o índice de reatividade; $F_{m}, F_{p}, F_{c}$ e $F_{t}$ são os fatores de influência normalizados, que representam a influência da umidade, porosidade, tensões de confinamento e temperatura respectivamente; $t^{p} F_{p}$ representa o tempo que o gel leva para preencher todos os poros do concreto. 
É possível observar na Equação 4.2 que, no momento em que $A_{1} F_{t}+t=t_{p} F_{p}$, ocorrerá uma singularidade. Dessa forma, Carrazedo (2004) propõe a inclusão de uma função Heaviside sobre $t$ e $t^{p}$, conforme indica a Equação 4.3. A função Heaviside valerá zero enquanto o tempo $t$ for menor do que o tempo $t^{p} F_{p}$, não evidenciando expansão para o primeiro estágio da reação, aquele em que ocorre a formação do gel dentro dos poros do concreto.

$$
\dot{\varepsilon}_{R A A}=H\left(t-t^{p} F_{p}\right) \frac{\varepsilon_{v o l}^{\max } A_{1} F_{t}}{\left(A_{1} F_{T}+t-t^{p} F_{p}\right)} \sqrt{F_{c} F_{m}}
$$

Com base nos comentários anteriores e com a finalidade de simplificar a representação da expansão por RAA, Carrazedo (2004) desenvolveu uma equação constitutiva alternativa à Equação 4.3.

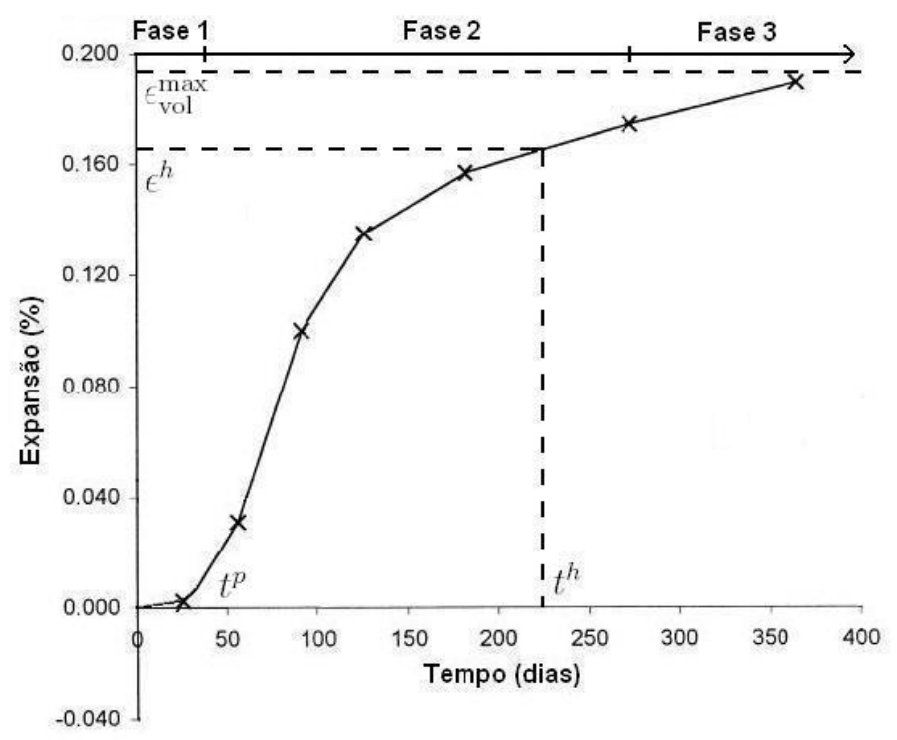

Figura 4.6 - Curva de expansão de uma amostra de concreto sujeita à expansão livre. Fonte: Carrazedo (2004).

A partir da curva de expansão observada na Figura 4.6, Carrazedo (2004) verificou que uma equação exponencial na forma da Equação 4.4 era capaz de representar as principais características da expansão.

$$
f(t)=H\left(t-t^{p}\right)\left[a_{0}-a_{1} \exp \left(-a_{2}\left(t-t^{p}\right)\right)\right]
$$


Assumido $f(t)$ como sendo a expansão volumétrica devido à RAA $\left(\varepsilon_{R A A}\right), t^{h}$ um tempo qualquer e $\varepsilon^{h}$ a sua expansão correspondente, é possível realizar as seguintes constatações expressas na Equação 4.5.

$$
\begin{aligned}
& \varepsilon_{R A A}=0 \text { enquanto } t \leq t^{p} \\
& \varepsilon_{R A A}=\varepsilon^{h} \text { quando } t=t^{h} \\
& \varepsilon_{R A A}=\varepsilon_{v o l}^{\max } \text { quando } t=\infty
\end{aligned}
$$

Com isso é possível determinar os coeficientes $a_{0}, a_{1}$ e $a_{2}$ (representados na Equação 4.6) da Equação 4.4.

$$
a_{0}=a_{1}=\varepsilon_{v o l}^{\max } \text { e } a_{2}=\frac{\ln \left(\frac{\varepsilon_{v o l}^{\max }-\varepsilon^{h}}{\varepsilon_{v o l}^{\max }}\right)}{t^{h}-t^{p}}
$$

Substituindo-se esses coeficientes na Equação 4.4, observa-se que o coeficiente $a_{2}$ tem o papel inverso do coeficiente $A_{1}$ na Equação 4.3, coeficiente este associado ao índice de reatividade dos constituintes do concreto e que altera a velocidade com que a reação atinge o seu máximo.

Como já foi discutido anteriormente, tendo em vista a anisotropia da expansão em função das tensões aplicadas ou induzidas, a Equação 4.7 a seguir inclui os fatores de influência normalizados para representar a equação constitutiva de expansão por RAA.

$$
\varepsilon_{R A A}=H\left(t-t^{p} F_{p}\right) \frac{\varepsilon_{v o l}^{\max }}{3}\left[1-\exp \left(\frac{-\left(t-t^{p} F_{p}\right)}{A_{2} F_{t}}\right)\right] \sqrt{F_{m}} F_{c}
$$

em que $\varepsilon_{R A A}$ é o valor da expansão para cada uma das direções principais da estrutura; $A_{2}=1 / a_{2}$.

O parâmetro referente às tensões $F_{c}$ assume diferentes valores em função da direção principal analisada, podendo ainda obedecer uma das duas leis de normalização discutidas no item anterior. Para obter a taxa de expansão, diferencia-se a Equação 4.7 com relação ao tempo, obtendo-se a Equação 4.8: 


$$
\dot{\varepsilon}_{\text {RAA }}=H\left(t-t^{p} F_{p}\right) \frac{\varepsilon_{v o l}^{\max }}{3}\left[\frac{\exp \left(\frac{-\left(t-t^{p} F_{p}\right)}{A_{2} F_{t}}\right)}{A_{2} F_{t}}\right] \sqrt{F_{m}} F_{c}
$$

Carrazedo (2004) ainda aplica técnicas de otimização para a calibração das variáveis associadas ao processo de expansão por RAA, a fim de que os resultados numéricos representem com maior exatidão os dados coletados dos ensaios experimentais ou da instrumentação da estrutura. O presente trabalho, entretanto, não utilizará das técnicas de otimização; em vez disso, os parâmetros necessários serão estimados a partir de ajustes que busquem a minimização da diferença entre os resultados numéricos e os resultados experimentais.

Além da Equação 4.8, este trabalho também avaliou outra equação constitutiva que vem sendo amplamente utilizada no meio acadêmico para a descrição da expansão por RAA. Essa equação se baseia na Equação 3.45 proposta por Larive (1998), reescrita abaixo em forma de taxa de expansão (Equação 4.9):

$$
\dot{\varepsilon}_{R A A}=\frac{\varepsilon_{v o l}^{\max }}{3} \frac{\exp \left(t / \tau_{c}\right)\left(\exp \left(\tau_{l} / \tau_{c}\right)+1\right)}{\tau_{c}\left(\exp \left(t / \tau_{c}\right)+\exp \left(\tau_{l} / \tau_{c}\right)\right)^{2}}
$$

em que $\tau_{c}$ e $\tau_{l}$ representam os tempos característico e de latência respectivamente, ambos dependentes da umidade e da temperatura da estrutura (Equações 3.50 e 3.51). 


\section{MODELAGEM DO CONCRETO ARMADO AFETADO PELA RAA}

A modelagem do material foi realizada por meio do Método de Elementos Finitos Posicional, no qual os parâmetros nodais considerados são as posições (adequado para problemas que envolvem grandes deslocamentos), e as deformações são medidas em relação à posição inicial do corpo, caracterizando uma descrição Lagrangeana total. A medida de deformação utilizada é a de Green (adequada para o caso de grandes deslocamentos e pequenas deformações) associada à lei constitutiva de Saint Venant-Kirchhoff e ao tensor de tensões de Piola-Kirchhoff de Segunda Espécie.

O problema do concreto reforçado com fibras ou armadura consiste no acoplamento de dois tipos de elementos, elemento de chapa 2D para a representação da matriz de concreto e elemento de treliça para representar as fibras e armaduras.

As deduções que se seguem tomam como base os trabalhos de Sampaio (2014) e Paccola et al. (2015).

\subsection{Problema de equilíbrio estático}

Um corpo em sua posição de referência indeformada $B_{0}$ se deforma e se desloca sob a ação de um conjunto de forças externas, passando a ocupar uma configuração deformada $B$ (Figura 5.1). Dessa forma, os pontos com coordenadas $X$ pertencentes ao corpo indeformado passam a ocupar as coordenadas $Y$, caracterizando uma mudança de configuração descrita pela função $f$. 


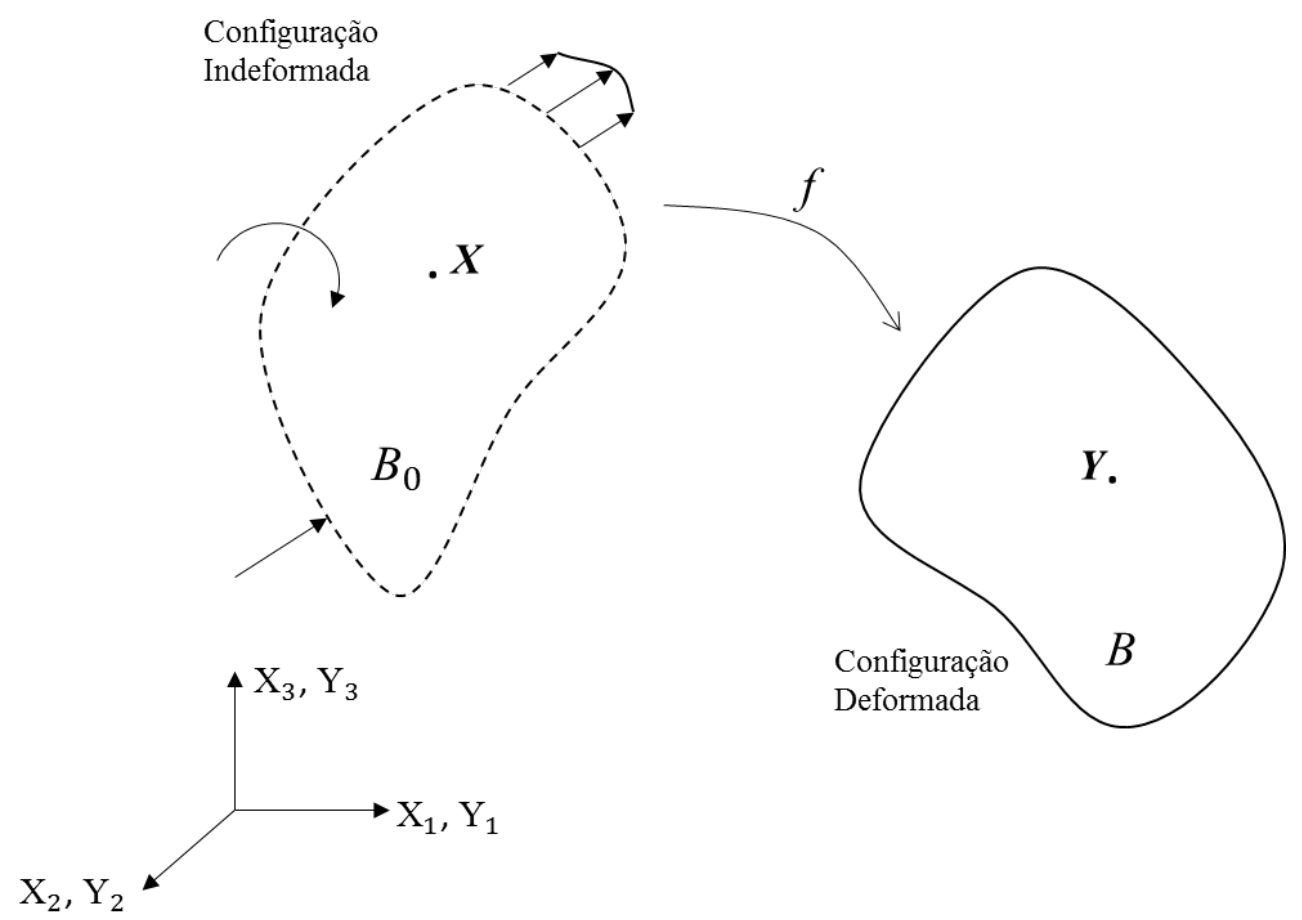

Figura 5.1 - Configuração de um corpo em equilíbrio.

A energia total gerada por essa mudança de configuração é dada pela Equação 5.1.

$$
\Pi=U+\Omega
$$

em que $\Pi$ é a energia potencial total do sistema, $U$ é a energia interna de deformação do material e $\Omega$ é a energia potencial total das forças externas aplicadas.

Considerando-se forças conservativas e o Princípio da Mínima Energia Potencial Estacionária para a solução do problema não linear geométrico, a energia potencial total pode ser escrita conforme a Equação 5.2. Destaca-se, nesta equação, duas parcelas referentes à energia de deformação, uma associada à matriz e outra associada às fibras.

$$
\Pi=\int_{V_{0}^{f}} \theta(E) d V_{0}^{f}+\int_{V_{0}^{m}} u_{e}(\boldsymbol{E}) d V_{0}^{m}-\boldsymbol{F} \cdot \boldsymbol{Y}
$$

em que $\theta$ é a energia específica de deformação das fibras, $u_{e}$ é a energia específica de deformação para a matriz elástica, $\boldsymbol{F}$ é o vetor de forças conservativas externas, $\boldsymbol{Y}$ é o vetor de posição nodal, $E$ é a deformação uniaxial de Green medida nas fibras, $\boldsymbol{E}$ é a deformação desenvolvida na matriz (tensor de deformação de Green), $V_{0}^{m}$ representa o volume inicial da matriz e $V_{0}^{f}$ representa o volume inicial das fibras contidas na matriz. 
Como a variação da energia potencial total é igual a zero na posição de equilíbrio, o problema consiste em determinar o vetor posição $\boldsymbol{Y}$ que satisfaça o equilíbrio. Assim, pode-se escrever a Equação 5.3.

$$
\delta \prod=\int_{V_{0}^{f}} \frac{\partial \theta}{\partial \boldsymbol{Y}} d V_{0}^{f} \cdot \delta \boldsymbol{Y}+\int_{V_{0}^{m}} \frac{\partial u_{e}}{\partial \boldsymbol{Y}} d V_{0}^{m} \cdot \delta \boldsymbol{Y}-\boldsymbol{F} \cdot \delta \mathbf{Y}=0
$$

Realizando-se substituições pelos respectivos conjugados energéticos, pode-se reescrever a Equação 5.3 na forma da Equação 5.4 .

$$
\delta \Pi=\left(\int_{V_{0}^{f}} S \frac{\partial E}{\partial \boldsymbol{Y}} d V_{0}^{f}+\int_{V_{0}^{m}} \boldsymbol{S}: \frac{\partial \boldsymbol{E}}{\partial \boldsymbol{Y}} d V_{0}^{m}-\boldsymbol{F}\right) \cdot \delta \boldsymbol{Y}=0
$$

em que $S$ é o segundo tensor de tensões de Piola-Kirchhoff uniaxial desenvolvido nas fibras e $\boldsymbol{S}$ é o segundo tensor de tensões de Piola-Kirchhoff desenvolvido na matriz elástica.

O sistema não-linear de equações representado pela Equação 5.4 pode ser resolvido por meio do processo iterativo de Newton-Raphson, o qual utiliza como estratégia de solução um vetor de desbalanceamento de forças $\boldsymbol{g}$ conforme indica a Equação 5.5 .

$$
\boldsymbol{g}(\boldsymbol{Y})=\left(\int_{V_{0}^{f}} S \frac{\partial E}{\partial \boldsymbol{Y}} d V_{0}^{f}+\int_{V_{0}^{m}} \boldsymbol{S}: \frac{\partial \boldsymbol{E}}{\partial \boldsymbol{Y}} d V_{0}^{m}\right)-\boldsymbol{F}=\boldsymbol{F}_{\mathrm{int}}^{f}+\boldsymbol{F}_{\mathrm{int}}^{m}-\boldsymbol{F}=0
$$

em que $\boldsymbol{F}_{\text {int }}^{f}$ é chamado de vetor de forças internas, com parcela de contribuição referente à fibra e $\boldsymbol{F}_{\text {int }}^{m}$ é a parcela referente à matriz.

Como o processo é não linear, a Equação 5.5 é expandida em série de Taylor conforme apresenta a Equação 5.6.

$$
\boldsymbol{g}(\boldsymbol{Y}) \cong \boldsymbol{g}\left(\boldsymbol{Y}_{0}\right)+\left.\frac{\partial \boldsymbol{g}}{\partial \boldsymbol{Y}}\right|_{\mathbf{Y}_{0}} \cdot \Delta \boldsymbol{Y}=\boldsymbol{g}\left(\boldsymbol{Y}_{0}\right)+\boldsymbol{H} \cdot \Delta \boldsymbol{Y}=0
$$

em que $\boldsymbol{Y}_{0}$ é uma posição tentativa e $\boldsymbol{H}$ é chamada de matriz Hessiana (ou matriz de rigidez tangente). Como as forças são conservativas, a matriz Hessiana pode ser escrita conforme a Equação 5.7, em que $\boldsymbol{H}^{f}$ é a parcela da hessiana referente à fibra e $\boldsymbol{H}^{m}$ é a parcela referente à matriz. 


$$
\boldsymbol{H}=\frac{\partial \boldsymbol{g}}{\partial \boldsymbol{Y}}=\left\{\left(\frac{\partial E}{\partial \boldsymbol{Y}} \frac{\partial^{2} \theta}{\partial E^{2}} \frac{\partial E}{\partial \boldsymbol{Y}}+S \frac{\partial^{2} E}{\partial \boldsymbol{Y} \partial \boldsymbol{Y}}\right)+\left(\frac{\partial \boldsymbol{E}}{\partial \boldsymbol{Y}}: \frac{\partial^{2} u_{e}}{\partial \boldsymbol{E} \partial \boldsymbol{E}}: \frac{\partial \boldsymbol{E}}{\partial \boldsymbol{Y}}+\boldsymbol{S}: \frac{\partial^{2} \boldsymbol{E}}{\partial \boldsymbol{Y} \partial \boldsymbol{Y}}\right)\right\}=\boldsymbol{H}^{f}+\boldsymbol{H}^{m}
$$

A resolução pelo Método de Newton-Raphson do sistema não-linear apresentado na Equação 5.6 fornece a correção $\Delta \boldsymbol{Y}$ da posição. Esse procedimento iterativo é repetido até que o erro dado por $|\Delta \boldsymbol{Y}| /|\boldsymbol{X}|$ seja menor do que uma dada tolerância, em que $\boldsymbol{X}$ representa o vetor posição inicial do corpo.

\subsection{Elemento de chapa 2D (matriz de concreto)}

A matriz é representada por meio de um elemento triangular de chapa 2D contendo 10 nós. A Figura 5.2 ilustra o mapeamento da configuração não deformada $B_{0}$ (cujos pontos têm coordenadas $x_{i}$ ) para a configuração deformada $B$ (com coordenadas $y_{i}$ ). Esse mapeamento utiliza uma configuração adimensional auxiliar $B_{1} \operatorname{com}$ coordenadas $\xi_{i}$, possibilitando o mapeamento tanto da configuração inicial quanto da configuração final por meio das funções de forma $\phi_{l}\left(\xi_{1}, \xi_{2}\right)$.

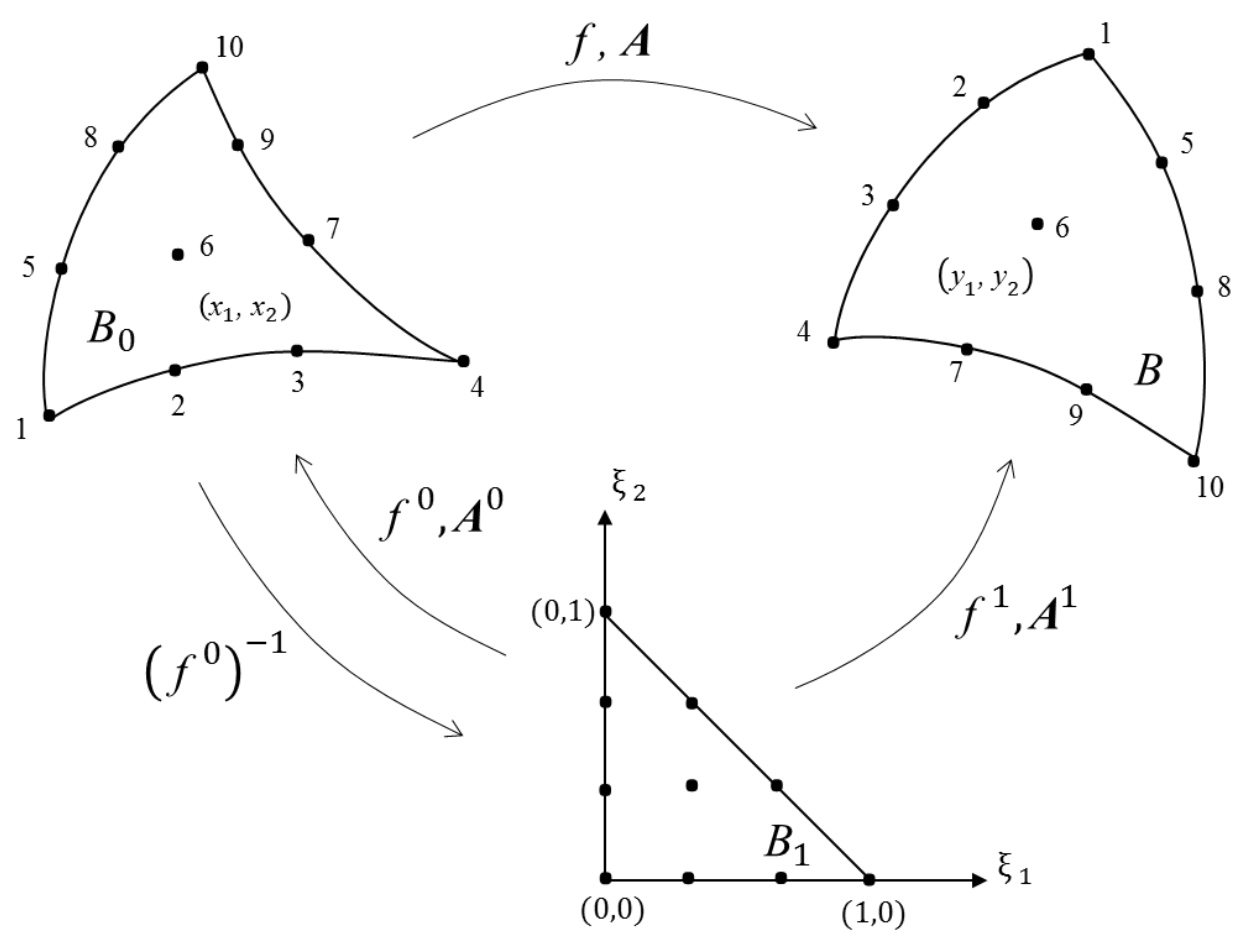

Figura 5.2 - Mapeamento da posição inicial e atual para o elemento de chapa 2D. 
Assim, as configurações $B_{0}$ e $B$ podem ser expressas por meio das funções de forma conforme indica a Equação 5.8.

$$
\begin{aligned}
& x_{i}=f_{i}^{0}=\phi_{l}\left(\xi_{1}, \xi_{2}\right) X_{i}^{l} \\
& y_{i}=f_{i}^{1}=\phi_{l}\left(\xi_{1}, \xi_{2}\right) Y_{i}^{l}
\end{aligned}
$$

em que $i$ corresponde à direção dos nós nas posições $l$. No caso $i$ varia de 1 a 2 e $l$ de 1 a 10 nós por elemento finito.

A função $f$ que mapeia a configuração inicial para a configuração deformada pode ser escrita como uma composição dos mapeamentos $f^{0}$ e $f^{1}$ segundo a Equação 5.9.

$$
f=f^{1} \circ\left(f^{0}\right)^{-1}
$$

Da mesma forma, também é possível escrever o gradiente das deformações $\boldsymbol{A}$ conforme a Equação 5.10.

$$
\boldsymbol{A}=\boldsymbol{A}^{1} \cdot\left(\boldsymbol{A}^{0}\right)^{-1} \text { em que } A_{i, j}^{0}=\frac{\partial f_{i}^{0}}{\partial \xi_{j}} \text { e } A_{i, j}^{1}=\frac{\partial f_{i}^{1}}{\partial \xi_{j}}
$$

Para simular a contribuição da matriz adota-se a energia específica de deformação de Saint-Venant-Kirchhoff, expressa pela Equação 5.11.

$$
u_{e}=\frac{1}{2} \boldsymbol{E}: \mathbb{C}: \boldsymbol{E}
$$

em que $\mathbb{C}$ é o tensor elástico do material e $\boldsymbol{E}$ é o tensor das deformações, expresso pela Equação 5.12 .

$$
E_{i j}=\frac{1}{2}\left(C_{i j}-\delta_{i j}\right)-\varepsilon_{i j}^{R A A}
$$

em que a primeira parcela refere-se à deformação de Green $\left(\boldsymbol{C}=\boldsymbol{A}^{t} \cdot \boldsymbol{A}\right.$ é o tensor de alongamento à direita de Cauchy-Green e $\delta$ representa o delta de Kronecker); $\varepsilon_{i j}^{R A A}$ é o tensor de deformação por RAA representado pelas Equações 4.8 ou 4.9. Essa decomposição aditiva do tensor de deformações apresentada na Equação 5.12 só é possível para um campo de pequenas deformações. 
Para o caso de Estado Plano de Deformação, a energia específica de deformação é dada pela Equação 5.13.

$$
u_{e}=\frac{1}{2}\left[(1-v) K\left(E_{11}^{2}-E_{22}^{2}\right)+2 K v\left(E_{11} E_{22}\right)+2 G\left(E_{11}^{2}-E_{22}^{2}\right)\right]
$$

em que $K=\mathbb{E} /((1+v)(1-2 v)) ; G=\mathbb{E} /(2(1+v)) ; v$ é o coeficiente de Poisson e $\mathbb{E}$ o módulo de Young.

Como já discutido em capítulos anteriores, sabe-se que o módulo de Young do concreto é reduzido em função do tempo de expansão por RAA, dessa forma, o trabalho aqui apresentado inclui a Equação 5.14, baseada nos trabalhos de Pietruszczak (1996), para considerar a redução do módulo de Young.

$$
\mathbb{E}(t)=\mathbb{E}_{0}\left[1-\left(1-B_{1}\right) \frac{\varepsilon_{R A A}(t)}{\varepsilon_{\text {vol }}^{\max }}\right]
$$

em que $\mathbb{E}$ é o módulo de elasticidade para um instante de tempo $t$ considerando a degradação por RAA; $\mathbb{E}_{0}$ é o módulo de elasticidade inicial do concreto (íntegro); $\varepsilon_{R A A}(t)$ é a soma das deformações livres por RAA em cada direção; $B_{1}$ é uma constante que representa o percentual máximo de degradação do módulo de elasticidade, é limitada entre 0 e 1, ou seja, quanto mais próximo de 1, menor o potencial de degradação do módulo de elasticidade do concreto.

Considerando-se a chapa com espessura constante e igual a um, determina-se a energia interna de deformação acumulada pela Equação 5.15.

$$
U_{e}=\int_{0}^{1} \int_{0}^{1-\xi_{2}} u_{e}\left(\xi_{1}, \xi_{2}\right) J_{0}\left(\xi_{1}, \xi_{2}\right) d \xi_{1} d \xi_{2}
$$

em que $J_{0}\left(\xi_{1}, \xi_{2}\right)=\operatorname{det}\left(\boldsymbol{A}^{0}\right)$ é o Jacobiano do mapeamento inicial.

A matriz de energia de deformação pode ser derivada em função das posições atuais do elemento, expressando o vetor de forças internas (Equação 5.16).

$$
\left(F_{\alpha}^{\beta}\right)_{m}^{\mathrm{int}}=\frac{\partial U_{e}}{\partial Y_{\alpha}^{\beta}}=\int_{0}^{1} \int_{0}^{1-\xi_{2}} \frac{\partial u_{e}}{\partial Y_{\alpha}^{\beta}} J_{0}\left(\xi_{1}, \xi_{2}\right) d \xi_{1} d \xi_{2}
$$


com $\alpha$ representando a direção e $\beta$ representando o nó.

Reordenando-se os termos dentro da integral da Equação 5.16 tem-se a Equação 5.17.

$$
\frac{\partial u_{e}}{\partial Y_{\alpha}^{\beta}}=\frac{\partial u_{e}}{\partial \boldsymbol{E}}: \frac{\partial \boldsymbol{E}}{\partial \boldsymbol{C}}: \frac{\partial \boldsymbol{C}}{\partial Y_{\alpha}^{\beta}}=\frac{1}{2} \boldsymbol{S}: \frac{\partial \boldsymbol{C}}{\partial Y_{\alpha}^{\beta}}
$$

em que $\boldsymbol{S}$ é o segundo tensor de tensões de Piola-Kirchhoff e, como $\boldsymbol{C}=\boldsymbol{A}^{t} \cdot \boldsymbol{A}$ e $\boldsymbol{A}=\boldsymbol{A}^{1} \circ\left(\boldsymbol{A}^{0}\right)^{-1}$, pode-se escrever a Equação 5.18 .

$$
\frac{\partial \boldsymbol{C}}{\partial Y_{\alpha}^{\beta}}=\left(\boldsymbol{A}^{0}\right)^{-T} \cdot \frac{\partial\left(\boldsymbol{A}^{1}\right)^{T}}{\partial Y_{\alpha}^{\beta}} \cdot \boldsymbol{A}^{1} \cdot\left(\boldsymbol{A}^{0}\right)^{-1}+\left(\boldsymbol{A}^{0}\right)^{-T} \cdot\left(\boldsymbol{A}^{1}\right)^{T} \cdot \frac{\partial \boldsymbol{A}^{1}}{\partial Y_{\alpha}^{\beta}} \cdot\left(\boldsymbol{A}^{0}\right)^{-1}
$$

Das Equações 5.8 e 5.10 resulta a seguinte relação (Equação 5.19):

$$
\frac{\partial A_{i j}^{1}}{\partial Y_{\alpha}^{\beta}}=\phi_{1, j}\left(\xi_{1}, \xi_{2}\right) \frac{\partial Y_{i}^{l}}{\partial Y_{\alpha}^{\beta}}=\phi_{l, j}\left(\xi_{1}, \xi_{2}\right) \delta_{\beta l} \delta_{\alpha i}=\phi_{\beta, j}\left(\xi_{1}, \xi_{2}\right) \delta_{\alpha i}
$$

Assim, a integral apresentada na Equação 5.16 pode ser resolvida numericamente utilizando-se a quadratura de Hammer (Equação 5.20), em que a integral é substituída por um somatório dos valores de $\left(F_{\alpha}^{\beta}\right)_{m}^{\text {int }}$ calculados em pontos $\left(\xi_{1}, \xi_{2}\right)$ estabelecidos e multiplicados pelos seus respectivos pesos de integração $w_{i}$ (ASSAN, 2003).

$$
\left(F_{\alpha}^{\beta}\right)_{m}^{\mathrm{int}}=\sum_{i h=1}^{n h}\left(\frac{\partial u_{e}}{\partial Y_{\alpha}^{\beta}}\right)_{i} w_{i} J_{0}\left(\xi_{1}, \xi_{2}\right)_{i}
$$

Ainda é necessário calcular a matriz Hessiana referente à chapa, dada pela Equação 5.21 .

$$
\left(H_{\alpha \beta \gamma \eta}\right)_{m}=\frac{\partial^{2} U_{e}}{\partial Y_{\alpha}^{\beta} \partial Y_{\gamma}^{\eta}}=\int_{0}^{1} \int_{0}^{1-\xi_{1}} \frac{\partial^{2} u_{e}}{\partial Y_{\alpha}^{\beta} \partial Y_{\gamma}^{\eta}} J_{0}\left(\xi_{1}, \xi_{2}\right) d \xi_{2} d \xi_{1}
$$

Cuja parcela dentro da integral pode ser expressa segundo a Equação 5.22.

$$
\frac{\partial^{2} u_{e}}{\partial Y_{\alpha}^{\beta} \partial Y_{\gamma}^{\eta}}=\frac{1}{4} \frac{\partial^{2} u_{e}}{\partial \boldsymbol{E} \partial \boldsymbol{E}}: \frac{\partial \boldsymbol{C}}{\partial Y_{\gamma}^{\eta}}: \frac{\partial \boldsymbol{C}}{\partial Y_{\alpha}^{\beta}}+\frac{1}{2} \frac{\partial u_{e}}{\partial \boldsymbol{E}}: \frac{\partial^{2} \boldsymbol{C}}{\partial Y_{\gamma}^{\eta} \partial Y_{\alpha}^{\beta}}
$$


em que (Equação 5.23):

$$
\frac{\partial^{2} \boldsymbol{C}}{\partial Y_{\gamma}^{\eta} \partial Y_{\alpha}^{\beta}}=\left(\boldsymbol{A}^{0}\right)^{-T} \cdot \frac{\partial\left(\boldsymbol{A}^{1}\right)^{T}}{\partial Y_{\alpha}^{\beta}} \cdot \frac{\partial \boldsymbol{A}^{1}}{\partial Y_{\gamma}^{\eta}} \cdot\left(\boldsymbol{A}^{0}\right)^{-1}+\left(\boldsymbol{A}^{0}\right)^{-T} \cdot \frac{\partial\left(\boldsymbol{A}^{1}\right)^{T}}{\partial Y_{\gamma}^{\eta}} \cdot \frac{\partial \boldsymbol{A}^{1}}{\partial Y_{\alpha}^{\beta}} \cdot\left(\boldsymbol{A}^{0}\right)^{-1}
$$

A Equação 5.21 também é resolvida numericamente por quadratura de Hammer (Equação 5.24).

$$
\left(H_{\alpha \beta \gamma \eta}\right)_{m}=\sum_{i h=1}^{n h}\left(\frac{\partial^{2} u_{e}}{\partial Y_{\alpha}^{\beta} \partial Y_{\gamma}^{\eta}}\right)_{i} w_{i} J_{0}\left(\xi_{1}, \xi_{2}\right)_{i}
$$

\subsection{Elemento de treliça (armadura e fibras)}

As barras de armadura e fibras presentes no concreto são representadas por elementos de treliça lineares contendo dois nós por elemento. A Figura 5.3 ilustra a configuração não deformada $B_{0}$ e a configuração deformada $B$ para o elemento de treliça.
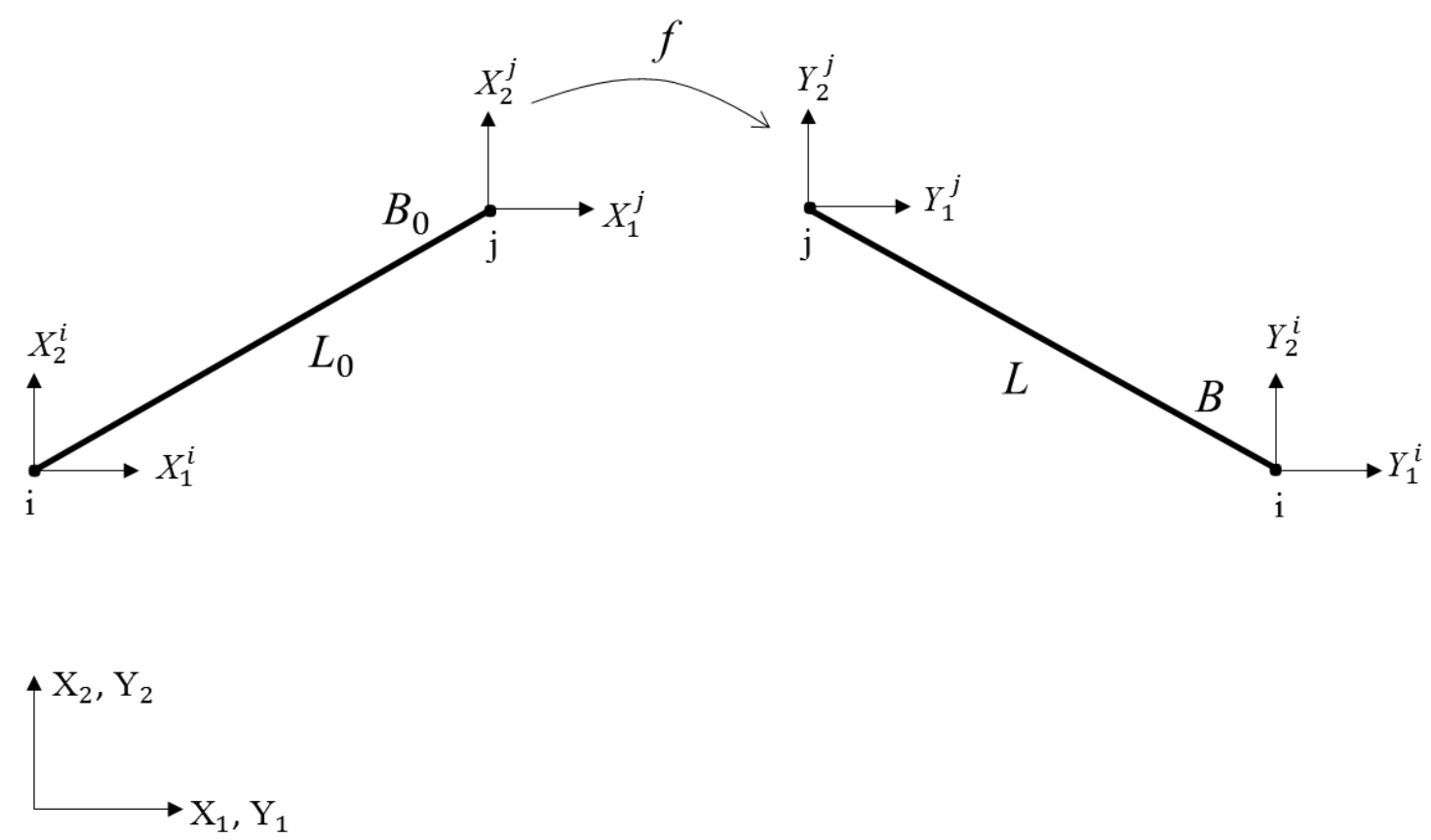

Figura 5.3 - Configuração inicial e atual para o elemento finito de fibra.

Os comprimentos $L_{0}$ da barra indeformada e $L$ da barra deformada podem ser expressos segundo as Equações 5.25. 


$$
\begin{gathered}
L_{0}^{2}=\left(X_{1}^{j}-X_{1}^{i}\right)+\left(X_{2}^{j}-X_{2}^{i}\right) \\
L^{2}=\left(Y_{1}^{j}-Y_{1}^{i}\right)+\left(Y_{2}^{j}-Y_{2}^{i}\right)
\end{gathered}
$$

em que $i$ corresponde ao nó inicial do elemento finito e $j$ ao nó final.

Assim, a deformação unidimensional de Green associada ao elemento de fibra é dada pela Equação 5.26 .

$$
E=\frac{1}{2}\left(\frac{L^{2}-L_{0}^{2}}{L_{0}^{2}}\right)
$$

Podendo-se escrever a energia específica de deformação como (Equação 5.27):

$$
\theta=\frac{1}{2} \mathrm{E}^{2}
$$

em que E é o módulo elástico tangente do material que, para o caso de pequenas deformações, se confunde com o módulo de Young.

Dando continuidade à análise do equilíbrio, o vetor de forças internas do nó $\beta$ da fibra na direção $\alpha$ pode ser escrito conforme a Equação 5.28, para um volume inicial da fibra de $V_{0}^{f}=A L_{0}$.

$$
\left(F_{\alpha}^{\beta}\right)_{f}^{\mathrm{int}}=\frac{\partial \Theta}{\partial Y_{\alpha}^{\beta}}=\int_{V_{0}^{f}} \frac{\partial \theta}{\partial Y_{\alpha}^{\beta}} d V_{0}^{f}=\int_{V_{0}^{f}} \frac{\partial \theta}{\partial E} \frac{\partial E}{\partial Y_{\alpha}^{\beta}} d V_{0}^{f}=\frac{1}{2} E E A L_{0} \frac{\partial E}{\partial Y_{\alpha}^{\beta}}
$$

As componentes da matriz Hessiana da fibra podem ser expressas segundo a Equação 5.29, por meio da segunda derivada da energia de deformação.

$$
\left(H_{\alpha \beta \eta \eta}\right)_{f}=\frac{\partial^{2} \Theta}{\partial Y_{\alpha}^{\beta} \partial Y_{\gamma}^{\eta}}=\int_{V_{0}^{f}} \frac{\partial^{2} \theta}{\partial Y_{\alpha}^{\beta} \partial Y_{\gamma}^{\eta}} d V_{0}^{f}=\frac{\partial}{\partial Y_{\alpha}^{\beta}}\left(\frac{1}{2} E E A L_{0} \frac{\partial E}{\partial Y_{\gamma}^{\eta}}\right)
$$

\subsection{Acoplamento fibra-matriz}

As deduções apresentadas anteriormente são referentes aos elementos de chapa e fibra separadamente. No entanto, é de interesse entender o comportamento dos dois materiais 
associados, dessa forma, as deduções que se seguem representam a matriz Hessiana e o vetor de forças internas para o elemento de chapa reforçado com fibras. Considera-se situação de perfeita aderência entre a fibra e a matriz, ou seja, não há escorregamento entre os materiais.

Vanalli (2004) apresenta uma maneira de se inserir fibras no domínio sem a necessidade de coincidência dos nós da fibra com os nós da chapa e sem aumentar o número de graus de liberdade do sistema. Para isso, as coordenadas adimensionais do elemento finito de fibra são escritas em função das coordenadas do elemento de chapa (Equação 5.30).

$$
X_{i}^{p}=\phi_{l}\left(\xi_{1}^{p}, \xi_{2}^{p}\right) X_{i}^{l}
$$

em que $\phi_{l}$ são as funções de forma do elemento finito de chapa calculadas para as coordenadas adimensionais $\xi_{i}^{p}$ referentes ao nó $p$ do elemento de fibra e $X_{i}^{l}$ são as coordenadas na posição inicial dos nós da chapa.

Para o ponto $p$ pertencente ao elemento finito de fibra (Figura 5.4), Vanalli (2004) apresenta a Equação 5.31, como uma maneira de se determinar as coordenadas adimensionais $\xi_{i}^{p}$ e identificar em qual elemento finito do domínio o nó da fibra está contido.

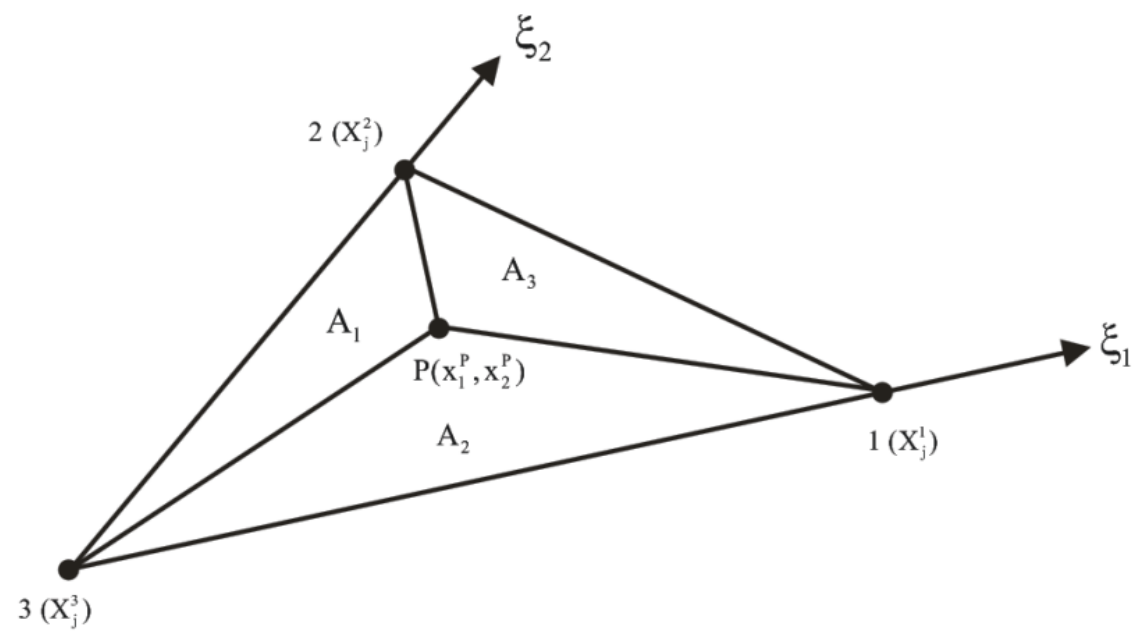

Figura 5.4 - Ponto $\mathrm{P}$ pertencente à fibra inserido em um elemento finito triangular.

Fonte: Sampaio (2014).

$$
\xi_{\alpha}^{p}=\frac{1}{2 A}\left(2 A_{0}^{\alpha}+b^{\alpha} X_{1}^{p}+a^{\alpha} X_{2}^{p}\right)
$$

em que (Equação 5.32): 


$$
\begin{aligned}
& a^{\alpha}=X_{1}^{k}-X_{1}^{m}, \\
& b^{\alpha}=X_{2}^{m}-X_{2}^{k}, \\
& 2 A_{0}^{\alpha}=X_{1}^{m} X_{2}^{k}-X_{1}^{k} X_{2}^{m}, \\
& A=\frac{1}{2}\left(b^{1} a^{2}-b^{2} a^{1}\right) .
\end{aligned}
$$

e as variáveis $\alpha, m$ e $k$ respeitam uma relação cíclica, ou seja, se $\alpha=1, m=2$ e $k=3$.

Assim, se pelo menos uma das coordenadas adimensionais $\xi_{\alpha}^{p}$ calculada pela Equação 5.31 apresentar valor negativo, conclui-se que o nó da fibra não pertence ao elemento finito de chapa testado.

Ressalta-se que as Equações 5.31 e 5.32 são limitadas a elementos de fibra lineares inseridas em domínios bidimensionais cujos elementos são triangulares com aproximações lineares. Para o caso de elementos de chapa ou fibras com ordens de aproximação superior, Sampaio (2014) propõe a expansão da Equação 5.29 em Série de Taylor para um par de coordenadas adimensionais $\left(\xi_{1}^{p t}, \xi_{2}^{p t}\right)$ tentativa (Equação 5.33):

$$
X_{i}^{p} \cong \phi_{l}\left(\xi_{1}^{p t}, \xi_{2}^{p t}\right) X_{i}^{l}+\left.\frac{\partial \phi_{l}\left(\xi_{1}, \xi_{2}\right)}{\partial \xi_{j}}\right|_{\xi_{1}^{p p}, \xi_{2}^{p t}} \quad \text { ou, } X_{i}^{p}=X_{i}^{p t}+H_{i j} \Delta \xi_{j}
$$

em que $X_{i}^{p t}$ é a posição tentativa dos nós da fibra calculada a partir das funções de forma do elemento bidimensional e das coordenadas adimensionais tentativas.

Para se determinar a correção das coordenadas adimensionais $\Delta \xi_{j}$, resolve-se a equação não linear (Equação 5.34) pelo Método de Newton-Raphson.

$$
H_{i j} \Delta \xi_{j}=X_{i}^{p}-X_{i}^{p t}
$$

Conhecendo agora em qual elemento finito do domínio o nó da fibra está contido e o par de coordenadas adimensionais $\left(\xi_{1}, \xi_{2}\right)$ associadas ao nó é possível calcular as posições atuais dos nós da fibra em função da posição atual dos nós da chapa (Equação 5.35).

$$
Y_{i}^{p}=\phi_{l}\left(\xi_{1}^{p}, \xi_{2}^{p}\right) Y_{i}^{l}
$$

em que $Y_{i}^{l}$ são as posições atuais dos nós do elemento finito de chapa. 
Dessa forma, a energia interna de deformação do material reforçado com fibras é dada pela soma da energia interna de deformação associada à chapa e da energia interna de deformação associada às fibras, conforme a Equação 5.36 .

$$
U=U_{e}+\Theta
$$

em que $U_{e}$ é a parcela da energia interna de deformação armazenada no elemento de chapa e $\Theta$ é a parcela da energia interna de deformação presente nas fibras.

Logo, o vetor de forças internas do nó $\beta$ na direção $\alpha$ do elemento de chapa reforçado com fibras é dado pela Equação 5.37.

$$
\left(F_{\alpha}^{\beta}\right)^{\mathrm{int}}=\frac{\partial\left(U_{e}+\Theta\right)}{\partial Y_{\alpha}^{\beta}}
$$

Podendo-se escrever a seguinte expressão para a energia de deformação do material composto (Equação 5.38).

$$
U=\int_{V_{0}^{f}} \theta\left(Y_{j}^{p}\right) d V_{0}^{f}+\int_{V_{0}^{m}} u_{e} d V_{0}^{m}
$$

em que a energia específica de deformação da fibra é função das posições nodais atuais da fibra $\left(Y_{j}^{p}\right)$.

Como as coordenadas dos nós da fibra podem ser escritos em função das coordenadas dos nós da chapa (Equação 5.35), pode-se reescrever a equação anterior da seguinte forma (Equação 5.39):

$$
U=\int_{V_{0}^{f}} \theta\left(Y_{j}^{p}\left(Y_{i}^{l}\right)\right) d V_{0}^{f}+\int_{V_{0}^{m}} u_{e} d V_{0}^{m}
$$

Substituindo a Equação 5.38 na Equação 5.36, tem-se (Equação 5.40):

$$
\left(F_{\alpha}^{\beta}\right)^{\mathrm{int}}=\frac{\partial U}{\partial Y_{\alpha}^{\beta}}=\int_{V_{0}^{m}} \frac{\partial u_{e}}{\partial Y_{\alpha}^{\beta}} d V_{0}^{m}+\int_{V_{0}^{f}} \frac{\partial \theta}{\partial Y_{\alpha}^{\beta}}\left(Y_{j}^{p}\left(Y_{i}^{l}\right)\right) d V_{0}^{m}
$$


A primeira parcela da Equação 5.40 é equivalente à Equação 5.15 apresentada no item 5.2 e representa a parcela referente à força interna da chapa. Já a segunda parcela pode ser escrita segundo a Equação 5.41.

$$
\frac{\partial \theta}{\partial Y_{\alpha}^{\beta}}=\frac{\partial \theta}{\partial Y_{i}^{p}} \frac{\partial Y_{i}^{p}}{\partial Y_{\alpha}^{\beta}}
$$

em que $\frac{\partial \theta}{\partial Y_{i}^{p}}$ representa o vetor de forças internas da fibra, expresso na Equação 5.28 do item 5.3. O termo $\frac{\partial Y_{i}^{p}}{\partial Y_{\alpha}^{\beta}}=\phi_{\beta}\left(\xi_{1}^{p}, \xi_{2}^{p}\right)$ incorpora os graus de liberdade da fibra como função dos graus de liberdade da matriz.

Assim, o vetor de forças internas para a chapa reforçada com fibras pode ser dado pela Equação 5.42.

$$
\left(F_{\alpha}^{\beta}\right)^{\mathrm{int}}=\frac{\partial U}{\partial Y_{\alpha}^{\beta}}=\left(F_{\alpha}^{\beta}\right)_{m}^{\mathrm{int}}+\phi_{\beta}\left(\xi_{1}^{p} \xi_{2}^{p}\right)\left(F_{j}^{p}\right)_{f}^{\mathrm{int}}
$$

Fazendo a segunda derivada da energia interna de deformação do material reforçado com fibras obtém-se a matriz Hessiana (ou matriz de rigidez tangente) expressa pela Equação 5.43 .

$$
H_{\alpha \beta \gamma \eta}=\frac{\partial^{2} U}{\partial Y_{\alpha}^{\beta} \partial Y_{\gamma}^{\eta}}=\int_{V_{0}^{m}} \frac{\partial^{2} u_{e}}{\partial Y_{\alpha}^{\beta} \partial Y_{\gamma}^{\eta}} d V_{0}^{m}+\int_{V_{0}^{f}} \frac{\partial^{2} \theta}{\partial Y_{\alpha}^{\beta} \partial Y_{\gamma}^{\eta}}\left(Y_{j}^{p}\left(Y_{i}^{l}\right)\right) d V_{0}^{m}
$$

Da Equação 5.43, pode-se observar que a primeira parcela é referente à Hessiana do elemento de chapa (Equação 5.21) apresentada no item 5.2. Já a segunda derivada da energia específica de deformação da fibra em relação aos parâmetros nodais da chapa pode ser expressa pela Equação 5.44 .

$$
\begin{aligned}
& \frac{\partial^{2} \theta}{\partial Y_{\alpha}^{\beta} \partial Y_{\gamma}^{\eta}}=\left(h_{\omega \rho \omega \rho}\right)_{f} \frac{\partial\left(Y_{\omega}^{\rho}\right)_{f}}{\partial Y_{\alpha}^{\beta}} \frac{\partial\left(Y_{\omega}^{\rho}\right)_{f}}{\partial Y_{\gamma}^{\eta}}+\left(h_{\omega \rho \pi \mu}\right)_{f} \frac{\partial\left(Y_{\omega}^{\rho}\right)_{f}}{\partial Y_{\alpha}^{\beta}} \frac{\partial\left(Y_{\pi}^{\mu}\right)_{f}}{\partial Y_{\gamma}^{\eta}}+\left(h_{\pi \mu \omega \rho}\right)_{f} \frac{\partial\left(Y_{\pi}^{\mu}\right)_{f}}{\partial Y_{\alpha}^{\beta}} \frac{\partial\left(Y_{\omega}^{\rho}\right)_{f}}{\partial Y_{\gamma}^{\eta}}+ \\
& +\left(h_{\pi \mu \pi \mu}\right)_{f} \frac{\partial\left(Y_{\pi}^{\mu}\right)_{f}}{\partial Y_{\alpha}^{\beta}} \frac{\partial\left(Y_{\pi}^{\mu}\right)_{f}}{\partial Y_{\gamma}^{\eta}}
\end{aligned}
$$


em que o termo $(h)_{f}$ representa a matriz Hessiana local das fibras expressas na Equação 5.29.

Integrando a Equação 5.44 no volume das fibras, resulta a Equação 5.45, que pode ser utilizada na Equação 5.7 para considerar o espalhamento da Hessiana (matriz de rigidez) das fibras na Hessiana da chapa e, dessa forma não aumentar o número de graus de liberdade do problema.

$$
\begin{aligned}
& \frac{\partial^{2} \Theta}{\partial Y_{\alpha}^{\beta} \partial Y_{\gamma}^{\eta}}=\left(H_{\omega \rho \omega \rho}\right)_{f} \frac{\partial\left(Y_{\omega}^{\rho}\right)_{f}}{\partial Y_{\alpha}^{\beta}} \frac{\partial\left(Y_{\omega}^{\rho}\right)_{f}}{\partial Y_{\gamma}^{\eta}}+\left(H_{\omega \rho \pi \mu}\right)_{f} \frac{\partial\left(Y_{\omega}^{\rho}\right)_{f}}{\partial Y_{\alpha}^{\beta}} \frac{\partial\left(Y_{\pi}^{\mu}\right)_{f}}{\partial Y_{\gamma}^{\eta}}+\left(H_{\pi \mu \omega \rho}\right)_{f} \frac{\partial\left(Y_{\pi}^{\mu}\right)_{f}}{\partial Y_{\alpha}^{\beta}} \frac{\partial\left(Y_{\omega}^{\rho}\right)_{f}}{\partial Y_{\gamma}^{\eta}}+ \\
& +\left(H_{\pi \mu \pi \mu}\right)_{f} \frac{\partial\left(Y_{\pi}^{\mu}\right)_{f}}{\partial Y_{\alpha}^{\beta}} \frac{\partial\left(Y_{\pi}^{\mu}\right)_{f}}{\partial Y_{\gamma}^{\eta}}
\end{aligned}
$$

Na Equação 5.45, os termos $\frac{\partial\left(Y_{\pi}^{\mu}\right)_{f}}{\partial Y_{\gamma}^{\eta}}$ dependem da posição que a fibra ocupa dentro da matriz, ou seja, do elemento de chapa em que o nó da fibra está inserido.

Como a malha da fibra é gerada independentemente da malha da chapa, a fibra pode apresentar diferentes configurações. A Figura 5.5 destaca 4 arranjos diferentes: os dois nós da fibra inseridos no mesmo elemento de chapa (fibra 1); nós da fibra em elementos vizinhos, apresentando mais do que um nó comum (fibra 2); nós da fibra em elementos vizinhos com apenas um nó em comum (fibra 3) ou nós da fibra em elementos finitos distantes, sem nós em comum (fibra 4).

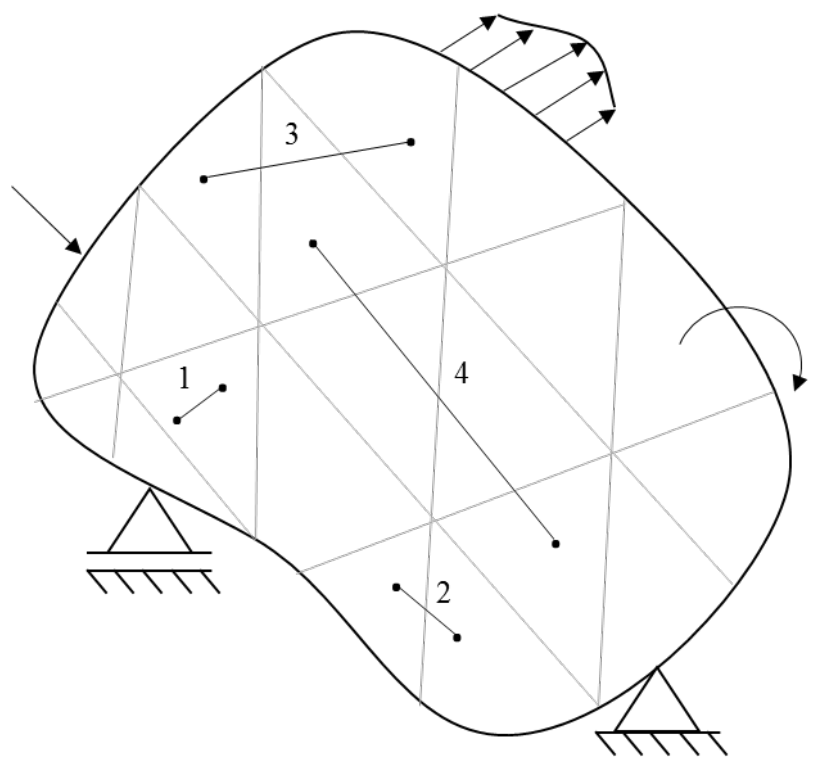

Figura 5.5 - Posição das fibras na matriz. 
Para as duas últimas configurações (fibras 3 e 4), os elementos finitos de chapa que são atravessados pela fibra, mas que não contém o nó da fibra, não apresentam contribuição desta no vetor de forças internas e na hessiana do elemento de chapa.

Reescrevendo-se a Equação 5.45 de forma matricial, a matriz Hessiana local da fibra $\left[H^{f}\right]_{4 \times 4}$ deve ser expandida em uma matriz de tamanho $4 N x 4 N$ em que $N$ é o número de nós do elemento de chapa (Equação 5.46).

$$
\left[H^{f}\right]_{4 N \times 4 N}=\left[\phi_{\beta}\right]_{4 N \times 4}^{T} \cdot\left[H^{f}\right]_{4 \times 4} \cdot\left[\phi_{\beta}\right]_{4 \times 4 N}
$$

Para o caso da fibra reta, as funções de forma ficam contidas em dois quadrantes conforme a Equação 5.47, na qual o índice $i$ está relacionado ao nó inicial da fibra e o índice $j$ ao nó final da fibra.

$$
\left[\phi_{\beta}\right]_{4 \times 4 N}=\left[\begin{array}{cccccccccccc}
\phi_{1}^{i} & 0 & \phi_{2}^{i} & \ldots & \phi_{n}^{i} & 0 & 0 & 0 & 0 & \ldots & 0 & 0 \\
0 & \phi_{1}^{i} & 0 & \ldots & 0 & \phi_{n}^{i} & 0 & 0 & 0 & \ldots & 0 & 0 \\
0 & 0 & 0 & \ldots & 0 & 0 & \phi_{1}^{j} & 0 & \phi_{2}^{j} & \ldots & \phi_{n}^{j} & 0 \\
0 & 0 & 0 & \ldots & 0 & 0 & 0 & \phi_{1}^{j} & 0 & \ldots & 0 & \phi_{n}^{j}
\end{array}\right]=\left[\begin{array}{cc}
{\left[\phi^{i}\right]} & {[0]} \\
{[0]} & {\left[\phi^{j}\right]}
\end{array}\right]
$$

O procedimento da Equação 5.46 possibilita a obtenção de uma matriz de rigidez expandida para cada fibra contida na chapa e que deve ser acrescida à matriz de rigidez global do problema, respeitando a incidência dos elementos de chapa.

\subsection{Fluxograma}

A seguir, a Figura 5.6 apresenta um fluxograma que resume as principais etapas do algoritmo implementado. 


\section{Início}

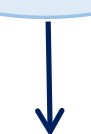

Determina-se a incidência da Fibra na Chapa

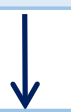

Calculam-se as coordenadas adimensionais dos nós da fibra

$$
\left(\xi_{1}^{p}, \xi_{2}^{p}\right)
$$

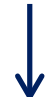

Calculam-se as funções de forma associadas aos nós da fibra

$$
\phi_{l}\left(\xi_{1}^{p}, \xi_{2}^{p}\right)
$$

\section{Tempo}

Calcula-se a força externa aplicada

$\boldsymbol{F}(t)$
Calcula-se a expansão por RAA e o módulo de elasticidade

$$
\varepsilon_{i j}^{R A A}
$$

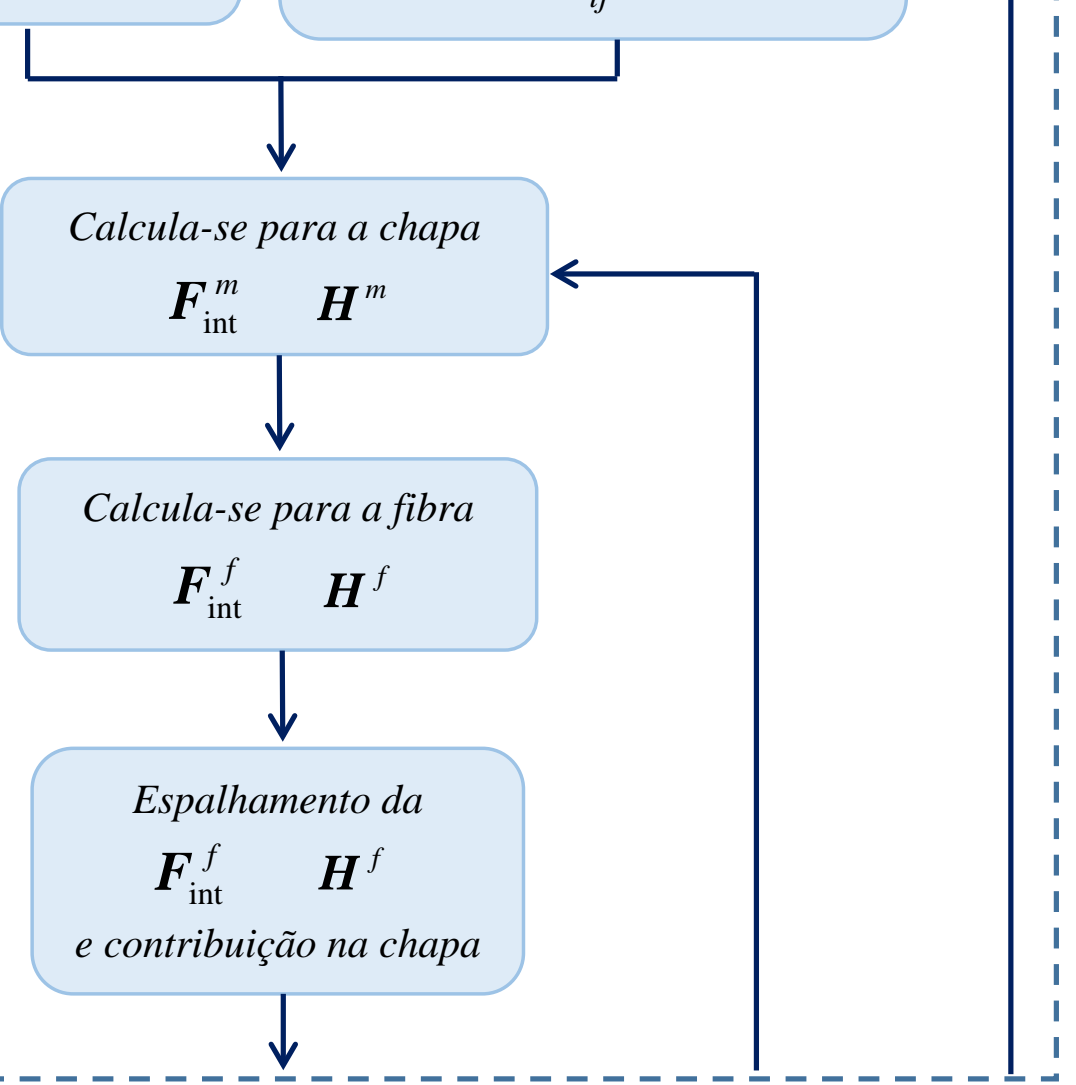




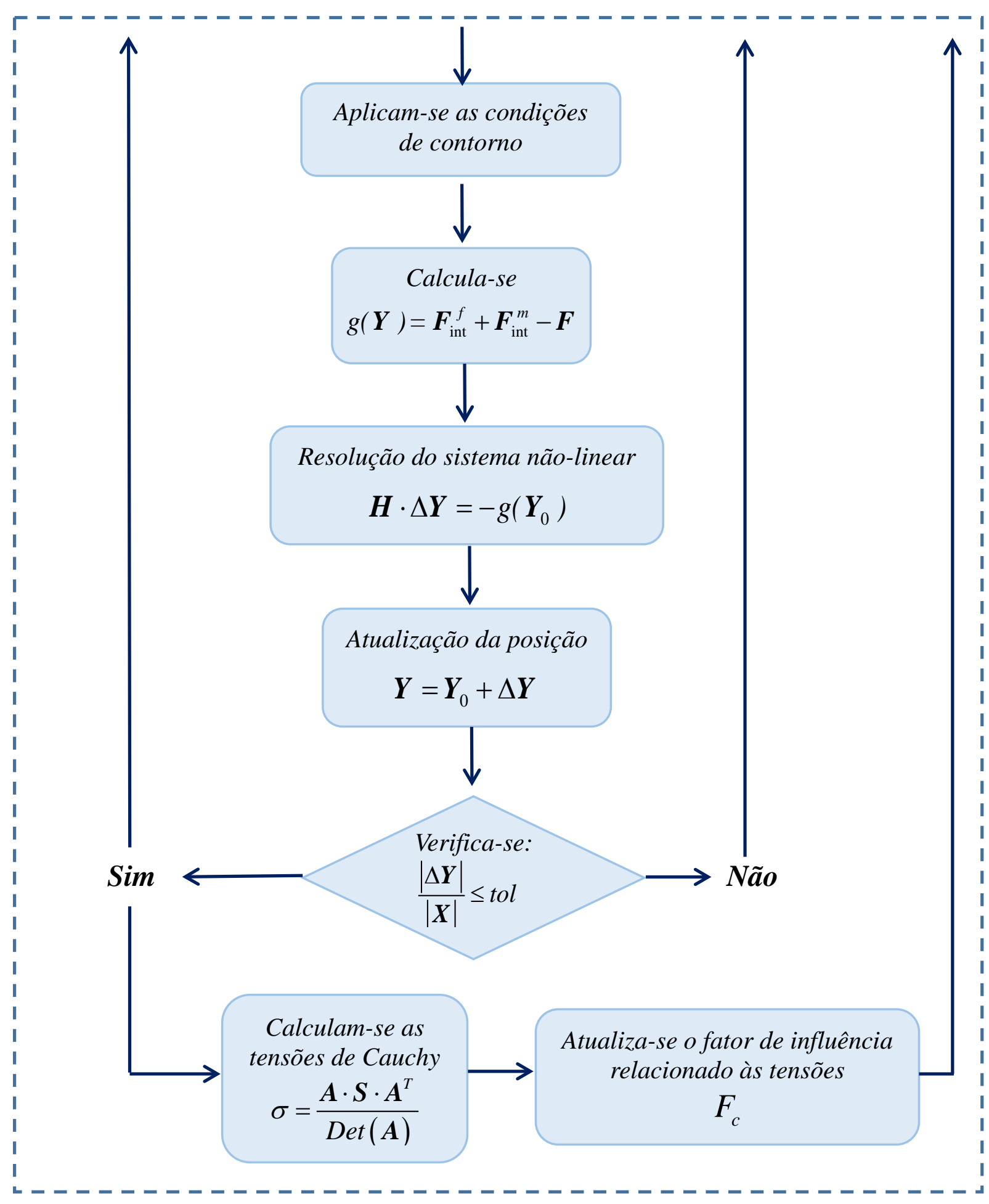

\section{Fim}

Figura 5.6 - Fluxograma. 


\section{EXEMPLOS NUMÉRICOS}

Nesse capítulo são apresentados 7 exemplos numéricos que tem por objetivo validar a formulação desenvolvida, apresentando as aplicações e potencialidades dessa ferramenta.

As malhas dos exemplos aqui apresentados foram geradas com o auxílio do software desenvolvido pelo Departamento de Engenharia de Estruturas da EESC-USP, AcadMesh2D. As discretizações adotadas foram sempre as mesmas: elementos isoparamétricos com aproximação cúbica para a discretização da matriz de concreto e elementos lineares para a representação das fibras e armaduras.

Para a visualização dos resultados de pós-processamento foi utilizado o software AcadView, também desenvolvido pelo Departamento de Engenharia de Estruturas, facilitando o pós-processamento dos resultados.

\subsection{Exemplo 1: Viga em concreto armado sujeita a grandes deslocamentos}

O primeiro exemplo tem por objetivo validar a formulação não-linear geométrica apresentada, bem como verificar o correto acoplamento da armadura à matriz. Este exemplo consiste em uma viga de concreto armado engastada em uma de suas extremidades e carregada na extremidade oposta, conforme ilustra a Figura 6.1. O módulo de elasticidade e o coeficiente de Poisson adotados para a matriz de concreto são, respectivamente, $E_{m}=2100 \mathrm{KN} / \mathrm{cm}^{2}$ e $v=0,0$. Para a armadura, adota-se módulo de elasticidade $E_{f}=21000 \mathrm{KN} / \mathrm{cm}^{2}$ e área $A_{f}=0,1 \mathrm{~cm}^{2}$. 


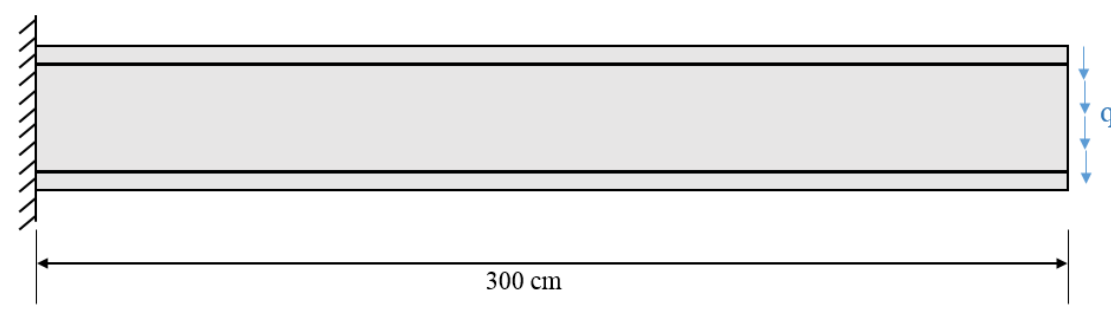

(a)

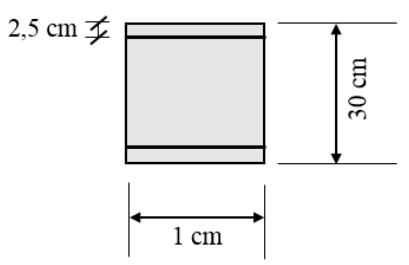

(b)

Figura 6.1 - (a) Viga engastada reforçada com fibras; (b) Seção transversal.

A discretização da viga consistiu em 484 elementos finitos triangulares para representar a matriz de concreto e 60 elementos finitos lineares representando as barras de armadura. $\mathrm{O}$ carregamento distribuído $q=19,9306 \mathrm{KN} / \mathrm{cm}$ é aplicado em 10 passos na extremidade livre da viga. Os resultados obtidos numericamente são comparados com os resultados analíticos apresentados por Mattiasson (1981).

Mattiasson (1981) apresenta, para o caso da viga engastada, relações envolvendo as grandezas adimensionais $u / L$ e $v / L$, em que $u$ e $v$ representam os deslocamentos horizontais e verticais do nó central da extremidade livre da viga, e a grandeza $P L^{2} / E I$, em que $P$ indica o carregamento aplicado, $L$ é o comprimento da viga, $E$ é o módulo de elasticidade do material e I o momento de inércia. Para o caso da viga em concreto armado, pode-se considerar uma inércia equivalente a uma seção homogênea equivalente de concreto, resultando na Equação 6.1.

$$
I_{e q}=\frac{30^{3}}{12}+2 \times 10 \times\left(\frac{0,1^{3}}{12}+0,1 \times 12,5^{2}\right)=2562,5017 \mathrm{~cm}^{4}
$$

A Figura 6.2 ilustra, para diferentes níveis de força, o comparativo entre os resultados analíticos apresentados por Mattiasson (1981) e os resultados numéricos obtidos por meio da formulação aqui empregada. Percebe-se que os resultados apresentam comportamento semelhante e pequenas diferenças relativas entre os resultados (menores do que $2 \%$ ).

Ainda vale ressaltar que as discrepâncias observadas entre os resultados se devem ao fato de o trabalho de Mattiasson (1981) considerar elemento finito de barra, portanto, as seções planas permanecem planas depois de deformadas. Como a formulação aqui empregada utiliza 
elementos finitos de chapa tal simplificação não é mais válida e, tal como mostram os resultados obtidos, espera-se uma estrutura mais flexível.

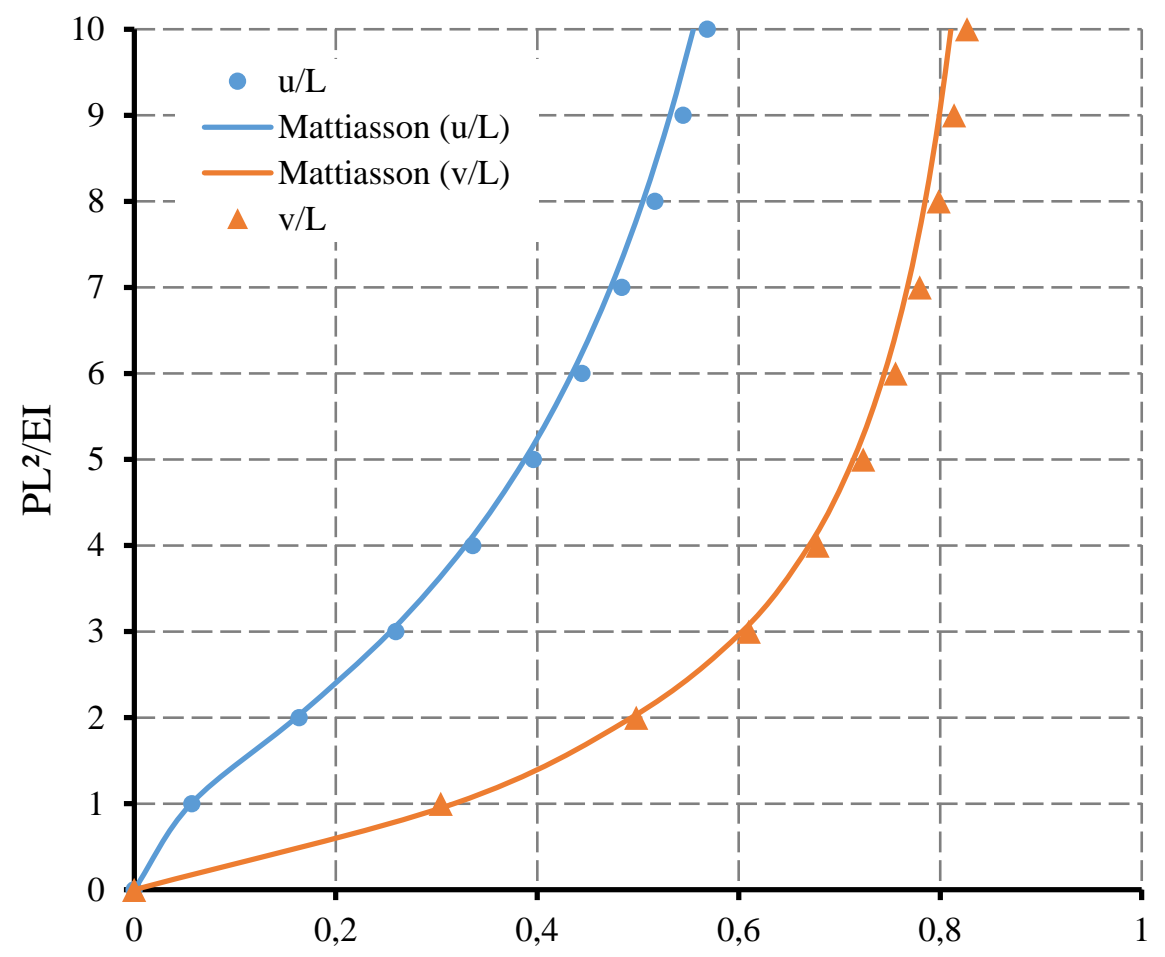

Figura 6.2 - Comparação entre os resultados analíticos e numéricos para a viga engastada.

Para ilustrar o devido acoplamento da fibra à matriz de concreto, as Figuras 6.3 e 6.4 apresentam em cores a configuração deformada das armaduras superior e inferior para dois passos de carregamento. Pode-se observar que a armadura permanece aderida à chapa e, portanto, contribui devidamente com a sua rigidez.

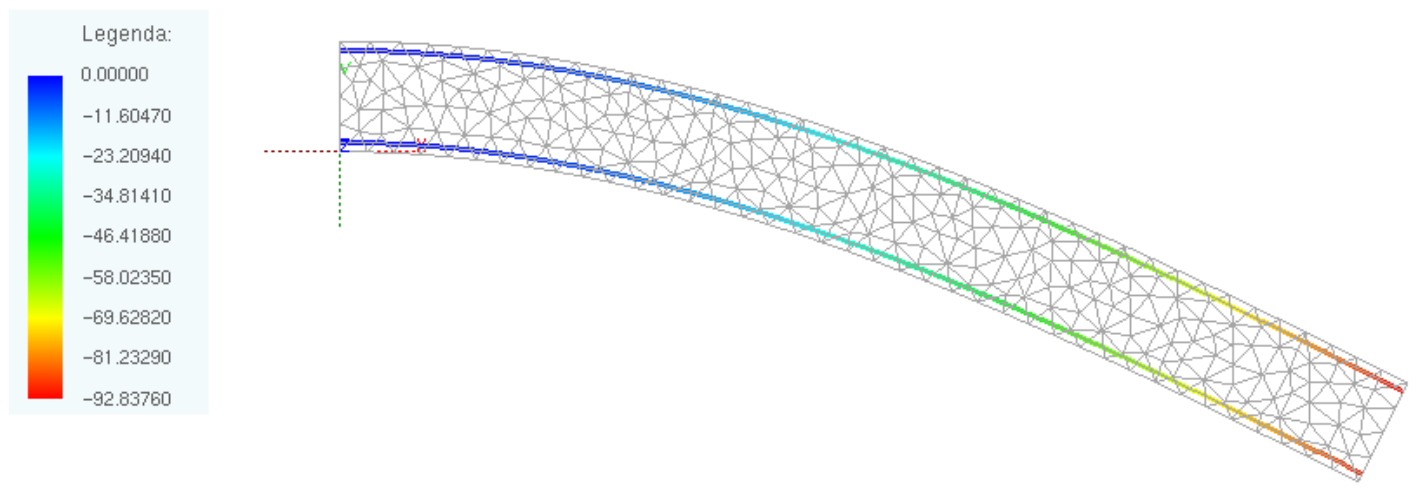

Figura 6.3 - Deslocamento vertical das barras de armadura para $P L^{2} / E I=1($ em $\mathrm{cm})$. 


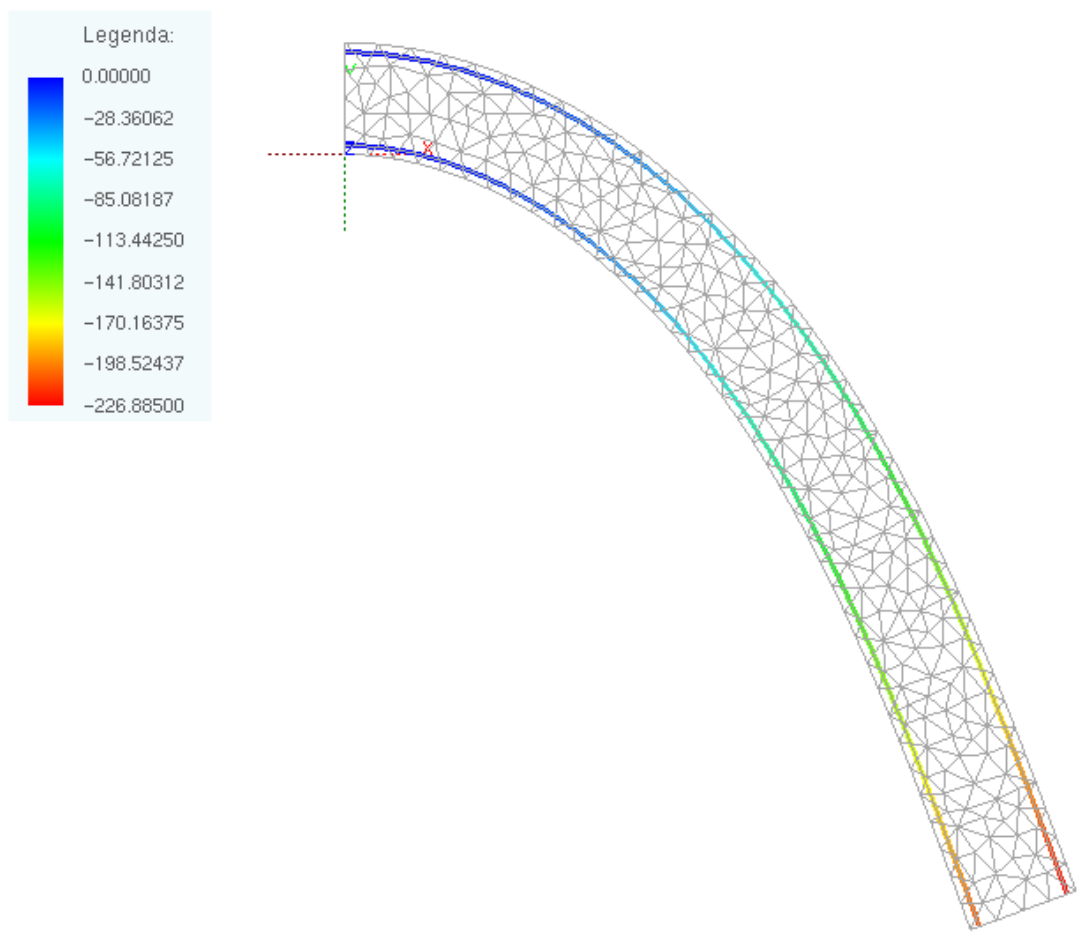

Figura 6.4 - Deslocamento vertical das barras de armadura para $P L^{2} / E I=5(\mathrm{em} \mathrm{cm})$.

Para o mesmo exemplo, com a finalidade de verificar as tensões desenvolvidas na estrutura, considera-se um regime linear de deslocamentos, portanto um carregamento $q=0,2 \mathrm{KN} / \mathrm{cm}$, permitindo a comparação dos resultados obtidos pela presente formulação com os resultados propostos pela teoria de Resistência dos Materiais.

Dessa forma, de acordo com a solução técnica, o deslocamento vertical na extremidade livre da viga é dado pela Equação 6.2.

$$
\delta_{y}=\frac{P \ell^{3}}{3 E I_{z}}=\frac{6 \times 300^{3}}{3 \times 2100 \times 2562,5017}=10,035 \mathrm{~cm}
$$

A Figura 6.5 ilustra o deslocamento vertical obtido por meio da formulação implementada, podendo-se observar que o deslocamento vertical obtido para a extremidade livre da viga foi de $10,116 \mathrm{~cm}$, apresentando uma diferença relativa de apenas $0,807 \%$ quando comparado com a solução proposta pela Resistência dos Materiais. 


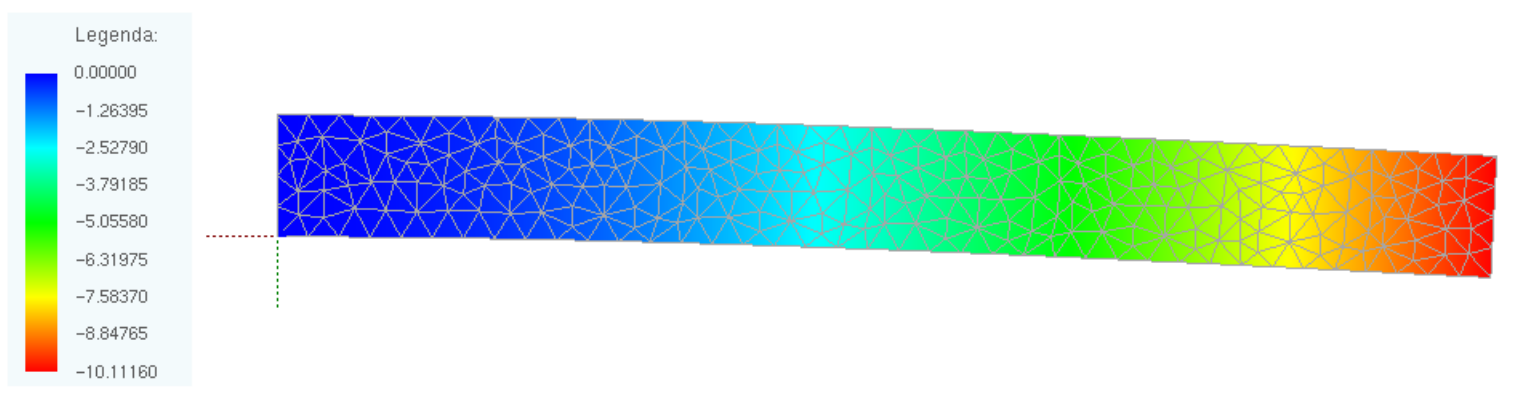

Figura 6.5 - Deslocamento vertical da viga (em cm).

A tensão na direção $x$, perpendicular à direção do carregamento, segundo a Resistência dos Materiais, é dada pela Equação 6.3.

$$
\sigma_{x}=\frac{M_{z}}{I_{z}} y=\frac{6 \times 300}{2562,5017} \times 15= \pm 10,5365 \mathrm{KN} / \mathrm{cm}^{2}
$$

A Figura 6.6 apresenta as máximas tensões obtidas numericamente pela formulação apresentada. As tensões máximas ocorrem em região próxima ao engaste, apresentando pequenas diferenças quando comparadas com o resultado obtido por meio da Resistência dos Materiais, sendo esta diferença relativa de aproximadamente 3,48\%. Essa diferença relativa se deve ao fato de os deslocamentos do engaste serem restritos pontualmente (nos nós) e não de forma distribuída ao longo do engaste, promovendo uma diferença relacionada ao princípio de Saint-Venant; também é possível que esta diferença se deva ao fato de ser utilizado um momento de inércia equivalente na Equação 6.3.

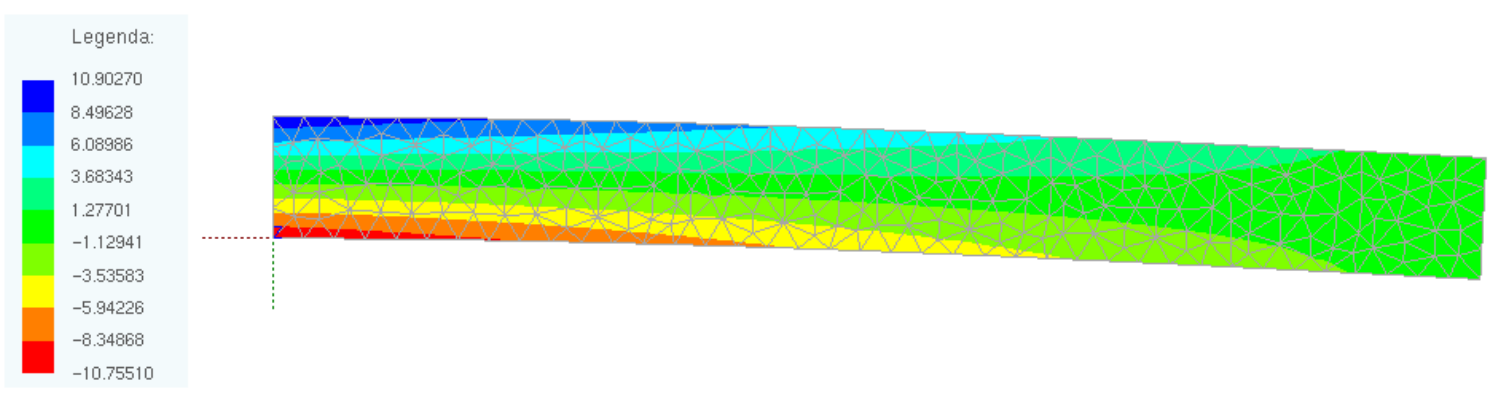

Figura 6.6 - Tensão na direção $x$ para a viga engastada (em KN/cm²). 
A tensão de cisalhamento máxima, de acordo com a Resistência dos Materiais, é dada pela Equação 6.4.

$$
\tau_{x y}=\frac{Q_{y} m_{s}^{y}(y)}{I_{z} b(y)}=\frac{-6 \times 125}{2562,5017}=-0,2927 \mathrm{KN} / \mathrm{cm}^{2}
$$

A Figura 6.7 apresenta as tensões de cisalhamento obtidas numericamente, pode-se observar que as tensões máximas ocorrem na região central da viga, apresentando pequenas diferenças quando comparadas com o resultado obtido por meio da Resistência dos Materiais, e, como já foi discutido anteriormente, se deve ao fato de que a Resistência dos Materiais considerar como simplificação o fato de seções planas permanecerem planas depois de deformadas.

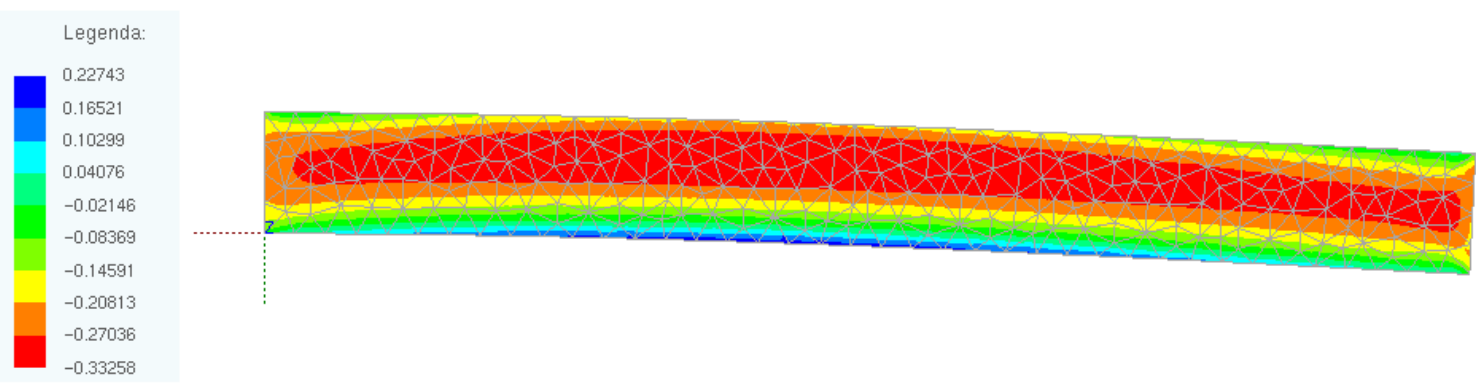

Figura 6.7 - Tensão de cisalhamento para a viga engastada $\left(\mathrm{em} \mathrm{KN} / \mathrm{cm}^{2}\right)$.

De maneira geral os resultados obtidos numericamente por meio da formulação aqui apresentada apresentam boa concordância e pequenas diferenças relativas quando comparados com soluções técnicas da Resistência dos Materiais e soluções analíticas, validando o modelo numérico de chapa reforçado com fibras.

\subsection{Exemplo 2: Chapa reforçada com fibras longas ordenadas e fibras curtas aleatórias}

Este exemplo tem por objetivo validar o reforço, tanto de fibras longas ordenadas como de fibras curtas dispersas aleatoriamente na matriz. Tomando como base o exemplo apresentado por Sampaio (2014), este exemplo consiste em uma chapa reforçada por fibras engastada em duas de suas extremidades e solicitada por carregamento uniformemente distribuído, conforme 
ilustra a Figura 6.8. O módulo de elasticidade e o coeficiente de Poisson adotados para a matriz são, respectivamente, $E_{m}=2000 \mathrm{KN} / \mathrm{cm}^{2}$ e $v=0,0$. Para as fibras longas e curtas, adota-se módulo de elasticidade $E_{f}=20000 \mathrm{KN} / \mathrm{cm}^{2}$ e área $A_{f}=0,1 \mathrm{~cm}^{2}$.

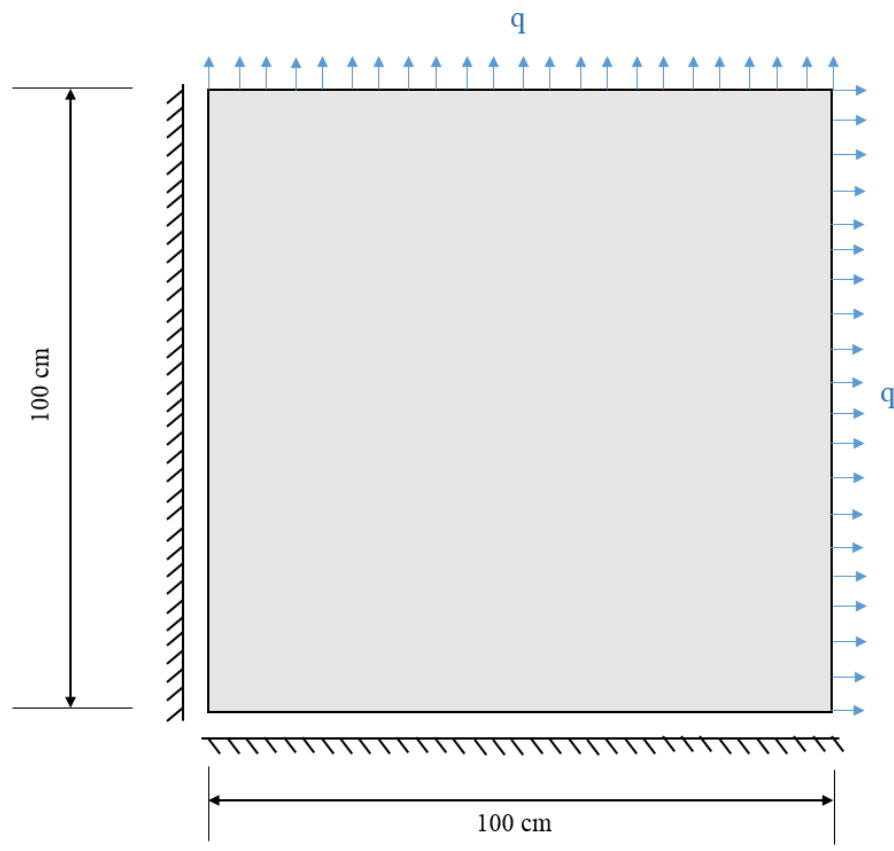

Figura 6.8 - Chapa reforçada com fibras.

A chapa foi discretizada em 192 elementos finitos triangulares e o carregamento distribuído $q=1000 \mathrm{KN} / \mathrm{cm}$ foi aplicado em 10 passos. As Figuras 6.9 e 6.10 apresentam os deslocamentos horizontais e verticais para o primeiro e último passo de carga da chapa, ainda sem o reforço de fibras.

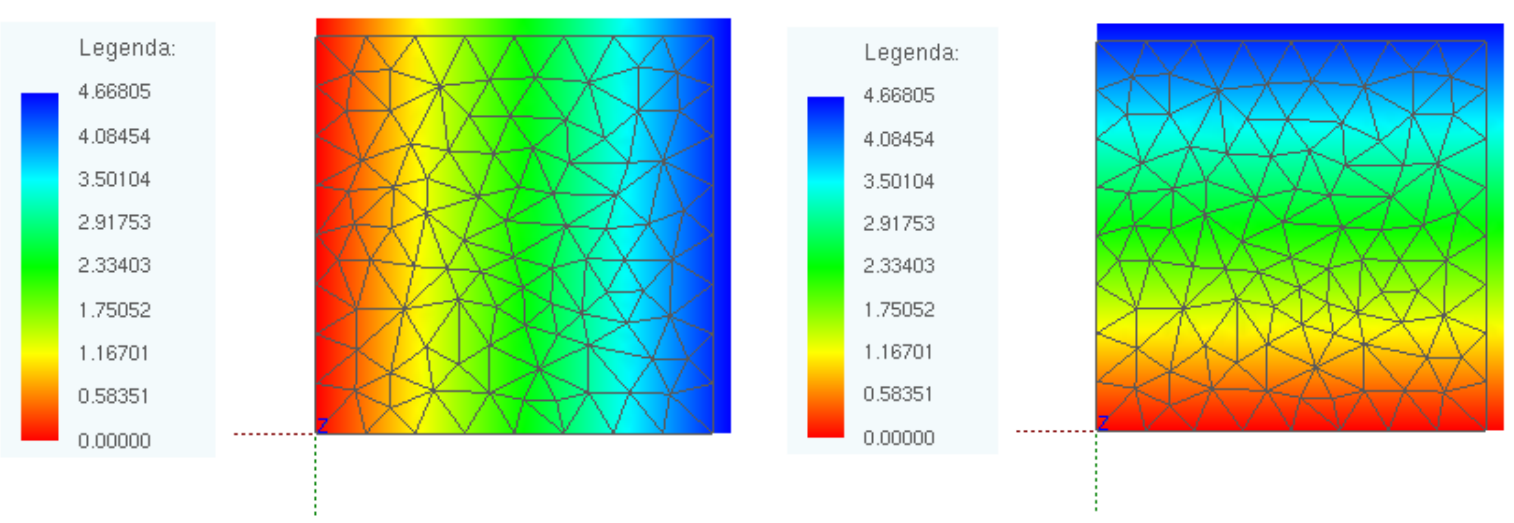

Figura 6.9 - Para o primeiro passo de carga (a) Deslocamento horizontal (em cm) e (b) deslocamento vertical $(\mathrm{em} \mathrm{cm})$ para a chapa sem reforço de fibras. 


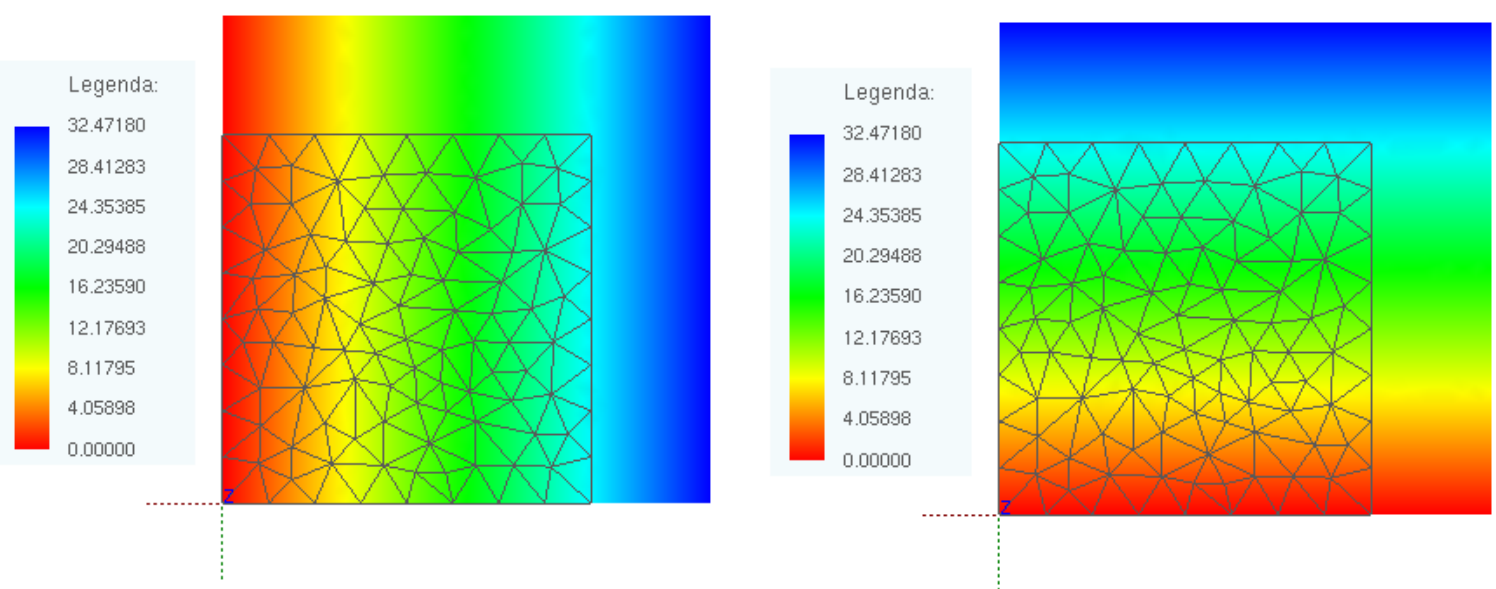

Figura 6.10 - Para o último passo de carga (a) Deslocamento horizontal (em cm) e (b) deslocamento vertical (em $\mathrm{cm})$ para a chapa sem reforço de fibras.

Para avaliar a correta contribuição da rigidez das fibras longas, foram avaliadas as situações de reforço apresentadas na Figura 6.11.
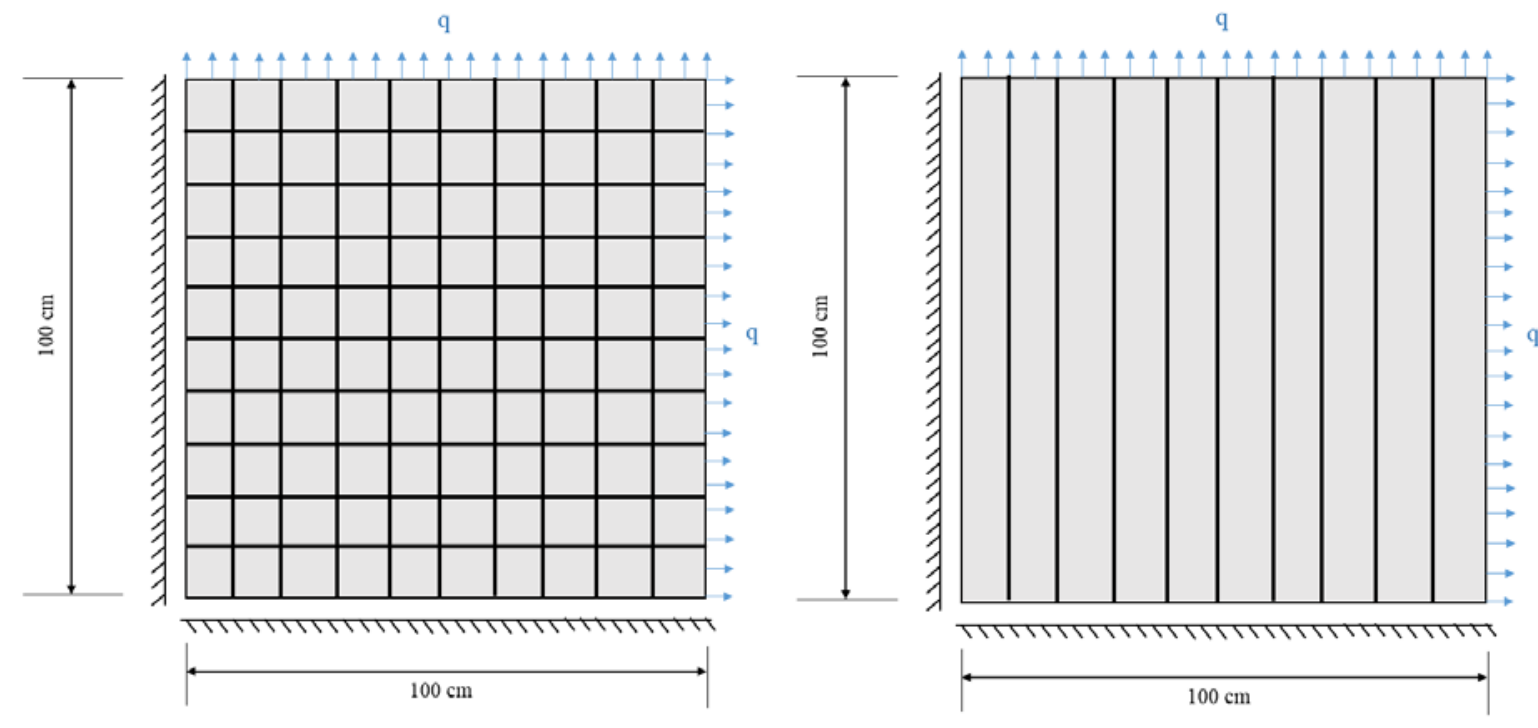

Figura 6.11 - Configurações de reforço utilizando fibras ordenadas.

Na Figura 6.11, cada uma das fibras longas foi discretizada em 10 elementos finitos lineares. Os resultados obtidos para os deslocamentos horizontais e verticais para a primeira configuração de reforço da Figura 6.11 são apresentados nas Figuras 6.12 e 6.13. 


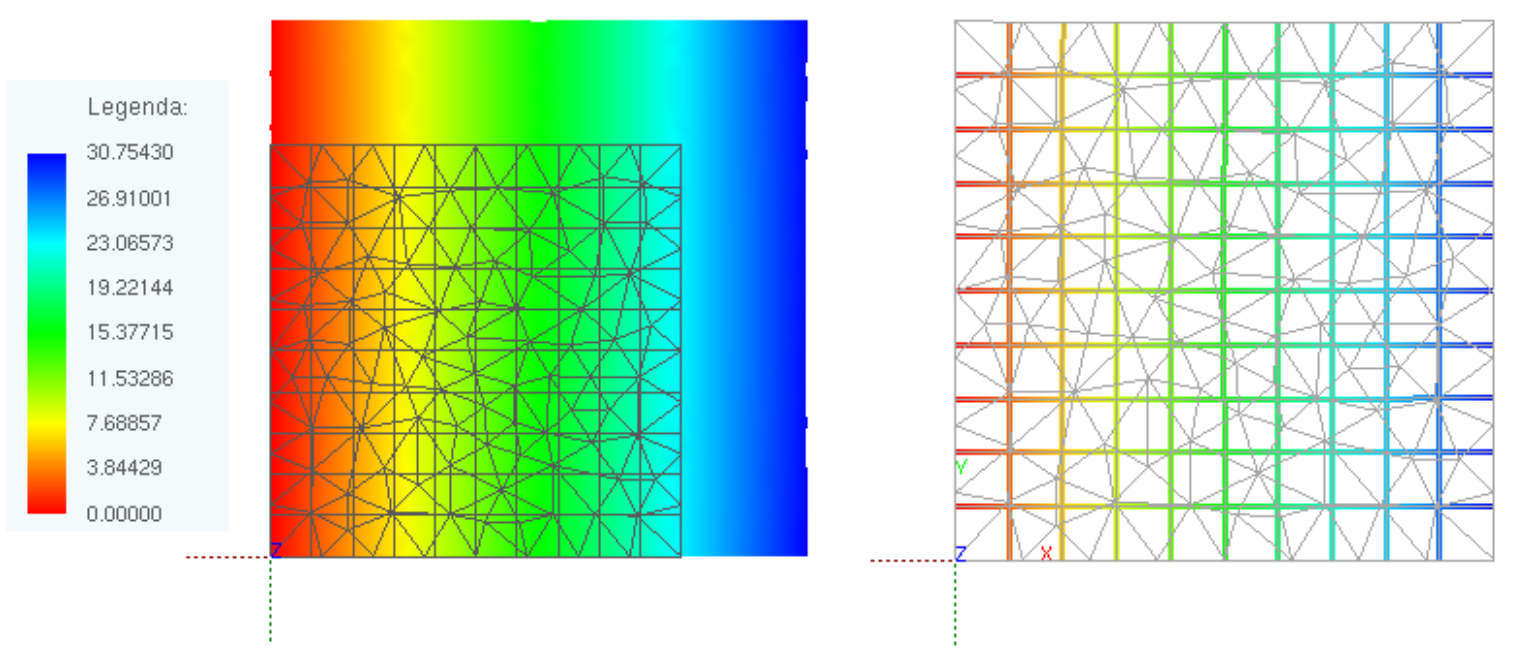

Figura 6.12 - Para o último passo de carga (a) Deslocamento horizontal (em cm) e (b) configuração deformada das fibras.
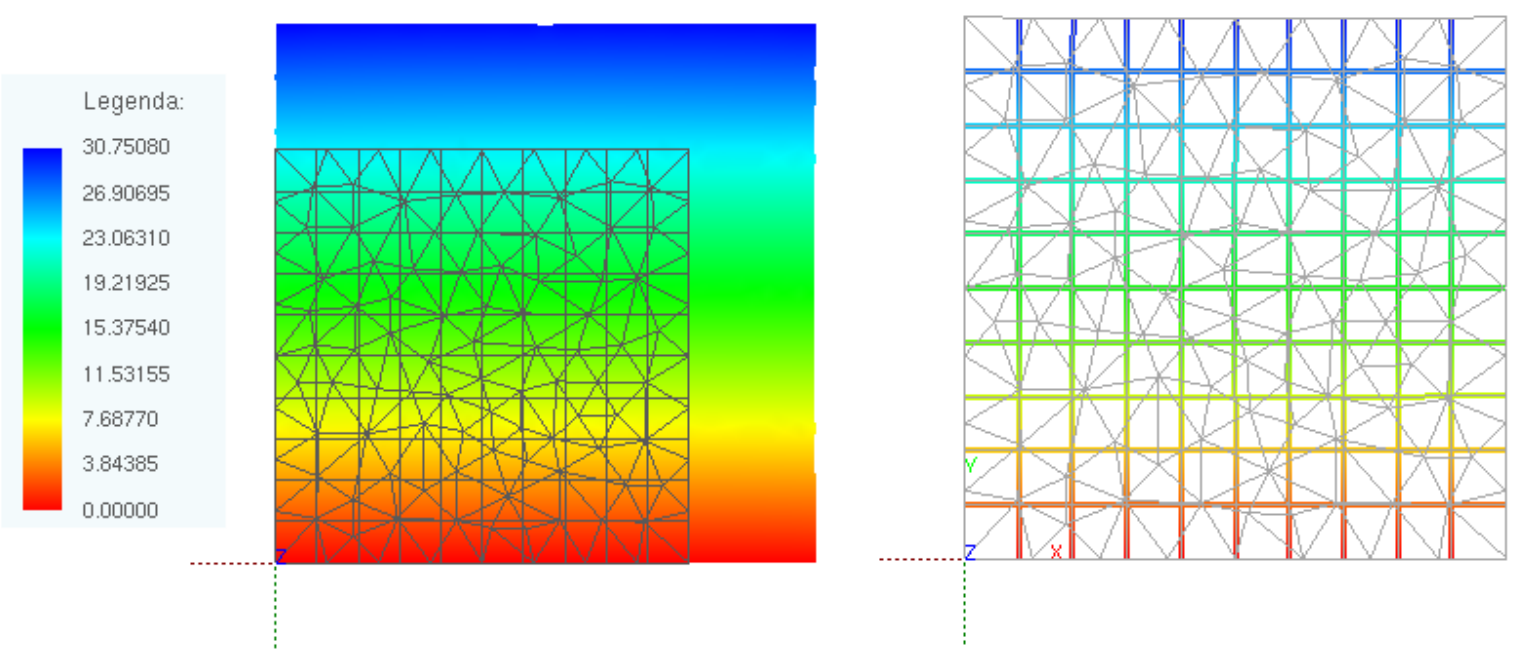

Figura 6.13 - Para o último passo de carga (a) Deslocamento vertical (em cm) e (b) configuração deformada das fibras.

Os resultados mostram que a inserção de fibras longas ordenadas aumentou a rigidez da chapa em 5,289\% na direção horizontal e 5,299\% na direção vertical, podendo-se também verificar o correto deslocamento das fibras associadas aos elementos de chapa.

As Figuras 6.14 e 6.15 apresentam os resultados para os deslocamentos verticais e horizontais para a segunda configuração de reforço apresentada na Figura 6.11. 


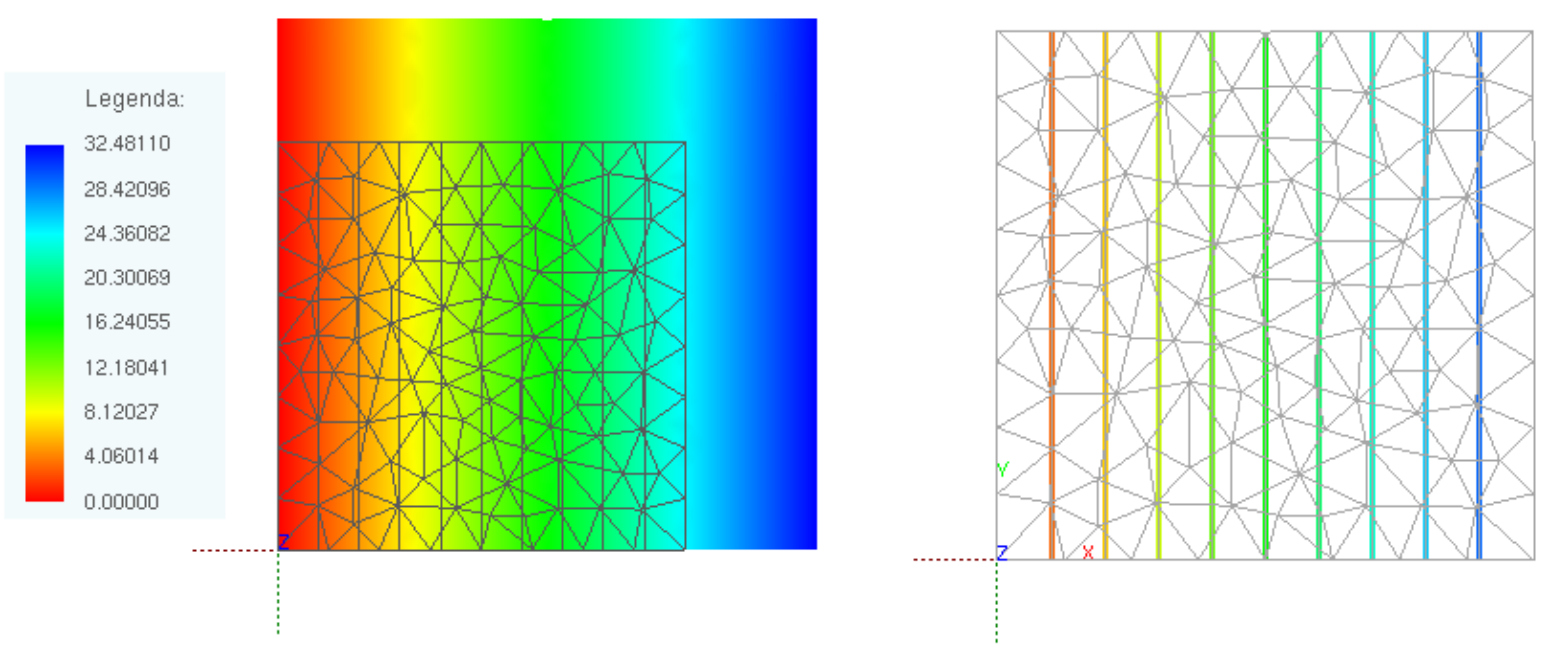

Figura 6.14 - Para o último passo de carga (a) Deslocamento horizontal (em cm) e (b) configuração deformada das fibras.
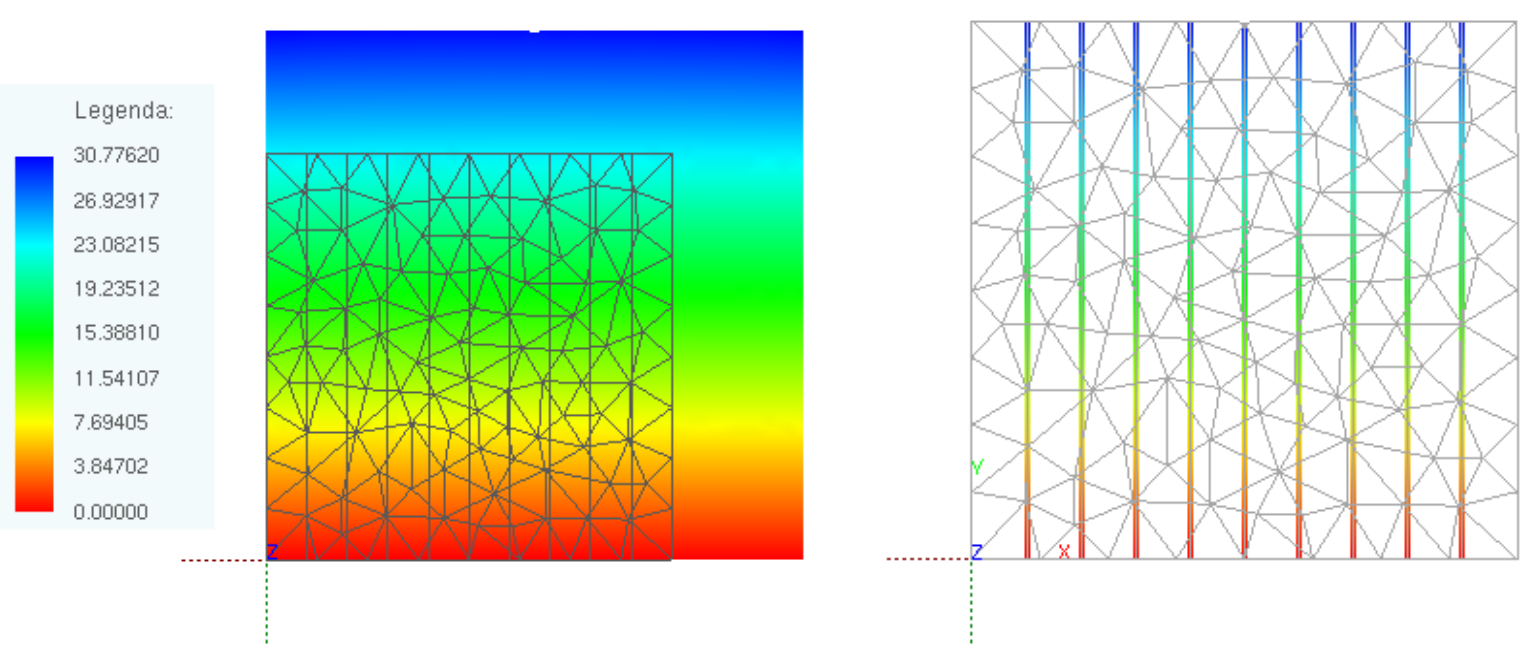

Figura 6.15 - Para o último passo de carga (a) Deslocamento vertical (em cm) e (b) configuração deformada das fibras.

Os resultados mostram que não houve aumento da rigidez na direção horizontal, o que já era de se esperar, uma vez que as fibras são discretizadas como elementos de treliça, apresentando rigidez apenas em uma direção. Para a direção vertical, o aumento da rigidez da chapa é de 5,222\%, muito próximo do aumento de rigidez obtido para a configuração de reforço apresentada anteriormente e, portanto, validando o reforço utilizando fibras longas.

Para avaliar a correta contribuição de fibras curtas, foram distribuídas aleatoriamente na chapa 180 fibras lineares com 10cm de comprimento. As Figuras 6.16 e 6.17 apresentam os 
resultados para os deslocamentos verticais e horizontais para a chapa reforçada com fibras curtas dispersas aleatoriamente.

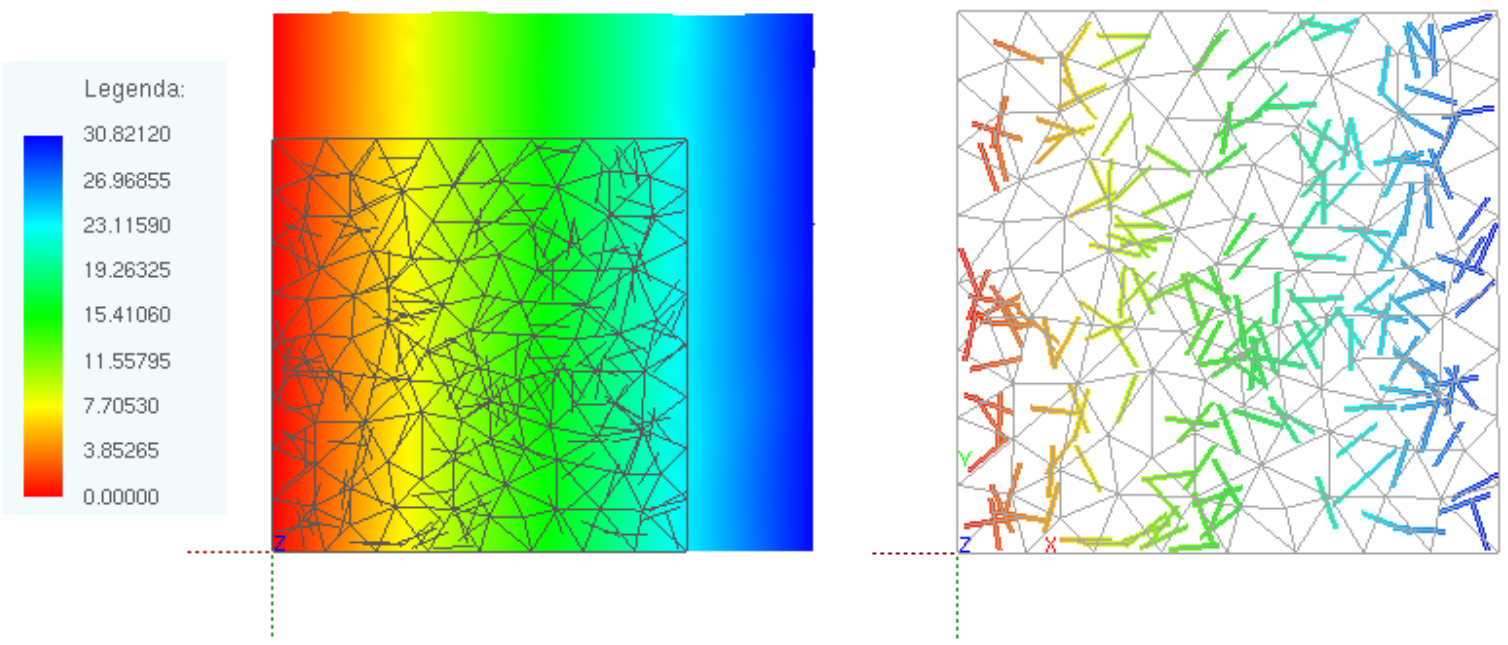

Figura 6.16 - Para o último passo de carga (a) Deslocamento horizontal (em cm) e (b) configuração deformada das fibras.
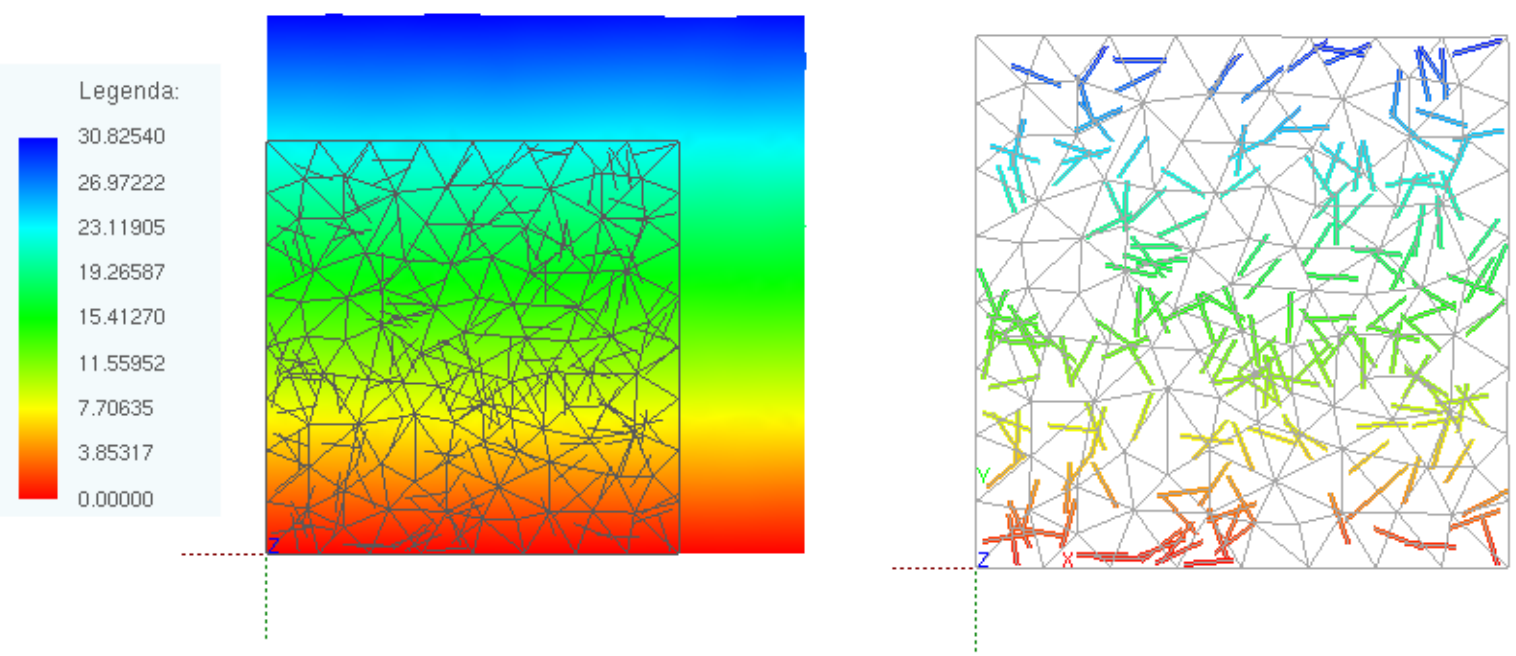

Figura 6.17 - Para o último passo de carga (a) Deslocamento vertical (em cm) e (b) configuração deformada das fibras.

Os resultados apresentados mostram que o reforço com fibras curtas aleatórias aumentou a rigidez da chapa em 5,083\% na direção horizontal e 5,07\% na direção vertical. O reforço em fibras curtas utilizou 1,8\% de fibras, mesma porcentagem utilizada para a primeira configuração de reforço em fibras longas (Figura 6.11), o que explica a semelhança do aumento 
de rigidez obtido para cada direção da chapa, validando o reforço em fibras curtas distribuídas aleatoriamente.

Pode-se concluir que os resultados apresentados comprovam a correta implementação do reforço, utilizando-se tanto fibras longas ordenadas quanto fibras curtas distribuídas aleatoriamente na chapa.

\subsection{Exemplo 3: Corpo de prova sujeito à expansão livre devido à RAA}

O objetivo deste exemplo é avaliar a representatividade das equações constitutivas apresentadas no item 4.2 para a expansão devido à RAA. Para isso foi modelado numericamente o experimento realizado por Boddy et al. (2000).

O experimento realizado por Boddy et al. (2000) avaliou a expansão livre devido à reação álcali-agregado em corpos de prova prismáticos com dimensões 7,5 x 7,5 x 30cm produzidos com agregado deletério e cimento altamente alcalino. Os corpos de prova foram mantidos durante 300 dias à temperatura de $38^{\circ} \mathrm{C}, 100 \%$ de umidade relativa e sem nenhuma restrição ao movimento e à expansão.

O modelo numérico utilizado para representar o corpo de prova foi discretizado em 186 elementos finitos triangulares. O comportamento do concreto foi considerado elástico-linear (desconsiderando a degradação das propriedades físicas) com módulo de elasticidade $E=2000 \mathrm{KN} / \mathrm{cm}^{2}$ e coeficiente de Poisson $v=0,2$.

A equação constitutiva proposta por Carrazedo (2004) (Equação 4.8) utiliza variáveis de projeto que são calibradas por meio de um processo de otimização, a fim de ajustar o modelo numérico com os resultados experimentais.

Carrazedo (2004) apresenta, para este exemplo, as seguintes variáveis de projeto e de calibração obtidas por processos de otimização (Tabela 6.1).

Tabela 6.1 - Variáveis de projeto e de calibração para a RAA.

\begin{tabular}{cc}
\multicolumn{3}{c}{ Variáveis } \\
\hline$A_{2}$ & 250,989 dias \\
$\varepsilon_{v o l}^{\max }$ & 0,001737 \\
$t^{p}$ & 52 dias \\
$k_{m}, k_{p}, k_{c}$ & 1,0 \\
$k_{t}$ & 0,2 \\
\hline
\end{tabular}


A Figura 6.18 apresenta o comparativo entre os resultados do experimento e os resultados obtidos por meio da equação constitutiva proposta por Carrazedo (2004). A Figura 6.19 ilustra os deslocamentos horizontais e verticais do corpo de prova.

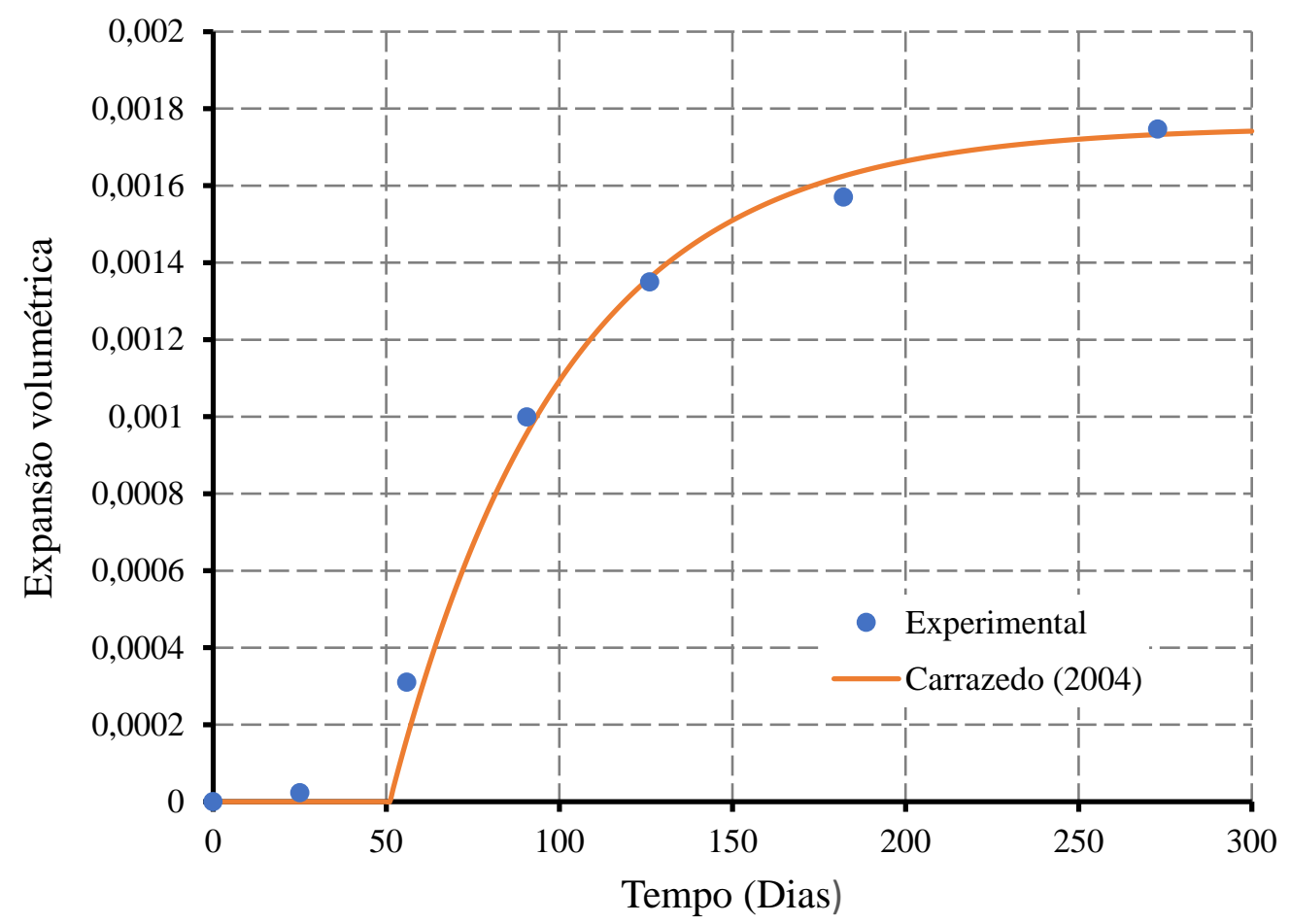

Figura 6.18 - Comparação dos pontos experimentais com a equação constitutiva proposta por Carrazedo (2004).

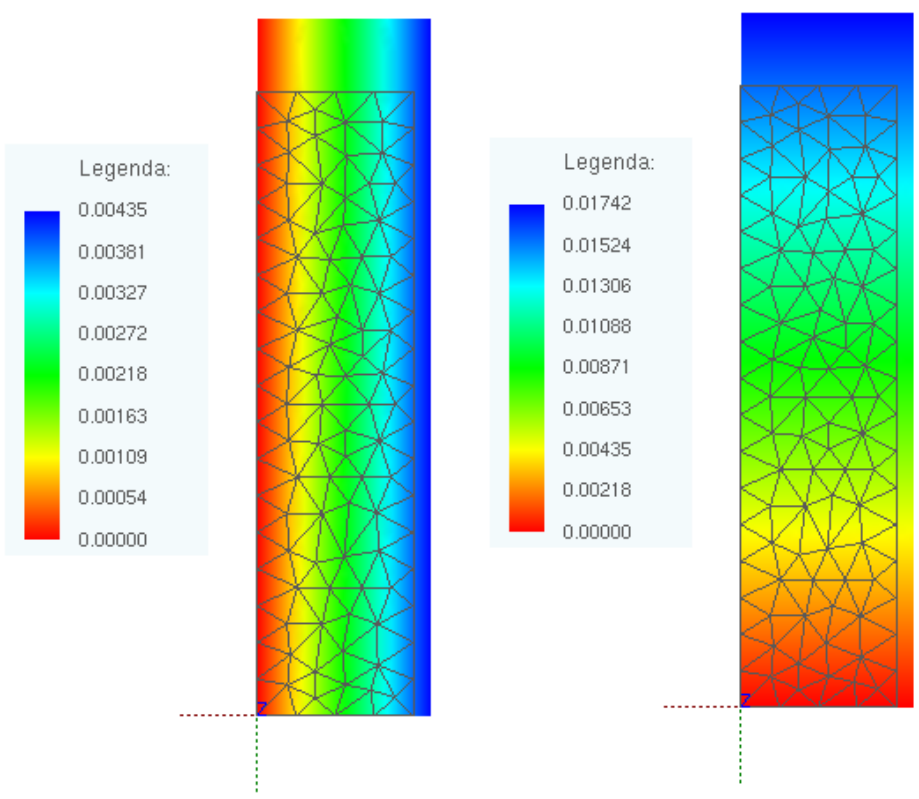

Figura 6.19 - Deslocamento (a) horizontal (em cm) e (b) vertical (em cm) aos 300. 
Da Figura 6.18, observa-se que os resultados obtidos pela Equação 4.8 proposta por Carrazedo (2004) apresentam pequenas divergências quando comparadas aos resultados experimentais. Entretanto, deve-se ressaltar que esta equação constitutiva não representa muito bem o primeiro estágio da expansão por RAA, uma vez que a Equação 4.8 só evidencia expansão a partir do momento em que os poros foram completamente preenchidos pelos produtos da RAA ( $t^{p}=52$ dias $)$.

A equação constitutiva proposta por Larive (1998) (Equação 4.9) utiliza, além da máxima expansão volumétrica esperada $\left(\varepsilon_{v o l}^{\max }=0,001737\right)$, outros dois parâmetros: o tempo característico e o tempo de latência, ambos dependentes da umidade e da temperatura. Os resultados experimentais realizados por este autor permitem ainda que, para a temperatura de $38^{\circ} \mathrm{C}$ a $100 \%$ de umidade relativa, sejam adotados tempos característico e de latência de 20 e 50 dias, respectivamente (valores apresentados na Tabela 3.1).

A Figura 6.20 apresenta o comparativo entre os resultados do experimento de Boddy et al. (2000) e os resultados obtidos por meio da equação constitutiva proposta por Larive (1998).

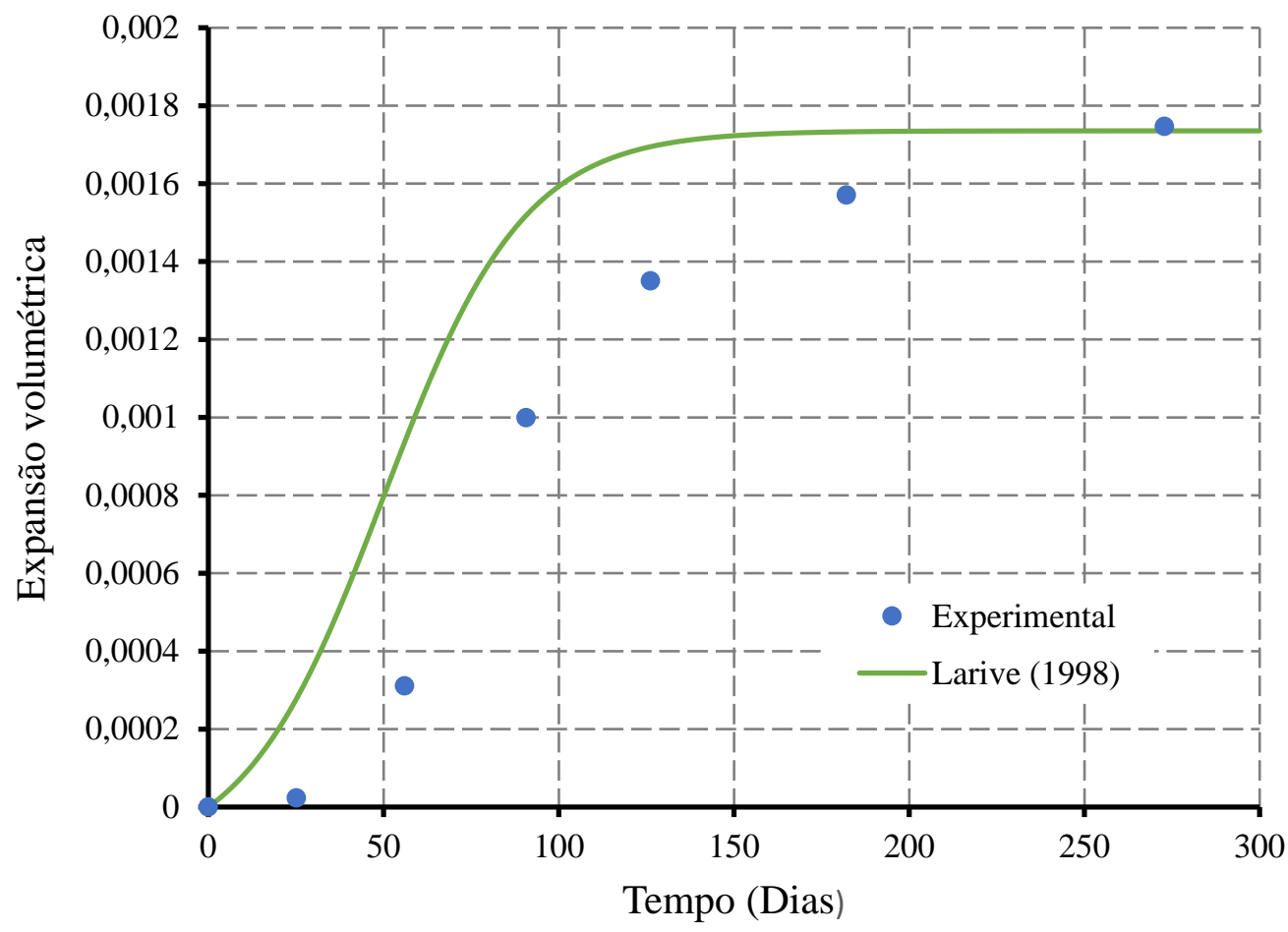

Figura 6.20 - Comparação dos pontos experimentais com a equação constitutiva proposta por Larive (1998).

Da Figura 6.20, observa-se que o modelo numérico que utiliza os parâmetros propostos por Larive (1998) apresenta grandes diferenças quando comparado com os resultados 
experimentais; isso se deve à variação dos tipos de agregados, conteúdo de álcalis utilizados ou mesmo das condições dos experimentos de Larive (1998) e de Boddy et al. (2000).

Saouma (2014) relata que nos ensaios realizados por Larive (1998) os tempos característico e de latência apresentam grande variabilidade para uma mesma amostra de concreto (mesma condição de temperatura e umidade), apresentando desvio padrão para o tempo característico de até 30\%. Portanto, os valores desses parâmetros podem ser considerados razoavelmente representativos na falta de dados experimentais.

Ajustando os parâmetros referentes ao tempo de latência e ao tempo característico em função dos dados obtidos experimentalmente por Boddy et al. (2000) é possível um melhor ajuste da curva obtida numericamente com os dados experimentais. Dessa forma, para um tempo característico de 30 dias e tempo de latência de 85 dias, a curva obtida é apresentada na Figura 6.21.

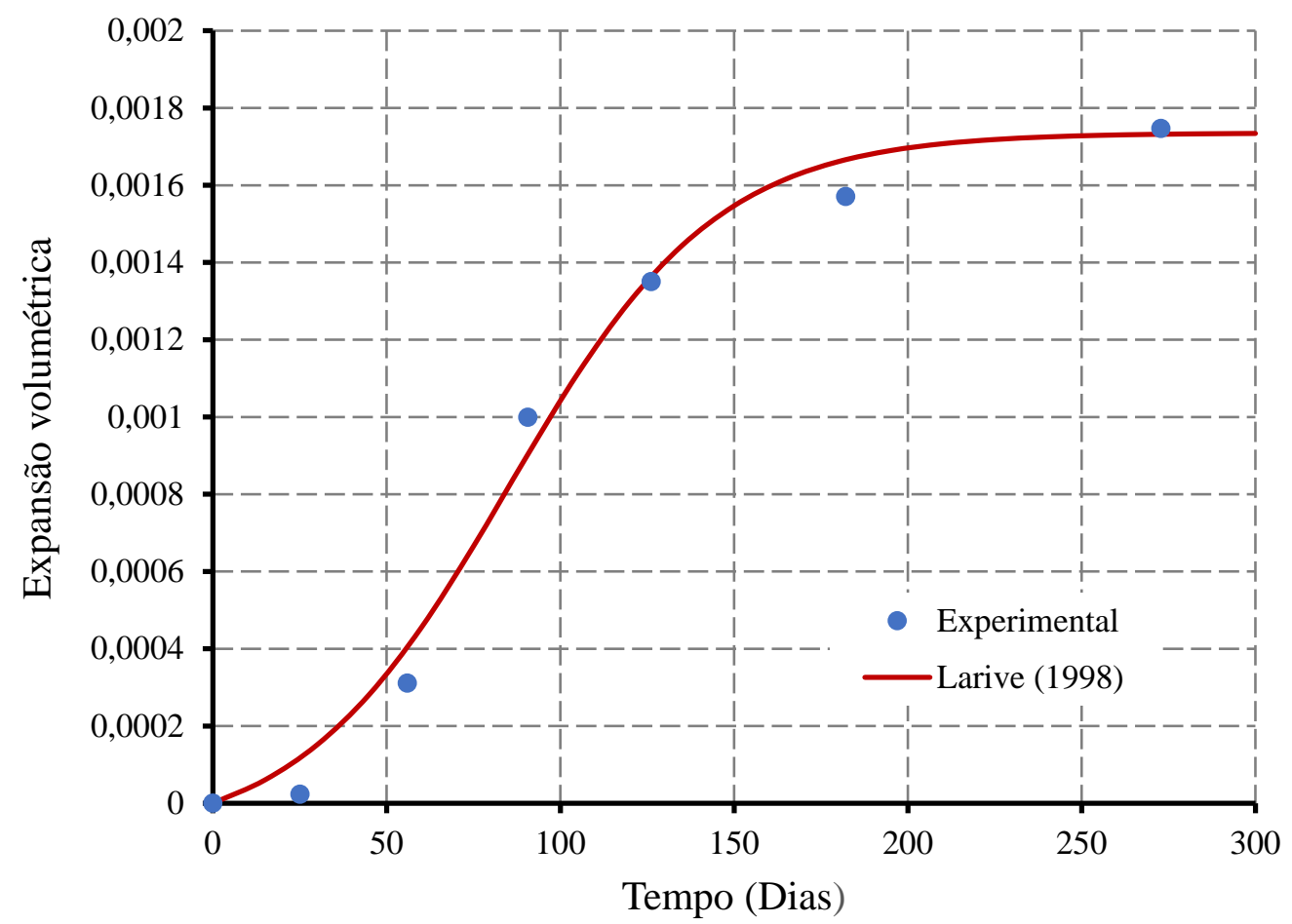

Figura 6.21 - Comparação dos pontos experimentais com a equação constitutiva proposta por Larive (1998).

Fica claro por meio da Figura 6.21 que a Equação 4.9 proposta por Larive (1998) para a representação da expansão por RAA é capaz de representar melhor o primeiro estágio da expansão (dois primeiros pontos experimentais). 
Por fim, conclui-se que ambas as equações constitutivas aqui avaliadas são capazes de representar o fenômeno de expansão livre devido à RAA, desde que as variáveis envolvidas nas equações sejam devidamente calibradas. Dessa forma, nos demais exemplos será empregada a equação constitutiva proposta por Carrazedo (2004) (Equação 4.8).

\subsection{Exemplo 4: Corpo de prova afetado por RAA sujeito a diferentes níveis de tensão aplicadas e induzidas.}

Este exemplo tem por objetivo avaliar as duas leis de normalização referentes às tensões apresentadas no item 4.1.5. Para isso, modelou-se numericamente o trabalho experimental realizado por Jones e Clark (1996).

Jones e Clark (1996) realizaram três séries de ensaios envolvendo 180 corpos de prova cilíndricos de $10 \mathrm{~cm}$ de diâmetro e $20 \mathrm{~cm}$ de altura com o objetivo de avaliar o efeito de diferentes níveis de tensão aplicadas e diferentes taxas de armadura na expansão por RAA.

Todos os corpos de prova ensaiados foram mantidos imersos em água e à temperatura de $38^{\circ} \mathrm{C}$ durante aproximadamente 250 dias.

\subsubsection{Primeira série de ensaios: tensão aplicada}

Na primeira série de ensaios, os corpos de prova foram submetidos a diferentes níveis de tensão de compressão aplicadas, variando de 1 a 7MPa. O modelo numérico utilizado para representar o corpo de prova foi discretizado em 92 elementos finitos triangulares. O comportamento do concreto foi considerado elástico-linear com módulo de elasticidade $E=2500 \mathrm{KN} / \mathrm{cm}^{2}$ e coeficiente de Poisson $v=0,2$.

Para este exemplo foram empregadas as seguintes variáveis de projeto e calibração (Tabela 6.2). 
Tabela 6.2 - Variáveis de projeto e de calibração para a RAA.

\begin{tabular}{cc}
\multicolumn{3}{c}{ Variáveis } \\
\hline$A_{2}$ & 110 dias \\
$\varepsilon_{v o l}^{\max }$ & 0,0165 \\
$t^{p}$ & 70 dias \\
$k_{m}, k_{p}$ & 1,0 \\
$k_{t}$ & 0,2 \\
$k_{c}$ & 0,0 \\
\hline
\end{tabular}

As Figuras 6.22 e 6.23 apresentam gráficos comparando os resultados obtidos pelo modelo numérico e os resultados obtidos experimentalmente para a expansão na direção do carregamento aplicado. As curvas numéricas apresentadas na Figura 6.22 empregam a normalização linear referente às tensões proposta por Pappalardo Jr. et al. (2000). Já as curvas da Figura 6.23 empregam a normalização logarítmica de tensões proposta por Léger et al. (1996).

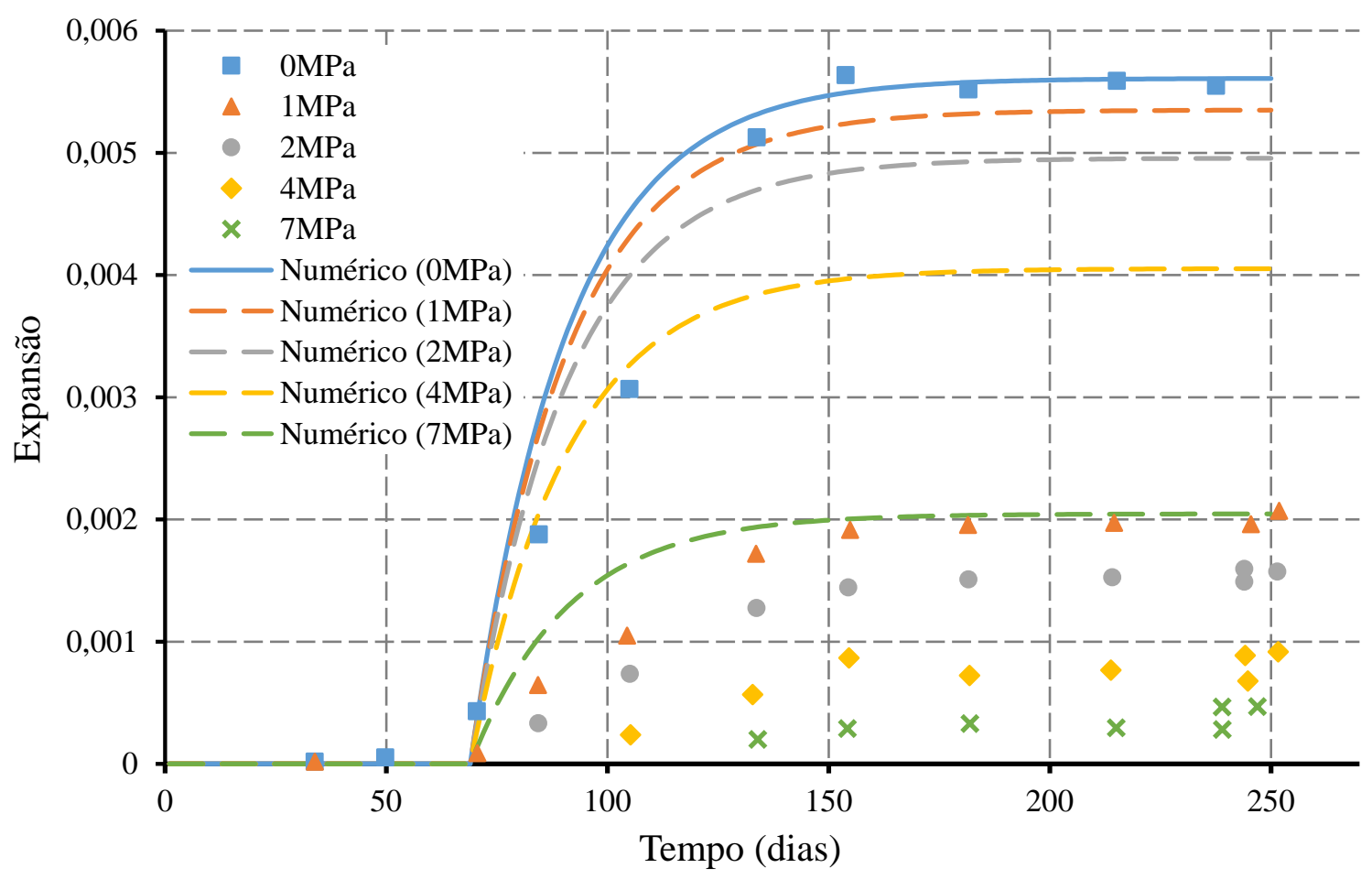

Figura 6.22 - Expansão dos corpos de prova sob diferentes níveis de tensão aplicadas (normalização de tensões proposta por Pappalardo Jr. et al. (2000)). 


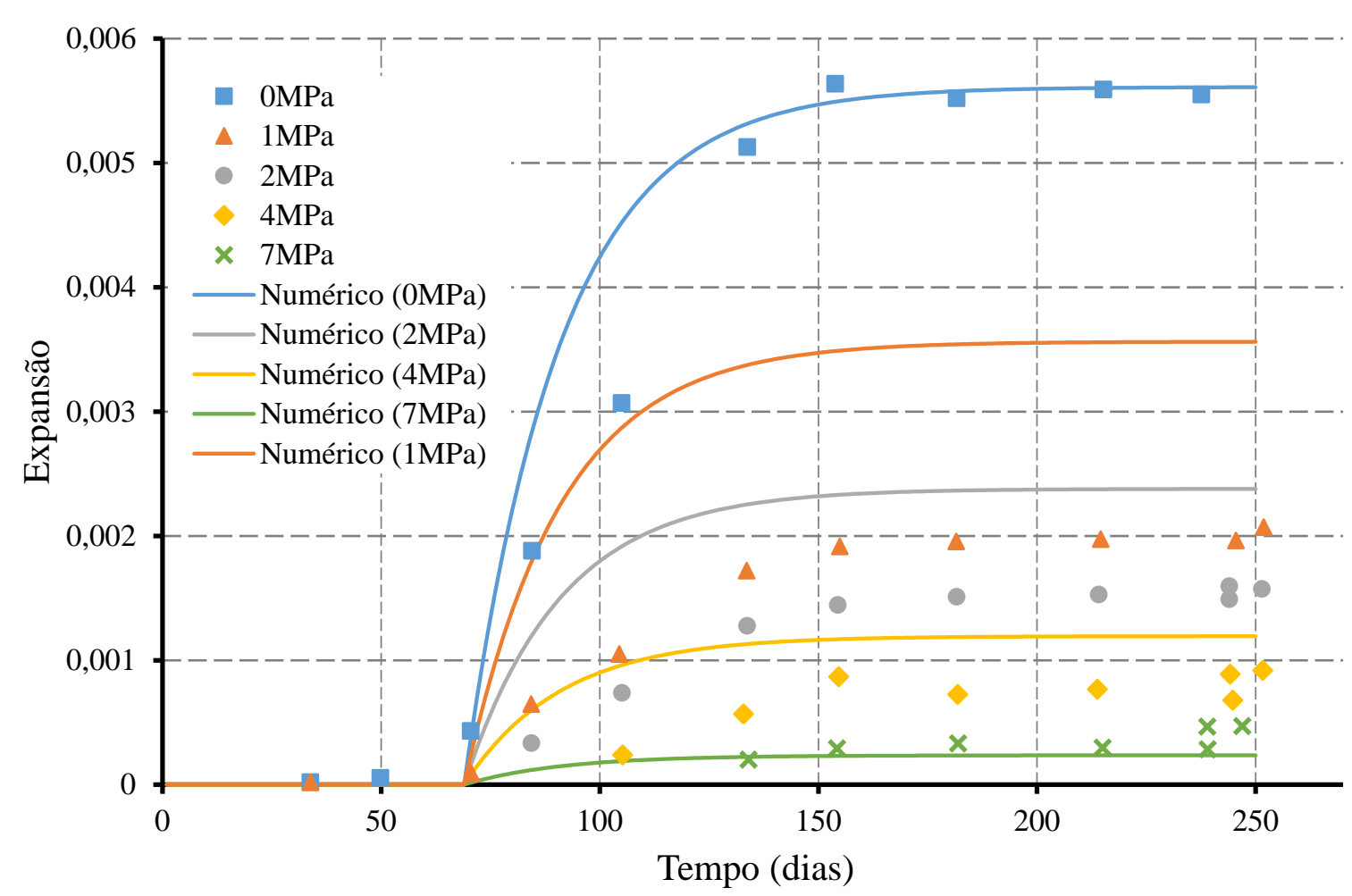

Figura 6.23 - Expansão dos corpos de prova sob diferentes níveis de tensão aplicadas (normalização de tensões proposta por Léger et al. (1996)).

Das Figuras 6.22 e 6.23 pode-se observar que as tensões aplicadas reduzem a magnitude da expansão devido à RAA na direção em que o carregamento é aplicado. Além disso, as curvas numéricas apresentadas pela Figura 6.23 são as que melhor representam os resultados experimentais. Contudo, deve-se ressaltar que para níveis de tensão de compressão mais baixos (1 e 2MPa), os resultados numéricos divergem dos resultados experimentais, o que pode estar associado ao fenômeno de fluência atuando sobre as amostras ensaiadas e que não é considerado no modelo numérico.

\subsubsection{Segunda série de ensaios: tensão induzida}

A segunda série de ensaios avaliou o efeito de diferentes taxas de armadura (de 0,25 a 2\%) na expansão dos corpos de prova. O modelo numérico utilizado para representar o corpo de prova foi novamente discretizado em 92 elementos finitos triangulares com módulo de elasticidade $E=2500 \mathrm{KN} / \mathrm{cm}^{2}$ e coeficiente de Poisson $v=0,2$. Nesse caso, uma única barra de aço com módulo de elasticidade $E=21000 \mathrm{KN} / \mathrm{cm}^{2}$ foi inserida no centro dos corpos de prova e discretizada em 20 elementos finitos lineares. 
A Tabela 6.3 apresenta as variáveis de projeto e calibração empregadas nesse exemplo.

Tabela 6.3 - Variáveis de projeto e de calibração para a RAA.

\begin{tabular}{cc}
\multicolumn{3}{c}{ Variáveis } \\
\hline$A_{2}$ & 130 dias \\
$\varepsilon_{v o l}^{\max }$ & 0,0174 \\
$t^{p}$ & 105 dias \\
$k_{m}, k_{p}$ & 1,0 \\
$k_{t}$ & 0,2 \\
$k_{c}$ & 0,0 \\
\hline
\end{tabular}

As Figuras 6.24 e 6.25 apresentam os resultados numéricos e experimentais para a expansão dos corpos de prova reforçados com diferentes taxas de armadura.

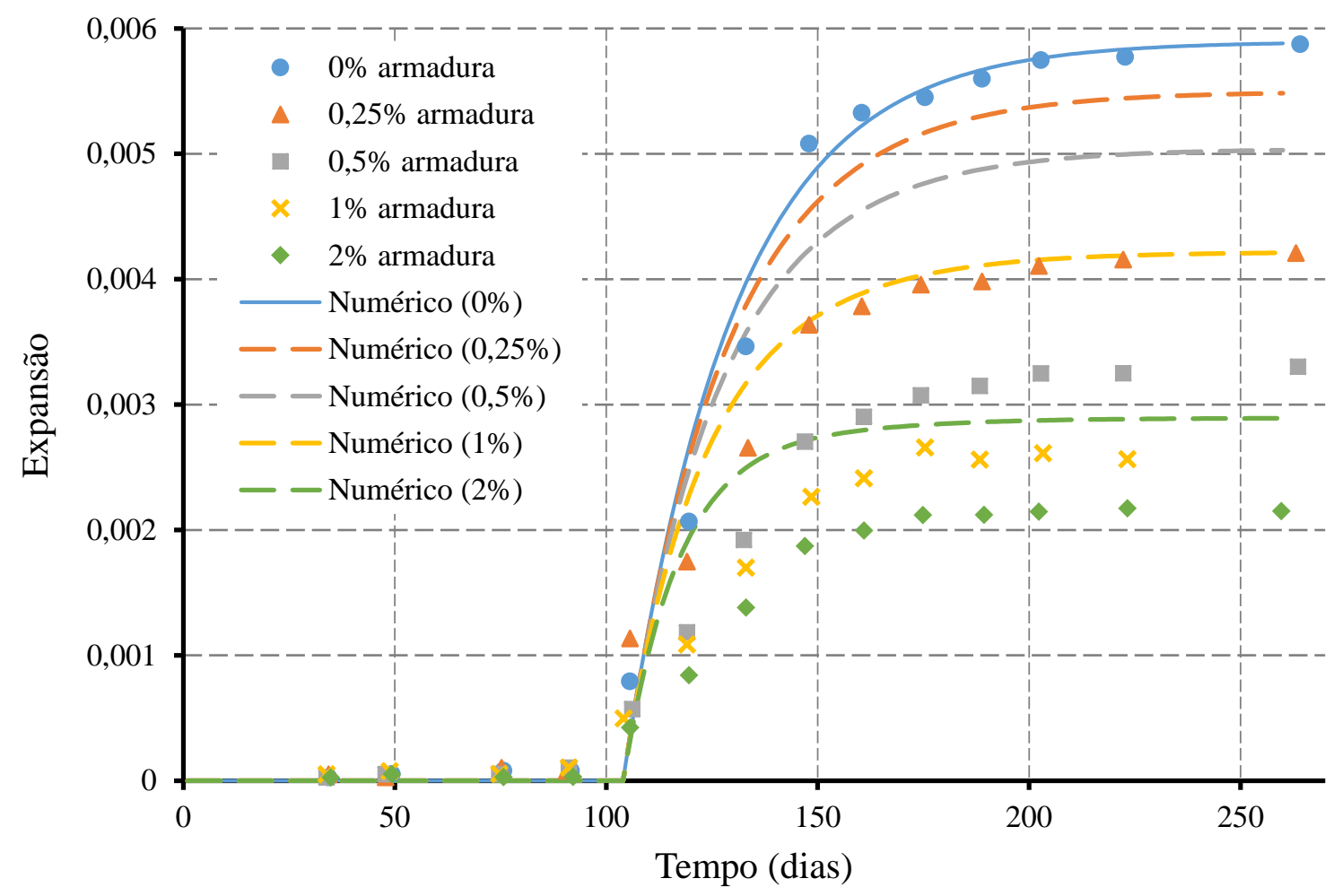

Figura 6.24 - Expansão dos corpos de prova contendo diferentes taxas de armadura (normalização de tensões proposta por Pappalardo Jr. et al. (2000)). 


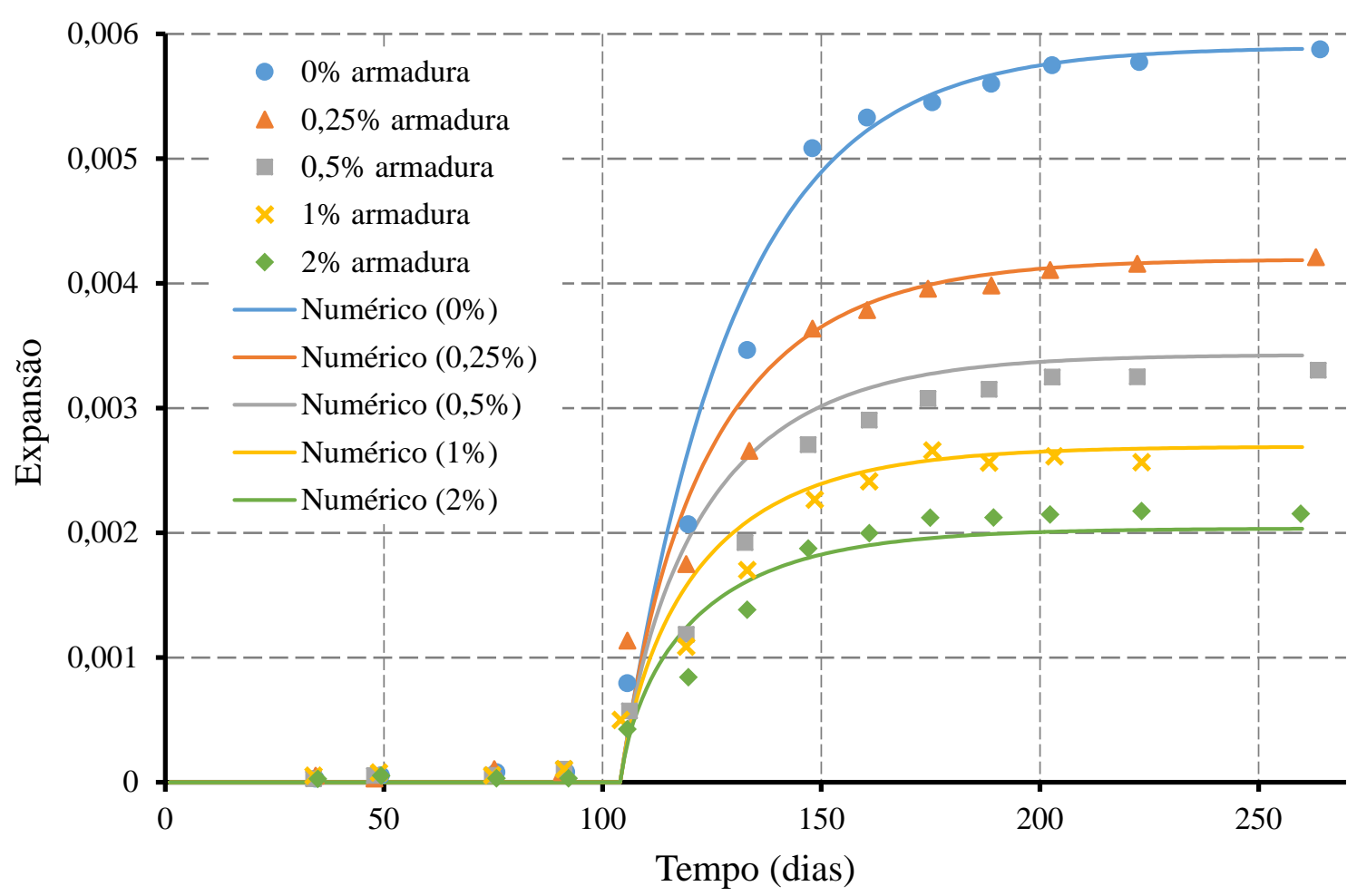

Figura 6.25 - Expansão dos corpos de prova contendo diferentes taxas de armadura (normalização de tensões proposta por Léger et al. (1996)).

Novamente, pode-se observar que o aumento das taxas de armadura reduz a expansão na direção paralela à armadura; também é possível verificar que as curvas numéricas apresentadas na Figura 6.25 que emprega a normalização de tensões proposta por Léger et al. (1996) são as que melhor representam os resultados obtidos experimentalmente.

A Figura 6.26 apresenta a evolução da tensão no concreto em direção paralela à armadura (direção y) para um nó na região central dos corpos de prova contendo diferentes taxas de armadura. As tensões de compressão são induzidas no concreto em função da restrição ao deslocamento imposta pela armadura; para o caso em que o corpo de prova apresenta $2 \%$ de armadura essa tensão pode atingir até $0,52 \mathrm{KN} / \mathrm{cm}^{2}$. 


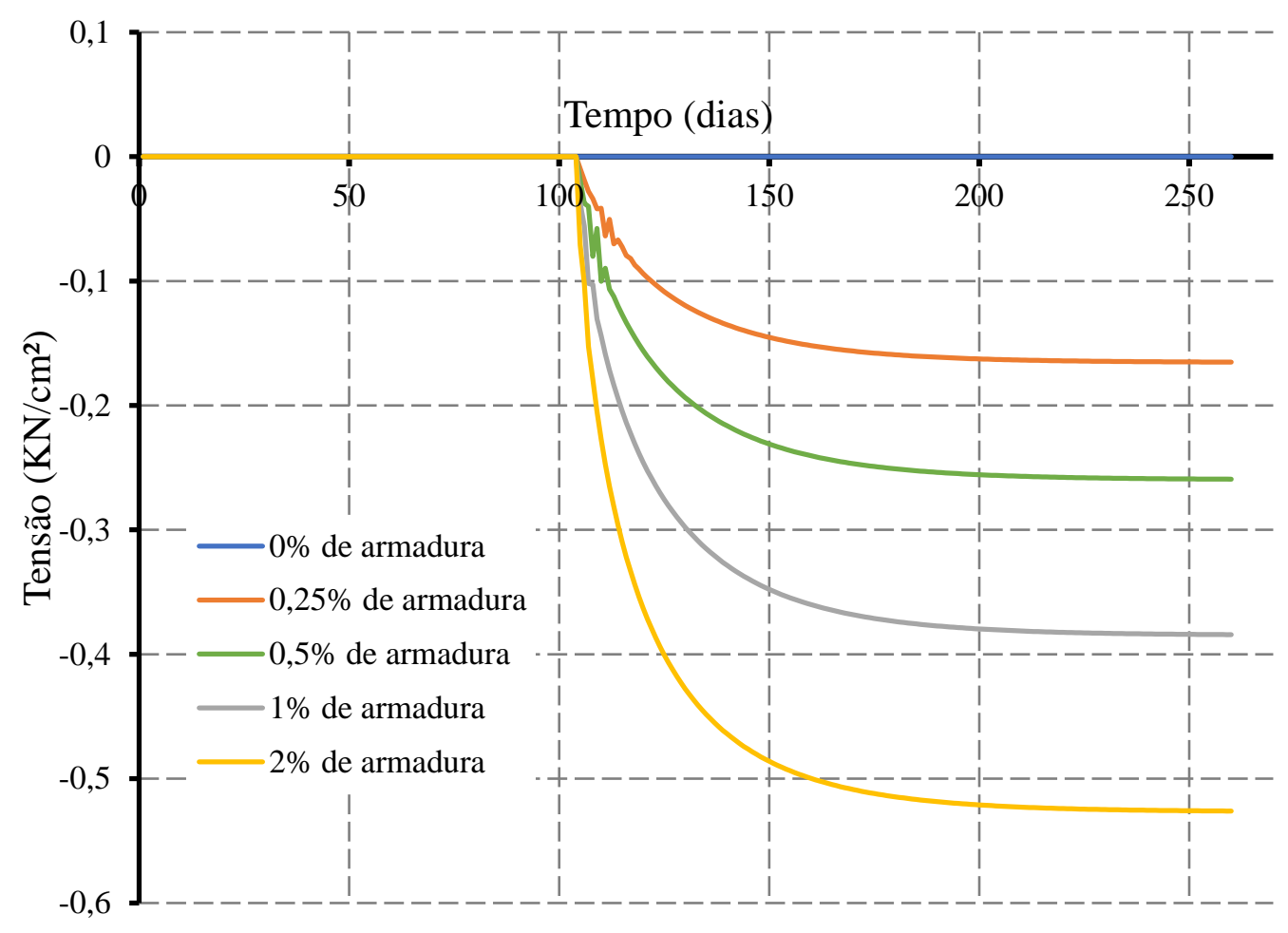

Figura 6.26 - Tensão na direção y para corpos de prova contendo diferentes taxas de armadura (normalização de tensões proposta por Léger et al. (1996)).

\subsubsection{Terceira série de ensaios: tensões aplicadas e induzidas simultaneamente}

A última série de ensaios avaliou o efeito de diferentes níveis de carregamento na expansão de corpos de prova contendo $1 \%$ de armadura. O modelo numérico considera as seguintes variáveis de projeto e calibração (Tabela 6.4).

Tabela 6.4 - Variáveis de projeto e de calibração para a RAA.

\begin{tabular}{cc}
\multicolumn{3}{c}{ Variáveis } \\
\hline$A_{2}$ & 120 dias \\
$\varepsilon_{\text {vol }}^{\max }$ & 0,0147 \\
$t^{p}$ & 75 dias \\
$k_{m}, k_{p}$ & 1,0 \\
$k_{t}$ & 0,2 \\
$k_{c}$ & 0,0 \\
\hline
\end{tabular}

A Figura 6.27 apresenta os resultados numéricos e experimentais obtidos utilizando-se a normalização de tensões proposta por Léger et al. (1996) para essa última série de ensaios. 


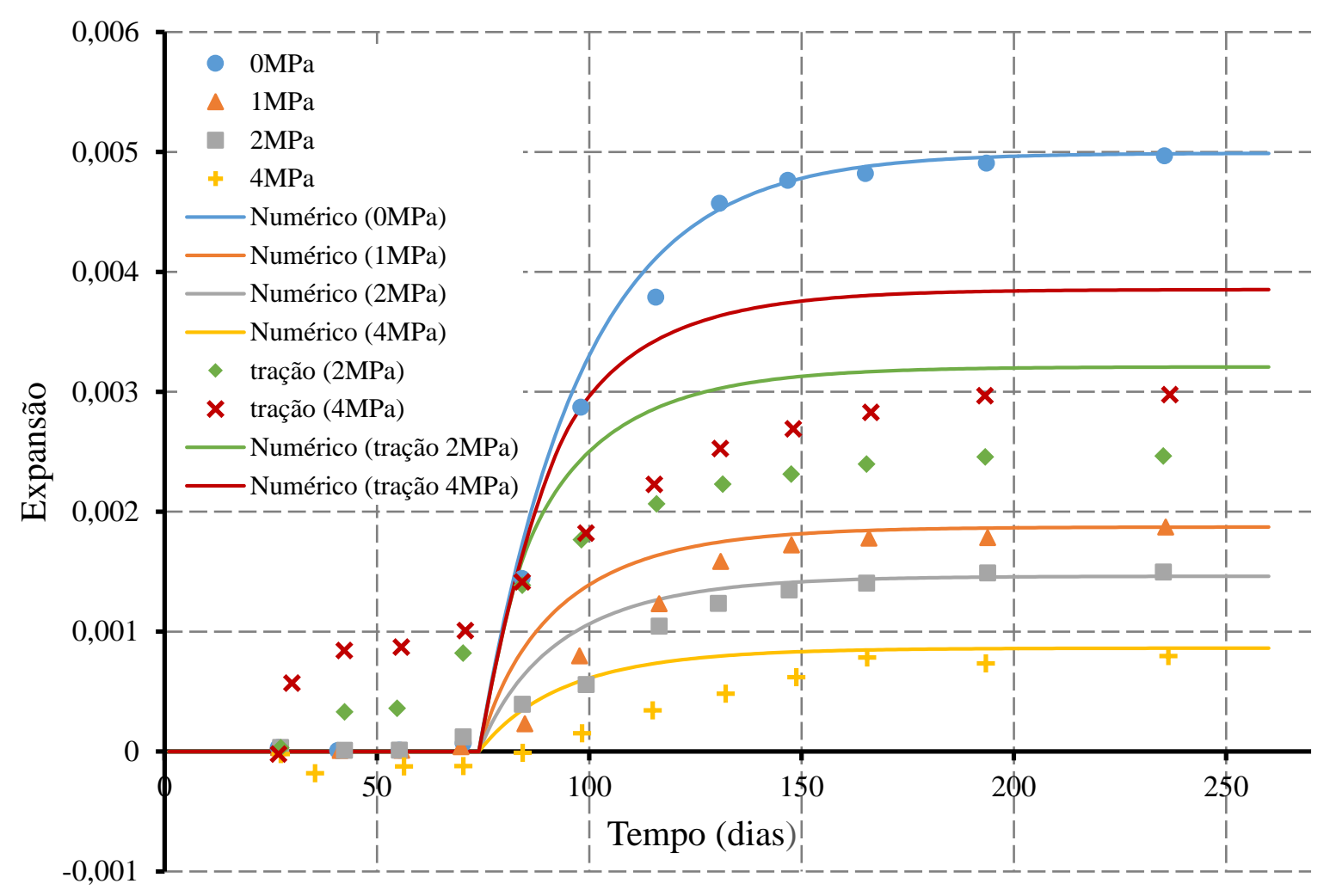

Figura 6.27 - Expansão dos corpos de prova sob diferentes níveis de tensão e contendo 1\% de armadura.

A Figura 6.27 comprova que o modelo numérico aqui apresentado também representa bem o caso em que as tensões são aplicadas e induzidas por armadura simultaneamente. Destaca-se ainda que o modelo numérico não é capaz de representar bem o caso em que o concreto armado é tracionado, uma vez que a redução da expansão associada às tensões de tração deve-se às macrofissuras que surgem no concreto e acomodam o gel de RAA; como o modelo numérico aqui apresentado não considera a fissuração do concreto, não é capaz de representar devidamente a redução da expansão para o caso de tensões de tração atuando nos corpos de prova.

Jones e Clark (1996) ressaltam que as curvas experimentais apresentadas na Figura 6.27 representam as expansões totais, sendo assim, os autores sugerem a redução das expansões observadas antes dos 50 dias (expansões possivelmente associadas às tensões e ao fenômeno de fluência), a fim de se obter as expansões associadas apenas à RAA.

Dessa forma, na Figura 6.28 são apresentadas as expansões associadas apenas à RAA para o caso em que tensões de tração são aplicadas. No mesmo gráfico também são apresentadas as curvas obtidas numericamente para uma amostra de concreto sujeita à expansão livre e para um corpo de prova contendo armadura e sem nenhuma tensão aplicada (0MPa). Pode-se 
observar que, tanto para as tensões de tração de $2 \mathrm{MPa}$ quanto para as tensões de $4 \mathrm{MPa}$ a magnitude da expansão por RAA é a mesma. Além disso, a expansão é um pouco reduzida quando comparada à curva numérica de expansão de um corpo de prova sujeito apenas à tensão induzida por armadura, isso possivelmente se deve à fissuração dos corpos de prova tracionados que permitem a acomodação da expansão do gel.

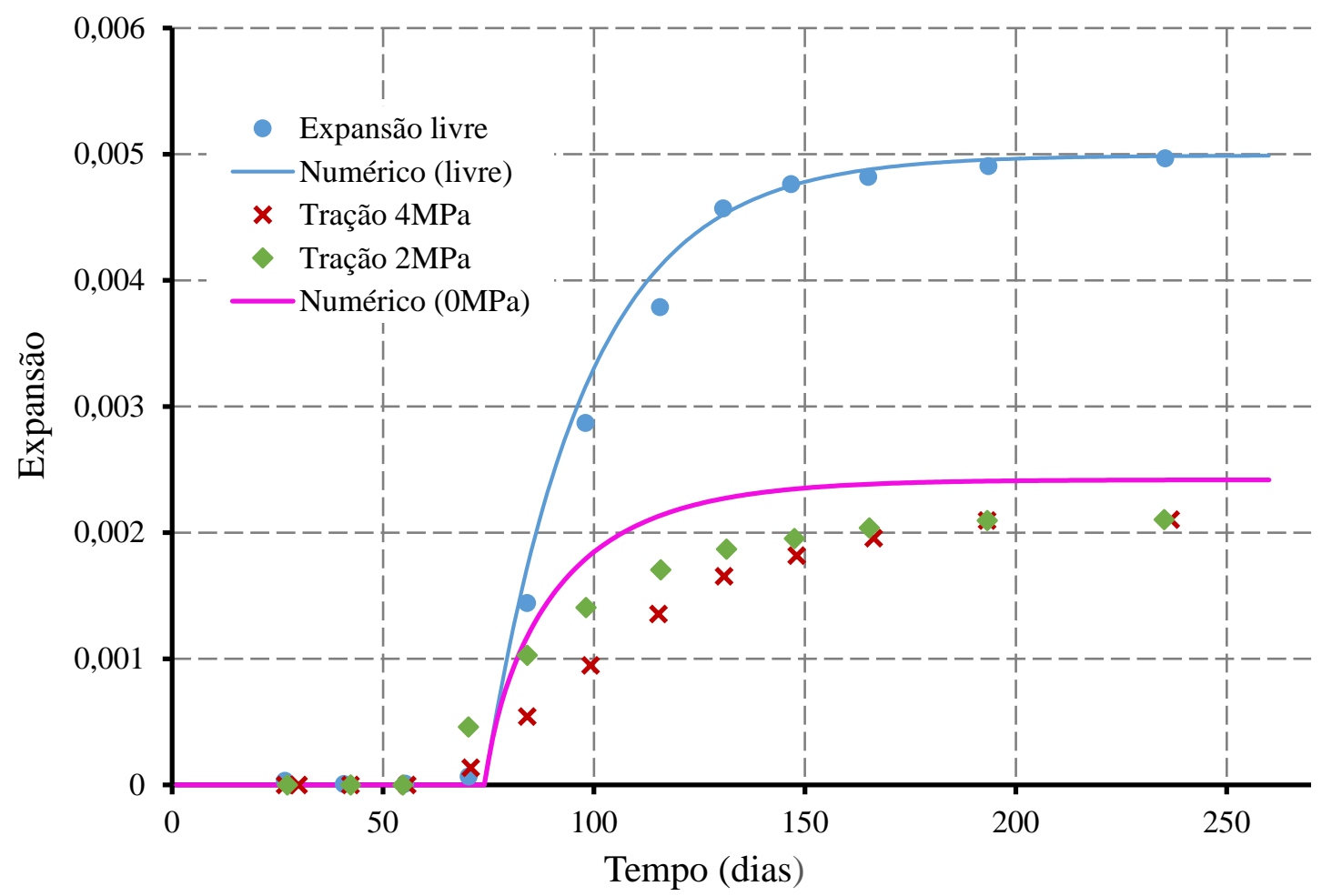

Figura 6.28 - Expansão apenas por RAA dos corpos de prova sob diferentes níveis de tensão e contendo 1\%.

Ainda para este modelo, a Figura 6.29 apresenta as curvas obtidas numericamente para as tensões na direção $y$ (direção paralela à armadura) desenvolvidas em um nó localizado no centro do corpo de prova ensaiado. 


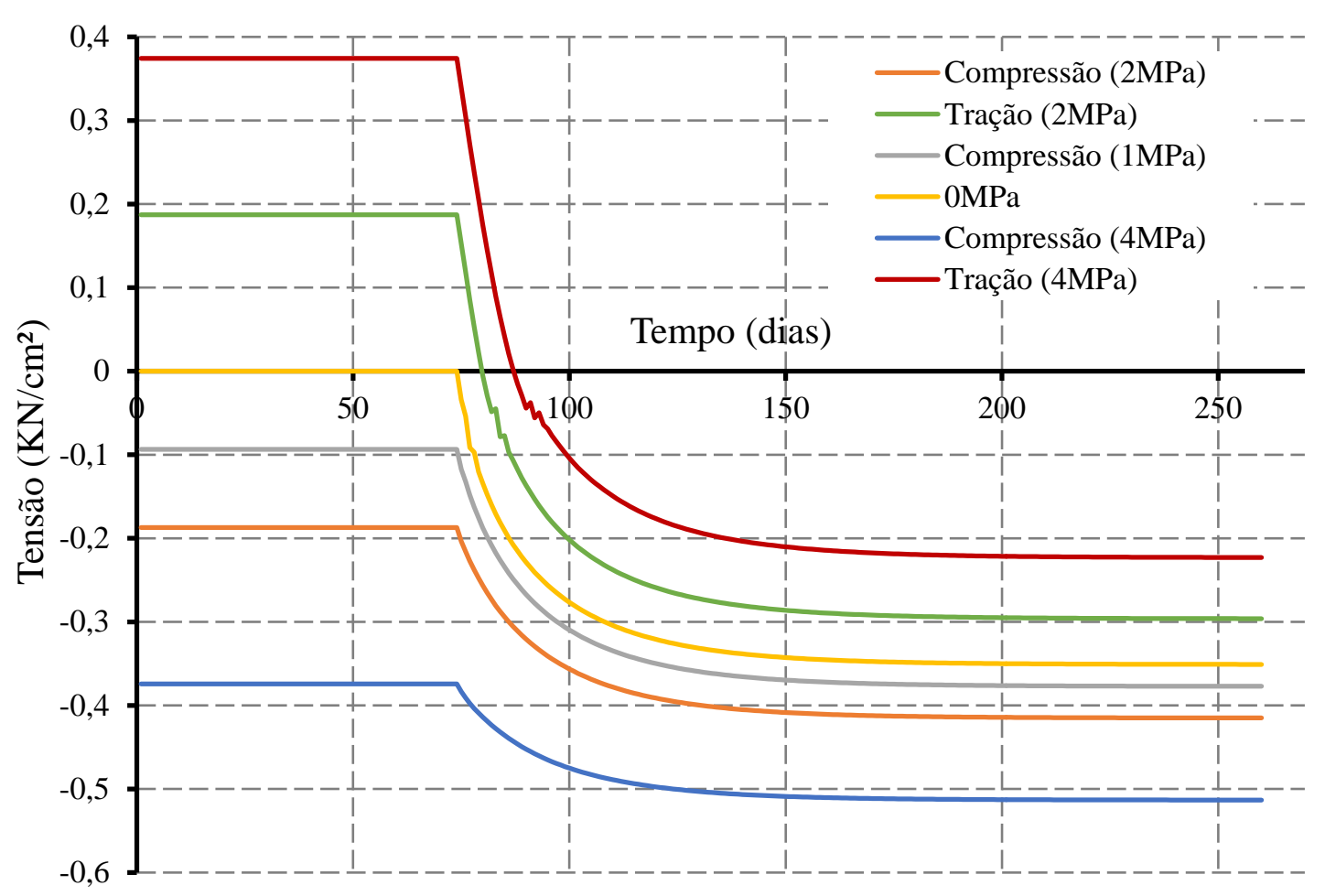

Figura 6.29 - Tensão na direção y para corpos de prova sob diferentes níveis de tensão e contendo 1\% de armadura.

Da Figura 6.29 é possível observar que as tensões no ponto permanecem constantes e muito próximas das tensões que são aplicadas, a partir do momento em que a reação tem início (momento em que $t^{p}=75$ dias), as tensões na matriz de concreto começam a reduzir em função da restrição ao deslocamento vertical imposta pela armadura. Também é possível observar que, mesmo para o caso em que não existem tensões aplicadas no corpo de prova (0MPa), as tensões de compressão desenvolvidas chegam a alcançar cerca de $0,35 \mathrm{KN} / \mathrm{cm}^{2}$.

As Figuras 6.30 e 6.31 ilustram os deslocamentos verticais obtidos aos 260 dias e as tensões desenvolvidas nesta direção para corpos de prova submetidos a 0MPa, 2MPa de tração e 2MPa de compressão. 


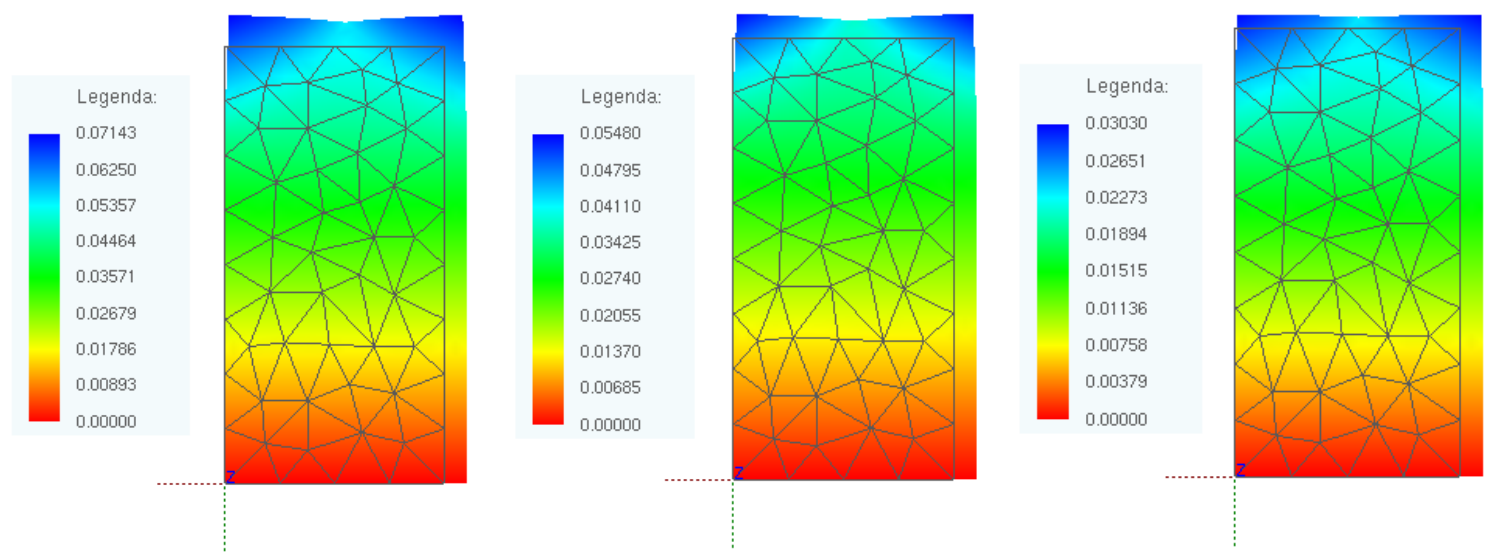

Figura 6.30 - Deslocamento vertical aos 260 dias (em cm) (a) para tensão de tração aplicada de 2MPa; (b) para tensão aplicada de 0MPa; (c) para tensão de compressão aplicada de 2MPa.
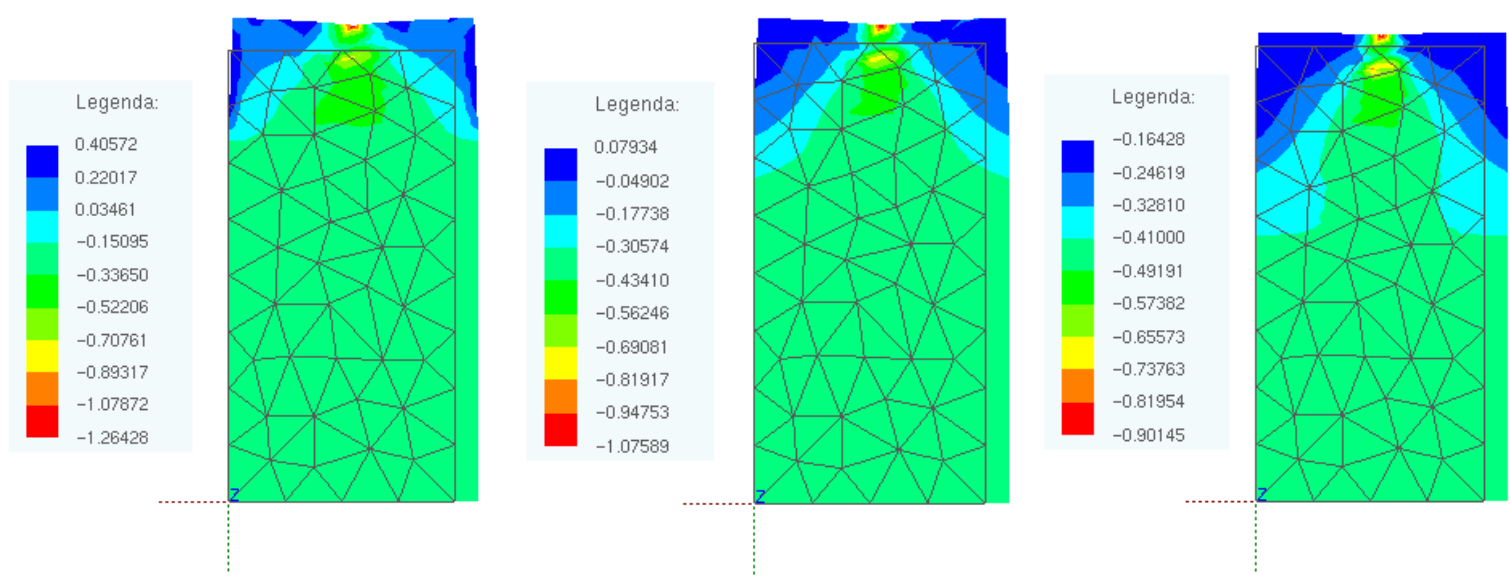

Figura 6.31 - Tensões desenvolvidas na direção y aos 260 dias (em KN/cm²) (a) para tensão de tração aplicada de 2MPa; (b) para tensão aplicada de 0MPa; (c) para tensão de compressão aplicada de 2MPa.

A comparação dos resultados obtidos numericamente com os resultados experimentais de Jones e Clark (1996) permitem afirmar que a normalização logarítmica de tensões proposta por Léger et al. (1996) é a que melhor representa tanto o caso em que as tensões de compressão são induzidas, como o caso em que as tensões são aplicadas e induzidas simultaneamente, dessa forma, os exemplos apresentados na sequência utilizam a normalização logarítmica de tensões.

Nesse ponto também vale destacar que o modelo numérico diverge dos resultados experimentais no caso em que as tensões são apenas aplicadas, o que pode estar associado ao fenômeno de fluência atuando sobre as amostras ensaiadas e que não é considerado no modelo numérico. Apesar de alguns pesquisadores como, por exemplo, Pappalardo Jr. et al. (2000) afirmarem que a RAA tende a intensificar a fluência do concreto, outros pesquisadores, como 
Serega et al. (2015), afirmam que o efeito da fluência pode ser desconsiderado sem grande prejuízo no caso de modelagem de estruturas em concreto massa.

\subsection{Exemplo 5: Expansão em prisma de concreto armado}

O objetivo deste exemplo é avaliar a expansão por RAA de prismas de concreto armado. Os resultados obtidos por meio do modelo numérico são comparados com os resultados do trabalho experimental de Fan e Hanson (1998).

Fan e Hanson (1998) analisaram experimentalmente prismas de concreto armado contendo agregado reativo com a geometria representada na Figura 6.32. Uma das amostras (sem armadura) foi sujeita à expansão livre, já outra foi reforçada ao longo da maior dimensão por barras de armadura No. 3, com diâmetro de 9,5mm.

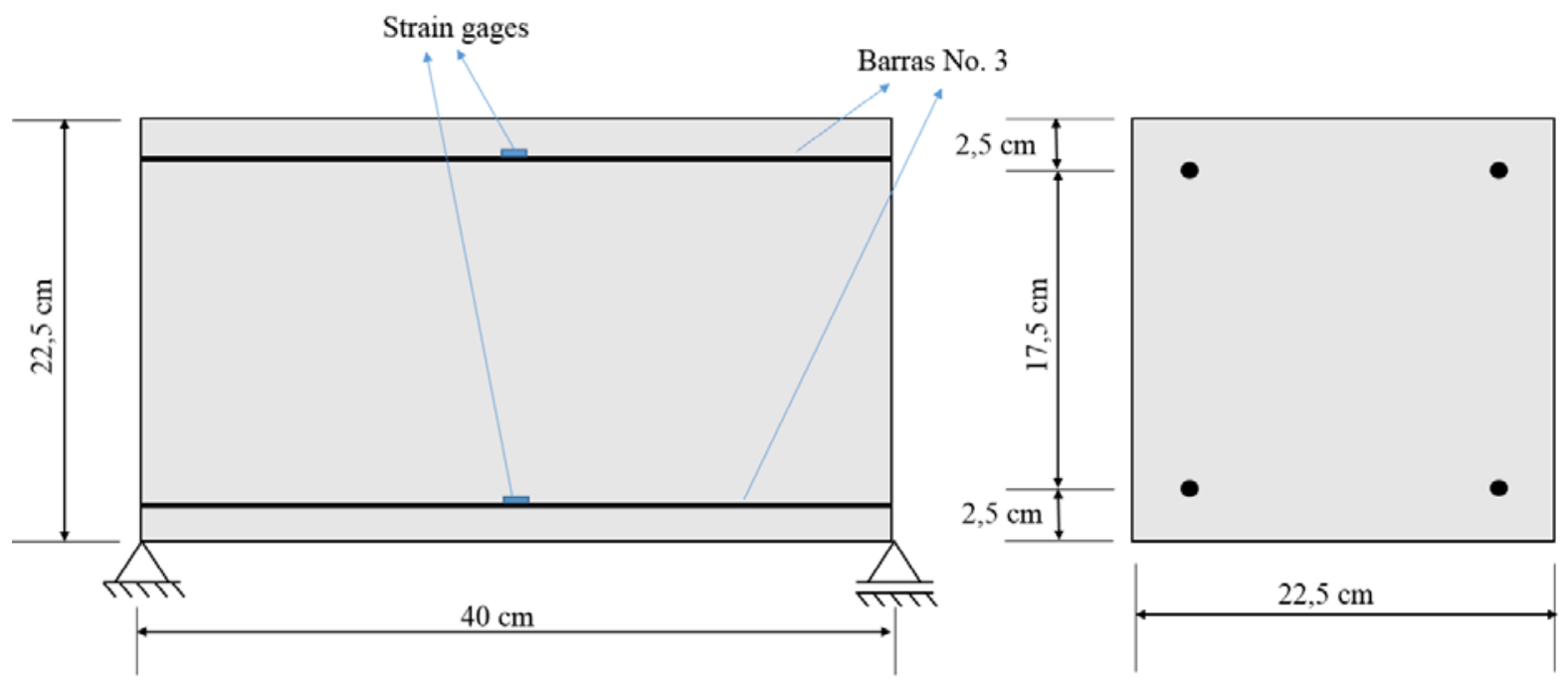

Figura 6.32 - Configuração dos prismas de concreto armado afetados pela RAA.

Todas as amostras foram mantidas imersas em água e à temperatura de $38^{\circ} \mathrm{C}$ durante 360 dias.

O modelo numérico utilizado para representar o prisma de concreto foi discretizado em 448 elementos finitos triangulares com módulo de elasticidade $E=3299 \mathrm{KN} / \mathrm{cm}^{2}$ e coeficiente de Poisson $v=0,2$. As barras de armadura foram discretizadas em 80 elementos finitos lineares com módulo de elasticidade $E=21000 \mathrm{KN} / \mathrm{cm}^{2}$ e resistência à tração de 43,3KN/cm² .

A Tabela 6.5 apresenta as variáveis de projeto e calibração empregadas neste exemplo. 
Tabela 6.5 - Variáveis de projeto e de calibração para a RAA.

\begin{tabular}{cc}
\multicolumn{3}{c}{ Variáveis } \\
\hline$A_{2}$ & 750 dias \\
$\varepsilon_{v o l}^{\max }$ & 0,0138 \\
$t^{p}$ & 115 dias \\
$k_{m}, k_{p}$ & 1,0 \\
$k_{t}$ & 0,2 \\
$k_{c}$ & 0,0 \\
\hline
\end{tabular}

A Figura 6.33 apresenta a comparação dos resultados numéricos e experimentais para a expansão longitudinal, tanto da amostra sujeita à expansão livre (sem armadura) quanto da amostra contendo armadura.

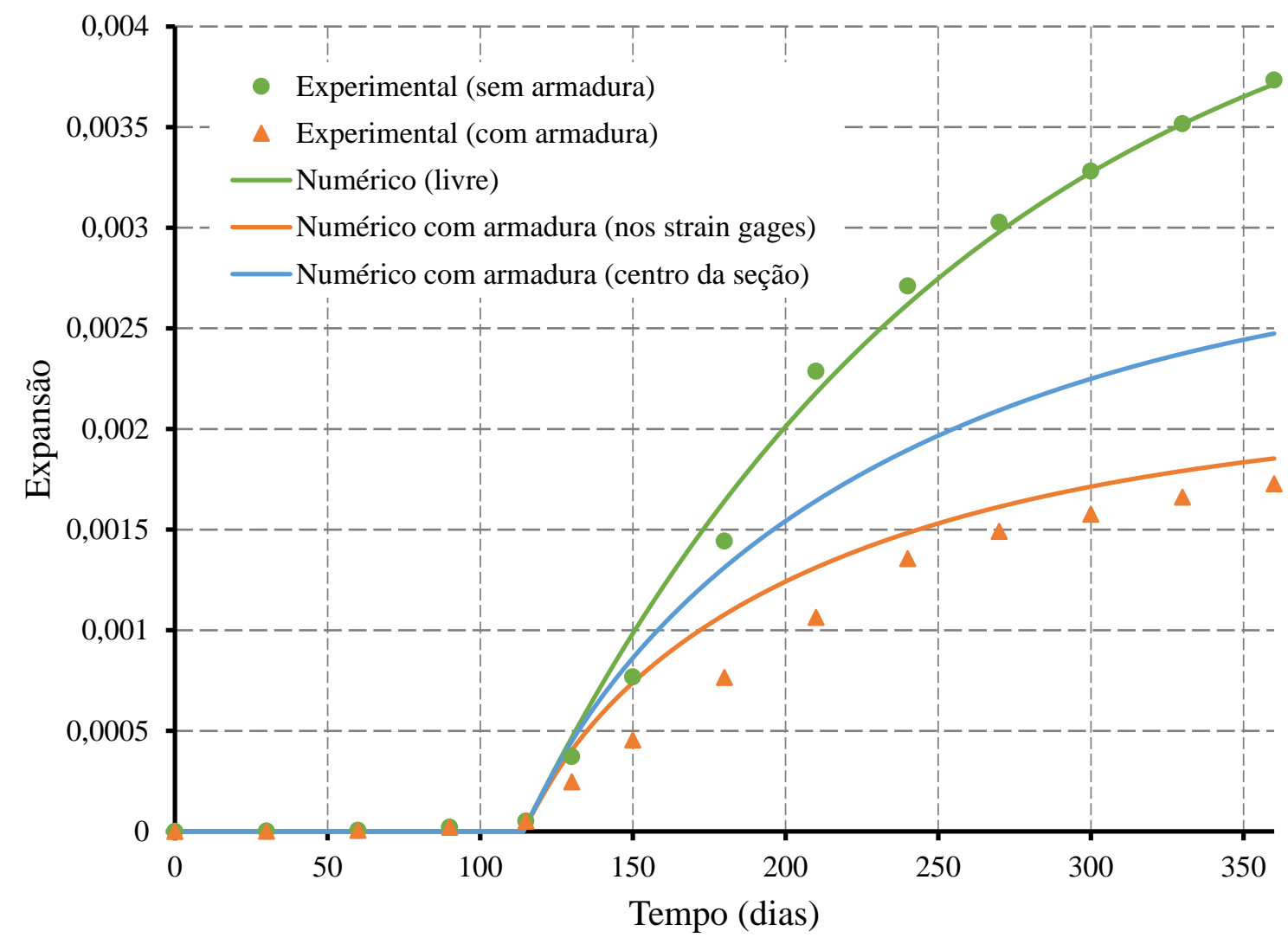

Figura 6.33 - Expansão do prisma em concreto armado afetado por RAA.

Os valores de expansão para o prisma de concreto armado apresentados na Figura 6.33 foram obtidos experimentalmente por meio da média das medidas obtidas em quatro strain gages instalados nas barras de armadura. Observa-se que a presença de barras de armadura reduz cerca de $50 \%$ a expansão por RAA. 
Na Figura 6.33 também é apresentada a curva numérica de expansão para a região central do prisma de concreto, região mais distante das armaduras. Verifica-se que a expansão para essa região é maior do que para a região próxima à armadura, em função da menor restrição ao deslocamento nessa região, como ilustra a Figura 6.34.

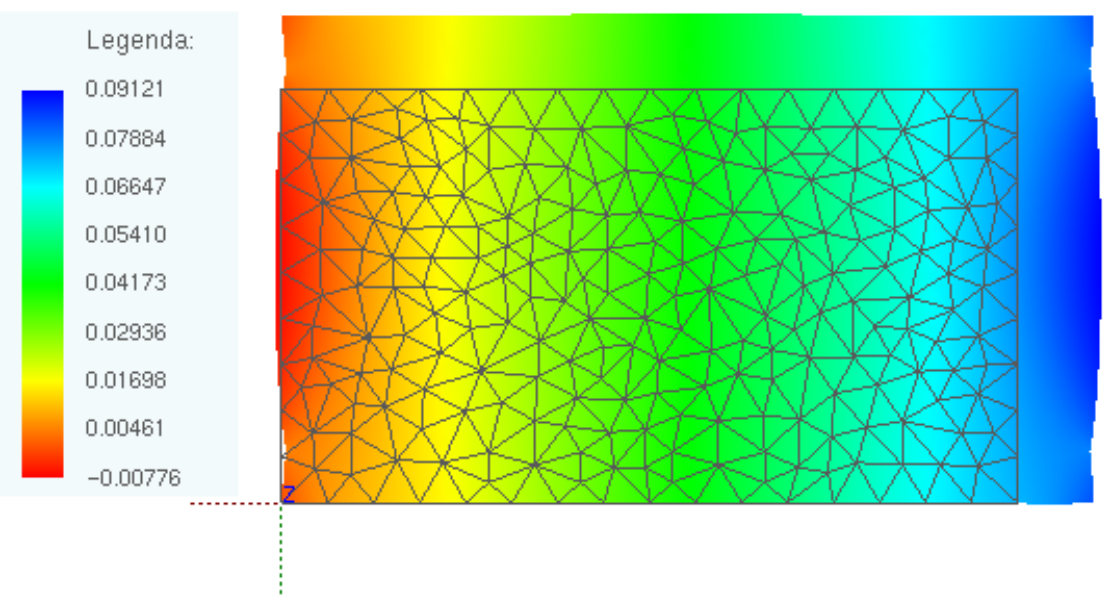

Figura 6.34 - Deslocamento horizontal aos 360 dias para o prisma de concreto armado (em cm).

O experimento realizado por Fan e Hanson (1998) ainda apresenta as diferenças entre os padrões de fissuração observados para o prisma de concreto, com e sem armadura (Figura 6.35), podendo-se verificar que o padrão de fissuração para o prisma armado passa a ser orientado e com fissuras mais espessas $(0,5 \mathrm{~mm})$.

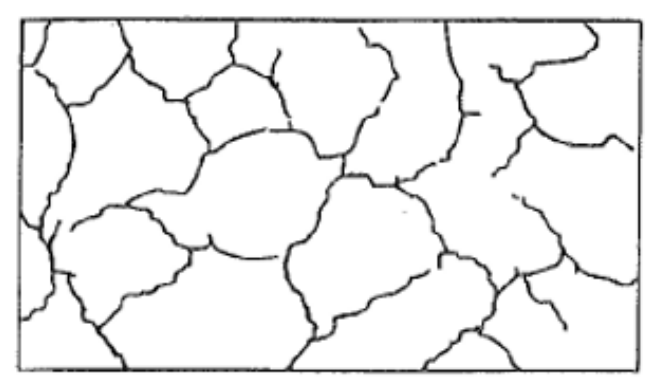

(a)

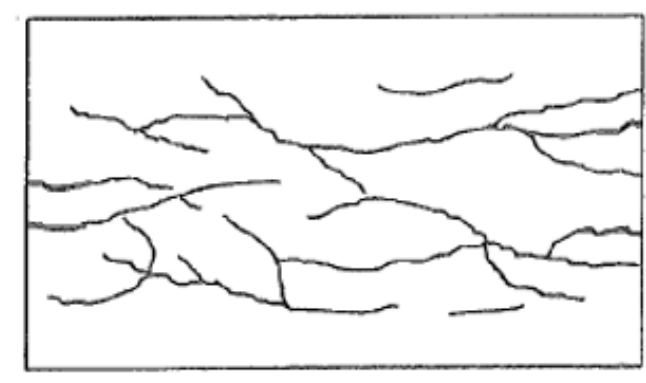

(b)

Figura 6.35 - Fissuração para o prisma de concreto aos 360 dias (a) sem armadura; (b) com armadura. Fonte: Fan e Hanson (1998)

Nas amostras armadas, a expansão por RAA gera deformação nas barras de armadura. A deformação das armaduras do prisma ensaiado gera uma tensão de compressão no concreto de $0,22 \mathrm{KN} / \mathrm{cm}^{2}$ aos 360 dias. Dessa forma, a Figura 6.36 indica as tensões de compressão 
induzidas na direção paralela à armadura (direção $x$ ), obtidas por meio do modelo numérico para um nó localizado na região central do prisma e para região próxima aos strain gages.

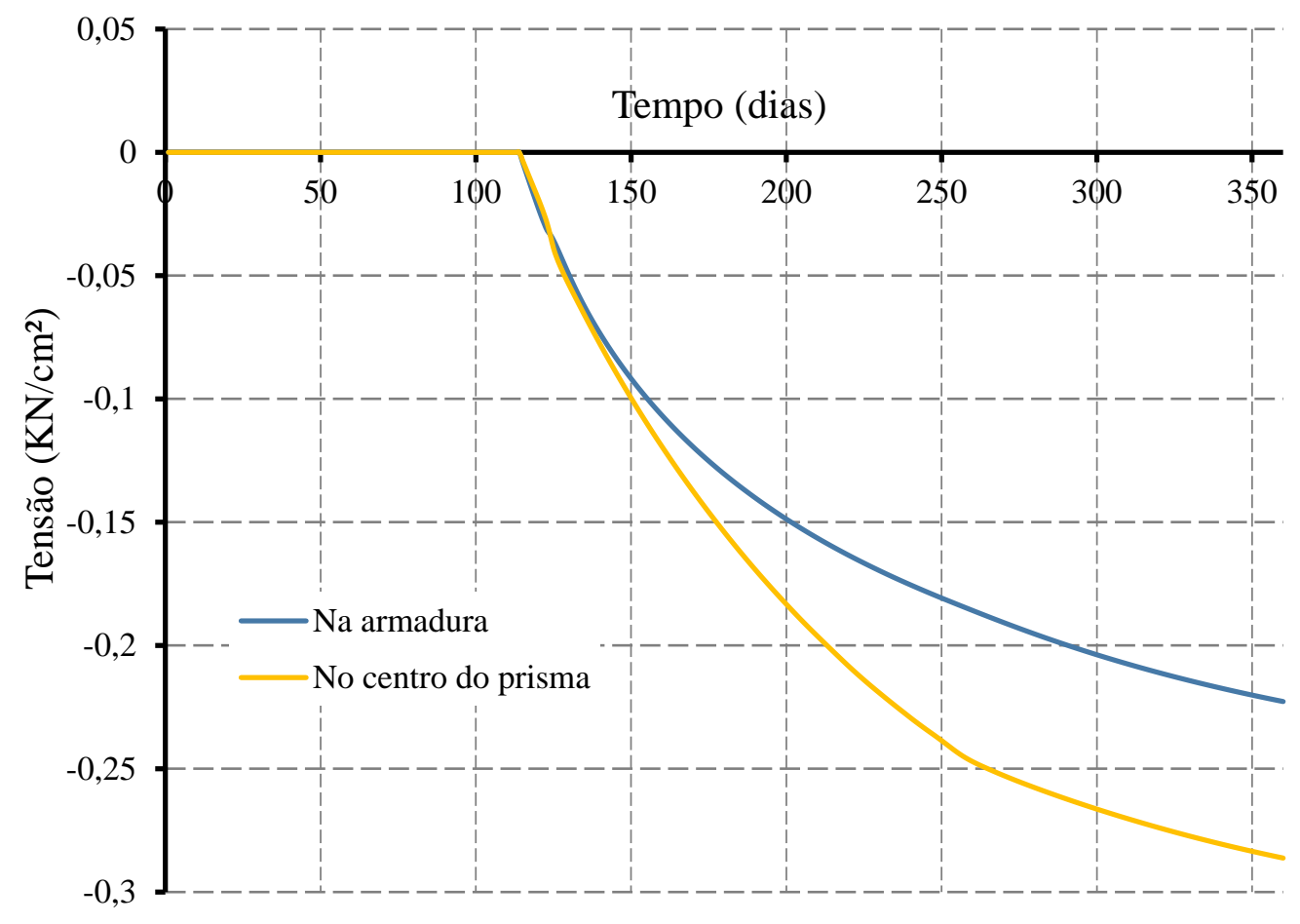

Figura 6.36 - Tensão na direção $x$ induzida no prisma de concreto.

Da Figura 6.36, observa-se que a tensão aos 360 dias para região próxima aos strain gages atinge uma tensão de compressão de aproximadamente $-0,22 \mathrm{KN} / \mathrm{cm}^{2}$, mesma tensão obtida experimentalmente.

Na Figura 6.36 também é apresentada a tensão induzida no centro do prisma. Verificase que esta tensão é maior do que a tensão desenvolvida próximo às armaduras, em função do efeito de confinamento atuando na região central do prisma. A Figuras 6.37 ilustra a evolução da tensão na direção $x$ (paralela à armadura) com a expansão por RAA. 


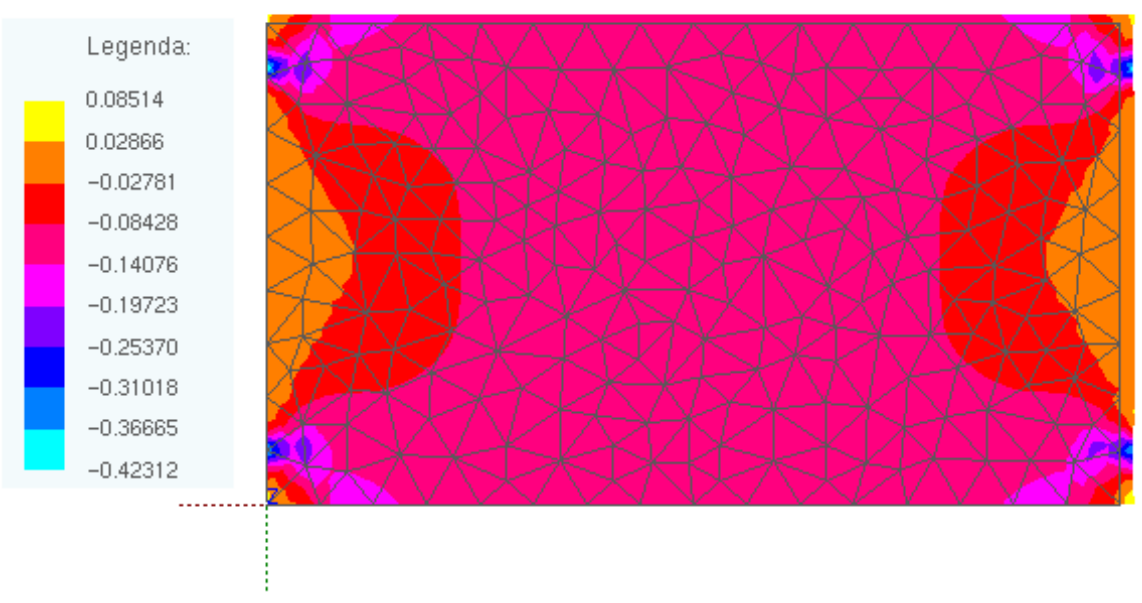

150 dias

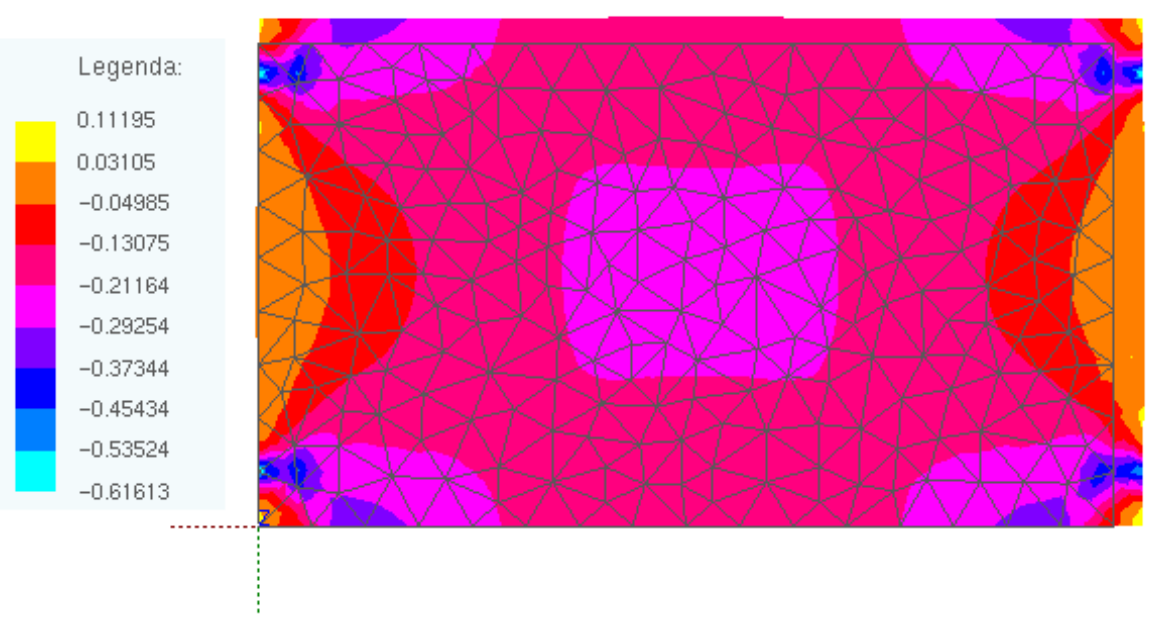

250 dias

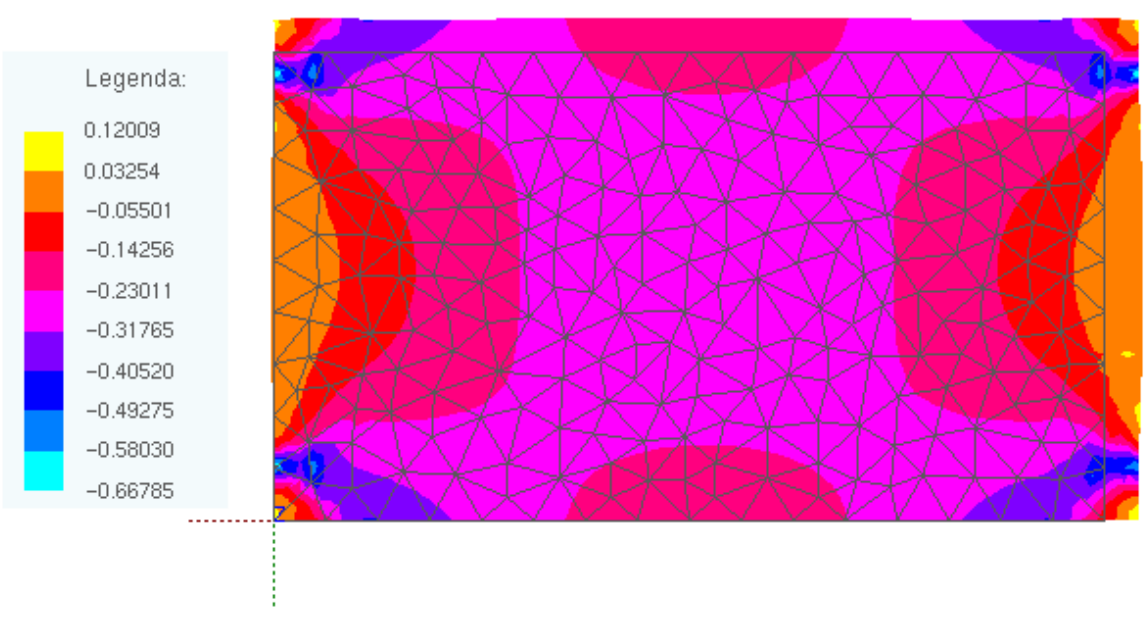

360 dias

Figura 6.37 - Tensões induzidas na direção $x$ no prisma de concreto $\left(\mathrm{em} \mathrm{KN} / \mathrm{cm}^{2}\right)$. 
Fan e Hanson (1998) também indicam que a deformação das armaduras não aumenta após os 360 dias indicando que possivelmente ocorra escorregamento das armaduras em função do aumento das fissuras no concreto.

\subsection{Exemplo 6: Expansão de prisma contendo fibras}

Este exemplo avalia a validade da normalização logarítmica de tensões proposta por Léger et al. (1996) para o caso de prismas de concreto reforçados com fibras metálicas dispersas aleatoriamente. Os resultados obtidos por meio do modelo numérico são comparados com os resultados do trabalho experimental de Giaccio et al. (2015).

Giaccio et al. (2015) analisaram experimentalmente prismas de concreto reforçados com fibras metálicas afetados por RAA, com geometria representada na Figura 6.38. Foram incorporadas $0,5 \%$ de fibras metálicas com $5 \mathrm{~cm}$ de comprimento e $1 \mathrm{~mm}$ de diâmetro.
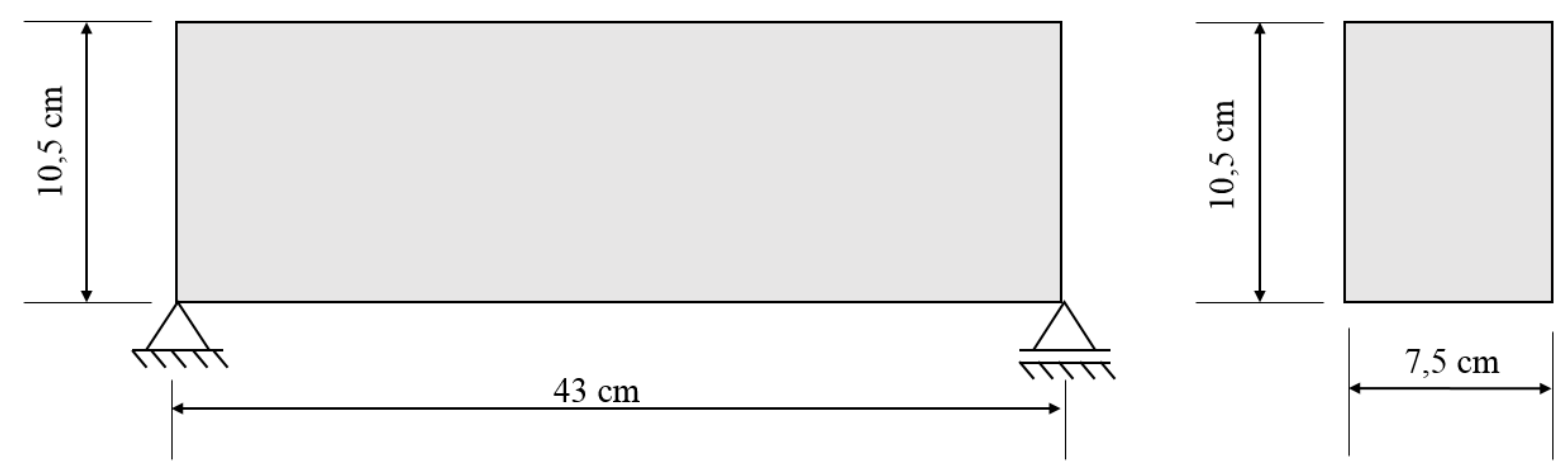

Figura 6.38 - Configuração dos prismas de concreto reforçados com fibras e afetados pela RAA.

Todas as amostras foram mantidas à umidade de $100 \%$ e à temperatura de $22^{\circ} \mathrm{C}$ durante 370 dias.

O modelo numérico utilizado para representar o prisma de concreto foi discretizado em 474 elementos finitos triangulares com módulo de elasticidade $E=3640 \mathrm{KN} / \mathrm{cm}^{2}$ e coeficiente de Poisson $v=0,2$. As fibras foram discretizadas em 58 elementos finitos lineares com módulo de elasticidade $E=21000 \mathrm{KN} / \mathrm{cm}^{2}$ distribuídas aleatoriamente na chapa de concreto.

A Tabela 6.6 apresenta as variáveis de projeto e calibração empregadas neste exemplo. 
Tabela 6.6 - Variáveis de projeto e de calibração para a RAA.

\begin{tabular}{cc}
\multicolumn{2}{c}{ Variáveis } \\
\hline$A_{2}$ & 370 dias \\
$\varepsilon_{v o l}^{\max }$ & 0,0066 \\
$t^{p}$ & 40 dias \\
$k_{m}, k_{p}$ & 1,0 \\
$k_{t}$ & 0,2 \\
$k_{c}$ & 0,0 \\
\hline
\end{tabular}

A Figura 6.39 apresenta a comparação dos resultados numéricos e experimentais para a expansão longitudinal, tanto da amostra sujeita à expansão livre quanto da amostra contendo fibras.

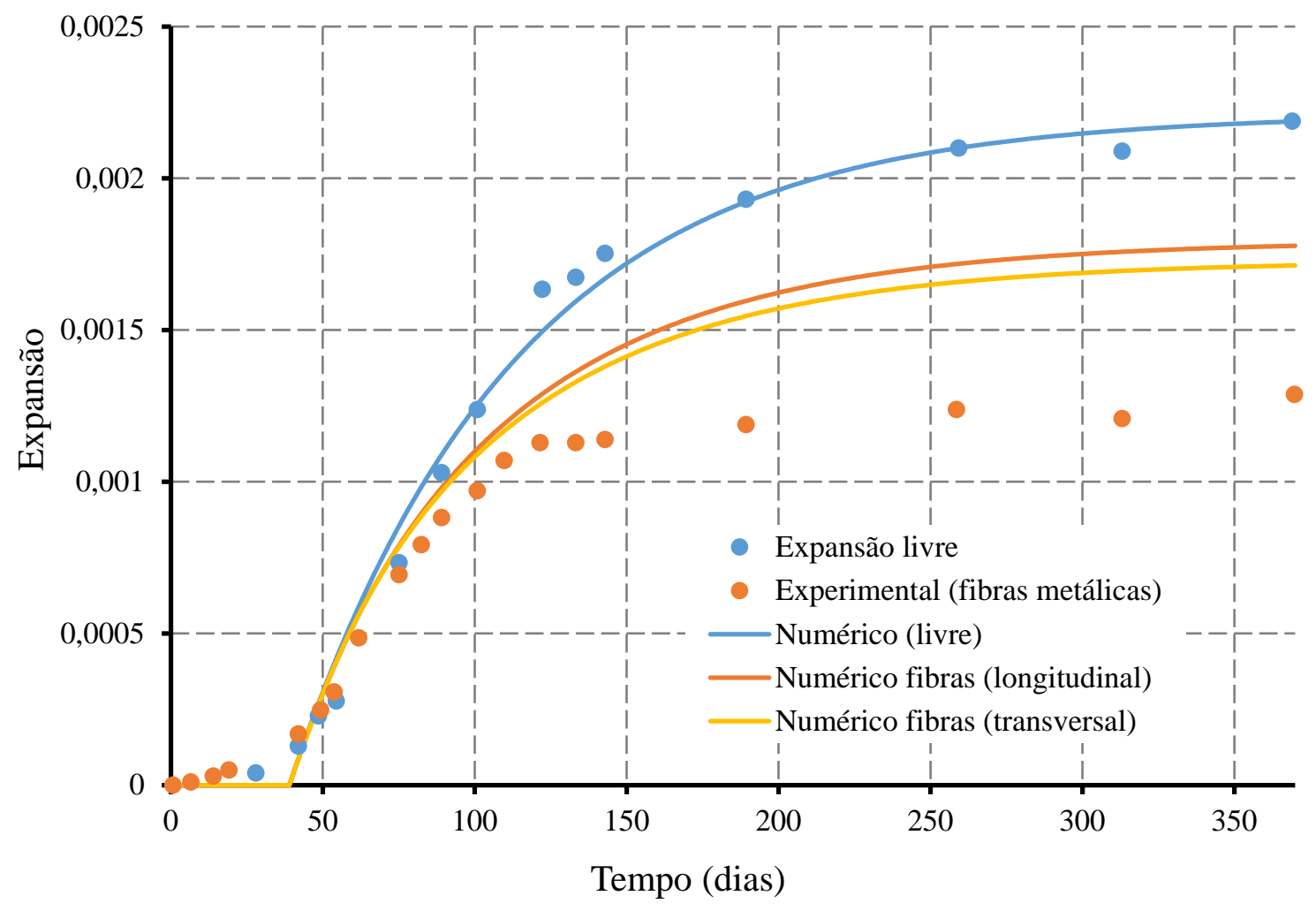

Figura 6.39 - Expansão do prisma de concreto reforçado com fibras afetado por RAA.

É possível verificar na Figura 6.39, que apesar da curva numérica de expansão para o concreto reforçado com fibras ter sua magnitude reduzida, seu comportamento ainda difere da curva experimental de expansão. Essa diferença pode estar associada ao fato de as fibras metálicas utilizadas nos experimentos apresentarem ganchos nas suas extremidades, o que não é considerado no modelo numérico, gerando assim deformações maiores do que os resultados 
experimentais. Outra possibilidade é que tenha ocorrido a plastificação das fibras, o que também limitaria a sua expansão.

Ainda é possível que tenha ocorrido um ordenamento das fibras metálicas ao longo da maior dimensão do prisma, dessa forma, é proposta a substituição dos 0,5\% de fibras metálicas dispersas aleatoriamente pela mesma taxa de armadura, conforme a configuração das Figuras 6.40 e 6.41.
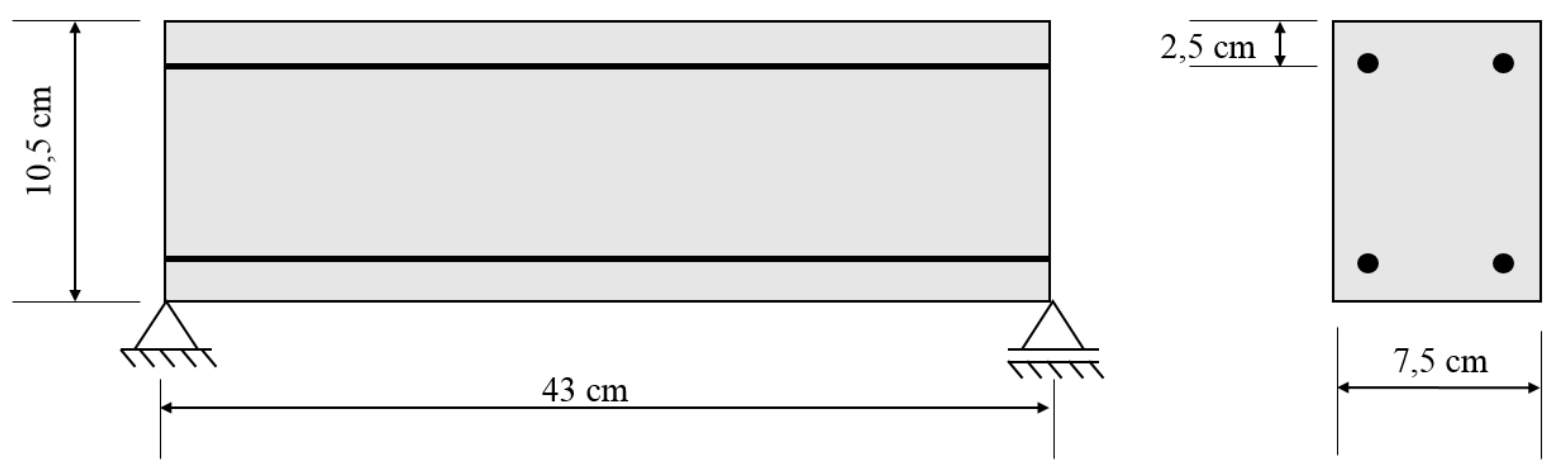

Figura 6.40 - Configuração alternativa para o prisma de concreto afetado por RAA contendo 0,5\% de armadura.
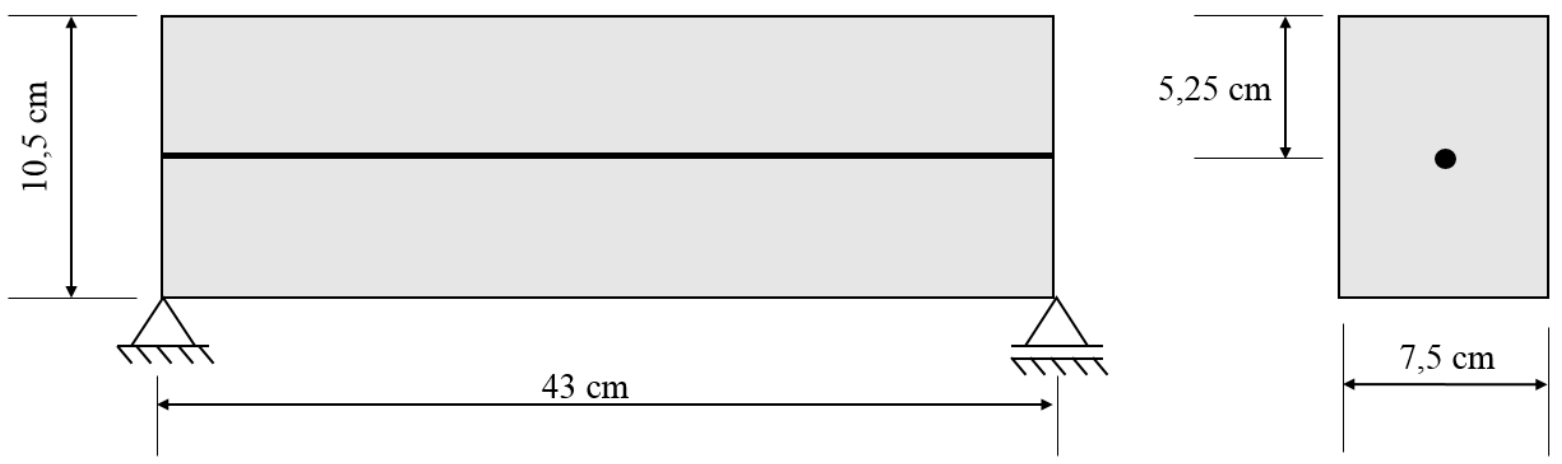

Figura 6.41 - Configuração alternativa para o prisma de concreto afetado por RAA contendo 0,5\% de armadura.

Para a configuração da Figura 6.40, os resultados numéricos de expansão encontram-se apresentados na Figura 6.42. 


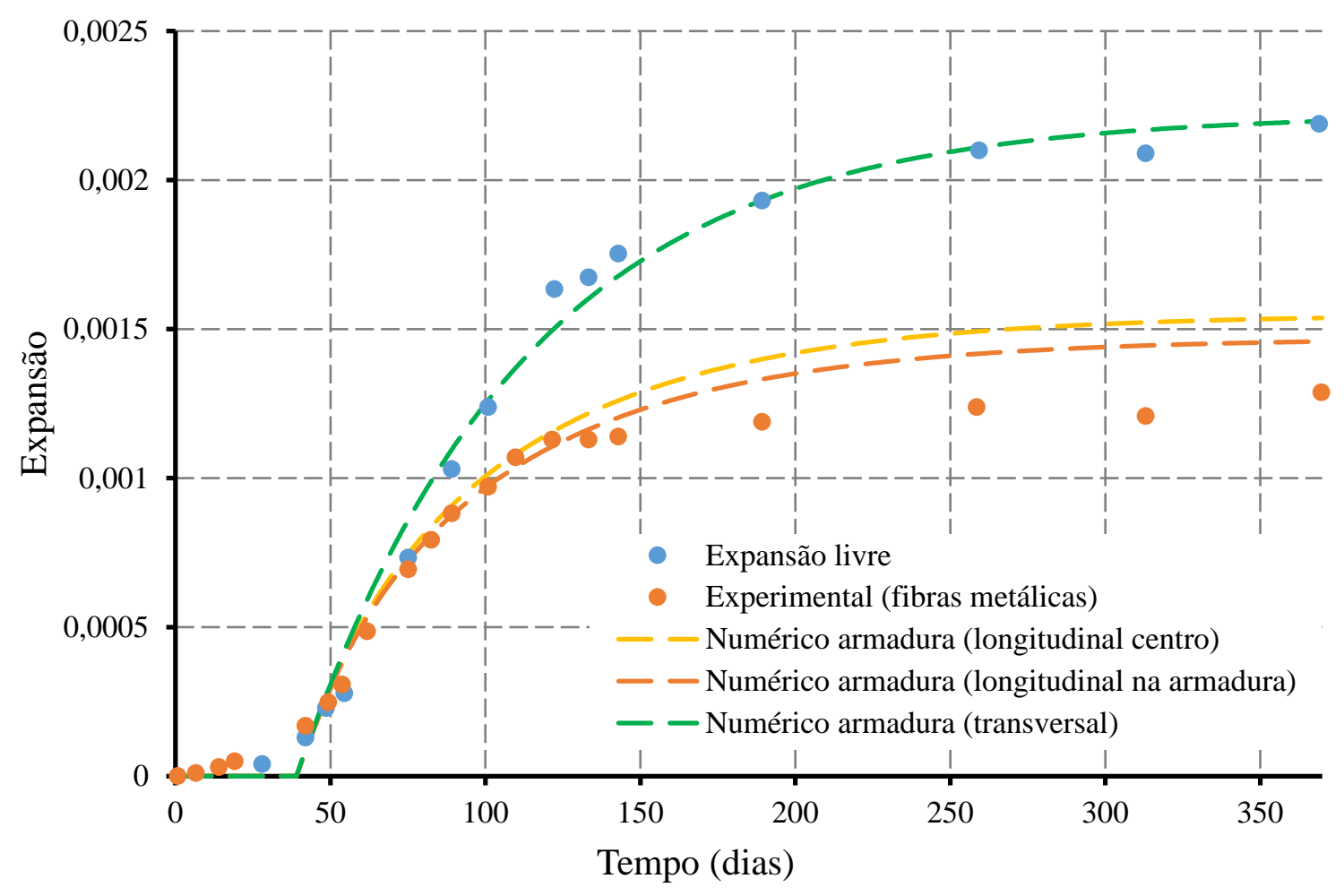

Figura 6.42 - Expansão do prisma em concreto armado (configuração da Figura 6.40).

Observa-se na Figura 6.42, que a expansão longitudinal obtida numericamente para o prisma contendo $0,5 \%$ de armadura apresenta resultados que se assemelham mais aos resultados obtidos experimentalmente. Ressalta-se ainda que a expansão transversal obtida nesse caso se assemelha à expansão livre do concreto pelo fato de os elementos de treliça que discretizam a armadura aumentarem a rigidez apenas em uma de suas direções.

Para a configuração apresentada na Figura 6.41, os resultados numéricos da expansão encontram-se na Figura 6.43. Verifica-se, novamente, que a curva numérica obtida substituindo-se as fibras distribuídas aleatoriamente por uma única barra de armadura centrada no prisma de concreto se aproxima mais dos resultados experimentais. 


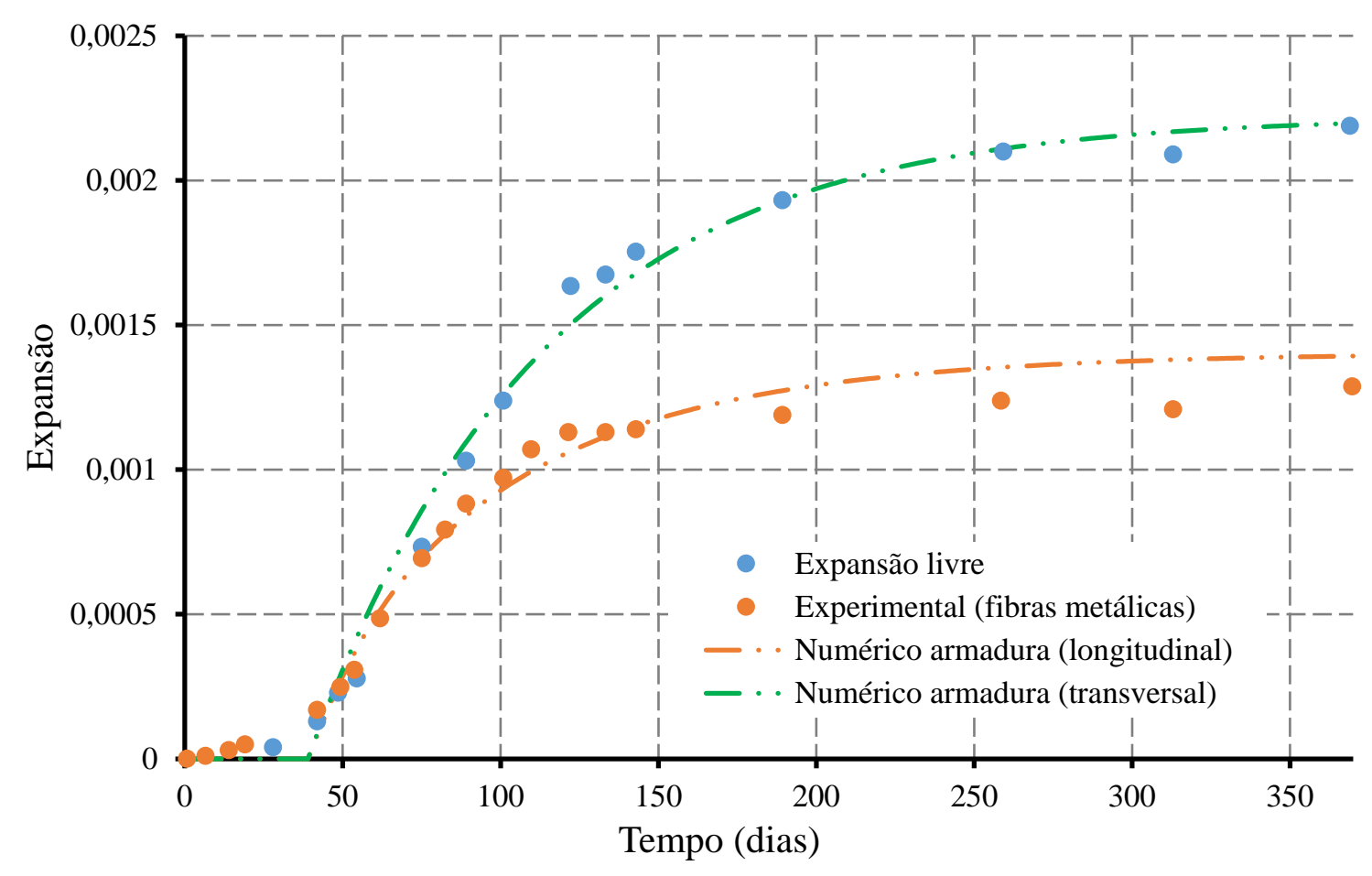

Figura 6.43 - Expansão do prisma em concreto armado (configuração da Figura 6.41).

De qualquer forma, o modelo numérico aqui apresentado não é capaz de representar devidamente a redução da expansão por RAA em concretos reforçados com fibras dispersas aleatoriamente.

As Figuras 6.44, 6.45 e 6.46 ilustram as tensões na direção $x$ (direção longitudinal) distribuídas na matriz de concreto em função da restrição promovida por armadura e fibras. Percebe-se que o comportamento da evolução das tensões para o caso de concreto reforçado com fibras é distinto do comportamento de concretos contendo armadura. Enquanto nos prismas de concreto armado as tensões de compressão se desenvolvem de uma maneira uniforme na matriz, o mesmo não acontece para os prismas de concreto contendo fibras. Neste caso, as tensões desenvolvidas, além de apresentarem magnitudes reduzidas quando comparadas às tensões desenvolvidas nas amostras de concreto armado, ainda apresentam uma distribuição não-uniforme na matriz, com regiões de concentração de tensões próximas às fibras. 


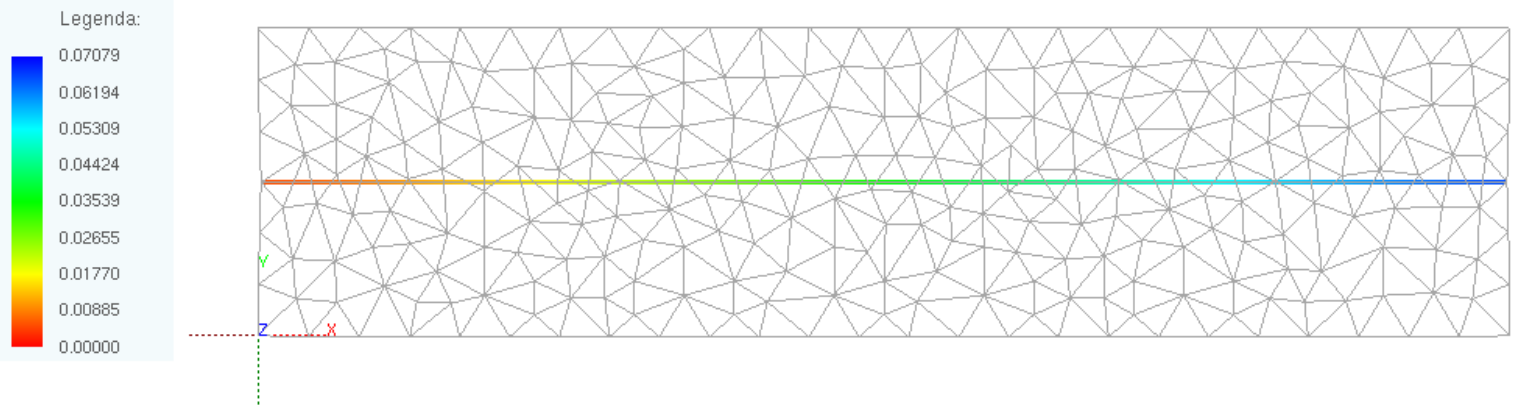

Figura 6.44 - (a) Deslocamento horizontal do prisma de concreto armado (em cm).

Figura 6.44 - (b) Tensões induzidas na direção $x$ no prisma de concreto armado (em KN/cm²).
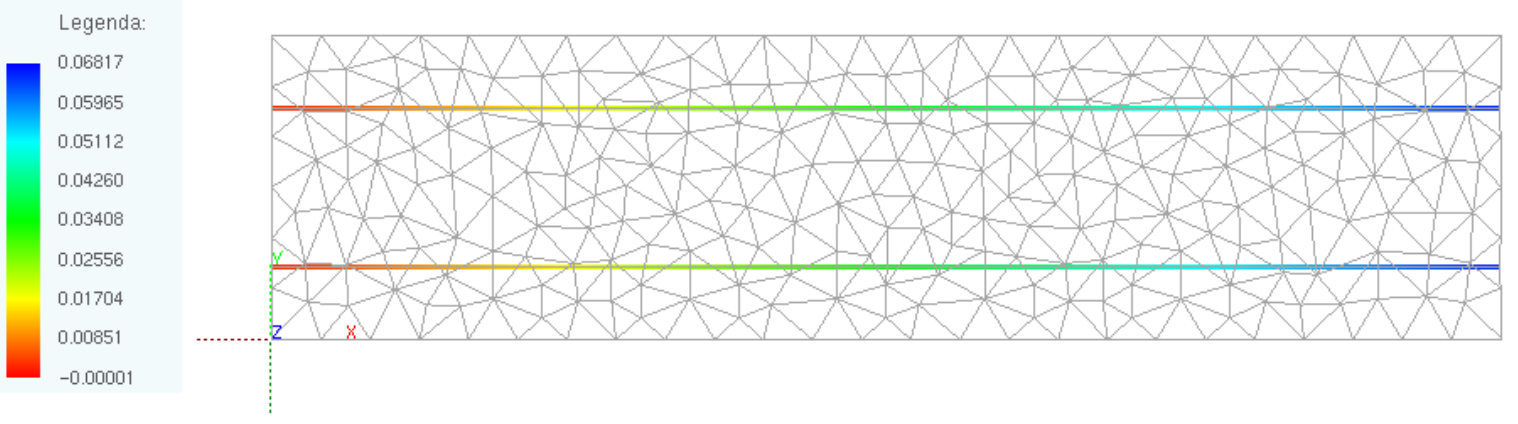

Figura 6.45 - (a) Deslocamento horizontal do prisma de concreto armado (em cm).

\begin{tabular}{|l}
\hline Legenda: \\
\hline 0.16020 \\
0.08758 \\
0.01497 \\
-0.05765 \\
-0.13027 \\
-0.20289 \\
-0.27551 \\
-0.34812 \\
-0.42074 \\
-0.49336
\end{tabular}

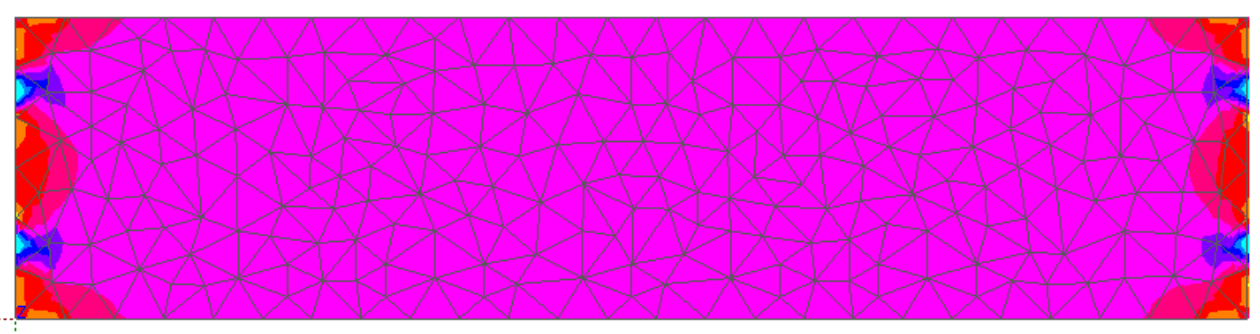

Figura 6.45 - (b) Tensões induzidas na direção $x$ no prisma de concreto armado (em KN/cm²). 


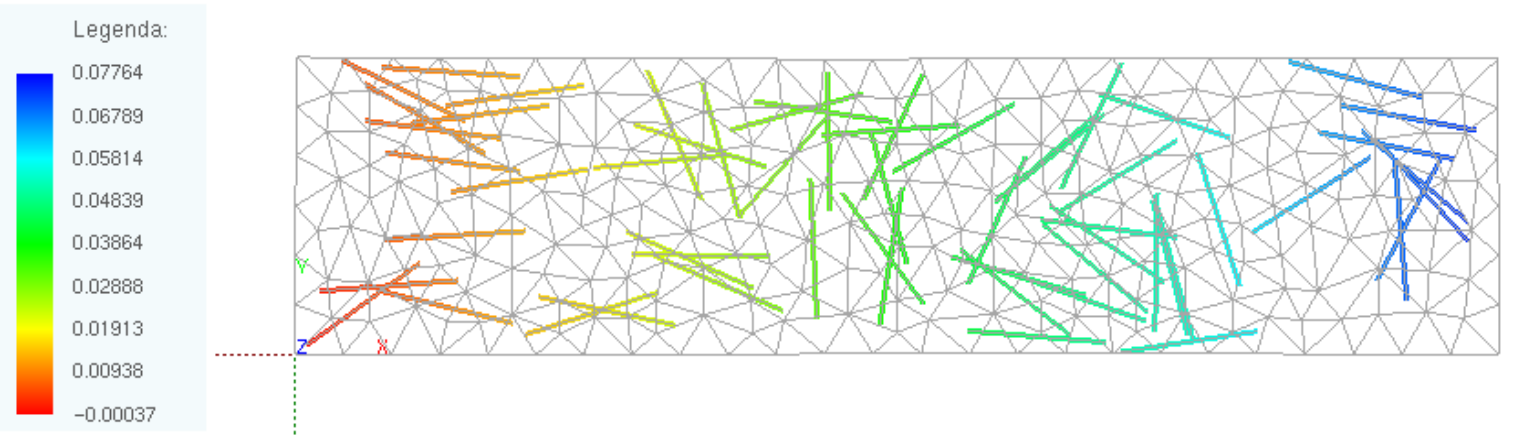

Figura 6.46 - (a) Deslocamento horizontal do prisma de concreto reforçado com fibras (em cm).

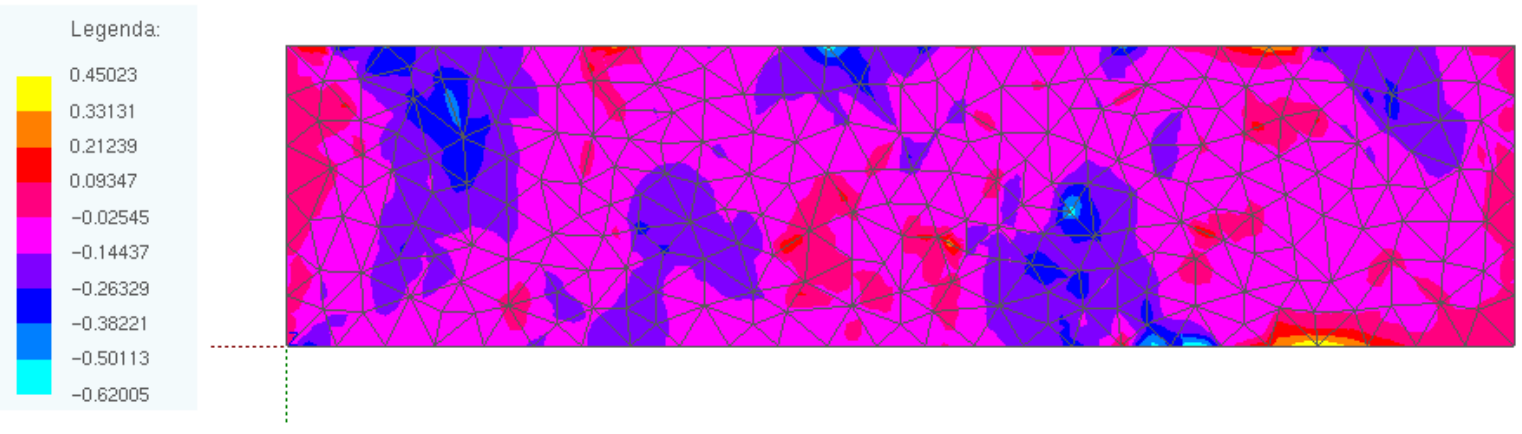

Figura 6.46 - (b) Tensões induzidas na direção $x$ no prisma de reforçado com fibras $\left(\mathrm{em} \mathrm{KN} / \mathrm{cm}^{2}\right)$.

\subsection{Exemplo 7: Viga em concreto armado sujeita à RAA}

Este exemplo tem por objetivo avaliar o efeito da redução do módulo de elasticidade no comportamento de vigas de concreto armado sujeitas à expansão por RAA. Os resultados numéricos são comparados com resultados obtidos experimentalmente por Swamy e Al-Asali (1990).

Swamy e Al-Asali (1990) analisaram experimentalmente o comportamento de vigas em concreto armado afetadas por RAA. A Figura 6.47 ilustra a geometria das vigas ensaiadas; todas foram mantidas à umidade de $100 \%$ e à temperatura de $22^{\circ} \mathrm{C}$ durante 700 dias. Uma das vigas foi sujeita à expansão livre, já outra foi reforçada ao longo da maior dimensão por 2 barras de armadura com 8mm de diâmetro e 2 barras com $6 \mathrm{~mm}$ de diâmetro. 


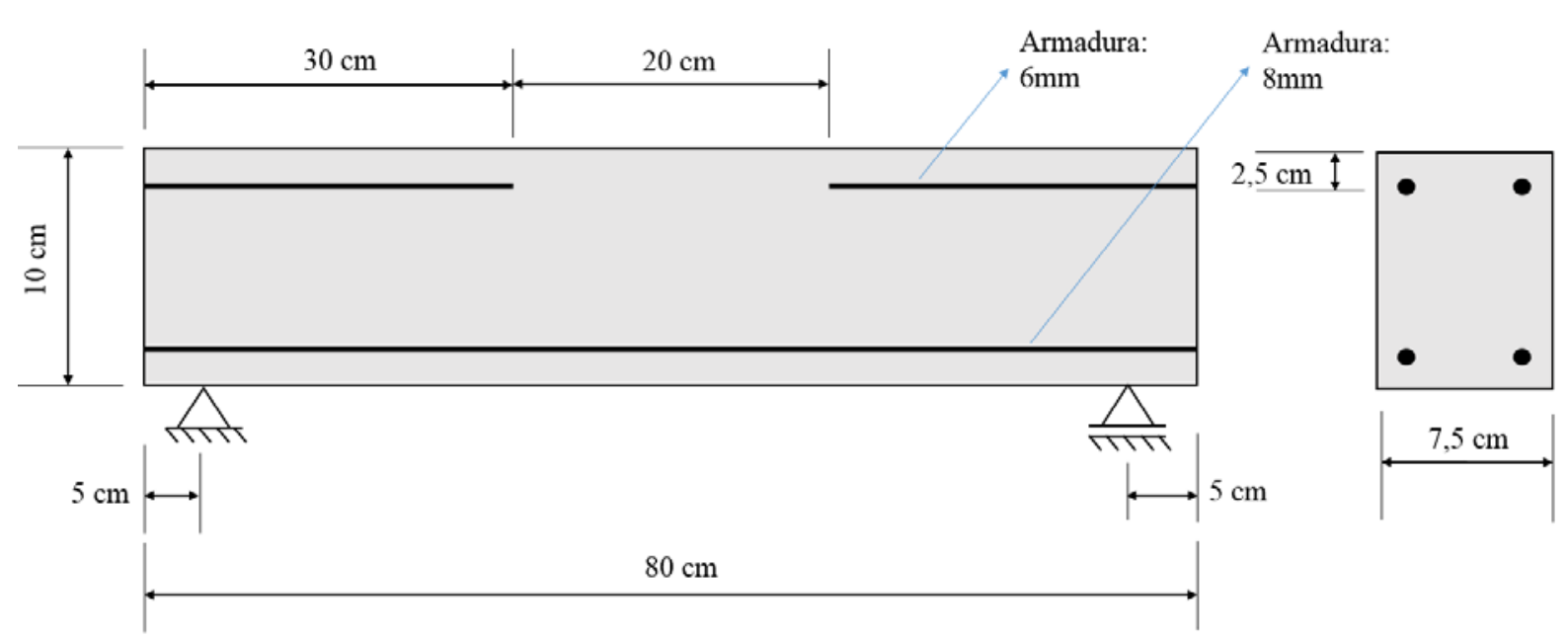

Figura 6.47 - Configuração das vigas em concreto armado sujeitas à RAA.

O modelo numérico utilizado para representar a viga de concreto foi discretizado em 614 elementos finitos triangulares com módulo de elasticidade $E=2500 \mathrm{KN} / \mathrm{cm}^{2}$ e coeficiente de Poisson $v=0,2$. As barras de armadura foram discretizadas em 70 elementos finitos lineares com módulo de elasticidade $E=21000 \mathrm{KN} / \mathrm{cm}^{2}$.

A Tabela 6.7 apresenta as variáveis de projeto e calibração empregadas no exemplo.

Tabela 6.7 - Variáveis de projeto e de calibração para a RAA.

\begin{tabular}{cc}
\multicolumn{2}{c}{ Variáveis } \\
\hline$A_{2}$ & 875 dias \\
$\varepsilon_{\text {vol }}^{\max }$ & 0,0078 \\
$t^{p}$ & 26 dias \\
$k_{m}, k_{p}$ & 1,0 \\
$k_{t}$ & 0,2 \\
$k_{c}$ & 0,0 \\
\hline
\end{tabular}

A Figura 6.48 apresenta a comparação entre os resultados obtidos experimentalmente e os resultados do modelo numérico para a expansão longitudinal da viga sujeita à expansão livre. 


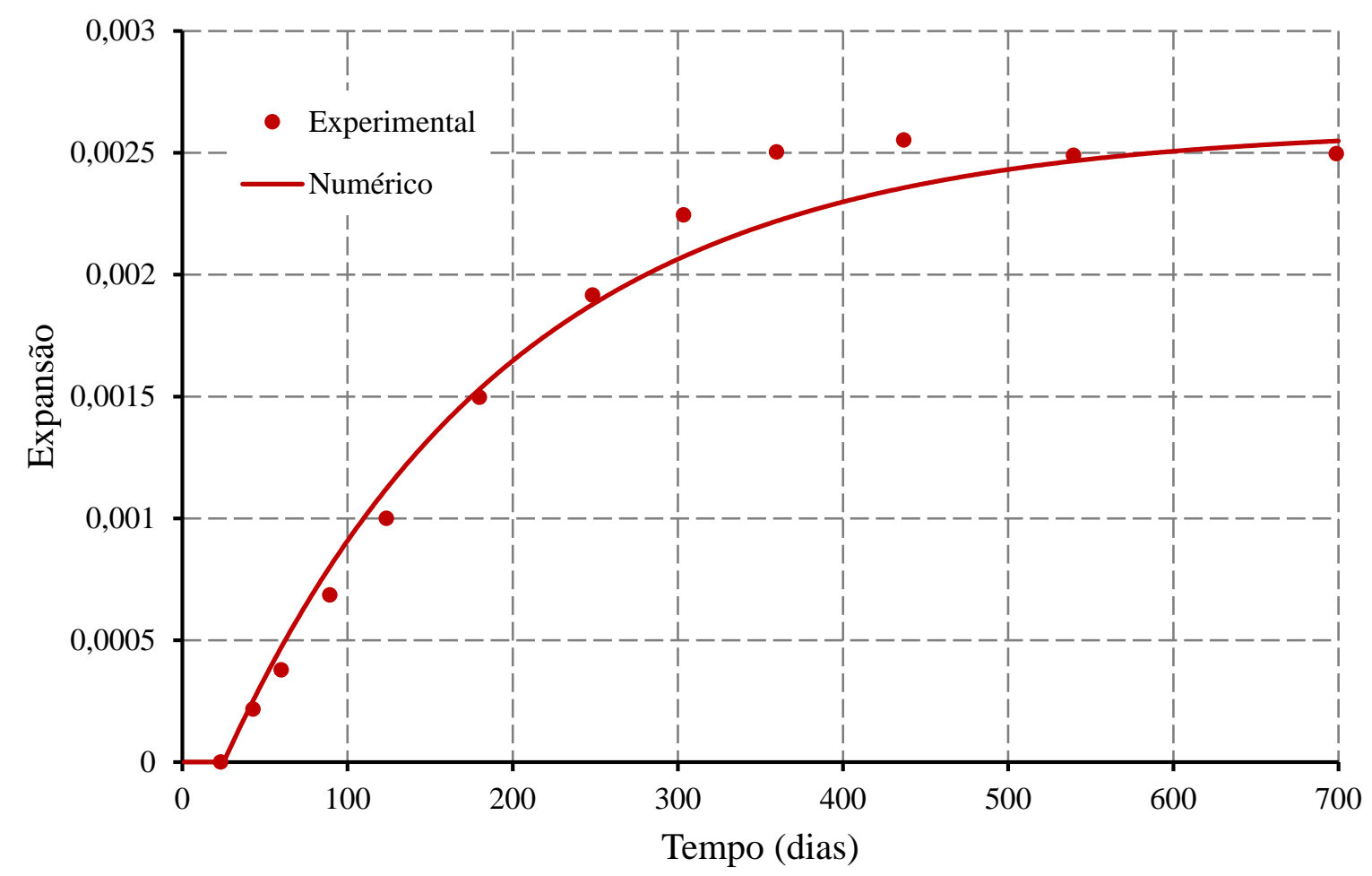

Figura 6.48 - Expansão de viga em concreto afetada por RAA.

Para a viga em concreto armado, foram obtidas experimentalmente medidas em quatro extensômetros com $10 \mathrm{~cm}$ de comprimento posicionados conforme ilustra a Figura 6.49 a seguir.

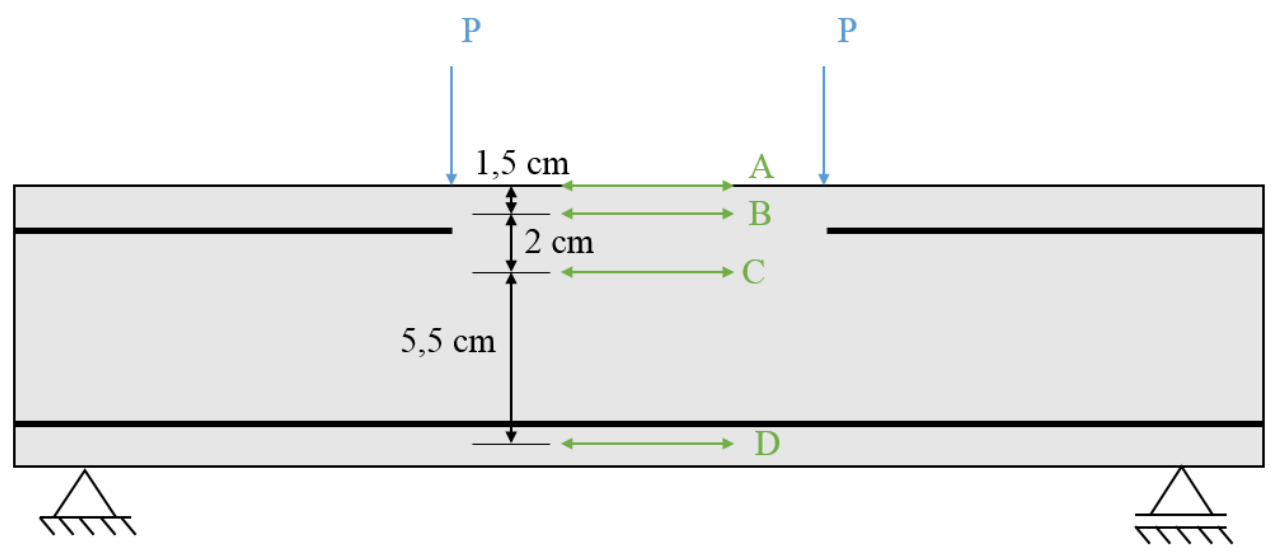

Figura 6.49 - Posição dos extensômetros na viga.

Dessa forma, a Figura 6.50 apresenta a comparação dos resultados numéricos e experimentais para as deformações longitudinais medidas em cada um dos extensômetros. 


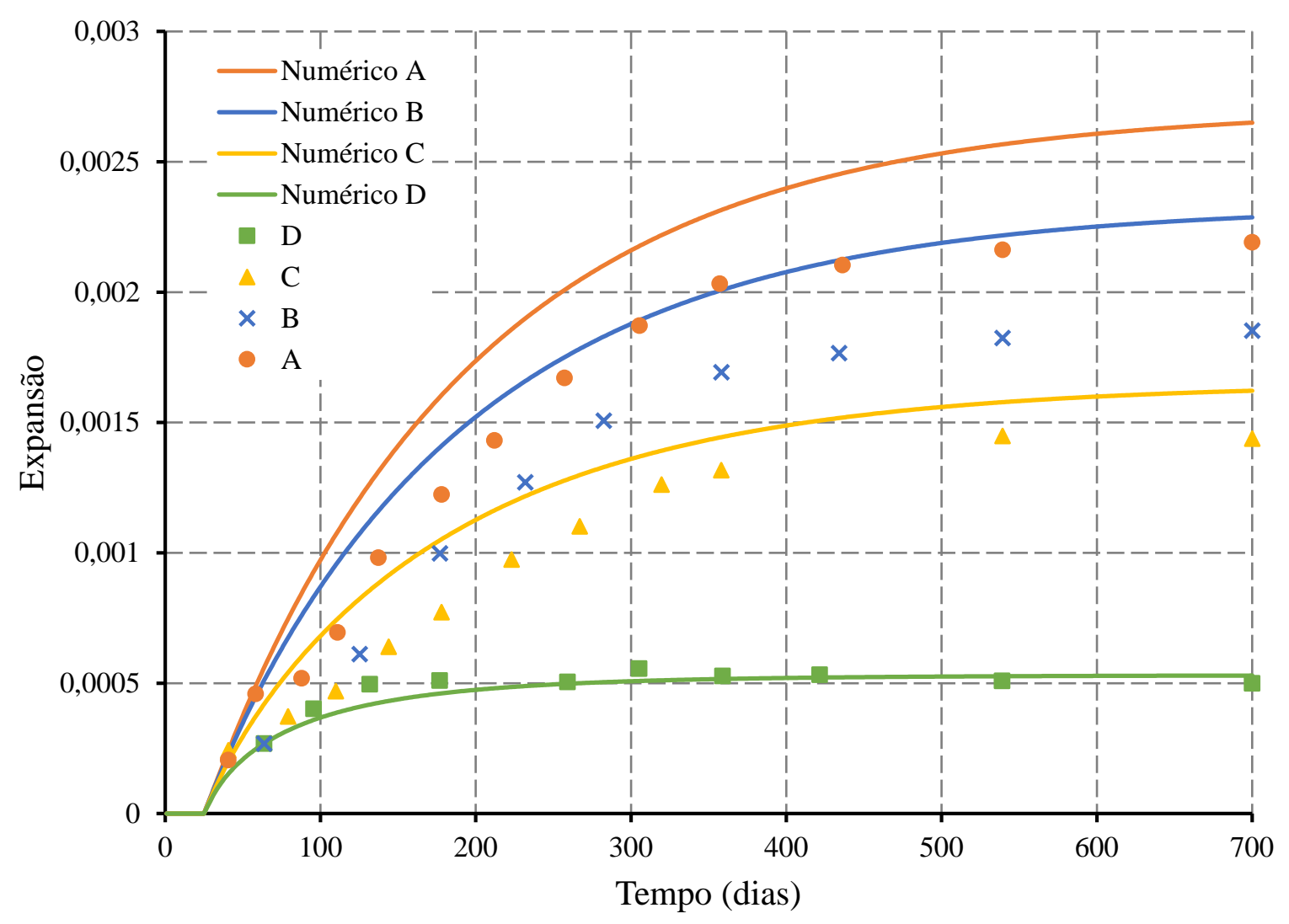

Figura 6.50 - Expansão longitudinal da viga em concreto armado.

Da Figura 6.50, pode-se observar que os resultados obtidos numericamente para a expansão longitudinal da viga em concreto armado se aproximam dos resultados obtidos experimentalmente. Maiores diferenças entre os resultados numéricos e experimentais são observadas para os extensômetros A e B, regiões que apresentam menos restrição ao deslocamento e que são solicitadas por tensões de tração devido à configuração arqueada que a viga deformada assume (Figura 6.51).

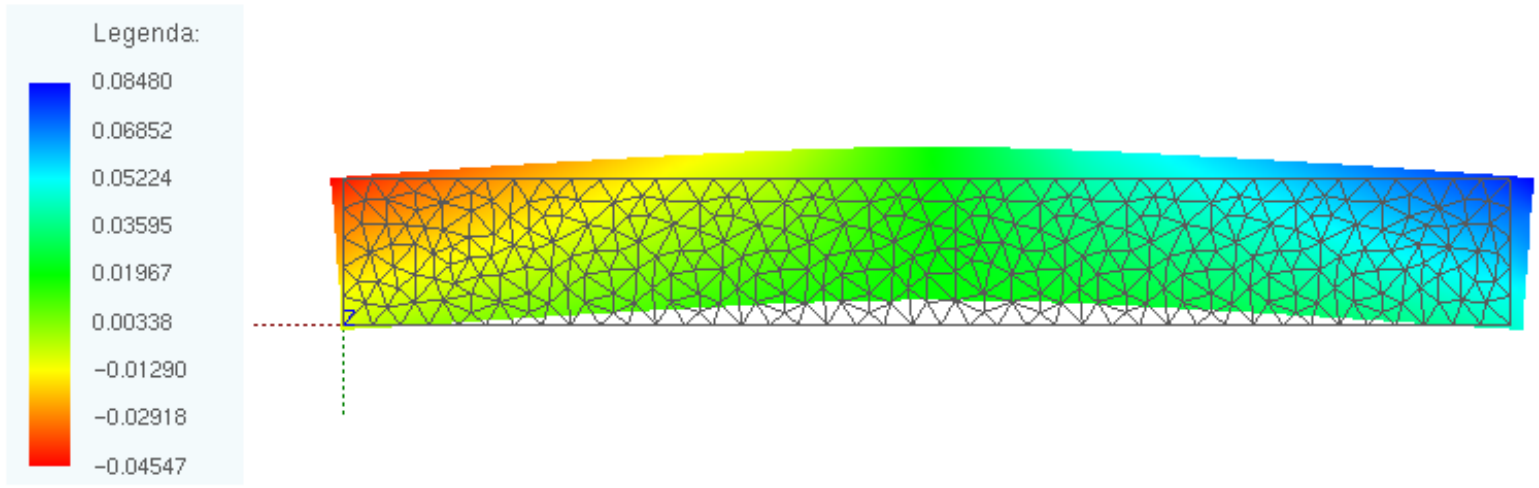

Figura 6.51 - Deslocamento horizontal aos 700 dias da viga em concreto armado (em cm). 
As tensões de tração induzidas na direção longitudinal próximo à região do extensômetro A chegam a atingir até $0,3 \mathrm{KN} / \mathrm{cm}^{2}$, conforme ilustra a Figura 6.52.

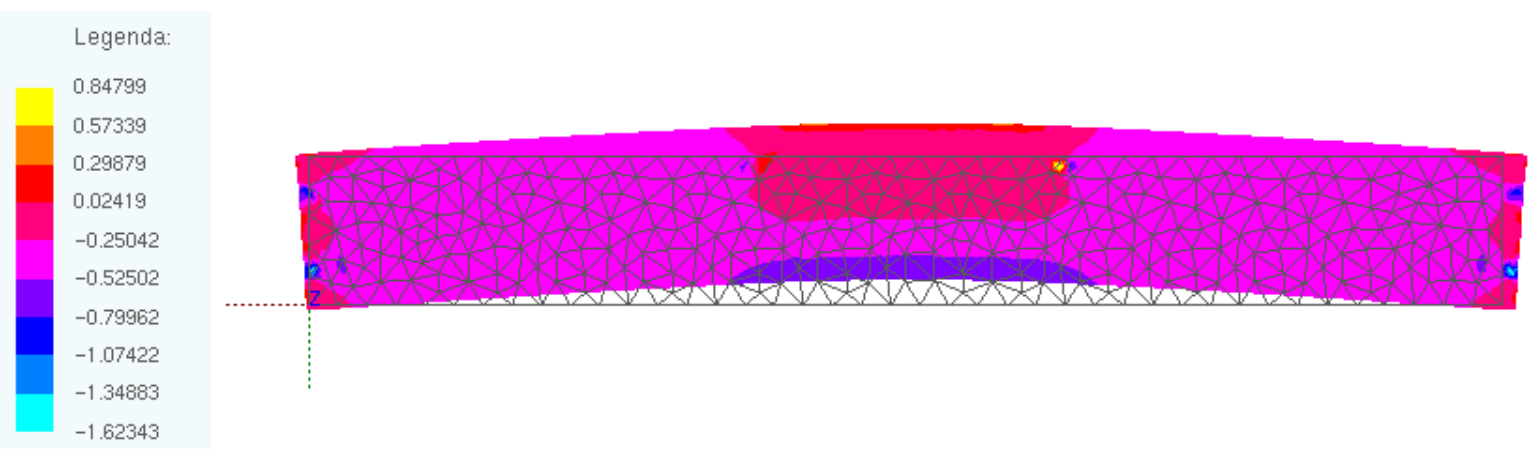

Figura 6.52 - Tensões induzidas na direção longitudinal da viga (em KN/cm²).

Como já foi discutido anteriormente no Exemplo 4, pode-se afirmar que o modelo numérico aqui apresentado irá superestimar a expansão em regiões solicitadas por tensões de tração, uma vez que o modelo numérico apenas considera redução da expansão quando tensões de compressão estejam atuando. Entretanto, experimentalmente é observada uma redução da expansão em regiões tracionadas, em função da fissuração do concreto, o que permite a acomodação da expansão do gel e, consequentemente, a redução da expansão.

Na Figura 6.52 ainda é possível observar um gradiente de tensões longitudinais induzidas ao longo da altura da viga. Isso ocorre em função das diferentes taxas de armadura nas faces superior e inferior da viga.

A Figura 6.53 apresenta a evolução das tensões longitudinais induzidas nas regiões próximas aos extensômetros. Essas tensões foram obtidas por meio do modelo numérico, podendo-se destacar as tensões de tração induzidas na face superior da viga e as tensões de compressão induzidas nas regiões inferiores. Destaca-se ainda o aumento das tensões de compressão induzidas no concreto nas regiões próximas à face inferior da viga (região em que se concentram as maiores taxas de armadura). 


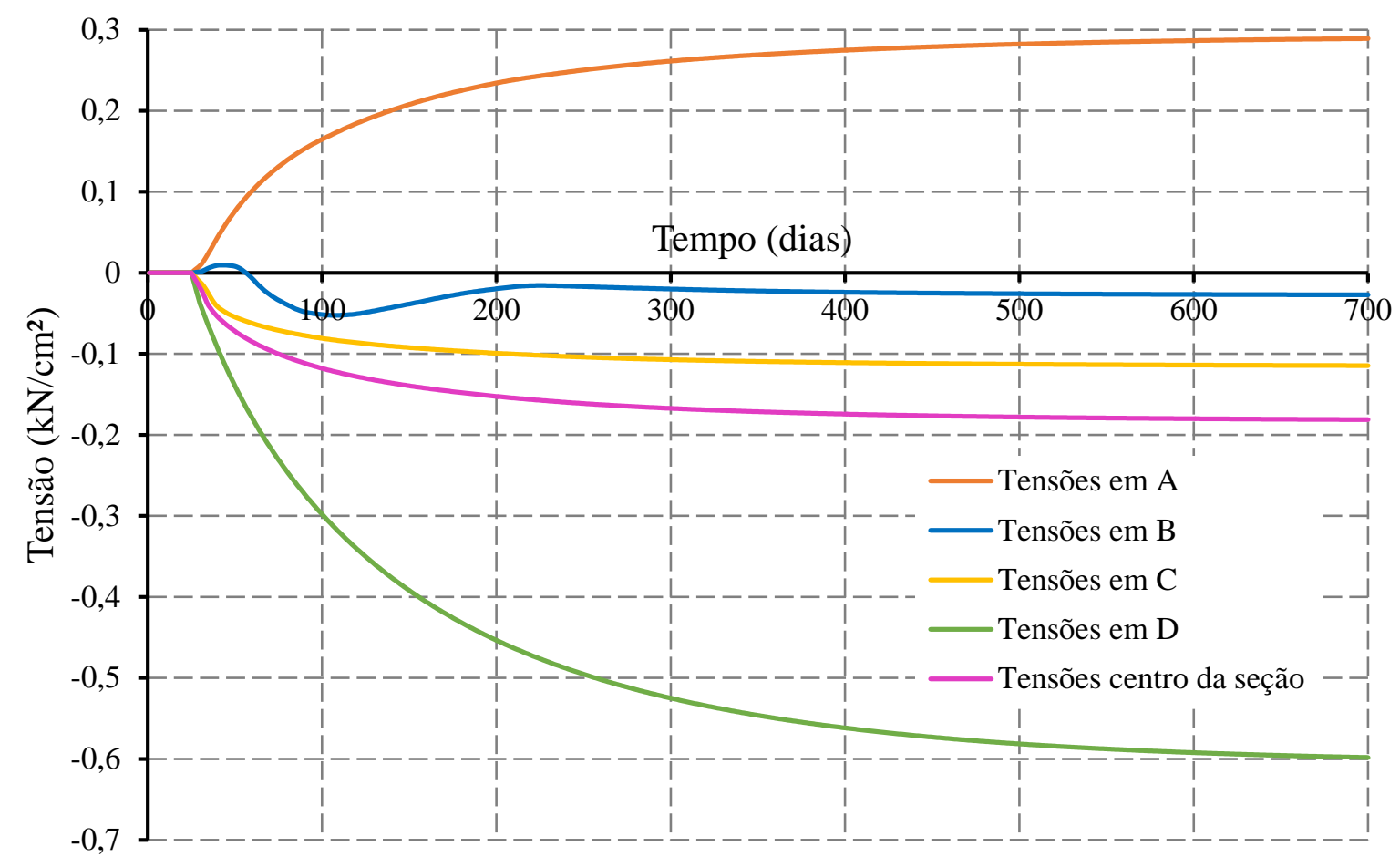

Figura 6.53 - Evolução das tensões induzidas na direção longitudinal da viga (em KN/cm²).

A Figura 6.54 apresenta a evolução das deformações obtidas numericamente e experimentalmente na armadura inferior da viga afetada por RAA.

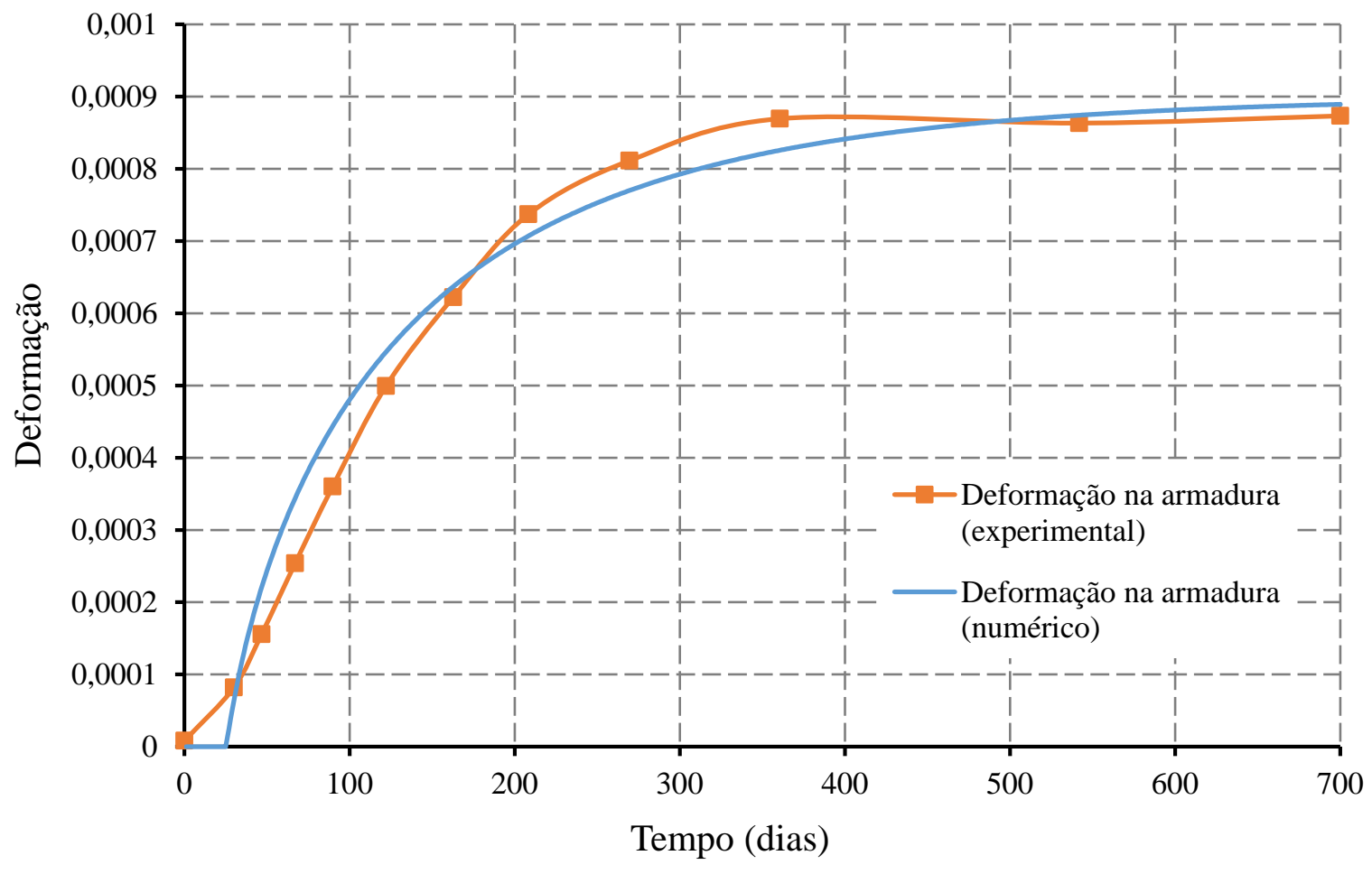

Figura 6.54 - Evolução das deformações na armadura inferior. 
A comparação entre os resultados numéricos e experimentais apresentada na Figura 6.54 permite a conclusão de que, possivelmente, não ocorreu escorregamento entre a armadura inferior e a matriz de concreto, uma vez que o modelo numérico considera as fibras perfeitamente aderidas à matriz de concreto.

Ao final dos 700 dias de ensaio, Swamy e Al-Asali (1990) avaliaram a capacidade de carga das vigas, ensaiando-as à flexão conforme a configuração apresentada na Figura 6.49.

Os resultados numéricos e experimentais de deformação longitudinal para uma viga não afetada por RAA são apresentados na Figura 6.55. Destaca-se que no modelo numérico a força $P=40 K N$ é aplicada em 10 passos, representando devidamente o comportamento da estrutura para pequenas deformações.

A partir da deformação de $0,1 \%$, maiores diferenças começam a ser observadas entre os resultados numérico e experimental. Isso se deve ao modelo constitutivo elástico-linear empregado no modelo numérico para descrever o comportamento do material; modelo constitutivo este que não é o mais adequado para representar estruturas em concreto.

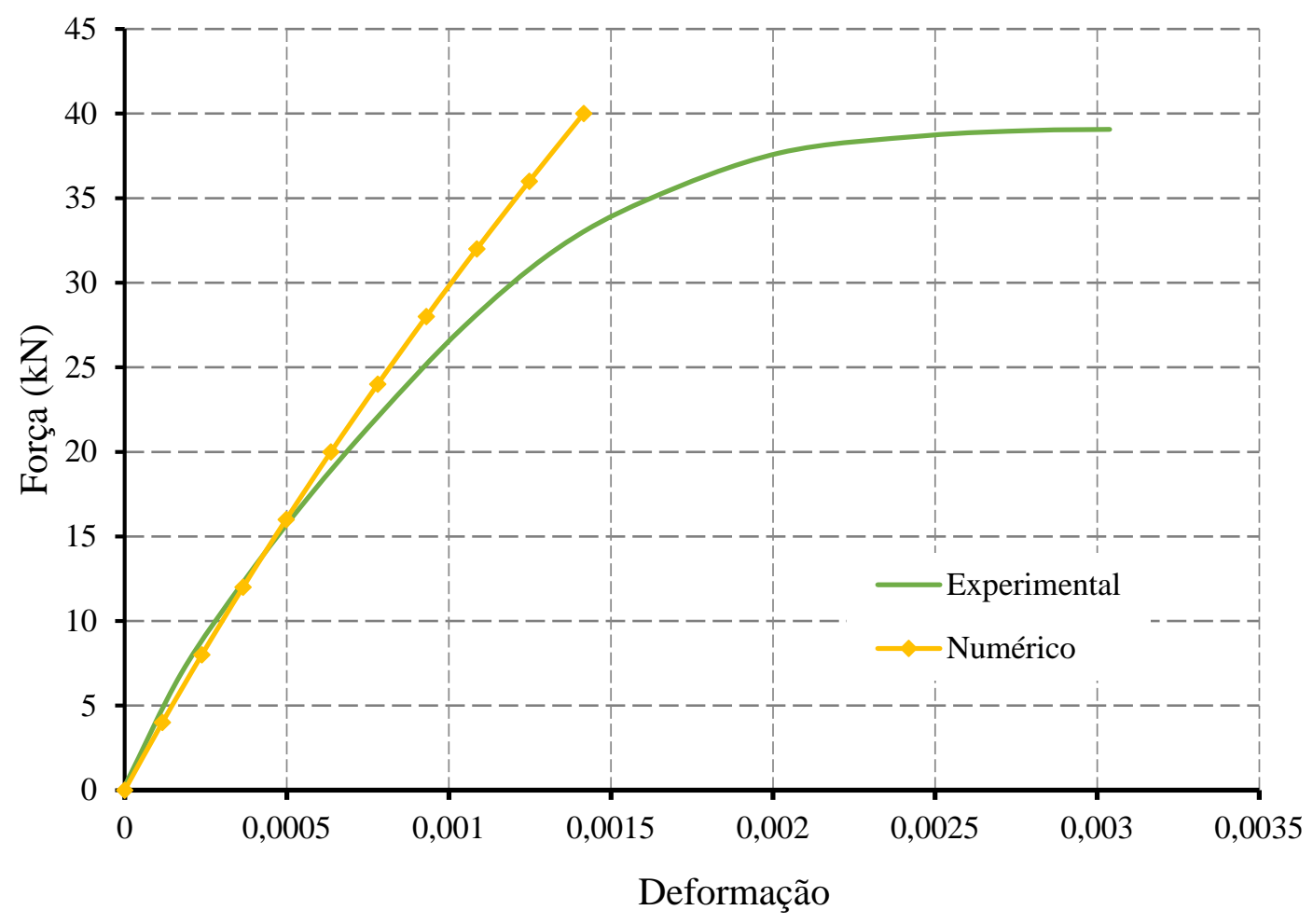

Figura 6.55 - Deformação longitudinal da viga de concreto ensaiada à flexão

Para a viga afetada por RAA, os resultados numéricos e experimentais encontram-se apresentados na Figura 6.56. 


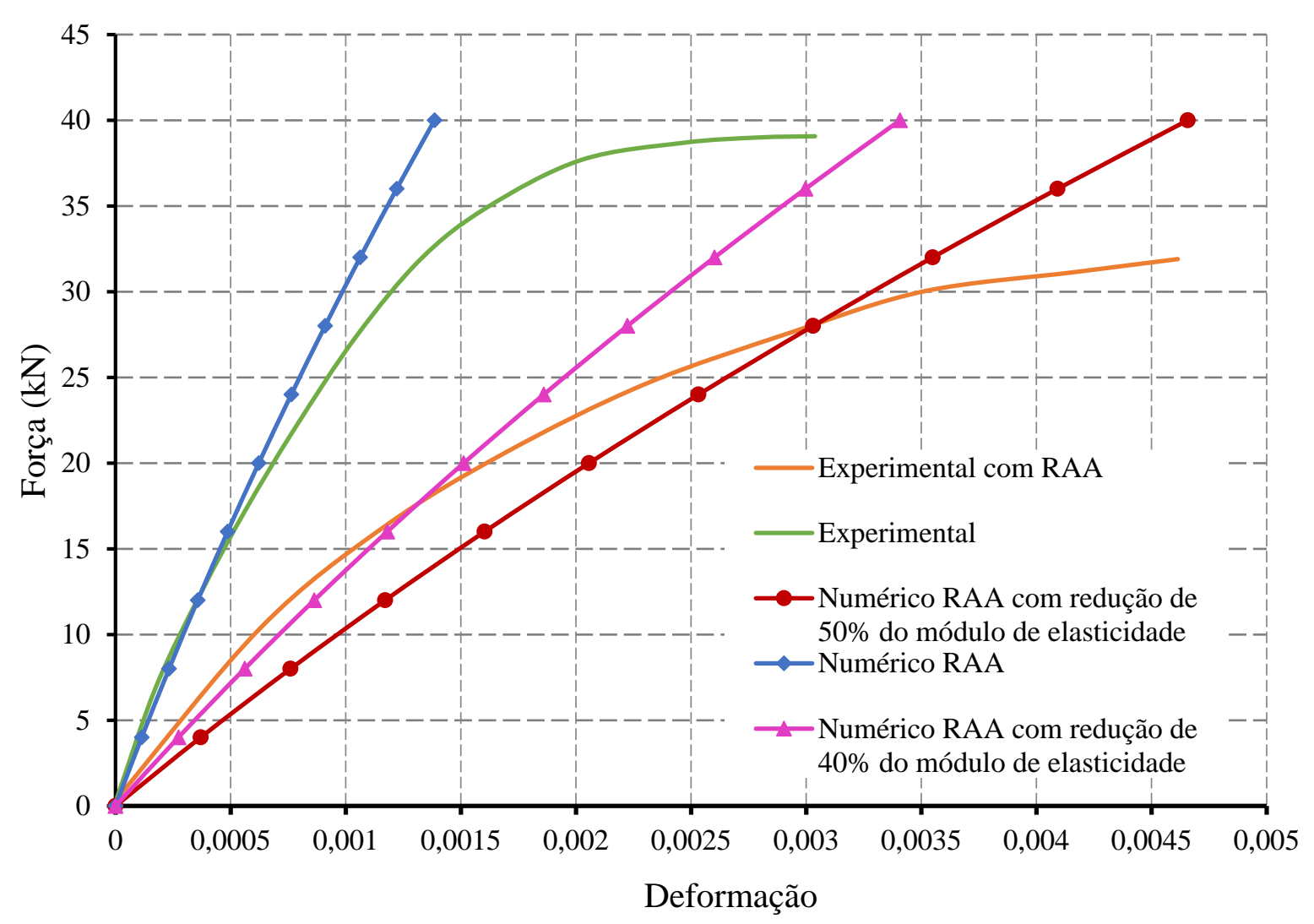

Figura 6.56 - Deformação longitudinal da viga de concreto ensaiada à flexão.

É possível observar na Figura 6.56 que a viga afetada por RAA ensaiada por Swamy e Al-Asali (1990) apresenta capacidade de carga reduzida em 15\%.

Ainda na Figura 6.56, fica evidente a necessidade de o modelo numérico considerar a redução do módulo de elasticidade com o avanço da reação. Neste caso, a viga ensaiada sofre uma redução de 40 a 50\% do seu módulo de elasticidade, resultando em consideráveis deformações devido à RAA. 


\section{CONCLUSÕES}

Nesta dissertação foi apresentado e implementado um modelo macroscópico paramétrico para a expansão por RAA em estruturas de concreto armadas e reforçadas com fibras.

O modelo mecânico do concreto reforçado com fibras foi implementado via MEFP, método este em que os parâmetros nodais considerados são as posições e as deformações são tomadas em relação à posição inicial do corpo. A matriz de concreto foi discretizada por meio de elementos finitos de chapa elásticos reforçados por elementos de fibra lineares.

As fibras foram consideradas perfeitamente aderidas à matriz de concreto e foram inseridas na chapa por meio de relações cinemáticas sem a necessidade de coincidência dos nós da fibra com os nós da chapa e sem aumentar o número de graus de liberdade do sistema.

Com relação ao modelo químico, que trata da expansão por RAA, a partir dos exemplos analisados no capítulo anterior é possível a realização das seguintes afirmações:

a) Quanto à representatividade das equações constitutivas avaliadas (Equação 4.8 proposta por Carrazedo (2004) e Equação 4.9 proposta por Larive (1998)), pode-se afirmar que ambas as equações são capazes de representar devidamente a expansão por RAA, desde que seus parâmetros sejam devidamente calibrados a partir de observações experimentais.

b) Quanto às leis de normalização referentes ao estado de tensões analisadas (Lei de normalização apresentada na Figura 4.4 proposta por Léger et al. (1996) e Lei de normalização apresentada na Figura 4.5 proposta por Pappalardo et al. (2000)), podese concluir que a lei de normalização proposta por Léger et al. (1996) é a que melhor representa a redução da expansão por RAA em função de tensões de compressão aplicadas e/ou induzidas pela presença de armadura.

c) Quanto à redução do módulo de elasticidade com o avanço da reação, fica claro no Exemplo 7 do capítulo anterior a necessidade de que seja devidamente considerada 
a redução deste parâmetro para a correta descrição do comportamento do concreto afetado pela RAA.

Embora o modelo numérico de expansão por RAA aqui apresentado seja capaz de representar devidamente a redução da expansão em estruturas armadas, o mesmo não foi observado para estruturas reforçadas com fibras, conforme apresentado no Exemplo 6 do capítulo anterior. Neste caso, possivelmente esteja ocorrendo algum fenômeno que não é considerado no modelo numérico, como, por exemplo, a plastificação das fibras, fissuração por tração e retração plástica do concreto.

Dessa forma, em função dos resultados obtidos por este trabalho e das potencialidades do modelo aqui empregado, são propostas algumas sugestões para trabalhos futuros:

a) Implementação da não-linearidade física da fibra e da possibilidade de escorregamento fibra-matriz;

b) Desenvolvimento de um modelo de dano ou fissuração para representação mais realista do comportamento da matriz de concreto;

c) Inserir o efeito da fluência do concreto no modelo de expansão por RAA;

d) Inserir, no modelo numérico apresentado, a redução da expansão por RAA em regiões onde atuem tensões de tração;

Por fim, ressalta-se a necessidade da realização de experimentos envolvendo protótipos de concreto afetados pela RAA para o melhor controle das condições e parâmetros envolvendo a reação, permitindo assim a devida calibração do modelo numérico aqui apresentado. 


\section{REFERÊNCIAS BIBLIOGRÁFICAS}

ACADMESH 2D. Software Acadêmico para geração de malhas não-estruturadas 2D para modelos de elementos finitos. Versão beta. Departamento de Engenharia de Estruturas, EESC, USP, São Carlos, 2012. Disponível em: <http://www.set.eesc.usp.br/portal/pt/softwares/27pesquisa/softwares/433-acad2d>

ACADVIEW. Software para pós-processamento em elementos finitos 2D e 3D. Versão beta. Departamento de Engenharia de Estruturas, EESC, USP, São Carlos, 2005. Disponível em: <http://www.set.eesc.usp.br/portal/pt/softwares/27-pesquisa/softwares/157-acadview>

ANDRADE, T; SILVA, J.J.R.; HASPARYK, N.P.; SILVA, C.M. Investigação do potencial de reatividade para o desenvolvimento de RAA dos agregados miúdos e graúdos comercializados na Região Metropolitana do Recife. In: SIMPÓSIO SOBRE REAÇÃO ÁLCALI-AGREGADO EM ESTRUTURAS DE CONCRETO, 2., 2006, Rio de Janeiro. Anais... Rio de Janeiro, 2006.

ASSAN, A.E. Método dos Elementos finitos: primeiros passos. 2. ed. Campinas: Editora da Unicamp, 2003, p.304.

ASSOCIAÇÃO BRASILEIRA DE CIMENTO PORTLAND (ABCP). A evolução da cultura da prevenção da reação álcali-agregado no mercado nacional. Concreto e Construções, v.83, p.39-43, 2016.

ASSOCIAÇÃO BRASILEIRA DE NORMAS TÉCNICAS (ABNT). NBR 15577-1: Agregados-Reatividade álcali-agregado - Parte 1: Guia para avaliação da reatividade potencial e medidas preventivas para uso de agregados em concreto. Rio de Janeiro, ABNT, 2008.

BATTAGIN, I.L.S.; BATTAGIN, A.F.; NETO, C.S. A norma brasileira de reação álcaliagregado faz seu primeiro aniversário. Concreto e Construções, n.54, p.34-47, 2009.

BAZANT, Z.P.; STEFFENS, A. Mathematical model for kinetics of alkali-silica reaction in concrete. Cement and Concrete Research, v.30, n.3, p.419-428, 2000.

BAZANT, Z.P.; ZI, G.; MEYER, C. Fracture mechanics of asr in concretes with waste glass particles of different sizes. Journal of Engineering Mechanics, v.126, n.3, p.226-232, 2000.

BEGLARIGAE, A.; YAZICI, H. The effect of alkali-silica reaction on steel fiber-matrix bond characteristics of cement based mortars. Construction and Buildings Materials, v.47, p.845860, 2013. 
BODDY, A.M.; HOOTON, R.D.; THOMAS, M.D.A. The effect of product form of silica fume on its ability to control alkali-silica reaction. Cement and Concrete Research, v.30, n.7, p.1139-1150, 2000.

BONET, J.; WOOD, R.D.; MAHANEY, J.; HEYWOOD, P. Finite element analysis of air supported membrane structures. Computer Methods in Applied Mechanics and Engineering, v.190, p.579-595, 2000.

CAPRA, B.; BOURNAZEL, J.P. Modeling of induced mechanical effects of alkali aggregate reactions, Cement and Concrete Research, v.28, p.251-260, 1998.

CAPRA, B.; SELLIER, A. Orthotropic modelling of alkali-aggregate reaction in concrete structures: numerical simulations. Mechanics of Materials, v.35, n.8, p.817-830, 2003. CARRAZEDO, R. Modelagem numérica da expansão do concreto devido a reação álcaliagregado. Dissertação (Mestre em Ciências) - Universidade Federal do Paraná (UFPR), Curitiba, 2004.

CARRAZEDO, R.; LACERDA, L.A. Parametric model for the analysis of concrete expansion due to alkali-aggregate reaction. The Journal of Strain Analysis for Engineering Design, v.43, n.5, p.325-335, 2008.

CARRAZEDO, R.; SANCHES, R.A.K.; LACERDA, L.A. Numerical modeling of orthotropic concrete expansion due to alkali-aggregate reaction with a parametric model. In: WORLD CONGRESS ON COMPUTACIONAL MECHANICS, 10., 2012, São Paulo. Proceedings... São Paulo, 2012.

CARVALHO, M.R.P.; FAIRBAIN, E.M.R.; TOLEDO-FILHO, R.D.; CORDEIRO, G.C.; HASPARYK, N.P. Influence of steel fibers on the development of alkali-aggregate reaction. Cement and Concrete Research, v.40, n.4, p.598-604, 2010.

CHARLWOOD, R. A review of alkali aggregate in hydro-electric plants and dams. Hydropower Dams, v.1, p.73-80, 1994.

CHARLWOOD, R.G.; SOLYMAR, S.V.; CURTIS, D.D. A review of alkali aggregate in hydro-eletric plants and dams. In: INTERNATIONAL CONFERENCE OF ALKALIAGGREGATE REACTION IN HYDROELECTRIC PLANTS AND DAMS, 129., 1992, Fredericton, Canada. Proceedings... Fredericton, 1992.

CLARK, L.A. Modelling the structural effects of alkali-silica reactions on reinforced concrete, ACI Materials Journal, v.88, p.271-277, 1991.

CODA, H.B. Análise não linear geométrica de sólidos e estruturas: uma formulação posicional baseada no MEF. Tese para concurso de professor titular. São Carlos, 2003.

CODA, H.B.; GRECO, M. A simple FEM formulation for large deflection 2D frame analysis based on position description. Computer Methods in Applied Mechanics and Engineering, v.193, p. 3541-3557, 2004. 
CODA, H.B.; PACCOLA, R.R. An alternative positional FEM formulation for geometrical non-linear analysis of shells: curved triangular isoparametric elements. Computational Mechanics, v.40, n.1, p.185-200, 2007.

CODA, H.B.; PACCOLA, R.R. A positional FEM formulation for geometrical non-linear analysis of shells. Latin American Journal of Solids and Structures, v.5, p.205-223, 2008.

CODA, H.B.; PACCOLA, R.R.; SAMPAIO, M.S.M. Positional description applied to the solution of geometrfically non-linear plates and shells. Finite Elements in Analysis and Design, v.67, p.66-75, 2013.

COMBY-PEYROT, I. Development and validation of a 3D computational tool to describe damage and fracture due to alkali-silica reaction in concrete structures. Thesis, École nationale Supérieure des Mines de Paris, 2007.

COMBY-PEYROT, I.; BERNARD, F.; BOUCHARD, P.; BAY, F.; GARCIA-DIAZ, E. Development and validation of a 3D computational tool to describe concrete behavior at mesoscale. Application to the alkali-silica reaction. Computational Materials Science, v.46, n.4, p.1163-1177, 2009.

COMI, C.; FEDELE, R.; PEREGO, U. A chemo-thermo-damage model for the analysis of concrete dams affected by alkali-silica reaction. Mechanics of Materials, v.41, p.210-230, 2009.

DENT GLASSER, L.S.; KATAOKA, N. The chemistry of alkali-aggregate reaction. Cement and Concrete Research, v.11, n.1, p.1-9, 1981.

DESCHENES, D.J. ASR/DEF-Damaged bent caps : shear tests and field implications. Tese, University of Texas, Austin, 2009.

DUNANT, C.F.; SCRIVENER, K.L. Micro-mechanical modelling of alkali-silica-reactioninduced degradation using the AMIE framework. Cement and Concrete Research, v.40, n.4, p.517-525, 2010.

ESPOSITO, R. The deteriorating impact of alkali-silica reaction on concrete: expansion and mechanical properties. Thesis, Delf University of Technology, Netherlands, 2016.

ESPOSITO, R.; HENDRIKS, M.A.N. Structural Modelling of ASR-affected concrete: The approach developed in the PAT-ASR project. In: NORDIC-BALTIC MINISEMINAR OF ALKALI-AGGREGATE REACTIONS (AAR) IN CONCRETE, 11., 2013, Riga, Latvia. Proceedings.... Riga, 2013.

FAN, S.; HANSON, J.M. Length expansion and cracking of plain and reinforced concrete prisms due to alkali-silica reaction. ACI Materials Journal, v.95, n.4, p.480-487, 1998.

FAIRBAIN, E.M.R.; RIBEIRO, F.L.B.; LOPES, L.E.; TOLEDO-FILHO, R.D.; SILVOSO, M.M. Modelling the structural behaviour of a dam affected by alkali-silica reaction.

Comunications in Numerical Methods in Engineering, v.22, n.1, p.1-12, 2005. 
FARAGE, M.C.R.; ALVES, J.L.D.; FAIRBAIRN, E.M.R. Macroscopic model of concrete subjected to alkali-aggregate reaction. Cement and Concrete Research, v.34, n.3, p.495505, 2004.

FERNANDES, I; BROEKMANS, M.A.T.M. Alkali-silica reactions: An overview. Part 1. Metallography, Microstructure and Analysis, v.2, n.4, p.257-267, 2013.

FHWA. Alkali-aggregate reactivity (AAR) Facts book. Technical report HIF-13-019, Federal Highway Administration, 2013.

FOURNIER, B. ; BÉRUBÉ, M. Alkali-aggregate reaction in concrete: areview of basic concepts and engineering implications. Canadian Journal of Civil Engineering, v.27, n.2 p.167-191, 2000.

FURUSAWA, Y.; OHGA, H.; UOMOTO, T. An analytical study concerning prediction of concrete expansion due to alkali-silica reaction. In: INTERNATIONAL CONFERENCE ON DURABILITY OF CONCRETE, 3., 1994, Nice, France. Proceedings... France, 1994.

GIACCIO, G.; BOSSIO, M.E.; TORRIJOS, M.C.; ZERBINO, R. Contribution of fiber reinforcement in concrete affected by alkali-silica reaction. Cement and Concrete Research, v.67, p.310-317, 2015.

GOMES, E.A.O. Recuperação estrutural de blocos de fundação afetados pela reação álcali-agregado - a experiência do Recife. Dissertação (Mestre em Engenharia) Universidade Católica de Pernambuco, Recife, 2008.

GRIMAL, E.; SELLIER, A.; LE PAPE, Y.; BOURDAROT, E. Creep, shrinkage, and anisotropic damage in alkali-aggregate reaction sweeling mechanism - Part I: a constitutive model. ACI Materials Journal, v.105, n.3, p.227-235, 2008.

GROVES, G.W.; ZHANG, X. A dilatation model for the expansion of silica glass/OPC mortars. Cement and Concrete Research, v.20, n.3, p.453-460, 1990.

HADDAD, R.H.; SMADI, M.M. Role of fibers in controling unrestrained expansion and arresting cracking in Portland cement concrete undergoing alkali-silica reaction. Cement and Concrete Research, v.34, p.103-108, 2004.

HASPARYK, N. P. Investigação dos Mecanismos da Reação Álcali- Agregado - Efeito da Cinza de Casca de Arroz e da Sílica Ativa. Dissertação (Mestrado em Engenharia) - Escola de Engenharia Civil, Universidade Federal de Goiás, Goiânia, 1999.

HASPARYK, N.P. Investigação de concretos afetados pela reação álcali-agregado e caracterização avançada do gel exsudado. Tese (Doutor em Engenharia Civil) Universidade Federal do Rio Grande do Sul, Porto Alegre, 2005.

HASPARYK, N.P. Reação álcali-agregado no concreto. In: ISAIA, G.C. Concreto: ciência e tecnologia, São Paulo, Brasil: IBRACON, 2011. Cap.27, p.933-1001. 
HASPARYK, N.P.; MUNHOZ, F.; SANCHES, L.; SALLES, F.; HAMASSAKI, L. Efeito dos álcalis e da finura do cimento nas expansões geradas pela reação álcali-agregdo. In: CONGRESSO BRASILEIRO DO CONCRETO, 49., Bento Gonçalves, 2007. Anais... Bento Gonçalves, 2007.

HOBBS, D.W. The alkali-silica reaction - a model for predicting expansion in mortar. Magazine of Concrete Research, v.33, n.117, p.208-220, 1981.

HOBBS, D.W. Alkali-silica reaction in concrete. London: Thomas Telford Ltd., 1988, p.192.

HOBBS, D.W. Cracking and expansion due to the alkali-silica reaction: its effect on concrete. Structural Egineering Review, v.2, p.65-70, 1990.

HUANG, M.; PIETRUSZCZAK, S. Modelling of thermomechanical effects of alkali-silica reaction. Journal of Engineering Mechanics, v.125, n.4, p.476-485, 1999.

ISE - Institution of Structural Engineers. Structural effects of alkali-silica reaction: technical guidance on the appraisal of existing structures. Technical Report, 1992.

JONES, A.E.K.; CLARK, L.A. The effects of restraint on ASR expansion of reinforced concrete. Magazine of Concrete Research, v.48, n.174, p.1-13, 1996.

JURCUT, A. Modelling of alkali-aggregate reaction effects in reinforced concrete structures. Thesis, University of Toronto, 2015.

KAGIMOTO, H.; YASUDA, Y.; KAWAMURA, M. ASR expansion, expansive pressure and cracking in concrete prisms under various degrees of restraint. Cement and Concrete Research, v.59, p.1-15, 2014.

KAGIMOTO, H.; YASUDA, Y.; KAWAMURA, M. Effects of expansion behavior of ASRaffected concrete in atmospheres with various values of relative humidity on surface cracking. In: INTERNATIONAL CONFERENCE OF ALKALI-AGGREGATE REACTION (ICAAR), 15., 2016, São Paulo. Proceedings... São Paulo, 2016.

KIHARA, Y.; SBRIGHI, C.N.; KUPERMAN, S.C. Reação álcali-agregado: visão atual e situação brasileira. In: SIMPÓSIO SOBRE DURABILIDADE DO CONCRETO, São Paulo, 1998. Anais... São Paulo, 1998.

KOBAYASHI, K.; FUKUSHIMA, T.; ROKYGO, K. Shear strength of ASR-deteriorated RC members and shear reinforcing effect of repair by adding rebar. In: INTERNATIONAL CONFERENCE ON FRACTURE MECHANICS OF CONCRETE AND CONCRETE STRUCTURES, 8., 2013, Toledo, Espanha Proccedings... Toledo, 2013.

LARIVE, C. Combined contribution of experiments and modelling to the understanding of alkali-aggregate reaction and its mechanical consequences (in: French). Thesis École Nationale des Ponts et Chaussées, 1998.

LÉGER, P.; COTE, P.; TINAWI, R. Finite element analysis of concrete due to alkaliaggregate reactions in dams. Computers and Structures, v.60, n.4, p.601-611, 1996. 
LEMARCHAND, E.; DORMIEUX, L.; ULM, F. A micromechanical approach to de modeling of swelling due to alkali-silica reaction. In: ENGINEERING MECHANICS CONFERENCE, 14., 2001, Austin, Texas. Proceedings... Austin, 2001.

LI, K.; COUSSY, O. Concrete ASR degradation: from material modeling to structure assessment. Concrete Science Engineering, v.4, p.35-46, 2002.

MATTIASSON, K. Numerical results from large deflection beam and frame problems analysed by means of elliptic integrals. International Journal for Numerical Methods in Engineering, v.17, p.145-153, 1981.

MADUREIRA, E.L. Simulação numérica do comportamento mecânico de elementos de concreto armado afetados pela reação álcali-agregado. Tese (Doutorado) - Universidade Federal do Pernambuco (UFPE), Recife, 2007.

MEHTA, P.K.; MONTEIRO, P.J.M. Concreto: estrutura, propriedades e materiais. São Paulo, Brasil: Pini, 2008, p. 751.

MIYAGAWA, T.; SETO, K.; SASAKI, K.; MIKATA, Y.; KUZUME, K. AND MINAMI, T. Fracture of Reinforcing Steels in Concrete Structures Damaged by Alkali-Silica Reaction Field Survey, Mechanism, and Maintenance. Journal of Advanced Concrete Technology. v.4, n.3, p.339-355, 2006.

MOUNDOUNGOU, I.; BULTEEL, D.; GARCIA-DIAZ, E.; THIÉRY, V.;

DÉGRUGILLIERS, P.; HAMMERSCHLAG, J.G. Reduction of ASR expansion in concretes based on reactive chert aggregates: effect of alkali neutrasilation capacity. Construction and Buildings Materials, v.54, p.147-162, 2014.

MULTON, S. Evaluation Expérimentale et Théorique de Effets Mécaniques de l'Alcali Réaction sur des Structures Módeles. Thesis Université de Marne la Vallée, France, 2003.

MULTON, S.; TOUTLEMONDE, F. Effect of applied stresses on alkali-silica reactioninduced expansions. Cement and Concrete Research, v.36, n.5, p.912-920, 2006.

MULTON, S.; TOUTLEMONDE, F.Effect of moisture conditions and transfers on alkali silica reaction damaged structures. Cement and Concrete Research, v.40 , p.924-934, 2010.

MULTON, S.; SEIGNOL, J.F.; TOUTLEMONDE, F. Structural Behavior of Concrete Beams Affected by Alkali-Silica Reaction. ACI Materials Journal, v.102, n.2, p.67-76, 2005.

NOEL, M.; SANCHEZ, L.; MARTIN, R.; FOURNIER, B.; BASTIEN, J.; MITCHELL, D. Structural implications of internal swelling reactions in concrete: a review. In:

INTERNATIONAL CONFERENCE OF ALKALI-AGGREGATE REACTION (ICAAR), 15., 2016, São Paulo. Proceedings... São Paulo, 2016.

OLIVEIRA, J.R.S. Modelagem da expansão do concreto devido à RAA com decaimento do módulo de elasticidade. Dissertação (Mestre em Ciências) - Universidade Federal do Paraná (UFPR), Curitiba, 2013. 
PACCOLA, R.R.; CODA, H.B. A direct FEM approach for particulate reinforced elastic solids. Composite Structures, v.141, p.282-291, 2016.

PACCOLA, R.R.; PIEDADE NETO, D.; CODA, H.B. Geometrical non-linear analysis of fiber reinforced elastic solids considering debounding. Composite Structures, v.133, p.343357, 2015.

PAN, J.W.; FENG, Y.T.; WANG, J.T.; SUN, Q.C; ZHANG, C.H.; OWEN, D.R.J. Modeling of alkali-silica reaction in concrete : a review. Frontiers of Structural and Civil

Engineering, v.6, n.1, p.1-18, 2012.

PAULON, V.A. Reações álcali-agregado em concreto. Dissertação (Mestre em Engenharia Civil) - Escola Politécnica de São Paulo, Universidade de São Paulo, São Paulo, 1981.

PAPPALARDO JR, A.; PAULETTI, R.M.O.; PIMENTA, P.M. Simulação numérica da reação álcali-agregado em barragens de concreto. Revista Mackenzie de Engenharia e Computação, v.1, n.1, p.181-199, 2000.

PAPPALARDO JR, A.; PAULETTI, R.M.O.; CARMONA, T.G.; CARMONA, T.G.; FILHO, A.C. Modelling the orthotropic expansion induced by alkali-aggregate-reaction: methodological review and practical application. In: INTERNATIONAL CONFERENCE OF ALKALI-AGGREGATE REACTION (ICAAR), 15., 2016, São Paulo. Proceedings... São Paulo, 2016.

PIETRUSZCZAK, S. On the mechanical behaviour of concrete subjected to alkali-aggregate reaction. Computers and Structures, v.58, n.6, p.1093-1097, 1996.

PIGNATELLI, R. Modelling of degradation induced by alkali-silica reaction in concrete structures. Thesis Politecnico di Milano, 2012.

RAJABIPOUR, F. GIANNINI, E.; DUNANT, C.; IDEKER, J.H.; THOMAS, M.D.A. Alkalisilica reaction: Current understanding of the reaction mechanisms and the knowledge gaps.

Cement and Concrete Research, v.76, p.130-146, 2015.

SAMPAIO, M.S.M. Análise não linear geométrica de cascas laminadas reforçadas com fibras. Tese (Doutor em Estruturas) - Escola de Engenharia de São Carlos, Universidade de São Paulo, São Carlos, 2014.

SAMPAIO, M.S.M.; PACCOLA, R.R.; CODA, H.B. Fully adherent fiber-matrix FEM formulation for geometrically nonlinear 2D solid analysis. Finite Elements in Analysis and Design, v.66, p.12-25, 2013.

SAOUMA, V. Numerical Modeling of AAR. London: CRC Press, Taylor and Francis, 2014, p.290.

SAOUMA, V.; PEROTTI, L. Constitutive model for alkali-aggregate reactions. ACI

Materials Journal, v.103, n.3, p.194-202, 2006. 
SAOUMA, V.E.; MARTIN, R.A.; HARIRI-ARDEBILI, M.A.; KATAYAMA, T. A mathematical model for the kinetics of the alkali-silica chemical reaction. Cement and Concrete Research, v.68, p.184-195, 2015.

SEREGA, S.; WINNICKI, A.; NORYS, F. Modelling of Alkali-Silica Reaction (ASR) Concrete Structures. In: INTERNATIONAL CONFERENCE ON MECHANICS AND PHYSICS OF CREEP, SHRINKAGE AND DURABILITY OF CONCRETE AND CONCRETE STRUCTURES, 10., 2015,Viena, Austria. Proceedings... Austria, 2015.

SILVA, P.N. Reação álcali-agregado nas usinas hidrelétricas do complexo Paulo Afonso/CHESF: influência da reação nas propriedades do concreto. Dissertação (Mestre em Engenharia) - Escola Politécnica de São Paulo, Universidade de São Paulo, São Paulo, 2007.

SMAOUI, N.; BISSONNETTE, B.; BÉRUBÉ, M.A.; FOURNIER, B. Stresses induced by alkali-silica reactivity in prototypes of reinforced concrete columns incorporating various types of reactive aggregates. Canadian Journal of Civil Engineering, v.34, p.1554-1566, 2007.

SOUZA, V.C.M.; RIPPER, T. Patologia, recuperação e reforço de estruturas de concreto. São Paulo: Pini, 2009, p.255.

STANTON, T.E. Expansion of concrete through reaction between cement and aggregates. Proceedings of ASCE, v.66, n.10, p.1781-1811, 1940.

STARK, D. Alkali-silica reactivity: some reconsiderations. Cement, Concrete and Aggregates, v.2, n.2, p.92-94, 1980.

SWAMY, R.N.; AL-ASALI, M.M. Control of alkali-silica reaction in reinforced concrete beams. ACI Materials Journal, v.87, n.1, p.133-142, 1990.

SWAMY, R.N. The alkali-silica reaction in concrete. London: CRC Press, 1992, p.336.

THOMPSON, G.; CHARLWOOD, R.; STEELE, R.; CURTIS, D. Mactaquac generating station intake and spillway remedial measures. In: INTERNATIONAL CONGRESS ON LARGE DAMS, 18., 1994, Durban, South-Africa. Proceedings... Durban, 1994.

ULM F.J.; COUSSY, O.; KEFEI, L; LARIVE, C. Thermo-chemo-mechanics of ASR expansion in concrete structures. Journal of Engineering Mechanics, v.126, p.233-242, 2000.

URHAN, S. Alkali silica and pozzolanic reactions in concrete. Part 1: Interpretation of published results and an hypothesis concerning the mechanism. Cement and Concrete Research. v.17, n.1, p.141-152, 1987.

VANALLI, L. O MEC e o MEF aplicados à análise de problemas viscoplásticos em meios anisotrópicos e compostos. Tese (Doutor em Estruturas) - Escola de Engenharia de São Carlos, Universidade de São Paulo, São Carlos, 2004. 
VANALLI, L.; PACCOLA, R.R.; CODA, H.B. A simple way to introduce fibers into FEM models. Communications in Numerical Methods in Engineering, v.24, p.585-603, 2008.

VILLEMURE, F.; FISET, M.; BASTEN, J.; MITCHELL, D.; FOURNIER, B.; BISSONNETTE, B. Study of bond between epoxy, steel reinforcing bars and concrete affected by alkali-silica reaction. In: INTERNATIONAL CONFERENCE OF ALKALIAGGREGATE REACTION (ICAAR), 15., 2016, São Paulo. Proceedings... São Paulo, 2016.

WINNICKI, A.; PIETRUSZCZAK, S. On mechanical degradation of reinforced concrete affected by alkali-silica reaction. Journal of Engineering Mechanics. v.134, n.8, p. 611-627, 2008.

WU, T.; TEMIZER, İ.; WRIGGERS, P. Multiscale hydro-thermo-chemo-mechanical coupling: Application to alkali-silica reaction. Computational Materials Science, v.84, p.381-395, 2014. 
